RENAN CERQUEIRA AFONSO ALVES

\title{
REDES DE SENSORES SEM FIO: ANÁLISE DE DESEMPENHO DA CAMADA DE ENLACE
}

Dissertação apresentada à Escola Politécnica da Universidade de São Paulo para obtenção do Título de Mestre em Ciências. 
RENAN CERQUEIRA AFONSO ALVES

\section{REDES DE SENSORES SEM FIO: ANÁLISE DE DESEMPENHO DA CAMADA DE ENLACE}

Dissertação apresentada à Escola Politécnica da Universidade de São Paulo para obtenção do Título de Mestre em Ciências.

Área de Concentração:

Engenharia de Computação

Orientador:

Prof $^{a}$. Dr ${ }^{a}$. Cíntia Borges Margi 
Este exemplar foi revisado e corrigido em relação à versão original, sob responsabilidade única do autor e com a anuência de seu orientador.

São Paulo, de dezembro de 2014.

Assinatura do autor

Assinatura do orientador

Catalogação-na-publicação

Alves, Renan Cerqueira Afonso

Redes de sensores sem fio: análise de desempenho da camada de enlace / R.C.A. Alves. -- versão corr. -- São Paulo, 2014.

$139 \mathrm{p}$.

Dissertação (Mestrado) - Escola Politécnica da Universidade de São Paulo. Departamento de Engenharia de Computação e Sistemas Digitais.

1.Redes de computadores 2.Wireless 3.Análise de desempenho 4.Redes de Petri I. Universidade de São Paulo. Escola Politécnica. Departamento de Engenharia de Computação e Sistemas Digitais II.t. 


\section{RESUMO}

As camadas de enlace empregadas em redes sem fio de baixo custo e desempenho limitado, como as redes de sensores sem fio, são implementadas segundo o padrão IEEE 802.15.4. Prever o desempenho deste padrão é importante para analisar a viabilidade e o desempenho esperado de projetos envolvendo esse tipo de rede. Constatou-se que trabalhos anteriores com esse objetivo são incompletos no tocante às métricas aferidas e tem foco no cálculo de probabilidades, o que não faz parte da especificação do padrão. Assim, o objetivo deste trabalho foi projetar e implementar um modelo comportamental do padrão IEEE 802.15.4, cujos parâmetros possam ser facilmente alterados e que seja capaz de aferir as principais métricas de uma rede: vazão, taxa de entrega, atraso e gasto de energia. Os objetivos foram cumpridos com a validação do modelo perante simulação com o NS2. Além disso, o modelo foi utilizado para estudar a variação dos parâmetros aMaxFrameRetries, macMaxCSMABackoffs, initialCW e aUnitBackoffPeriod do padrão IEEE 802.15.4, para estudar cenários em que os nós possuem tráfego assimétrico e cenários com diferentes relações de tamanho e taxa de chegada de pacotes, mantendo a taxa de bits constante.

Palavras-chave: Camada de enlace. Redes de sensores sem fio. Rede de Petri. Análise de desempenho. 


\begin{abstract}
Low cost and performance constrained wireless networks, such as wireless sensor networks, employ IEEE 802.15.4 standard as its MAC layer. Foreseeing this standard's performance is essential to analyze the feasibility and expected metrics results of these networks projects. It was observed that previous works with that aim are both incomplete regarding metrics of interest and focus on probability calculation, which is not part of the standard specification. Thus, the objective of this work is to project and implement a behavioral IEEE 802.15.4 standard model, which parameters may be easily set and that covers the main metrics of interest: throughput, delivery rate, delay and energy. The objectives were achieved, with model validation against NS2 simulations. Furthermore, the model was employed to analyze the performance variation caused by the parameters $a M a x$ FrameRetries, macMaxCSMABackoffs, initialCW and aUnitBackoffPeriod from the IEEE 802.15.4 standard and also scenarios with asymmetric traffic conditions and packet size and arrival rate variations, maintaining a constant bitrate.
\end{abstract}

Keywords: MAC layer. Wireless sensor networks. Petri net. Performance analysis. 


\section{LISTA DE ILUSTRAÇÕES}

1 Módulo sensor telosB . . . . . . . . . . . . . . . . 16

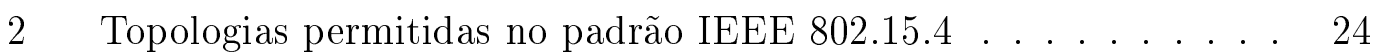

3 Estrutura do superframe ................. 25

$4 \quad$ Ilustração do IFS . . . . . . . . . . . . . . . . . . . . . . 27

5 Mecanismo de $\mathrm{CSMA} / \mathrm{CA} \ldots \ldots \ldots 28$

6 Linha do tempo do Slotted CSMA . . . . . . . . . . . . . 29

$7 \quad$ Formato geral de quadro . . . . . . . . . . . . . . 30

8 Formato do frame control field . . . . . . . . . . . . . . 31

$9 \quad$ Formato do quadro de beacon . . . . . . . . . . . . 31

10 Formato do quadro de ACK . . . . . . . . . . . . . 32

11 Representação gráfica de Rede de Petri . . . . . . . . . . . . . 33

12 Disparo de transição . . . . . . . . . . . . . . . . . . 34

13 Exemplo de espaço de estados . . . . . . . . . . . . . . . 34

14 Máquina de vendas automática .............. 35

15 Modelo de fila com rede de Petri estocástica generalizada . . . . . 37

16 Problema do jantar dos filósofos em rede de Petri colorida . . . . 39

17 Problema do jantar dos filósofos em CPN - marcação inicial . . . 40

18 Problema do jantar dos filósofos em CPN - após um disparo . . . 41

19 Mecanismo de controle e sincronismo . . . . . . . . . . . . . . . 48

20 Chegada de quadros . . . . . . . . . . . . . . . . 49

21 Transmissão de quadro no CFP . . . . . . . . . . . . . . . 50

22 Iniciando o processo de $\mathrm{CSMA} / \mathrm{CA} \ldots \ldots . \ldots 50$

$23 \mathrm{CSMA} / \mathrm{CA} \ldots \ldots \ldots \ldots \ldots \ldots \ldots$ 
24 Colisão . . . . . . . . . . . . . . . . . . . 52

25 Modelo de nó da rede . . . . . . . . . . . . . . 54

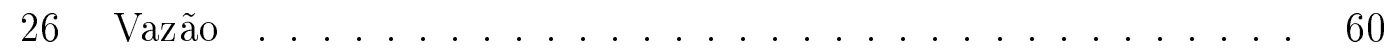

27 Taxa de perdas ....................... 61

28 Número de tentativas . . . . . . . . . . . . . . . . . 62

29 Modelo com três nós . . . . . . . . . . . . . . . . 63

30 Modelo CPN - Visão geral . . . . . . . . . . . . . . . . 66

$31 \quad$ Nó da rede . . . . . . . . . . . . . . . . 66

32 Envio por Contention Free Period . . . . . . . . . . . . 69

33 Rede de Petri para model check do algoritmo de CSMA/CA . . 70

34 Basestation ......................... 72

35 Meio de transmissão . . . . . . . . . . . . . . . 73

36 Espaço de estados do cenário 1: sem perdas e sem ACK . . . . . 75

37 Espaço de estados do cenário 2: sem perdas e com ACK . . . . 75

38 Espaço de estados do cenário 3: CSMA ok, com perdas e sem ACK 76

39 Padrão do cenário 4: com perdas e sem ACK . . . . . . . 76

40 Padrão do cenário 5: com ACK, sem perdas, com timeout precoce 77

41 Cenários 6 e 7 - com perdas e com ACK . . . . . . . 78

42 Padrão do cenário 8: com perdas, com ACK e com timeout precoce 80

43 Fragmentos do espaço de estados CSMA/CA . . . . . . . . 81

44 Visão geral do modelo CPN para análise de desempenho . . . . . 83

45 Nó da rede - fragmento análogo ao modelo da Seção 4.1 . . . . 85

46 Nó da rede - fragmento de controle de tempo . . . . . . . 86

47 Chegada de quadros . . . . . . . . . . . . 88

48 Envio por Contention Free Period . . . . . . . . . . . . 89

49 Modelo temporal do algoritmo de CSMA/CA . . . . . . . . 91 
50 Tratamento de ACK ..................... 94

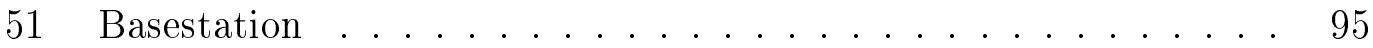

52 Meio de transmissão . . . . . . . . . . . . . . . . 996

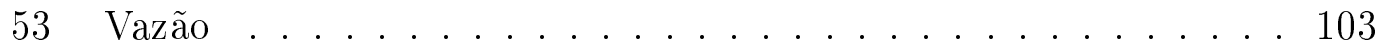

54 Taxa de Entrega ..................... 104

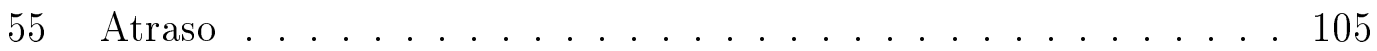

56 Histograma dos valores de atraso . . . . . . . . . . 105

57 Amostragem da taxa de chegada de pacotes . . . . . . . . 106

58 Atraso de quadros ao longo do superframe . . . . . . . . . . 107

59 Histograma dos instantes de ocorrência de colisão . . . . . . . . 107

60 Potência . . . . . . . . . . . . . . . . . 108

61 Variação do parâmetro AMAxFrameRETRIES - Taxa de tráfego . 113

62 Variação do parâmetro AMAxFrameRETRIES - Número de nós 114

63 Variação do parâmetro MACMAXCSMABACKOFFs - Taxa de trá-

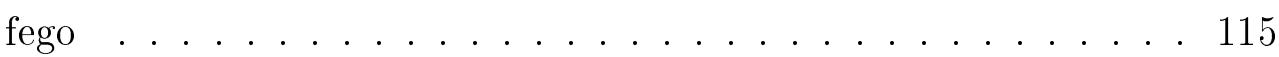

64 Variação do parâmetro MACMAXCSMABACKOFFs - Número de nós . . . . . . . . . . . . . . . . . . . . 116

65 Variação do parâmetro InitialCW - Taxa de tráfego . . . . . . . 117

66 Variação do parâmetro InitialCW - Número de nós . . . . . . 118

67 Variação do parâmetro AUnitBACKOFFPERIOD - Taxa de tráfego 119

68 Variação do parâmetro AUnitBACKOFfPERIOD - Número de nós 120

69 Estudo com tráfegos assimétricos . . . . . . . . . . . . . 122

70 Estudo de variação da proporção entre tamanho de quadro e taxa de quadro com taxa de bits constante . . . . . . . . . . . . 123 


\section{LISTA DE TABELAS}

$1 \quad$ Constantes e parâmetros do padrão IEEE 802.15 .4 . . . . . . . 30

2 Exemplo GSPN - marcações alcançáveis . . . . . . . . . . 37

3 Exemplo GSPN - Número médio de marcas em cada lugar . . . . 37

4 Exemplo CPN - declarações . . . . . . . . . . . . . . 39

$5 \quad$ Resumo das principais características dos trabalhos relacionados . 44

6 Métricas ......................... 45

$7 \quad$ Parâmetros . . . . . . . . . . . . . . 46

8 Taxas de chegada de quadros . . . . . . . . . . 56

9 Tempos - modelo de nó $\ldots \ldots \ldots \ldots$. . . . . . . . 57

10 Sumário de parâmetros - NS2 . . . . . . . . . . . . 58

11 Intervalo de confiança (95\%) para as simulações NS2 LOW BUF: valor absoluto e em relação ao valor médio da métrica . . . . . . . 59

12 Taxa de perdas somada à Vazão $[$ quadros $/ \mathrm{s}] \ldots$. . . . . . . . . . 61

13 Colorsets de nó . . . . . . . . . . . . . . . 67

14 Consequência da escolha das prioridades das transições relacionadas ao ACK, Timed out ACK e ACK PACKET . . . . . . . . 69

15 Cenários de model checking . . . . . . . . . . . 74

16 Variação de taxas de chegada de quadros e tempos de execução 101

17 Variação do número de nós e tempos de execução . . . . . . . . . 101

18 Intervalo de confiança (95\%) para as resultados do modelo CPN e do NS2: valor em relação ao valor médio da métrica . . . . . . . . 103

19 Parâmetros variados . . . . . . . . . . . . . . . 112

20 Valores de taxa de bits e parâmetros adotados . . . . . . . . . . 123 
21 Aumento dos valores das métricas nos cenários com maior agregação de dados em relação ao cenário com menos agregação . . . . . 124

22 Variação do parâmetro AMAXFRAMERETRIES - desvio padrão em relação ao valor médio da métrica . . . . . . . . . . . 135

23 Variação do parâmetro MACMAXCSMABACKOFFS - desvio padrão em relação ao valor médio da métrica . . . . . . . . . . 136

24 Variação do parâmetro INITIALCW - desvio padrão em relação ao valor médio da métrica . . . . . . . . . . . . . . 137

25 Variação do parâmetro AUNITBACKOFFPERIOD - desvio padrão em relação ao valor médio da métrica . . . . . . . . . . . . 138

26 Estudo com tráfegos assimétricos - desvio padrão em relação ao valor médio da métrica . . . . . . . . . . . . . . . . . . . 139

27 Estudo de variação da proporção entre tamanho de quadro e taxa de quadro com taxa de bits constante - desvio padrão em relação ao valor médio da métrica . . . . . . . . . . . . . . . . . 139 


\section{LISTA DE ABREVIATURAS E SIGLAS}

\begin{tabular}{|c|c|}
\hline $\mathrm{ACK}$ & ACKnowledgement \\
\hline $\mathrm{BE}$ & Backoff Exponent \\
\hline $\mathrm{BO}$ & Beacon Order \\
\hline BS & Base Station \\
\hline CAP & Contention Access Period \\
\hline $\mathrm{CCA}$ & Clear Clannel Assesment \\
\hline $\mathrm{CPN}$ & Coloured Petri Net \\
\hline CFP & Contention Free Period \\
\hline $\mathrm{CSMA} / \mathrm{CA}$ & Carrier Sense Multiple Access with Colision Avoidance \\
\hline $\mathrm{CW}$ & Contention Window \\
\hline FFD & Full Function Device \\
\hline GSPN & General Stochastic Petri Net \\
\hline GTS & Guaranteed Time Slot \\
\hline IEEE & Instituto de Engenheiros Eletricistas e Eletrônicos \\
\hline IFS & Inter-Frame spacing \\
\hline IoT & Internet of Things \\
\hline LR-WPAN & Low-Rate Wireless Personal Network \\
\hline MAC & Medium Access Control \\
\hline NB & Number of Backoffs \\
\hline PAN & Personal Area Network \\
\hline RFD & Reduced Function Device \\
\hline RSSF & Rede de Sensores Sem Fio \\
\hline $\mathrm{SO}$ & Superframe Order \\
\hline WLAN & Wireless Local Area Network \\
\hline
\end{tabular}




\section{SUMÁRIO}

$\begin{array}{llr}1 & \text { Introdução } & 15\end{array}$

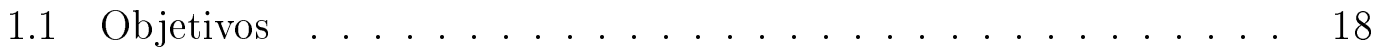

1.2 Justificativa . . . . . . . . . . . . . . . . . . . . . . . 19

1.3 Método ............................... 19

1.4 Organização do documento . . . . . . . . . . . . . . . . 20

2 Revisão Bibliográfica $\quad 22$

2.1 Padrão IEEE $802.15 .4 \ldots \ldots$. . . . . . . . . . . . . . 22

2.1.1 Formatos de quadro . . . . . . . . . . . . . . . 30

2.2 Redes de Petri ........................ 32

2.2.1 Rede de Petri Estocástica Generalizada . . . . . . . . . 35

2.2.2 Rede de Petri Colorida . . . . . . . . . . . . . . 38

2.3 Trabalhos Relacionados . . . . . . . . . . . . . . . . . 41

3 Modelo em Rede de Petri Estocástica Generalizada 47

3.1 Escopo do Modelo . . . . . . . . . . . . . . . . . . . 47

3.2 Mecanismo de controle e sincronismo . . . . . . . . . . . . 48

3.3 Modelo de nó da rede . . . . . . . . . . . . . . . . . . . 49

3.4 Validação . . . . . . . . . . . . . . . . . 55

3.4.1 Métricas de Desempenho . . . . . . . . . . . 55

3.4.1.1 Vazão ..................... 55

3.4.1.2 Taxa de perdas por nó . . . . . . . . . 55

3.4.1.3 Número médio de tentativas . . . . . . . . . 56

3.4 .2 Cenários ......................... 56 
3.4 .3 Resultados e Discussão . . . . . . . . . . . . . . . 58

3.5 Considerações do Capítulo . . . . . . . . . . . . . . 62

4 Modelo em Rede de Petri Colorida $\quad 64$

4.1 Modelo para análise do espaço de estados . . . . . . . . . . . 65

4.1.1 Visão Geral . . . . . . . . . . . . . . . . . 65

4.1 .2 Nó da rede. . . . . . . . . . . . . . 66

4.1.2.1 Envio por CFP . . . . . . . . . . . 69

4.1.2.2 Envio por CAP . . . . . . . . . . . . 69

4.1.3 Sorvedouro ..................... 72

4.1.4 Meio de transmissão . . . . . . . . . . . . . . 73

4.1.5 Análise do Modelo de rede . . . . . . . . . . . . . . 74

4.1.5.1 Análise do Modelo de CSMA/CA . . . . . . 81

4.1 .6 Considerações da seção . . . . . . . . . . . . . . . . 82

4.2 Modelo para análise de desempenho . . . . . . . . . . . . 82

4.2 .1 Visão Geral . . . . . . . . . . . . . . . . 83

4.2 .2 Nó da rede. . . . . . . . . . . . . . . . . . . 84

4.2.2.1 Processo de chegada de quadros . . . . . . . 87

4.2.2.2 Envio por CFP . . . . . . . . . . 89

4.2.2.3 Envio por CAP . . . . . . . . . . . 91

4.2.2.4 Tratamento de ACK . . . . . . . . . 93

4.2 .3 Sorvedouro . . . . . . . . . . . . . . . . 95

4.2 .4 Meio de transmissão . . . . . . . . . . . . . . . 96

4.2 .5 Validação . . . . . . . . . . . . . . . . . . . 98

4.2.5.1 Métricas de Desempenho.......... 98

4.2.5.1.1 Vazão . . . . . . . . . . . 9 98 
4.2.5.1.2 Taxa de entrega . . . . . . . . 99

4.2.5.1.3 Atraso ............... 99

4.2.5.1.4 Energia ............ 100

4.2.5.2 Cenários . . . . . . . . . . . 100

4.2.5.3 Resultados e Discussão . . . . . . . . . . . . . . 102

4.3 Considerações do Capítulo . . . . . . . . . . . . . . 109

5 Uso do modelo para análise de variação de parâmetros 111

5.1 Variação de Parâmetros . . . . . . . . . . . . . . . . 112

5.2 Tráfego assimétrico . . . . . . . . . . . . . . . . 121

5.3 Cenário de uso geral . . . . . . . . . . . . . . . . . 122

5.4 Considerações do capítulo . . . . . . . . . . . . . . . 124

6 Considerações Finais 126

6.1 Trabalhos Futuros . . . . . . . . . . . . . 126

6.2 Publicações . . . . . . . . . . . . . . . . . 127

$\begin{array}{lr}\text { Referências } & 128\end{array}$

Apêndice A - Tabelas de dispersão relativas ao uso do modelo para $\begin{array}{ll}\text { variação de parâmetros } & 134\end{array}$ 


\section{INTRODUÇÃO}

Este trabalho trata de redes de sensores sem fio (RSSF). Esta categoria de rede difere da rede local sem fio, frequentemente encontrada em nosso cotidiano (WLAN - Wireless Local Area Network), devido às diferenças no propósito, disposição espacial e características dos dispositivos envolvidos.

O objetivo das RSSF contempla aplicações de monitoramento. Diferentes alvos podem ser monitorados, como as condições do ambiente, por exemplo através de sensores de temperatura e umidade, seja em ambientes externos como florestas, plantações e parques (ANASTASI et al., 2009) ou em ambientes internos como fábricas, escritórios e residências (LU et al., 2010). Indivíduos de uma população de animais também podem ser monitorados, promovendo, por exemplo, o estudo de sua movimentação e hábitos (JUANG et al., 2002). Até mesmo seres humanos podem fornecer medidas de interesse, através de sensores de movimentação, batimentos cardíacos e outros indicadores de saúde (ALVES et al., 2012).

O emprego de RSSF é chave para implementação da Internet das Coisas (Internet of Things - IoT), conceito em que objetos da vida cotidiana são munidos de poder computacional e colaboram através da internet para atingir uma aplicação alvo (ATZORI; IERA; MORABITO, 2010). As cidades inteligentes (termo conhecido como smart city, em inglês) são uma faceta de IoT com o objetivo de facilitar o acesso a informações e serviços públicos de uma cidade. Este tema também se apoia em RSSF e tem sido discutido com frequência (ZANELLA et al., 2014; JIN et al., 2014).

Esta gama de aplicações faz com que a quantidade de dispositivos (também chamados de nós) varie entre as configurações de redes. Além da quantidade de nós, outros fatores são a densidade da rede (esparsa ou densa) e mobilidade dos dispositivos (fixos ou móveis em diferentes padrões de movimento) (CULLER; ESTRIN; SRIVASTAVA, 2004). 
Os dispositivos utilizados geralmente são miniaturizados e possuem poder computacional reduzido, com microcontroladores com frequência na faixa de 4 a $200 \mathrm{MHz}$ e memórias RAM e ROM de poucos quilobytes. Os transceptores de radiofrequência presentes nestes dispositivos também são simples e de potência reduzida. Um exemplo de dispositivo é o telosB da Memsic, exibido na Figura 1. Suas características são: processador de $8 M H z, 10 k B$ de memória RAM, $16 k B$ de memória ROM e rádio de potência variável entre -24 e 0dBm (MEMSIC INC., 2004).

Figura 1: Módulo sensor telosB

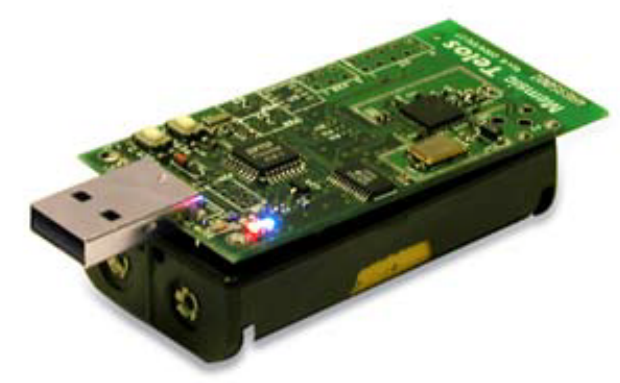

Fonte: MEMSIC Inc. (2004)

Estas restrições são importantes para possibilitar a redução de custo de implantação e aumentar o tempo de vida dos dispositivos, através da diminuição do consumo de energia, estendendo a duração da reserva energética tipicamente limitada pelo uso de baterias cuja troca pode não ser trivial ou viável (por exemplo, caso a frequência de troca seja elevada ou os dispositivos sejam numerosos ou de difícil acesso).

No tocante à economia de energia, atenção especial precisa ser dada aos protocolos de comunicação, pois grande parte dos recursos energéticos do nó sensor são dispendidos na troca de dados (MARGI et al., 2010).

O modelo inicialmente idealizado para estabelecer comunicação entre dispositivos computacionais é o Modelo Open Systems Interconnection (OSI) de sete camadas (ISO Standard, 1994). No contexto da Internet, as três camadas superiores (sessão, apresentação e aplicação) são unificadas na camada de aplicação, no que pode ser chamado de Modelo Internet de cinco camadas. Especificamente quando se trata de RSSF a camada de transporte em geral não existe ou é fundida às camadas adjacentes. Isto ocorre pois conexões fim-a-fim podem ser difíceis de manter ou desnecessárias (KAWADIA; KUMAR, 2005). 
Por esta razão, há bastante pesquisa sobre as camadas de enlace e roteamento. O desenvolvimento de protocolos específicos é necessário pois os protocolos de enlace e roteamento empregados em WLANs estruturadas são inapropriados para RSSF, pois estes não tem como prioridade a economia dos recursos limitados, principalmente a energia.

Da mesma forma, os protocolos de roteamento clássicos empregados em redes ad-hoc (DSDV, DSR e AODV (PERKINS; BHAGWAT, 1994; IETF, 2007; PERKINS; ROYER, 1999)) apresentam tradeoffs em relação à vazão alcançada, sobrecarga e custo energético de forma que nenhum deles é adequado para RSSF. Portanto, foram propostos protocolos específicos, como o LEACH (HEINZELMAN; CH; BALAKRISHNAN, 2000), que faz uso de clustering e o Data Mules (SHAH et al., 2003), utilizado para redes esparsas. Alguns protocolos cooperam com a aplicação para melhorar a performance, como o SPIN (KULIK; HEINZELMAN; BALAKRISHNAN, 2002) que faz agregação de dados e o Directed Difusion (INTANAGONWIWAT et al., 2003), que se baseia no interesse dos nós em receber os dados.

Protocolos de camada 2 também foram propostos, baseando-se em diferentes estratégias, como S-MAC (YE; HEIDEMANN; ESTRIN, 2004) e T-MAC (DAM; LANGENDOEN, 2003) baseados em acesso aleatório e que utilizam períodos de desativação dos nós. Outra estratégia é a multiplexação no tempo (scheduling), na qual o momento de transmissão de pacotes é acordado, evitando colisões e retransmissões, caso do TRAMA (RAJENDRAN; OBRACZKA; GARCIA-LUNA-ACEVES, 2003) e FLAMA (RAJENDRAN; GARCIA-LUNA-AVECES; OBRACZKA, 2005).

Contudo, o protocolo implementado na maioria dos dispositivos é o especificado no padrão IEEE 802.15.4 (ATZORI; IERA; MORABITO, 2010; IEEE, 2003). Este protocolo possibilita tanto o uso de acesso aleatório quanto scheduling, além de conter especificações sobre a camada física. Diversos protótipos de aplicações no contexto de IoT e cidades inteligentes utilizam este padrão (ZANELLA et al., 2014; ALVES et al., 2012; SILVA; ALVARO, 2012).

Apesar do padrão IEEE 802.15.4 ser prominente em RSSF, este ainda passa por estudos de modificações e ajustes de parâmetros (VALLE et al., 2012; SEMPREBOM et al., 2009; PETROVA et al., 2006) e alterações ou adendos (IEEE, 2012a; IEEE, 2012b; IEEE, 2012c). 
Através de modelos é possível estudar tanto a realidade em si quanto alterações da mesma, sem a necessidade de construir ou interferir concretamente no objeto de estudo. Assim, a existência de um modelo deste padrão propicia o estudo de ajustes de parâmetros e alterações no comportamento do protocolo e a obtenção de uma estimativa inicial do desempenho resultante antes de submeter as alterações à implementação real.

Uma das etapas da modelagem de protocolos de rede é a determinação da probabilidade de sucesso da transmissão dos quadros. Se o protocolo modelado pertencer a uma das camadas mais altas da pilha de protocolos, este parâmetro pode ser abstraído para uma porcentagem, de acordo com o nível de congestionamento esperado na rede. Porém, os protocolos de camada de enlace utilizam o estado do meio de transmissão como subsídio para sua execução, necessitando de uma modelagem cuidadosa da ocorrência de colisões.

Como será detalhado na Seção 2.3, os trabalhos de modelagem do padrão IEEE 802.15.4 se baseiam fortemente no cálculo explícito das probabilidades de se encontrar o meio ocupado e de ocorrência de colisão, que requerem que uma séria de hipóteses sejam feitas, por vezes não intencionalmente (MISIC; MISIC; SHAFI, 2004; SHUAIB; MAHMOODI; AGHVAMI, 2009; FARIDI et al., 2010).

Desta forma, o principal progresso entre os trabalhos ao longo do tempo é o aprimoramento das hipóteses realizadas para o cálculo destas probabilidades. Observa-se a existência de retrabalho, uma vez que os modelos são reconstruídos sem se basear nos anteriores, ao passo que os esforços poderiam ser concentrados em modelar outros aspectos do protocolo ou obter maior quantidade de métricas. Mudar a forma como a modelagem é realizada poderia quebrar este ciclo de retrabalho, por exemplo utilizando uma abordagem comportamental invés de probabilística.

Seria possível modelar o protocolo inerente ao padrão IEEE 802.15.4 através de uma abordagem comportamental?

\section{$1.1 \quad$ Objetivos}

O objetivo deste trabalho é demonstrar que é possível realizar a modelagem comportamental de um protocolo de camada de enlace através de um modelo para 
análise de desempenho do padrão IEEE 802.15.4. Espera-se que esta abordagem permita a modelagem de cenários assimétricos e que os parâmetros do padrão possam ser alterados com facilidade. Para verificar a validade do método, métricas obtidas através do modelo serão comparadas com valores de referência, obtidos através de simulação. As métricas de interesse são vazão, taxa de perdas, gasto de energia, atraso e número médio de tentativas para enviar um quadro.

\subsection{Justificativa}

Uma abordagem frequente para modelar o IEEE 802.15.4 é a Cadeia de Markov (NORRIS, 1998), na qual todos os estados do sistema devem ser discriminados e as taxas de transição entre um estado e outro devem ser todas determinadas. Neste trabalho as Redes de Petri (MURATA, 1989) serão utilizadas. Neste formalismo é possível realizar a modelagem com foco no comportamento desejado, diferentemente de nos estados alcançáveis. Com o modelo comportamental será possível contornar o cálculo explícito das probabilidades.

Além disso, utilizar Redes de Petri permite que cada nó da rede seja discriminado, de forma que a rede possa ser assimétrica devido aos diferentes parâmetros. Analogamente, permite a alteração simples desses parâmetros, como número de retransmissões, tempo de backoff, proporção entre tempo ativo e inativo, bem como facilita alterações mais profundas na estrutura do protocolo. Outra possibilidade é utilizar o modelo para realizar o model check, ou seja, verificar se o modelo está aderente ao padrão através da análise do espaço de estados.

\subsection{Método}

O primeiro passo para a elaboração do modelo foi o estudo detalhado do padrão IEEE 802.15.4, através de sua especificação. Os aspectos essenciais para transmissão de dados foram selecionados para a modelagem, o que inclui algoritmos, métodos de acesso, formatos de quadro e as durações dos tempos de atraso.

Um modelo utilizando rede de Petri generalizada estocástica foi concebido, visando a implementar os aspectos citados no parágrafo anterior, utilizado a ferramenta PIPE (BONET et al., 2007). Observe-se que não foram utilizados cálculos 
de probabilidades para concretizar o modelo.

Com o modelo pronto, foram extraídas as métricas de vazão, taxa de perdas e número médio de tentativas para se enviar um quadro através da resolução analítica do modelo. Utilizou-se os parâmetros padrão, variando-se a taxa de envio de quadros, para uma rede com dois nós e um sorvedouro (ou base station - BS, em inglês). Os resultados foram comparados com simulações realizadas no NS2 (MCCANNE; FLOYD, 2012), que é amplamente utilizado em RSSF, seja por outros trabalhos de modelagem do padrão IEEE 802.15.4, tais como Park et al. (2005) e Wen et al. (2009), ou para aferir o desempenho de outros protocolos da camada de enlace e roteamento, como o S-MAC (YE; HEIDEMANN; ESTRIN, 2004) e Directed Difusion (INTANAGONWIWAT et al., 2003) .

O próximo teste seria aumentar o número de dispositivos na rede, porém esse passo se mostrou impraticável devido à explosão combinatória do tamanho do espaço de estados. Um modelo utilizando redes de Petri coloridas (JENSEN; KRISTENSEN, 2009) foi derivado do primeiro modelo com a finalidade de contornar essa limitação através da simulação do modelo. A ferramenta utilizada foi o CPN Tools (RATZER et al., 2003).

O processo de model checking foi conduzido para verificar a aderência à especificação. Novos experimentos foram realizados com objetivo de validar o modelo, coletando as métricas de vazão, taxa de entrega, gasto de energia e atraso. Novamente os resultados foram comparados com simulações no NS2.

Após a validação, o modelo foi utilizado para estudar cenários com variação de parâmetros do padrão IEEE 802.15.4, com assimetrias de tráfego entre os nós da rede e com taxa de bits constante, variando a proporção entre o tamanho e a taxa de chegada de pacotes. Os experimentos foram realizados com objetivo de demonstrar o uso prático do modelo, em cenários que seriam difíceis de se reproduzir no simulador NS2 ou em outros modelos.

\subsection{Organização do documento}

O restante deste documento está organizado da seguinte forma: o Capítulo 2 contém a revisão bibliográfica, contemplando o padrão IEEE 802.15.4, conceitos de rede de Petri e trabalhos anteriores da literatura. Os Capítulos 3 e 4 mos- 
tram os modelos produzidos, detalhando o processo de concepção e validação. $O$ Capítulo 5 exibe cenários de uso do modelo. Por fim, o Capítulo 6 apresenta as considerações finais, incluindo trabalhos futuros e a lista de publicações realizadas durante o mestrado. 


\section{REVISÃO BIBLIOGRÁFICA}

Este capítulo apresenta a revisão bibliográfica contendo a descrição do padrão IEEE 802.15.4, conceitos de redes de Petri e uma discussão sobre os trabalhos relacionados.

\subsection{Padrão IEEE 802.15.4}

A primeira versão do padrão IEEE 802.15.4 foi publicada em 2003 pelo Instituto de Engenheiros Eletricistas e Eletrônicos (IEEE) com objetivo de fornecer padronização para comunicação sem fio de baixo custo, complexidade, consumo de energia e taxa de dados reduzida. O projeto foi idealizado para dispositivos simples, baratos e com restrições de fonte de energia, móveis ou fixos (IEEE, 2003).

Inicialmente este padrão foi criado para redes pessoais (low-rate wireless personal network, LR-WPAN), tipicamente contidas em um espaço de até 10 metros. Porém, as implementações alcançam até várias dezenas de metros (MEMSIC INC., 2004), possibilitando aplicação em redes de sensores sem fio, uma vez que há requisitos semelhantes de restrição de complexidade, custo e energia.

O padrão contém definições sobre a camada física e a camada de acesso ao meio (medium access control, MAC). Na primeira versão do padrão (IEEE, 2003), a camada física poderia operar na frequência de $868 \mathrm{M} \mathrm{Hz}, 900 \mathrm{MHz}$ ou $2.4 \mathrm{GHz}$, com taxa de dados nominal de 20, 40 e $250 \mathrm{~kb} / \mathrm{s}$, respectivamente. Em 2006 foi realizada a primeira revisão do padrão, incorporando novos tipos de modulação na camada física (compatibilidade com padrão europeu) e algumas mudanças e modificações na camada de enlace (IEEE, 2006). Na versão de 2011 foram editadas as emendas de 2006, 2007 e 2009, sendo que as principais alterações nas duas últimas se referem a novas camadas físicas (uma delas específica para fazer medições de distância e outras por compatibilidade com as frequências utilizadas 
localmente no Japão e na China) (IEEE, 2011).

Em 2012 foram propostas três emendas. O IEEE 802.15.4e especifica mecanismos para melhorar o suporte a aplicações industriais, utilizando o $D e$ terministic and Synchronous Multi-channel Extension (DSME), entre outras modificações (IEEE, 2012a). Nas outras duas emendas, IEEE 802.15.4f e IEEE 802.15.4g (IEEE, 2012b; IEEE, 2012c), o foco são novas possibilidades na camada física, bem como eventuais alteração na camada MAC, necessárias para acomodar as mudanças da outra camada. De forma semelhante, dois adendos foram incorporados em 2013, IEEE 802.15.4j e IEEE 802.15.4k, com novas possibilidades para a camada física (IEEE, 2013a; IEEE, 2013b).

Uma lista completa das mudanças pode ser encontrada na introdução de cada versão da especificação do padrão. As descrições contidas neste documento têm como base a versão de 2011 (IEEE, 2011), com foco na camada MAC.

O padrão define dois tipos de nó na rede: Dispositivo de Capacidade Plena (Full Function Device - FFD) ou Dispositivo de Capacidade Reduzida (Reduced Function Device - RFD). O primeiro tipo pode, além de enviar e receber dados, definir uma nova rede à qual outros dispositivos podem se associar, tornando-se o que é chamado na nomenclatura do protocolo de coordenador de PAN (Personal Area Network). Alternativamente, um FFD pode se associar a um coordenador de PAN e ser responsável por prover sincronização a outros nós associados, caso em que exerce a função de nó coordenador. Outra diferença é que somente os coordenadores de PAN possuem a capacidade de administrar os slots de tempo utilizados para multiplexar a troca de quadros (GTSs - Guaranteed Time Slots). Os RFDs tem a capacidade somente de enviar e receber dados, associando-se a no máximo um FFD.

Quanto à topologia, o padrão permite duas formas de organização: estrela, na qual toda a comunicação é centralizada no coordenador de PAN e, portanto, os nós da rede não se comunicam entre si; e ponto-a-ponto, na qual qualquer nó pode se comunicar com qualquer outro de sua vizinhança. Um caso especial da topologia ponto-a-ponto consiste na formação de clusters, na qual cada coordenador de PAN estabelece um cluster. Uma ilustração destes tipos de topologia é exibida na Figura 2. A formação da topologia não é definida no padrão e fica a cargo das camadas de rede superiores. 
Figura 2: Topologias permitidas no padrão IEEE 802.15.4
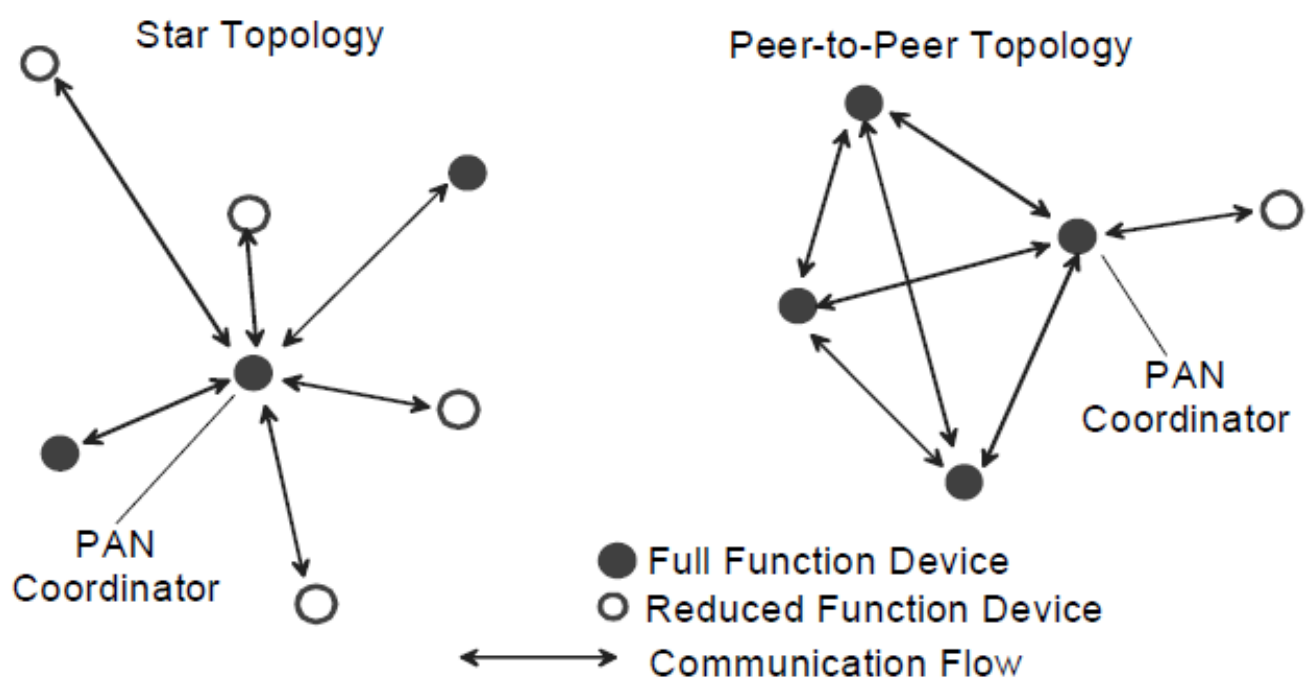

Fonte: IEEE (2011, p. 9)

A transmissão dos dados pode ocorrer de forma direta ou indireta. No caso da topologia estrela, só pode ocorrer de forma indireta, pois os quadros são entregues primeiramente ao coordenador. Para que o quadro chegue ao seu destino, o destinatário deve pedir o encaminhamento ao coordenador. Se for uma rede com Beacon $^{1}$, o destinatário sabe que há um quadro para ele através de informações contidas no Beacon. Numa rede sem Beacon, o destinatário deve perguntar periodicamente ao coordenador por quadros pendentes. As transmissões diretas são mais simples, pois um dispositivo simplesmente envia o quadro ao outro. Porém caso os dispositivos utilizem uma política de desligar o rádio para poupar energia, estes devem encontrar uma forma de se sincronizar, o que está fora do escopo do padrão.

A camada MAC suporta dois modos de operação: modo com Beacon e modo sem Beacon. No modo de operação sem Beacon todos os dispositivos (sejam FFD ou RFD) enviam quadros através de um algoritmo baseado em unslotted CSMA/CA (Carrier Sense Multiple Access with Colision Avoidance). Não é possível utilizar guaranteed time slots (GTSs) e não há sincronia entre os dispositivos.

No modo com Beacon é utilizada uma estrutura de tempo para sincronizar e organizar a troca de dados entre os nós da rede. Esta é denominada superframe e seu formato é exibido na Figura 3.

\footnotetext{
${ }^{1}$ quadro de controle periódico, mais informação a seguir
} 
Figura 3: Estrutura do superframe

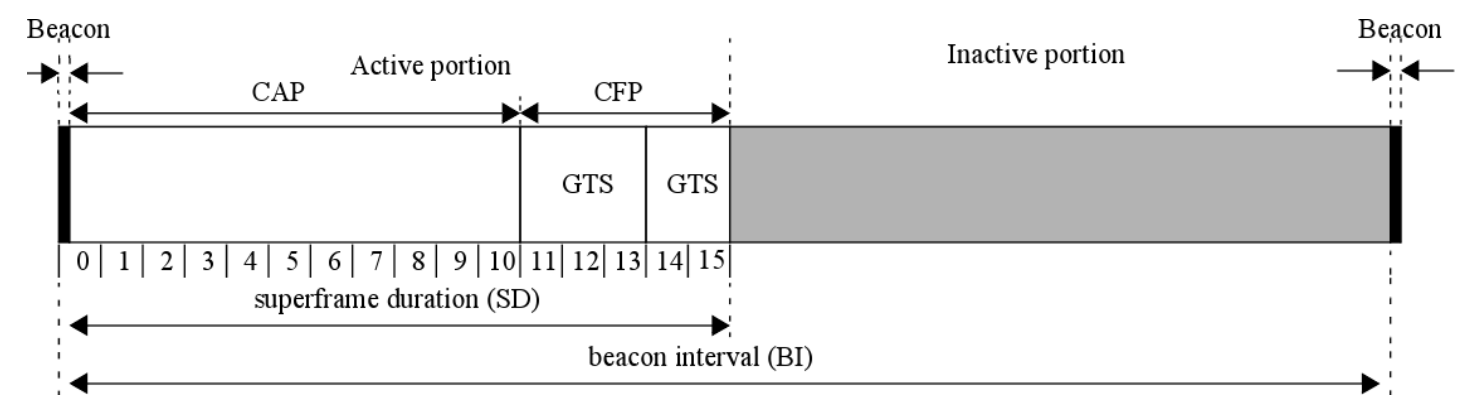

Fonte: IEEE (2011, p. 20)

O superframe inicia-se com um quadro de controle (o Beacon), enviado pelo coordenador de PAN, e contém informações de sincronismo e da organização do superframe que virá a seguir. Depois do Beacon há um período em que os nós disputam o acesso ao meio (CAP - Contention Access Period). Um algoritmo baseado em slotted CSMA/CA é utilizado.

Após o CAP, pode haver um período no qual os quadros são enviados sem competição para acessar o meio (CFP - Contention Free Period). A alocação de um Guaranteed Time Slot (GTSs) inicia-se com uma mensagem de requisição enviada pelo nó ao coordenador de PAN, contendo a quantidade de slots e a direção do GTS. Os critérios que definem o momento de disparo da requisição de GTS estão fora do escopo do padrão e ficam a cargo das camadas superiores da pilha de protocolos.

Somente o coordenador de PAN pode realizar a alocação de GTS e estes podem ser utilizados somente para comunicação entre dispositivo e coordenador de PAN. A requisição é respondida com um ACK ao ser recebida. Porém isso não significa que o GTS foi alocado, apenas que a requisição foi entregue com sucesso. O coordenador de PAN decide se a alocação é possível de acordo com os recursos disponíveis. O CAP não deve se tornar menor do que aMinCAPLength, que é equivalente a 440 símbolos. Após decidir, o coordenador de PAN inclui em seu beacon um descritor de GTS, contendo o endereço do nó, o slot em que o GTS se inicia e a quantidade de slots alocados. Se o GTS não foi alocado com sucesso, o slot de início é preenchido com zero. Caso contrário, é preenchido com o slot de início do GTS, escolhido de forma que todos os GTSs fiquem no final do período ativo do superframe. A alocação de um GTS dura por, no máximo, aGTSDescPersistenceTime Beacons, podendo ser descartado antes 
disso, a pedido do coordenador de PAN ou do dispositivo.

Por fim, há um período de inatividade opcional, encerrado pela transmissão do próximo quadro Beacon. Durante este período, os dispositivos podem desativar o circuito de rádio com o objetivo de economizar energia. Se assim for feito, é necessário reativar o rádio no modo de recepção na iminência do envio esperado do próximo Beacon. O dispositivo pode desligar seu rádio durante o CAP também, se o parâmetro macRxOnWhenIdle estiver igual a falso. Durante o CFP, o dispositivo deve ligar seu receptor se possuir algum GTS alocado para recepção de dados, caso contrário pode mantê-lo desligado.

A duração de cada período é determinada por alguns parâmetros. Os valores temporais são baseados no parâmetro constante aBaseSuperframeDuration, cujo valor é definido a partir de outros dois, multiplicando aBaseSlotDuration pelo aNumSuperframeSlots. O primeiro diz respeito à duração mínima de um slot (caso em que Superframe Order $=$ Beacon Order $=0)$, que equivale a 60 símbolos, e o segundo diz que a parte ativa do superframe é dividida em 16 slots, totalizando 960 símbolos.

A taxa nominal de transmissão de dados do padrão é $250 \mathrm{kbps}$ na sua versão de $2.4 G H z$, e cada símbolo carrega 4 bits, resultando na taxa de símbolos de $62.5 k s p s$. Consequentemente, o valor de aBaseSuperframeDuration convertido para unidade temporal é $\frac{960}{62.5}=15.36 \mathrm{~ms}$.

A razão entre o tempo ativo (contemplando CAP e CFP) e o tempo inativo é dado por dois parâmetros, BO (Beacon Order) e SO (Superframe Order). O período ativo é chamado de superframe duration (SD) e o período entre um beacon e outro é chamado de beacon interval (BI). A duração dos períodos SD, BI e inativo podem ser calculados pelas Equações 2.1, 2.2 e 2.3, respectivamente.

$$
\begin{aligned}
S D & =\text { aBaseSuper frameDuration } * 2^{S O} \\
B I & =\text { aBaseSuperframeDuration } * 2^{B O} \\
T_{\text {inativo }} & =T_{B I}-T_{S D}
\end{aligned}
$$

Uma nova PAN pode ser formada por um FFD a pedido da camada superior da pilha de protocolos. O dispositivo deve reiniciar os parâmetros da camada MAC e realizar uma varredura dos canais disponíveis. A camada superior então 
escolhe o identificador $(P A N i d)$ e o canal de operação da nova PAN. Para se associar a uma PAN um outro dispositivo realiza a varredura dos canais e a camada superior deve escolher a qual PAN deseja se associar.

Qualquer que seja o modo de operação, deve haver um tempo mínimo entre o envio de quadros, conforme ilustrado na Figura 4. Este intervalo é chamado de espaçamento inter-quadros (inter frame spacing, IFS) e sua duração depende do tamanho do quadro. Após o envio de um quadro menor de 18 bytes o atraso será o equivalente a 12 símbolos (short IFS ou SIFS), caso contrário durará 40 símbolos (long IFS ou LIFS).

Figura 4: Ilustração do IFS

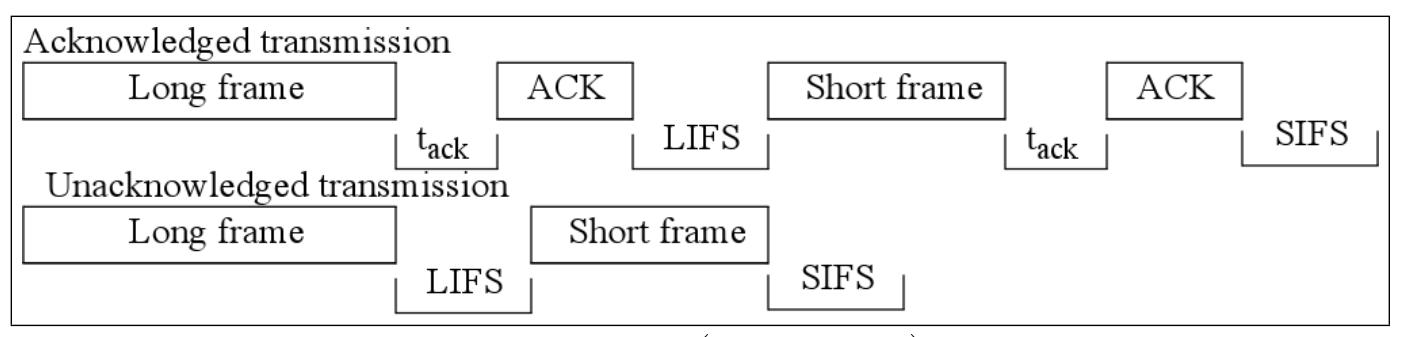

Fonte: IEEE (2011, p. 21)

Se a transmissão com confirmação estiver habilitada (acknowledged transmission), o IFS é realizado somente após o quadro de confirmação, entre o quadro de dados e o ACK ocorre um atraso variável $\left(\mathrm{t}_{\text {ack }}\right)$, de no mínimo macSIFSPeriod e no máximo macSIFSPeriod + aUnitBackoffPeriod. Na versão inicial do padrão era exigido sincronia entre os dispositivos e o ACK deveria ser enviado em um momento exato (chamado backoff boundary, explicado abaixo), porém, por simplicidade, na versão mais recente essa exigência foi removida, mas a possibilidade foi mantida para que haja compatibilidade.

Em termos de algoritmo, os mecanismos de CSMA/CA executam o procedimento exibido no diagrama da Figura 5. A unidade de tempo utilizada é chamada de período de backoff, com a duração de aUnitBackoffPeriod. A maioria das ações são realizadas nos limites entre os períodos de backoff. Esse limite é também chamado de backoff boundary. 
Figura 5: Mecanismo de CSMA/CA

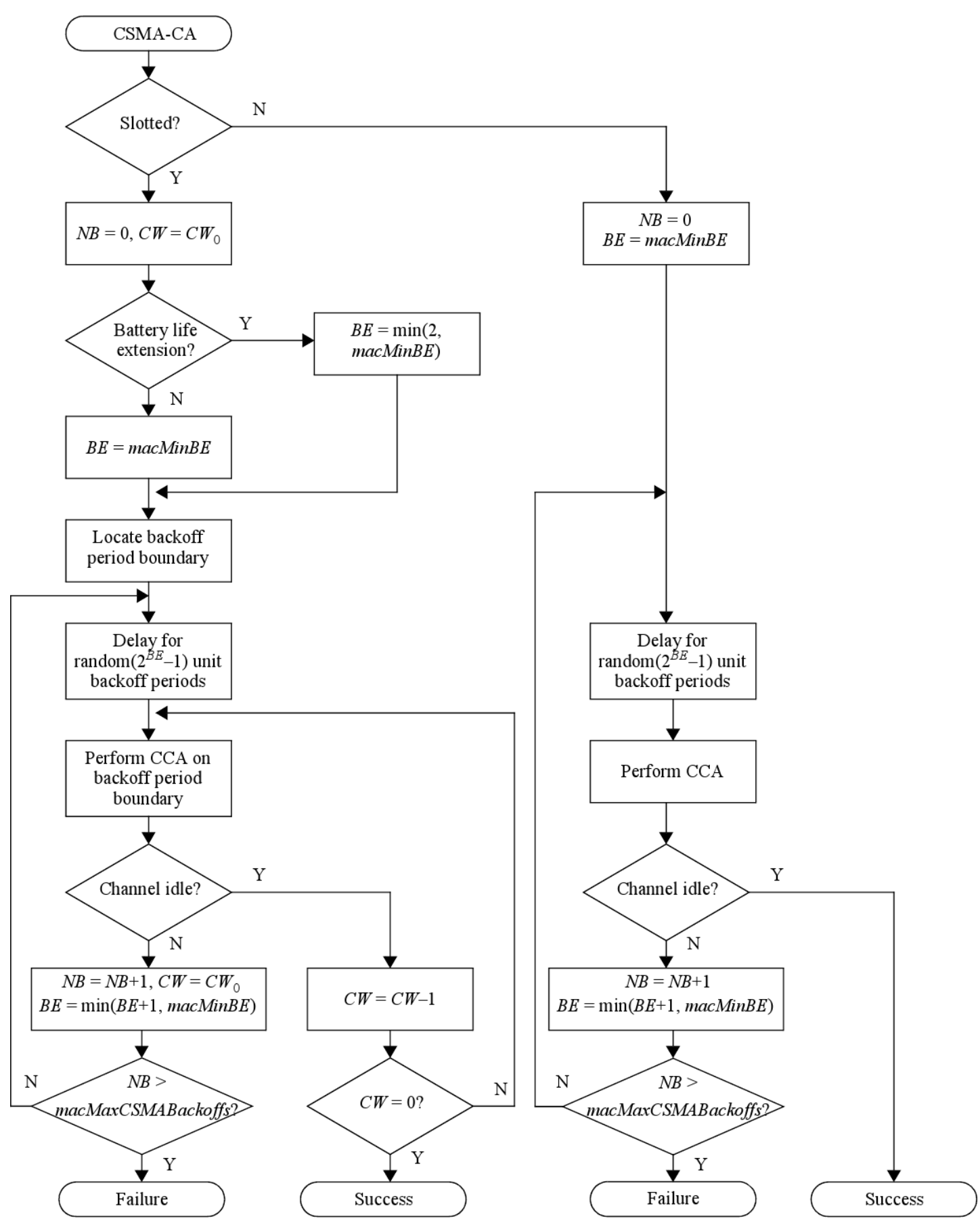

Fonte: IEEE (2011, p. 23) 
Nas redes com Beacon, a versão slotted é utilizada durante o CAP. As variáveis mantidas durante a execução do algoritmo são BE (backoff exponent), NB (number of backoffs) e CW (contention window). O procedimento inicia-se com um atraso de valor aleatório contido no intervalo $\left[1,2^{B E}-1\right]$. O próximo passo é escutar o canal (CCA Clear Clannel Assesment) para verificar se o meio está livre. Se for dado como ocioso CW vezes seguidas, o nó inicia a transmissão. Se o canal for dado ocupado alguma vez, o valor de CW é reiniciado e soma-se um a $\mathrm{BE}$ e NB, sendo que BE não ultrapassa o valor de macMaxBE. Antes de verificar o meio novamente, aguarda-se um intervalo de valor aleatório contido no intervalo $\left[1,2^{B E}-1\right]$. Se NB chegar ao valor máximo, a transmissão é dada como falha.

A Figura 6 ilustra a execução do algoritmo ao longo do tempo, indicando o instante de ocorrência dos eventos. As linhas verticais representam os slot boundaries, instantes em que o período de backoff deve iniciar e terminar. Também é o instante em que o CCA se inicia, porém observe-se que o meio só é verificado de fato após a sua duração de 8 símbolos. A propagação do quadro não precisa seguir a divisão dos slot boundaries. A Figure também explicita a diferença entre sincronizar ou não o envio do ACK com o backoff boundaries.

Figura 6: Linha do tempo do Slotted CSMA

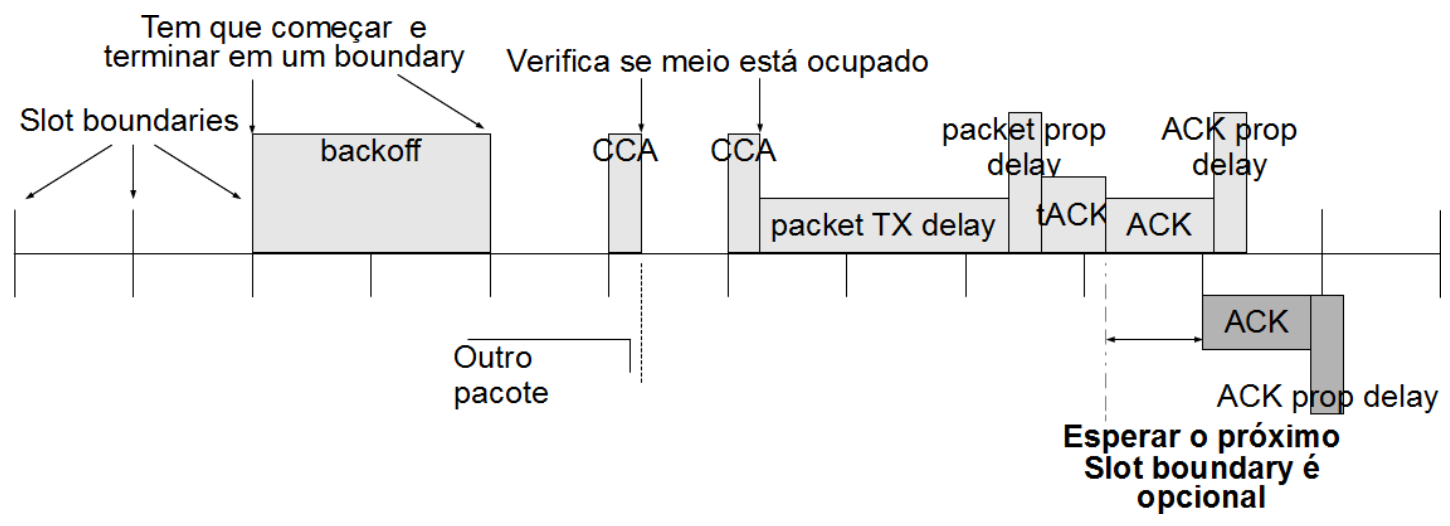

Fonte: Autor

Nas redes sem Beacon a versão unslotted é utilizada. O procedimento é semelhante, porém sem o mecanismo do CW, ou seja, o quadro é enviado assim que o meio for encontrado disponível.

A Tabela 1 contém um resumo de parâmetros mais relevantes do padrão. A lista completa pode ser obtida na especificação (IEEE, 2011). 
Tabela 1: Constantes e parâmetros do padrão IEEE 802.15.4

\begin{tabular}{|c|c|}
\hline Constante ou parâmetro & Valor \\
\hline aBaseSlotDuration & 60 símbolos \\
aGTSDescPersistenceTime & 4 beacons \\
aMaxSIFSFrameSize & 18 bytes \\
aMinCAPLength & 440 símbolos \\
aUnitBackoffPeriod & 20 símbolos \\
macAckWaitDuration & símbolos (para $2.4 \mathrm{GHz}$ ) \\
macBeaconOrder & de 0 a 15 \\
macSuperframeOrder & de 0 a 15 \\
macMaxBE & de 3 a 8, padrão 5 \\
macMinBE & de macMaxBE, padrão 3 \\
macMaxCSMABackoffs & de a 5, padrão 4 \\
macMaxFrameRetries & de 0 a 7, padrão 3 \\
macLIFSPeriod & 40 símbolos \\
macSIFSPeriod & 12 símbolos \\
macRxOnWhenIdle & verdadeiro ou falso, padrão falso \\
\hline
\end{tabular}

Fonte: IEEE (2011)

\subsubsection{Formatos de quadro}

Os quadros da camada MAC deste padrão possuem a estrutura exibida na Figura 7. Existem quatro tipos de quadros: de dados, beacon, comando e acknowledgement.

Figura 7: Formato geral de quadro

\begin{tabular}{|c|c|c|c|c|c|c|c|c|}
\hline Octets: 2 & 1 & $0 / 2$ & $0 / 2 / 8$ & $0 / 2$ & $0 / 2 / 8$ & $0 / 5 / 6 / 10 / 14$ & variable & 2 \\
\hline \multirow[t]{2}{*}{$\begin{array}{l}\text { Frame } \\
\text { Control }\end{array}$} & \multirow[t]{2}{*}{$\begin{array}{l}\text { Sequence } \\
\text { Number }\end{array}$} & $\begin{array}{c}\text { Destination } \\
\text { PAN } \\
\text { Identifier }\end{array}$ & $\begin{array}{c}\text { Destination } \\
\text { Address }\end{array}$ & $\begin{array}{c}\text { Source } \\
\text { PAN } \\
\text { Identifier }\end{array}$ & $\begin{array}{c}\text { Source } \\
\text { Address }\end{array}$ & \multirow[t]{2}{*}{$\begin{array}{c}\text { Auxiliary } \\
\text { Security } \\
\text { Header }\end{array}$} & \multirow[t]{2}{*}{$\begin{array}{l}\text { Frame } \\
\text { Payload }\end{array}$} & \multirow[t]{2}{*}{ FCS } \\
\hline & & \multicolumn{4}{|c|}{ Addressing fields } & & & \\
\hline \multicolumn{7}{|c|}{ MHR } & $\begin{array}{c}\text { MAC } \\
\text { Payload }\end{array}$ & MFR \\
\hline
\end{tabular}

Fonte: IEEE (2011, p. 57)

O primeiro campo é o Frame Control Field, composto por dois octetos, detalhado na Figura 8. Este campo contém informações sobre o tipo do quadro (frame type), segurança do quadro (security enabled), se há mais quadros a serem enviados (frame pending), se ACK é requerido (AR), um parâmetro de compressão do endereçamento (PAN ID Compression), informações sobre o endereço do remetente e do destinatário (que pode ser curto, longo ou ausente) (Destination 
Addressing Mode e Source Addressing Mode) e um campo sobre compatibilidade entre as versões do padrão (Frame Version).

Figura 8: Formato do frame control field

\begin{tabular}{|c|c|c|c|c|c|c|c|c|}
\hline $\begin{array}{c}\text { Bits: } \\
\mathbf{0 - 2}\end{array}$ & $\mathbf{3}$ & $\mathbf{4}$ & $\mathbf{5}$ & $\mathbf{6}$ & $\mathbf{7 - 9}$ & $\mathbf{1 0 - 1 1}$ & $\mathbf{1 2 - 1 3}$ & $\mathbf{1 4 - 1 5}$ \\
\hline $\begin{array}{c}\text { Frame } \\
\text { Type }\end{array}$ & $\begin{array}{c}\text { Security } \\
\text { Enabled }\end{array}$ & $\begin{array}{c}\text { Frame } \\
\text { Pending }\end{array}$ & AR & $\begin{array}{c}\text { PAN ID } \\
\text { Compression }\end{array}$ & Reserved & $\begin{array}{c}\text { Dest. } \\
\text { Addressing } \\
\text { Mode }\end{array}$ & $\begin{array}{c}\text { Frame } \\
\text { Version }\end{array}$ & $\begin{array}{c}\text { Source } \\
\text { Addressing } \\
\text { Mode }\end{array}$ \\
\hline
\end{tabular}

Fonte: IEEE (2011, p. 57)

O segundo campo contém o data sequence number (DSN) do quadro, um número utilizado para identificar o quadro. O DSN é inicializado de forma aleatória e é incrementado a cada quadro enviado, sendo permitido o estouro após alcançar o valor máximo. Os campos seguintes são de endereçamento, indicando o identificador de PAN e endereço do destinatário e remetente. Se um deles estiver ausente, assume-se que é o endereço do coordenador da rede. O campo de segurança contém as informações necessárias para realizar o procedimento de segurança, se security enabled for verdadeiro no Frame Control Field (IEEE, 2011, cap. 7). Depois há o payload, discutido adiante. O último campo é o frame check sequence (FCS), que possui a finalidade de verificar a integridade do quadro.

O campo de payload contém as informações transmitidas. Se for um quadro de dados, o conteúdo deste campo é repassado para a camada superior da pilha de protocolos. Se for um quadro com um comando, a camada MAC deve decodificar e executar o comando recebido. No caso de quadros de beacon, o payload é uma série de dados de controle, como mostra a Figura 9.

Figura 9: Formato do quadro de beacon

\begin{tabular}{|c|c|c|c|c|c|c|c|c|}
\hline Octets: 2 & $\mathbf{1}$ & $\mathbf{4 / 1 0}$ & $\mathbf{0 / 5 / 6 / 1 0 / 1 4}$ & $\mathbf{2}$ & variable & variable & variable & $\mathbf{2}$ \\
\hline $\begin{array}{c}\text { Frame } \\
\text { Control }\end{array}$ & $\begin{array}{c}\text { Sequence } \\
\text { Number }\end{array}$ & $\begin{array}{c}\text { Addressing } \\
\text { fields }\end{array}$ & $\begin{array}{c}\text { Auxiliary } \\
\text { Security } \\
\text { Header }\end{array}$ & $\begin{array}{c}\text { Superframe } \\
\text { Specification }\end{array}$ & $\begin{array}{c}\text { GTS } \\
\text { fields }\end{array}$ & $\begin{array}{c}\text { Pending } \\
\text { address } \\
\text { fields }\end{array}$ & $\begin{array}{c}\text { Beacon } \\
\text { Payload }\end{array}$ & FCS \\
\hline \multicolumn{70}{|c|}{ MHR } & \multicolumn{3}{c|}{ MAC Payload } & MFR \\
\hline
\end{tabular}

Fonte: IEEE (2011, p. 61)

O campo superframe specification contém os valores de $\mathrm{BO}$ e SO, o tamanho do CAP, o parâmetro batery life extension, a informação sobre quem enviou o beacon (se é coordenador de PAN ou não), e se novas associações são permitidas. 
Em seguida, há os campos relacionados aos GTSs, que contém a quantidade de GTS alocados, a direção de cada um e a descrição. A descrição inclui o endereço curto do nó, o número do slot e o comprimento do GTS. Em seguida, há a quantidade e lista de endereços dos nós da rede que possuem quadros a serem entregues armazenados no coordenador. Por fim, há o campo de payload, contendo dados enviados pela camada superior da pilha de protocolos.

O quadro de ACK possui menor número de campos, conforme a estrutura da Figura 10. Não há parâmetros de segurança, payload ou endereçamento. A verificação de qual quadro o ACK pertence é feita pelo número de sequência.

Figura 10: Formato do quadro de ACK

\begin{tabular}{|c|c|c|}
\hline Octets: 2 & $\mathbf{1}$ & $\mathbf{2}$ \\
\hline Frame Control & Sequence Number & FCS \\
\hline \multicolumn{2}{|c|}{ MHR } & MFR \\
\hline
\end{tabular}

Fonte: IEEE (2011, p. 65)

Todo quadro de camada MAC é acompanhado pelo cabeçalho da camada física, que contém um preâmbulo, um campo com a quantidade de octetos do payload e outro campo com dados, que são os quadros da camada MAC.

\subsection{Redes de Petri}

Rede de Petri é uma ferramenta de modelagem, proposta em 1962 por Carl Adam Petri (MURATA, 1989). A definição formal de uma Rede de Petri PN é a tupla apresentada na Equação 2.4 .

$$
P N=\left\{P, T, F, W, C_{0}\right\}
$$

Na qual:

- $P=\left\{p_{1}, p_{2}, \ldots p_{m}\right\}$ é um conjunto finito de $m$ lugares, com $m>0$,

- $T=\left\{t_{1}, t_{2}, \ldots t_{n}\right\}$ é um conjunto finito de $n$ transições, com $n>0$. A intersecção $P \cap T$ deve ser vazia,

- $F \subseteq(P \times T) \cup(T \times P)$ é um conjunto de arcos,

- $F \rightarrow \mathbb{N}^{*}$ é a função que define o peso dos arcos, 
- $C_{0}$ é a marcação inicial.

Graficamente, é representada por um grafo direcionado, no qual as arestas são chamadas de arcos e há dois tipos de vértices, os lugares e as transições. Um número inteiro não-negativo é associado aos lugares. Este número representa a quantidade de marcas de cada lugar. As marcas podem representar a abstração de algum elemento da realidade. A representação gráfica dos elementos em uma rede clássica é exibida na Figura 11.

Figura 11: Representação gráfica de Rede de Petri

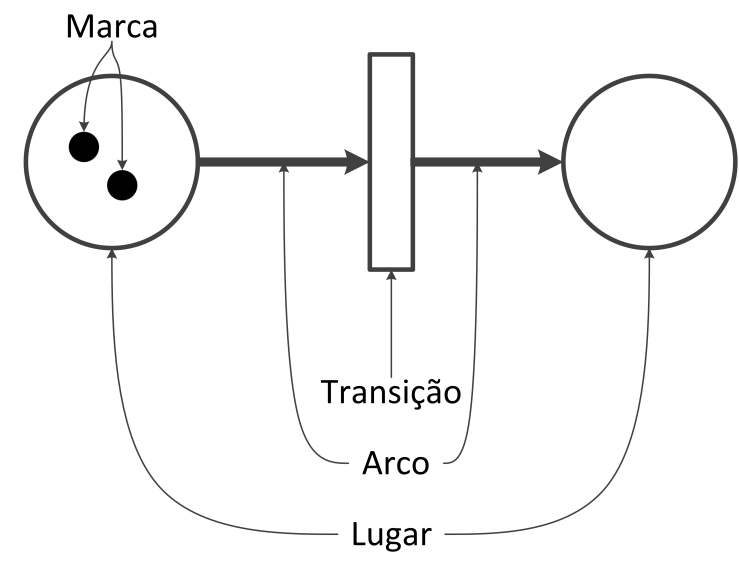

Fonte: Autor

O conjunto de pares ordenados formados por cada lugar e seu número de marcas define o estado da Rede de Petri que é alterado de acordo com o disparo de transições. O estado de uma Rede de Petri pode ser chamado alternativamente de marcação. No momento em que a transição é disparada uma marca é retirada de cada lugar de entrada da transição (i.e. lugares que possuem um arco para a transição) e uma marca é adicionada a cada lugar de saída da transição (i.e. lugares que possuem um arco da transição para o lugar), como mostrado na Figura 12. Uma transição pode disparar somente se estiver habilitada, ou seja, se os lugares de entrada possuírem marcas. Caso mais de uma transição estiver habilitada ao mesmo tempo, apenas uma delas poderá disparar. Note que arcos devem ser posicionados entre tipos diferentes de vértices e que uma transição pode disparar somente se cada lugar de entrada possuir pelo menos uma marca.

O conjunto de todas as marcações alcançáveis a partir de uma marcação inicial dada é chamado de espaço de estados da Rede de Petri. Por exemplo, o espaço de estados da rede ilustrada na Figura 11 é exibido na Figura 13. 
Figura 12: Disparo de transição

(a) Antes de disparar

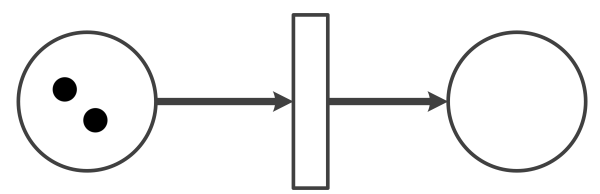

(b) Depois de disparar

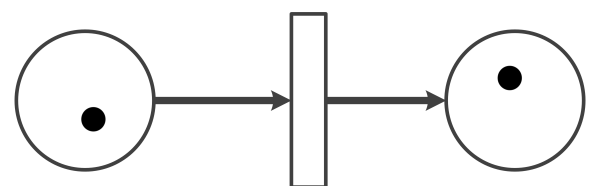

Fonte: Autor

Propriedades podem ser verificadas através do estudo do espaço de estados. Algumas delas são: alcançabilidade, na qual é verificado se determinada marcação é alcançável a partir de outra; o estudo do número de marcas (boundedness), na qual verifica-se o número máximo de marcas nos lugares da rede; vivacidade, que verifica se a rede de Petri estudada pode alcançar uma marcação em que nenhuma transição pode disparar. Outras propriedades são chamadas de estruturais, pois não dependem da marcação da rede, como o estudo dos invariantes (MURATA, 1989).

Figura 13: Exemplo de espaço de estados

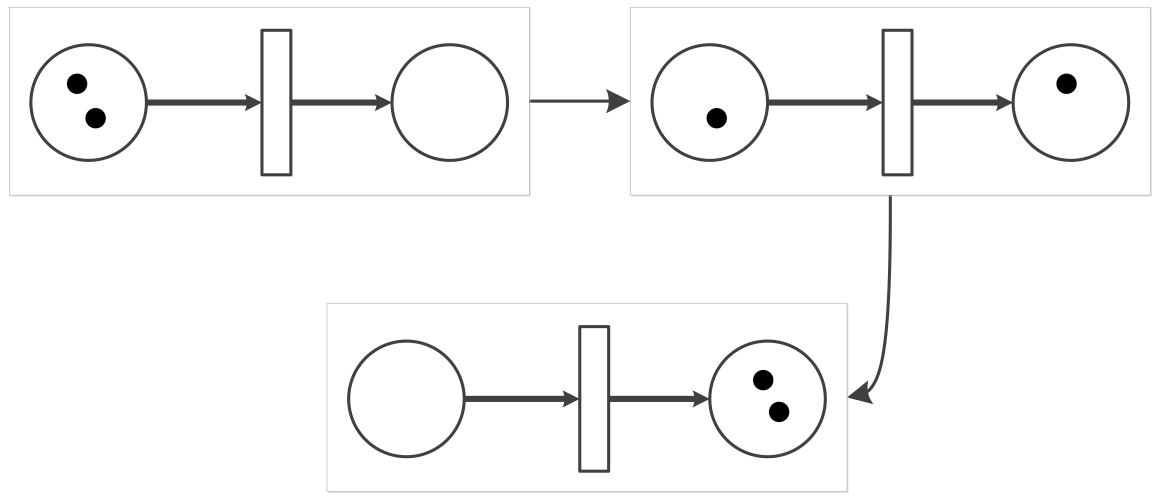

Fonte: Autor

Um exemplo de modelagem de um sistema em rede de Petri é exibido na Figura 14, no qual uma máquina de vendas automática é modelada. A figura exibe a marcação inicial da rede, onde a máquina está com seu estoque cheio (marcas no lugar estoque) e está pronta para receber uma moeda para ser trocada por uma mercadoria. Após a ocorrência do evento de recepção da moeda, há duas ações possíveis: rejeição da moeda que faz o sistema retornar ao estado inicial, ou a aceitação da moeda que permite a liberação da mercadoria. Mercadorias podem ser liberadas até que o estoque acabe, ponto em que a rede só pode evoluir o jogo de marcas após a reposição de itens. 
Figura 14: Máquina de vendas automática

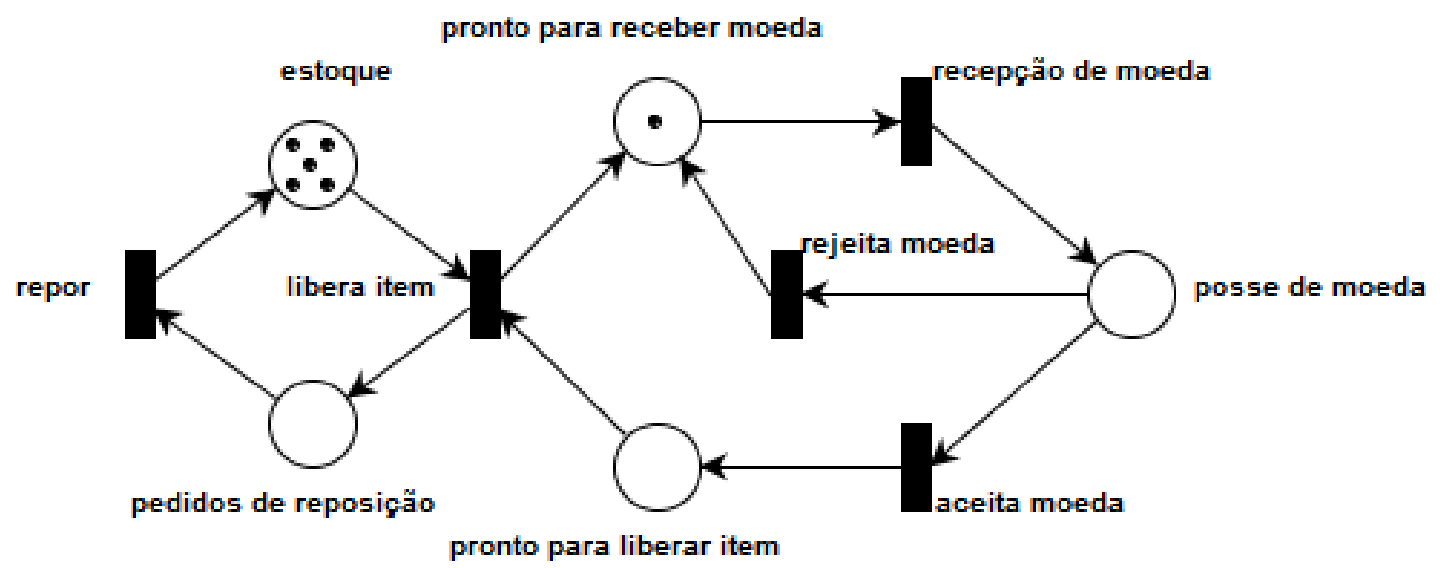

Fonte: Autor

Este é um exemplo bastante simples e melhorias poderiam ser feitas, dentre as quais adicionar a detecção de tipos de moedas ou permitir a existência de itens diferentes.

Com o passar do tempo, modificações foram propostas ao formalismo original, como a adição de arcos inibidores e de peso nos arcos (MURATA, 1989), a possibilidade de distinção entre marcas (redes de Petri coloridas e redes de alto nível) (JENSEN; KRISTENSEN, 2009; SMITH, 1998) e a introdução de noção de tempo (rede de Petri temporizada, temporal e estocástica) (RAMCHANDANI, 1974; MERLIN, 1974; MOLLOY, 1982). Os formalismos utilizados neste trabalho são a Rede de Petri Estocástica Generalizada (CHIOLA et al., 1993) e a Rede de Petri Colorida Temporizada (JENSEN; KRISTENSEN, 2009).

\subsubsection{Rede de Petri Estocástica Generalizada}

Formalmente, uma rede de Petri estocástica generalizada (ou GSPN - General Stochastic Petri Net, em inglês) é definida pela tupla exibida na Equação 2.5 (adaptado de Chiola et al. (1993)).

$$
R=\left\{P, T, I, O, W, L, C_{0}\right\}
$$

Na qual:

- $P=\left\{p_{1}, p_{2}, \ldots p_{m}\right\}$ é um conjunto finito de $m$ lugares, com $m>0$, 
- $T=\left\{t_{1}, t_{2}, \ldots t_{n}\right\}$ é um conjunto finito de $n$ transições, com $n>0$. A intersecção $P \cap T$ deve ser vazia,

- $I: T \rightarrow\left(P, \mathbb{N}^{*}\right)$ é a função de entrada, que define os lugares de entrada das transições e o peso do arco que os conecta,

- $O: T \rightarrow\left(P, \mathbb{N}^{*}\right)$ é a função de saída, que define os lugares de saída das transições e o peso do arco que os conecta,

- $W: T \rightarrow P$ é a função de arcos inibidores,

- $L=\left\{l_{1}, l_{2}, \ldots l_{n}\right\}$ é o conjunto de taxas de disparo associadas às transições temporais ou o valor de prioridade para as transições imediatas,

- $C_{0}$ é a marcação inicial.

Devido a esta extensão, uma transição temporal não dispara assim que se torna habilitada; mas ela dispara após um tempo sorteado a partir de uma distribuição exponencial. O parâmetro da distribuição é a taxa associada à transição, definida por L. Esta extensão permite estabelecer uma cadeia de Markov equivalente, da qual é possível retirar métricas relacionadas ao tempo, como taxa de disparo efetiva das transições e distribuição estatística do número de marcas em cada lugar. Transições instantâneas ainda podem existir e graficamente são exibidas como barras preenchidas em lugar de barras brancas.

Um exemplo deste tipo de rede de Petri é exibido na Figura 15. Uma fila única está modelada, de forma que o limite de usuários na fila é igual a cinco e há somente um servidor para atender aos usuários do sistema. Os eventos do sistema consistem na chegada de usuários à fila, no início do atendimento ao usuário e no fim do atendimento. A chegada e o fim do atendimento são temporais, de forma que as transições que representam estes eventos são temporais.

Os estados em que o sistema pode se encontrar são as marcações alcançáveis no modelo, exibidas na Tabela 2. As marcações equivalem ao estados em que o servidor está ocioso e aos estados em que o servidor está ocupado, variando-se o tamanho da fila de zero até 5, totalizando sete estados alcançáveis. Foram considerados somente as marcações perenes, ou seja, aquelas que não existem por tempo nulo. 
Figura 15: Modelo de fila com rede de Petri estocástica generalizada

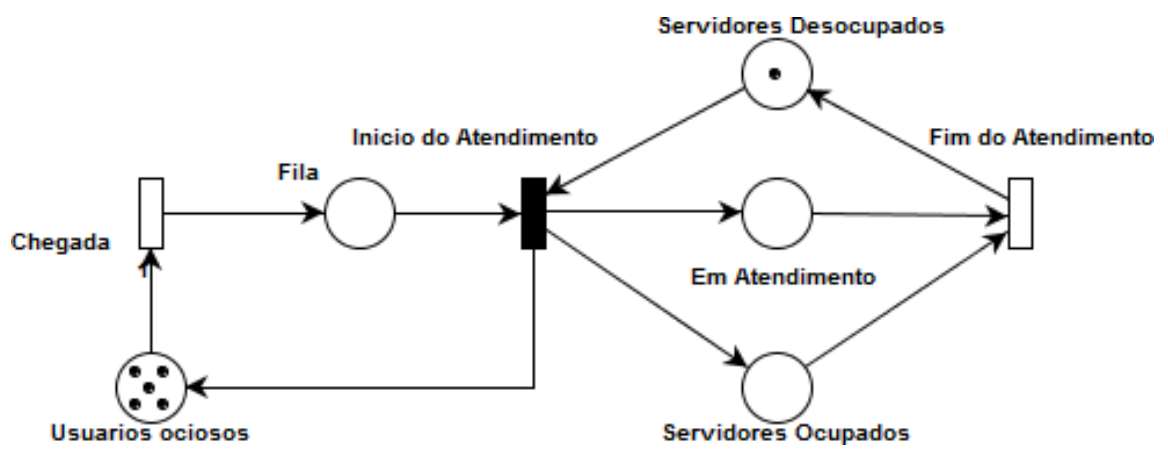

Fonte: Autor

Tabela 2: Exemplo GSPN - marcações alcançáveis

\begin{tabular}{|c|c|c|c|c|c|}
\hline Marcação & Fila & $\begin{array}{c}\text { Usuários } \\
\text { ociosos }\end{array}$ & Em Atendimento & $\begin{array}{c}\text { Servidores } \\
\text { Desocupados }\end{array}$ & $\begin{array}{c}\text { Servidores } \\
\text { Ocupados }\end{array}$ \\
\hline M0 & 0 & 5 & 0 & 1 & 0 \\
M1 & 0 & 5 & 1 & 0 & 1 \\
M2 & 1 & 4 & 1 & 0 & 1 \\
M3 & 2 & 3 & 1 & 0 & 1 \\
M4 & 3 & 2 & 1 & 0 & 1 \\
M5 & 4 & 1 & 1 & 0 & 1 \\
M6 & 5 & 0 & 1 & 0 & 1 \\
\hline
\end{tabular}

Fonte: Autor

Após resolver o sistema, pode-se obter o número médio de marcas em cada lugar, exibido na Tabela 3. A partir destes valores obtém-se algumas métricas de desempenho. Por exemplo, pelo número de marcas no lugar SERvidores OCUPADOS, sabe-se que o fator de utilização do servidor é $74.69 \%$ e pelo número de marcas no lugar FILA, o tamanho médio da fila é aproximadamente 1.4 usuários.

Tabela 3: Exemplo GSPN - Número médio de marcas em cada lugar

\begin{tabular}{|c|c|}
\hline Lugar & Número médio de marcas \\
\hline Fila & 1.39551 \\
Usuários ociosos & 3.60449 \\
Em Atendimento & 0.74693 \\
Servidores Desocupados & 0.25307 \\
Servidores Ocupados & 0.74693 \\
\hline
\end{tabular}

Fonte: Autor 


\subsubsection{Rede de Petri Colorida}

Formalmente podemos definir uma rede de Petri Colorida Temporizada (ou Timed Coloured Petri Net - CPN) pela tupla exibida na Equação 2.6 (JENSEN; KRISTENSEN, 2009).

$$
C P N_{T}=\{P, T, A, \Sigma, V, C, G, E, I\}
$$

Onde:

- $P$ é um conjunto finito de lugares,

- $T$ é um conjunto finito de transições e $P \cap T=\varnothing$,

- $A$ é um conjunto de arcos, $A \subseteq P \times T \cup T \times P$,

- $\Sigma$ é um conjunto finito de tipos (coloursets). Cada tipo é temporizado ou não temporizado,

- $V$ é um conjunto de variáveis, cujos tipos pertencem a $\Sigma$,

- $C: P \rightarrow \Sigma$ é uma função que atribui um tipo a cada lugar,

- $G: T \rightarrow$ Expr é uma função que atribui uma expressão de guarda booleana a cada transição,

- E : $A \rightarrow$ Expr é uma função que atribui uma expressão a cada arco,

- $I: P \rightarrow E x p r$ é uma função que atribui uma marcação inicial a cada lugar.

A marcação de um lugar utiliza o conceito de multiset, que é uma extensão da definição tradicional de conjuntos, porém seus elementos possuem multiplicidade. No caso de tipos temporizados, utiliza-se um multiset temporizado, onde os elementos possuem um atributo de tempo. Este formalismo possui um nível de abstração alto, possibilitando a distinção entre as marcas, que podem ser de vários tipos: unit (ou seja, sem distinção), inteiro, indexado, booleano, texto, entre outros.

É possível realizar operações com as marcas e elaborar condições de disparo de transições complexas. O software canonicamente utilizado é o CPN Tools (RATZER et al., 2003), baseado na linguagem de programação funcional StandardML. 
Figura 16: Problema do jantar dos filósofos em rede de Petri colorida

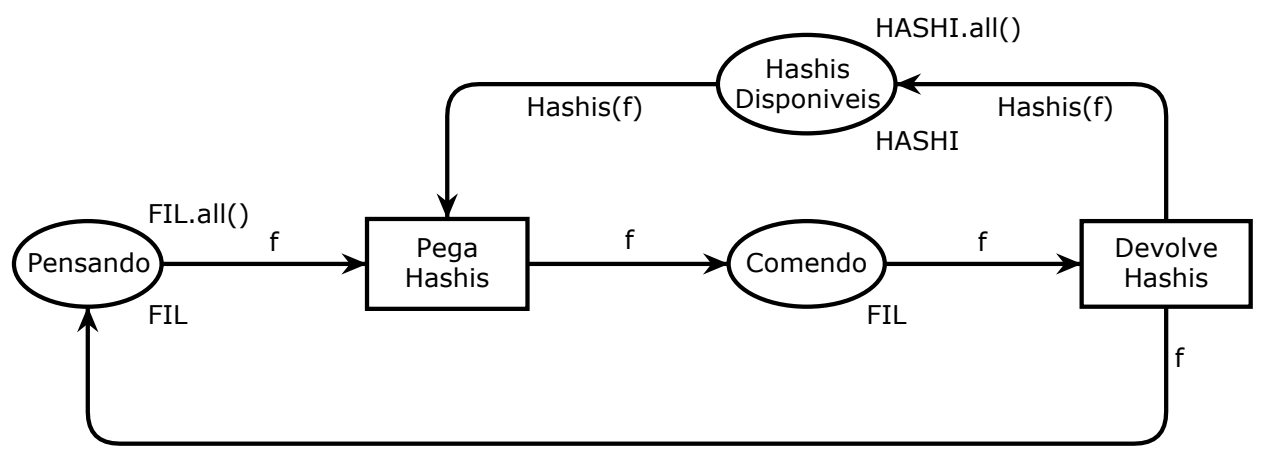

Fonte: Autor

Um modelo para o problema do jantar dos filósofos é exibido na Figura 16. O cenário do problema consiste em um conjunto de filósofos (originalmente cinco) jantando ao redor de uma mesa sobre a qual estão hashis (talheres orientais) na mesma quantidade de filósofos. Os talheres estão dispostos nos dois lados de cada prato de tal forma que há apenas um hashi entre cada dois filósofos. Os filósofos alternam entre pensar e comer, sendo que para comer precisam dos hashis que estão à sua esquerda e à sua direita.

Uma característica dos modelos em rede de Petri colorida é que a representação gráfica não é o suficiente para definir o modelo completamente. É necessário que o conjunto de declarações seja apresentado. Para o caso deste exemplo, as declarações são definidas na Tabela 4, de acordo com a linguagem CPN ML, utilizada na ferramenta CPNTools.

Tabela 4: Exemplo CPN - declarações

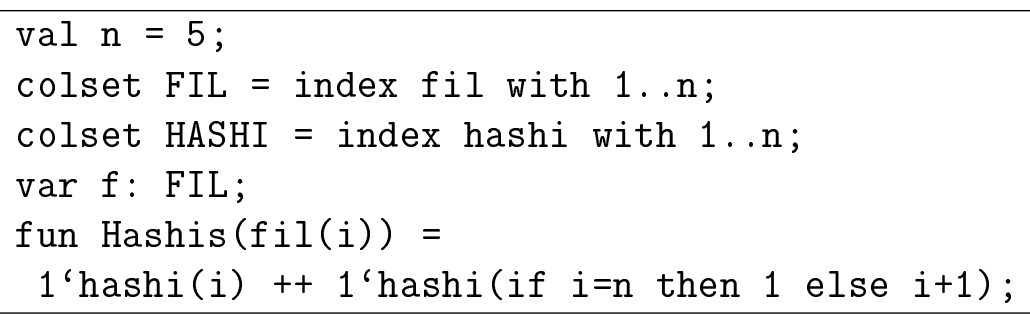

Fonte: Autor

Estas definições contém uma constante (n) que representa o número de filósofos e hashis no sistema. Os tipos (colorsets) utilizados são FIL e HASHI, ambos do tipo indexado. Há também uma variável do tipo filósofo e uma função que, dado um filósofo, retorna o seu par de hashis.

A marcação inicial da rede é exibida na Figura 17. A única transição habilitada é a PEGA HASHIs, porém qualquer um dos cinco filósofos pode ser atribuído 
à variável f. Binding é o nome do processo de atribuição de marcas às variáveis em uma transição. Uma vez escolhido o filósofo, os hashis são determinados automaticamente pela função Hashis ().

A Figura 18 exibe a marcação da rede após o disparo de PEGA HASHIS se a marca $\operatorname{FIL}(3)$ for atribuída à variável f. As marcas HASHI(3) e HASHI(4) são consumidas do lugar HASHIS DisPONíveIs e a marca FIL(3) passa para o lugar Comendo.

Figura 17: Problema do jantar dos filósofos em CPN - marcação inicial

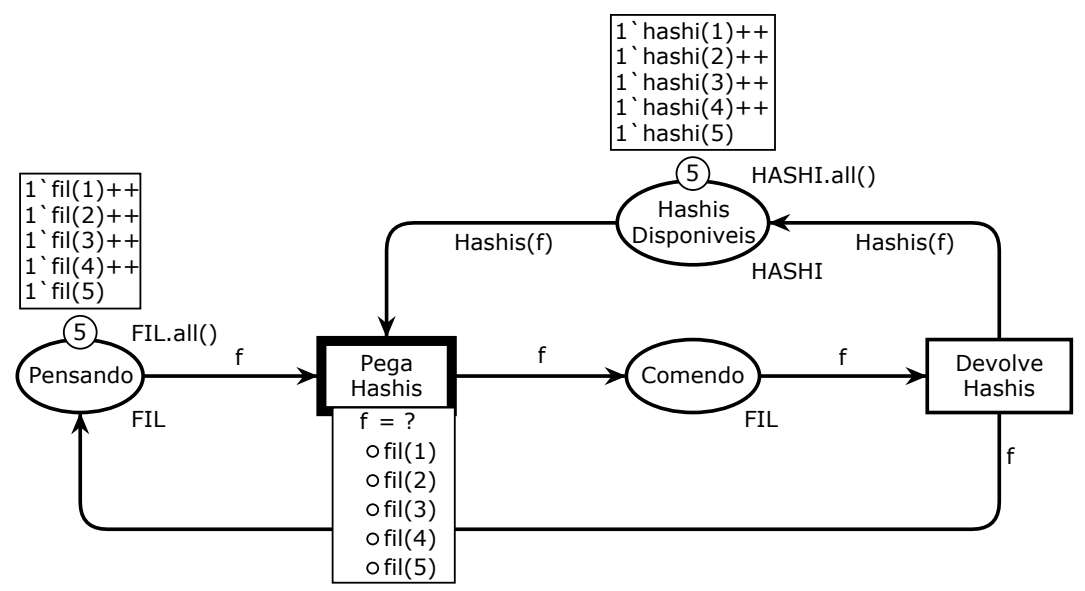

Fonte: Autor

Apesar da transição PEGA HASHIS continuar habilitada e haver quatro marcas no lugar PENSANDO, somente as marcas FIL(1) e FIL(5) podem ser atribuídas à variável $f$, devido à restrição da disponibilidade de hashis. A transição Devolve HAshis está habilitada nesta marcação, na qual a marca FIL(3) pode ser atribuída à variável $f$. Se esta transição for disparada, o sistema retorna à marcação inicial.

Uma vantagem de modelar este problema com rede de Petri colorida é que é muito simples alterar o tamanho do problema, isto é, o número de filósofos. Bastaria alterar o valor da constante $\mathrm{n}$ para o número desejado. Se o problema fosse modelado com rede de Petri clássica, seria necessário fazer mudanças estruturais na rede, adicionando ou removendo lugares e transições. 
Figura 18: Problema do jantar dos filósofos em CPN - após um disparo

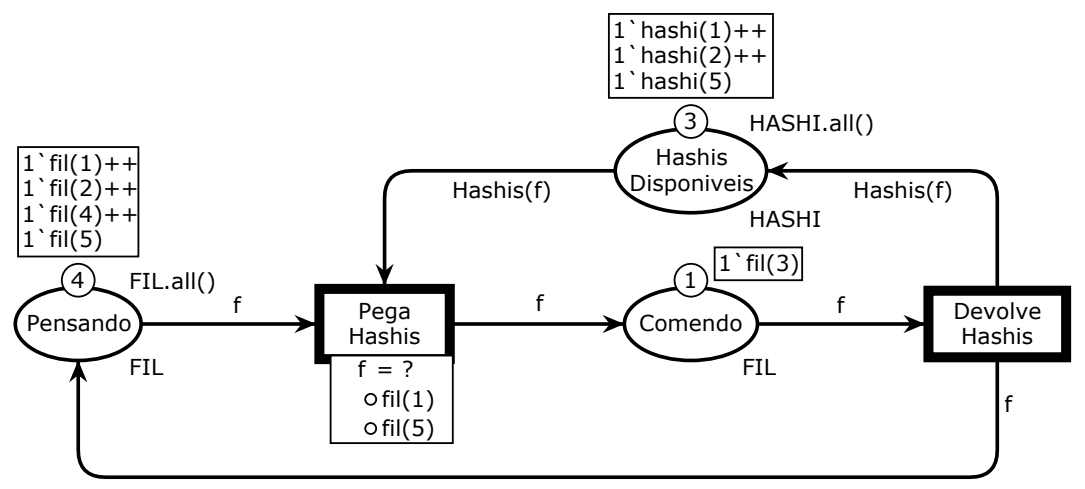

Fonte: Autor

\subsection{Trabalhos Relacionados}

Esta seção apresenta a revisão bibliográfica sobre as abordagens de modelagem do padrão IEEE 802.15.4 encontradas na literatura. Os trabalhos são abordados em conjunto segundo os tópicos de discussão escolhidos, que são o formalismo ou estratégia de modelagem empregada, as hipóteses simplificadoras adotadas, topologia e validação (valores de referência, métricas e parâmetros variados ou fatores).

A maioria dos trabalhos encontrados baseia-se em cadeia de Markov. O primeiro, de Misic, Misic e Shafi (2004), combinou teoria de filas para obter resultados na forma de fórmulas fechadas.

Park et al. (2005) e Wen et al. (2009) basearam-se em um modelo clássico do padrão IEEE 802.11 de Bianchi (2000), provendo resultados analíticos. Outros seguiram metodologias próprias (BURATTI, 2010; FARIDI et al., 2010; PARK; FISCHIONE; JOHANSSON, 2013), apesar de também utilizarem exclusivamente cadeia de Markov. Este três últimos trabalhos necessitam executar algoritmos de resolução em um computador para obter os resultados.

Os trabalhos que compartilham o uso do formalismo de cadeias de Markov têm um número grande de estados, tornando o modelo pouco intuitivo e dificultando seu maior uso.

Outros formalismos foram utilizados em uma quantidade menor de trabalhos. Shuaib, Mahmoodi e Aghvami (2009) empregaram uma rede de Petri clássica com sub-rotinas associadas às transições para auxilar o cálculo de estatísticas. 
Os autores não apresentaram fórmulas fechadas no artigo. Outra abordagem, utilizada por Fruth (2006), faz uso de um autômato estocástico temporizado, com verificação probabilística dos resultados.

Todos os modelos assumem hipóteses ao abstrair a realidade. Algumas hipóteses são escolhidas conscientemente para testar uma condição específica, aferir uma fração escolhida da especificação ou para facilitar a implementação do modelo, enquanto que outras podem ser consequências implícitas de escolhas de modelagem.

Um ponto de atenção é a modelagem do modo beacon e do CFP. Apenas dois dos trabalhos pesquisados levaram em conta o CFP em sua modelagem (BURATTI, 2010; PARK; FISCHIONE; JOHANSSON, 2013); todos os outros modelaram apenas o algoritmo de CSMA/CA do padrão.

A especificação do padrão IEEE 802.15.4 prevê acknowledgements opcionais. A maioria dos autores opta por modelar transmissões com ACK. Dos autores citados, somente Buratti (2010) modela transmissões sem ACK e somente Fruth (2006) permite ambos. Misic, Misic e Shafi (2004), apesar de considerar ACK, consideram infinitas retransmissões, até que o quadro seja reconhecido.

O envio de quadros pela camada dois está condicionado à geração de quadros nas camadas superiores. Portanto, é necessário modelar como esses quadros chegam na fila de envio da camada MAC, o que pode ser traduzido no tamanho dos quadros e chegada deles à fila de envio. A maioria dos autores optou por tamanho de quadro fixo (MISIC; MISIC; SHAFI, 2004; WEN et al., 2009; PARK et al., 2005; BURATTI, 2010; FARIDI et al., 2010; PARK; FISCHIONE; JOHANSSON, 2013). Fruth (2006) permite que os quadros tenham tamanhos não determinísticos. No modelo de Shuaib, Mahmoodi e Aghvami (2009), o tamanho dos quadros segue uma distribuição de Poisson. O principal argumento para se considerar o tamanho dos quadros como constante é que, em aplicações de RSSF, os quadros têm tamanhos bem determinados de acordo com os dados que transmite. Além disso, o tamanho fixo pode facilitar a tratabilidade analítica.

Constata-se uma variedade maior de hipóteses no que se refere à chegada de quadros. Alguns trabalhos consideram que os nós operam em condição de saturação, o que significa que sempre há um quadro para ser enviado, isto é, a fila do nó nunca está vazia (PARK et al., 2005; FARIDI et al., 2010). Misic, Misic 
e Shafi (2004) e Wen et al. (2009) consideram que os quadros são gerados de acordo com um processo de Poisson, enquanto que para Shuaib, Mahmoodi e Aghvami (2009) os quadros são enviados entre intervalos constantes. Buratti (2010) idealizou um modelo de tráfego em que o nó coordenador da rede requer dados ao enviar o quadro de Beacon, assim, os nós da rede enviam um quadro por superframe.

Já Park, Fischione e Johansson (2013) basearam-se em probabilidades. Ao terminar o processo de envio de um quadro há uma probabilidade do nó começar imediatamente o envio de um novo quadro. Se não for iniciar um outro envio imediatamente, após um período de tempo é feito um novo sorteio de envio de quadro baseado em uma outra taxa de probabilidade. Além disso, os quadros são probabilisticamente classificados entre críticos ou não, o que decide se o quadro será enviado por CAP ou CFP. No modelo de Fruth (2006) não há chegada de quadros, o cenário análise prevê que cada nó da rede possui apenas um quadro para ser enviado. Cada modelo de tráfego visa a representar um tipo de aplicação específica, de forma que todos os modelos são válidos de alguma forma. Contudo, ao utilizar os dados de experimentos para prever o desempenho em cenários reais, deve-se tomar cuidado com esta hipótese devido ao descolamento que pode haver entre o modelo e a realidade, e, consequentemente, no desempenho previsto.

O tamanho do buffer determina a quantidade máxima de quadros na fila nos trabalhos que consideram de alguma forma a chegada de quadros. Dois trabalhos permitem tamanho de buffer arbitrário (MISIC; MISIC; SHAFI, 2004; PARK; FISChIONE; JOHANSSON, 2013). Park et al. (2005) considera nós sem buffer, ou seja, se chegar um segundo quadro durante o envio de outro, o recém-chegado será descartado. Shuaib, Mahmoodi e Aghvami (2009) não revelam explicitamente como consideraram esta questão, porém percebe-se que este modelo considera buffer infinito. Nos outros trabalhos não faz sentido falar em tamanho de fila visto que ou é considerado um cenário de saturação (PARK et al., 2005; FARIDI et al., 2010) ou os nós mantém posse de somente um quadro por vez (FRUTH, 2006; BURATTI, 2010).

Todos os trabalhos consideraram topologia em estrela, exceto por Buratti (2010), que, além da topologia em estrela, utilizou o tipo de aplicação escolhida para facilitar a modelagem de um cenário com topologia em árvore. 
A Tabela 5 exibe um resumo das características apresentadas até o momento.

Tabela 5: Resumo das principais características dos trabalhos relacionados

\begin{tabular}{|l|c|c|l|l|l|l|}
\hline Autor & Formalismo & Topologia & Tráfego & CFP & ACK & Buffer \\
\hline $\begin{array}{l}\text { Misic, Mi- } \\
\text { sic e Shafi } \\
(2004)\end{array}$ & Markov & Estrela & Poisson & Não & Sim & $\begin{array}{l}\text { Arbi- } \\
\text { trário }\end{array}$ \\
\hline $\begin{array}{l}\text { Park et al. } \\
(2005)\end{array}$ & Markov & Estrela & Saturado & Não & Sim & $\begin{array}{l}\text { Satu- } \\
\text { rado }\end{array}$ \\
\hline $\begin{array}{l}\text { Wen et al. } \\
(2009)\end{array}$ & Markov & Estrela & Poisson & Não & Sim & $\begin{array}{l}\text { Unitá- } \\
\text { rio }\end{array}$ \\
\hline $\begin{array}{l}\text { Buratti } \\
(2010)\end{array}$ & Markov & Hierarquia & $\begin{array}{l}\text { Sob de- } \\
\text { manda }\end{array}$ & Sim & Não & $\begin{array}{l}\text { Unitá- } \\
\text { rio }\end{array}$ \\
\hline $\begin{array}{l}\text { Faridi et } \\
\text { al. }(2010)\end{array}$ & Markov & Estrela & Saturado & Não & Sim & $\begin{array}{l}\text { Satu- } \\
\text { rado }\end{array}$ \\
\hline $\begin{array}{l}\text { Park, Fis- } \\
\text { chione e } \\
\text { Johansson } \\
(2013)\end{array}$ & Markov & Estrela & $\begin{array}{l}\text { Constante } \\
\text { com con- } \\
\text { dicionais }\end{array}$ & Sim & Sim & $\begin{array}{l}\text { Arbi- } \\
\text { trário }\end{array}$ \\
\hline $\begin{array}{l}\text { Shuaib, } \\
\text { Mahmoodi } \\
\text { e Aghvami } \\
(2009)\end{array}$ & RdP Clássica & Estrela & Constante & Não & Sim & $\begin{array}{l}\text { Infi- } \\
\text { nito }\end{array}$ \\
\hline $\begin{array}{l}\text { Fruth } \\
(2006)\end{array}$ & Autômato & Estrela & Não tem & Não & $\begin{array}{l}\text { Opci- } \\
\text { onal }\end{array}$ & $\begin{array}{l}\text { Unitá- } \\
\text { rio }\end{array}$ \\
\hline $\begin{array}{l}\text { Este traba- } \\
\text { lho }\end{array}$ & GSPN/CPN & Estrela & $\begin{array}{l}\text { Poisson / } \\
\text { Arbitrário }\end{array}$ & Sim & $\begin{array}{l}\text { Opci- } \\
\text { onal }\end{array}$ & $\begin{array}{l}\text { Arbi- } \\
\text { trário }\end{array}$ \\
\hline
\end{tabular}

Fonte: Autor

A etapa que segue a concepção do modelo é a validação. Este passo consiste em realizar experimentos para comparar as métricas providas pelo modelo com valores de referência, em função dos parâmetros escolhidos.

As métricas mais relevantes no contexto de RSSF são vazão, taxa de entrega, gasto de energia e atraso de entrega de quadros. A Tabela 6 exibe quais trabalhos contemplam essas métricas, incluindo também as métricas aferidas por este trabalho. Os trabalhos divergem sobre a forma de aferir o gasto de energia, considerando o gasto energético por slot, bit, frame ou tempo.

Alguns trabalhos aferiram outras métricas. Misic, Misic e Shafi (2004) estudaram a probabilidade de um quadro ser descartado devido a estouro de buffer. Faridi et al. (2010) mediram a probabilidade de colisão. Park, Fischione e Johansson (2013) estudaram o comportamento transiente, além do regime permanente. 
Shuaib, Mahmoodi e Aghvami (2009) aferiram o número médio de CCAs para se enviar um frame e a quantidade de tempo desperdiçada no CAP.

Tabela 6: Métricas

\begin{tabular}{|l|c|c|c|c|}
\hline Autor & Vazão & Entrega & Energia & Atraso \\
\hline Misic, Misic e Shafi (2004) & Sim & - & - & Sim \\
\hline Park et al. (2005) & Sim & - & $\mathrm{mJ} / \mathrm{slot}$ & - \\
\hline Wen et al. (2009) & Sim & - & $\mathrm{mJ} / \mathrm{bit}$ & Sim \\
\hline Buratti (2010) & Sim & Sim & - & Sim \\
\hline Faridi et al. (2010) & Sim & Sim & Watts & Sim \\
\hline $\begin{array}{l}\text { Park, Fischione Johansson } \\
\text { (2013) }\end{array}$ & Sim & Sim & - & Sim \\
\hline $\begin{array}{l}\text { Shuaib, Mahmoodi e Agh- } \\
\text { vami (2009) }\end{array}$ & Sim & - & mJ/frame & - \\
\hline Fruth (2006) & - & Sim & - & Sim \\
\hline Este Trabalho & Sim & Sim & Watts & Sim \\
\hline
\end{tabular}

Fonte: Autor

Os parâmetros que cada autor variou (fatores) para observar as métricas estão na Tabela 7. Os principais são intensidade de tráfego, tamanho do quadro e quantidade de nós da rede. Somente um trabalho variou a capacidade do buffer. Alguns parâmetros do padrão IEEE 802.15.4 também são utilizados, como o macMinBE, quantidade máxima de backoffs (NB) e superframe order (SO). Este trabalho variou alguns outros parâmetros do padrão, como o limite de tentativas de envio (number of tries - NoT), o tamanho da janela de contenção (contention window - CW) e a unidade básica do backoff (BkPeriod). Embora não tenha sido realizado, é possível variar o tamanho do buffer e o tamanho dos quadros neste trabalho. Não há duas linhas iguais na tabela, o que dificulta a comparação entre modelos, já que a variação dos parâmetros utilizados é diferente.

Os valores de referência utilizados para validar os modelos geralmente são obtidos através de simuladores de rede. Park et al. (2005) e Wen et al. (2009) utilizaram o NS2, o mesmo utilizado para validar o modelo proposto neste trabalho. Alguns autores optaram por desenvolver simuladores próprios (BURATTI, 2010; FARIDI et al., 2010), o que pode ser tendencioso, já que o simulador pode conter as mesmas premissas estabelecidas pelo modelo. Buratti (2010) comparou apenas as probabilidades com a simulação, não comparando as métricas finais. Faridi et al. (2010) utilizaram resultados parciais da simulação para refinar os resultados do modelo. Shuaib, Mahmoodi e Aghvami (2009) realizaram simulação 
com o Opnet Modeler (Opnet Modeler, 2014). Alguns autores não ofereceram comparação de resultados (FRUTH, 2006; MISIC; MISIC; SHAFI, 2004). Park, Fischione e Johansson (2013) utilizaram o simulador COOJA (OSTERLIND et al., 2006) e também realizaram alguns experimentos com nós reais.

Tabela 7: Parâmetros

\begin{tabular}{|l|c|c|c|c|c|}
\hline Autor & Tráf. & Tam. & \# nós & Buf. & Parâmetros 802.15.4 \\
\hline $\begin{array}{l}\text { Misic, Misic e } \\
\text { Shafi (2004) }\end{array}$ & Sim & Sim & Sim & Sim & - \\
\hline $\begin{array}{l}\text { Park et al. } \\
(2005)\end{array}$ & - & Sim & Sim & - & - \\
\hline $\begin{array}{l}\text { Wen et al. } \\
(2009)\end{array}$ & Sim & - & Sim & - & minBE, NB \\
\hline Buratti (2010) & - & Sim & Sim & - & SO \\
\hline $\begin{array}{l}\text { Faridi et al. } \\
\text { 2010) }\end{array}$ & - & - & Sim & - & - \\
\hline $\begin{array}{l}\text { Park, Fischione } \\
\text { e Johansson } \\
(2013)\end{array}$ & Sim & - & Sim & - & SO \\
\hline $\begin{array}{l}\text { Shuaib, Mah- } \\
\text { moodi e Agh- } \\
\text { vami (2009) }\end{array}$ & Sim & Sim & - & - & SO \\
\hline Fruth (2006) & - & Sim & - & - & minBE \\
\hline Este trabalho & Sim & - & Sim & - & NoT, NB, CW, BkPeriod \\
\hline
\end{tabular}

Fonte: Autor

Além destes trabalhos já descritos e analisados, outros trabalhos de menor relevância ou impacto foram encontrados na literatura (MAHMOOD et al., 2014; LING et al., 2007; GOYAL et al., 2009; BURATTI; VERDONE, 2009; MARTALÒ; BUSANELLI; FERRARI, 2009; POLLIN et al., 2008; JUNG et al., 2009).

O trabalho apresentado neste documento se diferencia dos anteriores por utilizar um formalismo diferente, a rede de Petri estocástica generalizada e a rede de Petri colorida. Com esta abordagem é possível realizar uma modelagem comportamental, evitando o cálculo explícito de probabilidades, que é um ponto central nos trabalhos baseados em cadeias de Markov. As métricas obtidas foram validadas através de simulações com o NS2 (MCCANNE; FLOYD, 2012). O modelo e os resultados do modelo utilizando rede de Petri estocástica generalizada foram publicados em uma conferência internacional (ALVES; MARGI, 2013). 


\section{MODELO EM REDE DE PETRI ESTOCÁSTICA GENERALIZADA}

Neste capítulo um modelo do padrão IEEE 802.15.4 é proposto e validado. O modelo visa a realizar análise de desempenho no tocante às métricas de vazão, taxa de perdas e número médio de tentativas para enviar um quadro, considerando a estrutura do superframe e permitindo a distinção dos nós da rede. Os resultados apresentados nesta seção foram publicados na conferência ACM PEWASUN 2013 (ALVES; MARGI, 2013).

O modelo foi construído sobre o formalismo de Rede de Petri estocástica generalizada. Esta abordagem foi escolhida pois permite evitar o cálculo direto de probabilidades, deixando este passo a cargo da resolução do modelo e, como é um formalismo com maior nível de abstração que cadeia de Markov, o resultado final é mais intuitivo e fácil de entender.

O modelo possui dois componentes principais. O primeiro representa o controle e sincronismo, de acordo com o estado da rede: enviando Beacon, CAP, CFP ou inativo. O segundo componente representa a operação de um nó da rede, e possui a maior parte do comportamento descrito no padrão. O escopo e os detalhes do modelo são apresentados nas seções seguintes. Os nomes de lugares e transições estão escritos em SMALL CAPS.

\subsection{Escopo do Modelo}

O modelo engloba transmissão de acordo com o modo Beacon, sem distinguir quadros de dados e de controle (e.g. acknowledgments). Assume-se que os nós da rede estão associados à basestation no momento da análise. Está hipótese é unânime entre os trabalhos previamente citados. Ainda, alocação/desalocação dinâmica de slots durante o CFP não foi considerada, uma vez que os critérios 
de requisição de alocação não estão definidos no padrão. A topologia considerada é em estrela, devido ao seu uso comum em RSSF. Esta hipótese é considerada na maioria dos trabalhos citados, exceto por Buratti (2010), que deriva o modelo baseando-se em um tipo específico de aplicação.

\subsection{Mecanismo de controle e sincronismo}

Este fragmento de rede de Petri alimenta o fluxo do modelo dos nós da rede, provendo informações sobre o momento atual do superframe. A representação deste comportamento em Rede de Petri é uma cadeia sequencial, exibida na Figura 19a.

Figura 19: Mecanismo de controle e sincronismo

(a) Ciclo completo

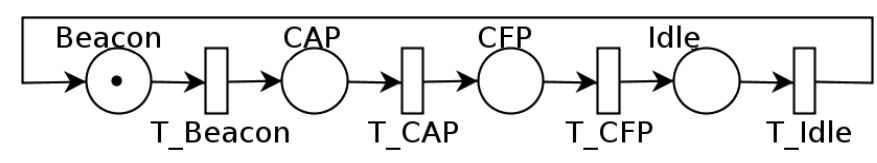

(b) Eliminação do Beacon e CFP

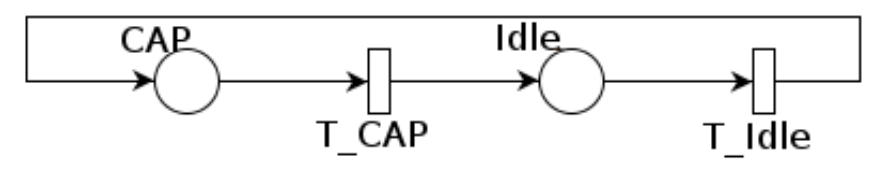

Fonte: Autor

O período da transmissão de Beacon pode ser abstraído aglutinando-o com o período inativo. Esta simplificação é possível pois o quadro de Beacon é pequeno e as informações de controle que ele carregaria são predefinidas e incorporadas no modelo anteriormente à sua analise. Além disso, caso o CFP não seja desejado, o ciclo pode ser reduzido novamente como exibido na Figura 19b.

A fase crítica neste estágio é atribuir corretamente o tempo de duração de cada transição. Uma explicação de como calcular os valores de taxa de transição para os parâmetros $S O=8$ e $B O=7$ é apresentado na Seção 3.4.3. 


\subsection{Modelo de nó da rede}

O segmento mais complexo do modelo é o que representa o nó da rede, que inclui a modelagem da taxa de tráfego, o slotted $C S M A / C A$ executado para acessar o meio durante o CAP e o comportamento durante o CFP.

A transição mais acima na Figura 20, FRAME ARRIVAL, representa a taxa de chegada de quadros ao sistema. Numa situação real de resolução do modelo, esta transição deve ser limitada pelo número de marcas do lugar FRAME LIMIT, como exibido na Figura 20, na qual o limite é de 5 quadros.

Figura 20: Chegada de quadros

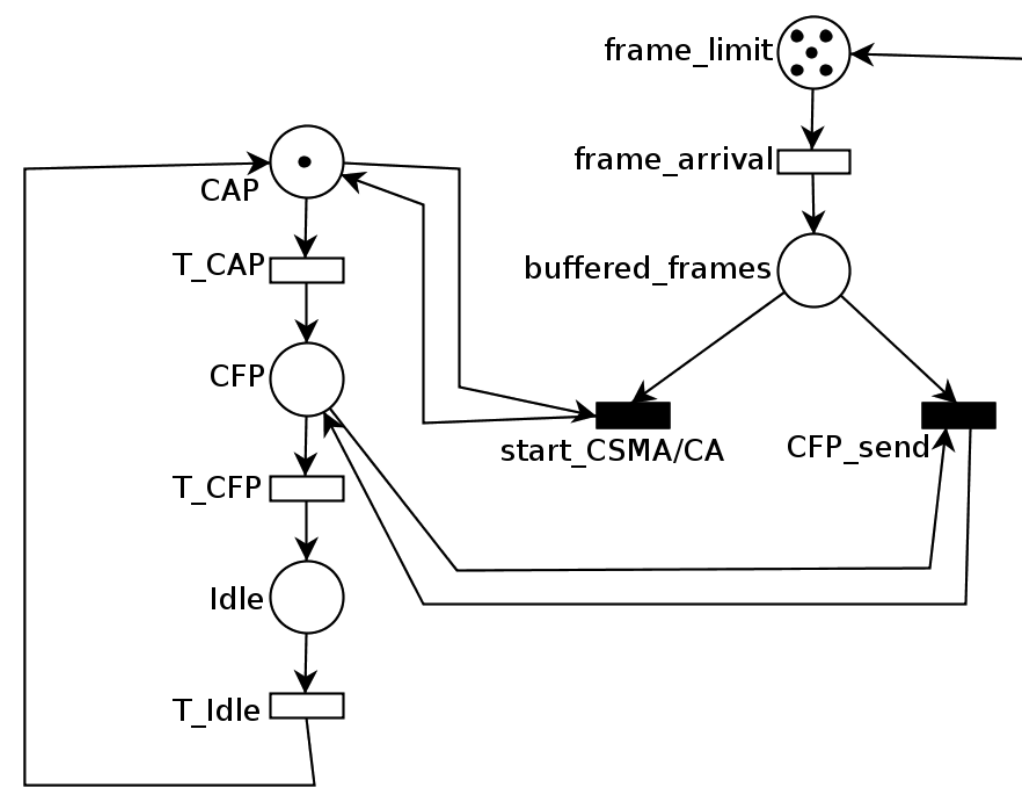

Fonte: Autor

Além de permitir a resolução analítica do modelo, tornando o espaço de estados finito, a marcação inicial no lugar FRAME LIMIT representa a quantidade de quadros que um nó pode comportar, representando a capacidade máxima de seu buffer.

Dependendo da marcação do mecanismo de controle e sincronismo, dois caminhos podem ser seguidos pelo quadro a ser enviado: transmissão através do CAP ou CFP, como ilustrado na Figura 20. O segmento da direita (transição CFP SEND) é ativado caso a rede esteja no estado CFP. Neste caso, cada quadro é enviado após um tempo médio definido de acordo com a quantidade de slots alocados para o nó em questão, conforme mostra a Figura 21. 
Após disparar a transição CFP TRANSMISSION, o quadro é considerado entregue com sucesso e uma marca deve ser adicionada ao lugar FRAME LIMIT, representando a liberação de uma posição no buffer do dispositivo.

Figura 21: Transmissão de quadro no CFP

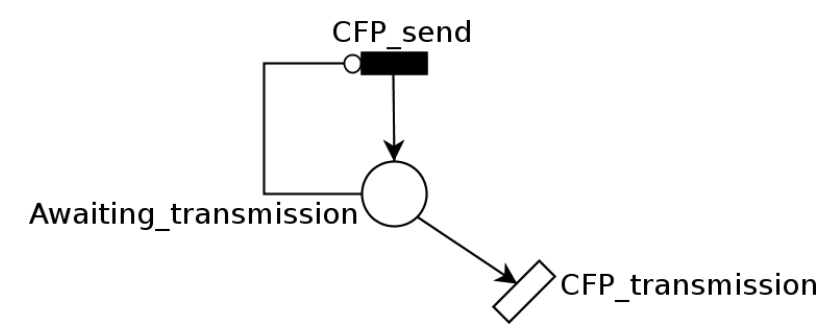

Fonte: Autor

O procedimento de contenção do canal executado durante o CAP é iniciado com o disparo da transição START CSMA/CA, sendo modelado pelos fragmentos apresentados nas Figuras 22 e 23. Além da marcação no mecanismo de controle e sincronismo, o disparo de START CSMA/CA é condicionado pelo lugar ALLOW NEW CSMA/CA, como mostrado da Figura 22. Esta restrição limita a execução do procedimento de CSMA/CA para um quadro por vez; caso contrário, mais de um quadro seria enviado ao mesmo tempo pelo mesmo nó da rede, o que não condiria com a realidade.

Figura 22: Iniciando o processo de CSMA/CA

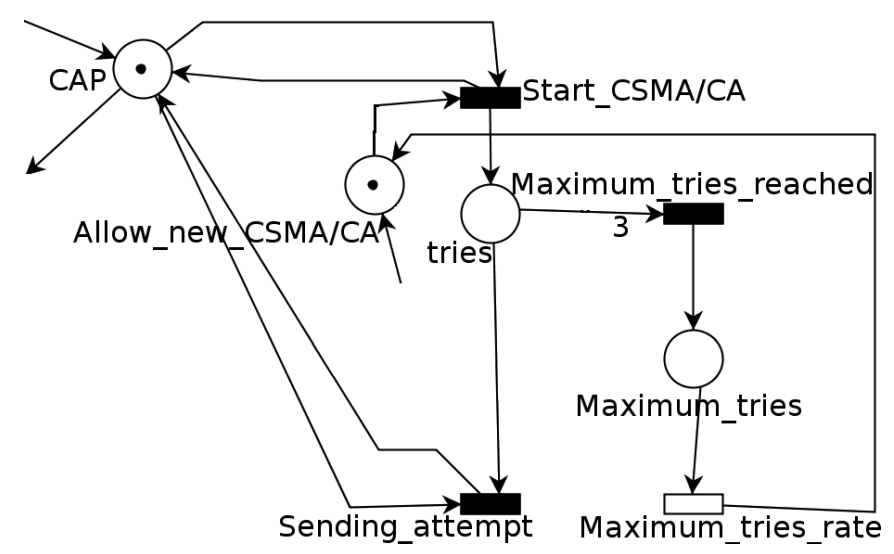

Fonte: Autor

Após o disparo de START CSMA/CA, o procedimento de CSMA/CA pode se iniciar. Contudo, algumas condições devem ser verificadas antes que a transmissão continue, como representado na Figura 22. O CAP já pode ter acabado, o que causaria a interrupção do processo de CSMA/CA. Isto é feito pelo arco do 
lugar CAP para a transição SENDing ATTEMPT. Além disso, uma marca deve ser adicionada aos lugares ALLOw NEW CSMA/CA e FRAME LIMIT.

Outro evento que pode evitar a tentativa de transmissão do quadro é atingir o número máximo de tentativas para enviar um quadro. Isto ocorre se o número de marcas no lugar TRIES for grande o suficiente para disparar a transição MAXIMUM TRIES REACHED (ou seja, três marcas no exemplo da Figura 22). Analogamente ao tratamento de fim do CAP, a taxa de perdas devido ao número máximo de tentativas é medida pela transição MAXIMUM TRIES RATE. Uma marca deve ser adicionada aos lugares ALLOW NEW CSMA/CA e FRAME LIMIT também.

Figura 23: CSMA/CA

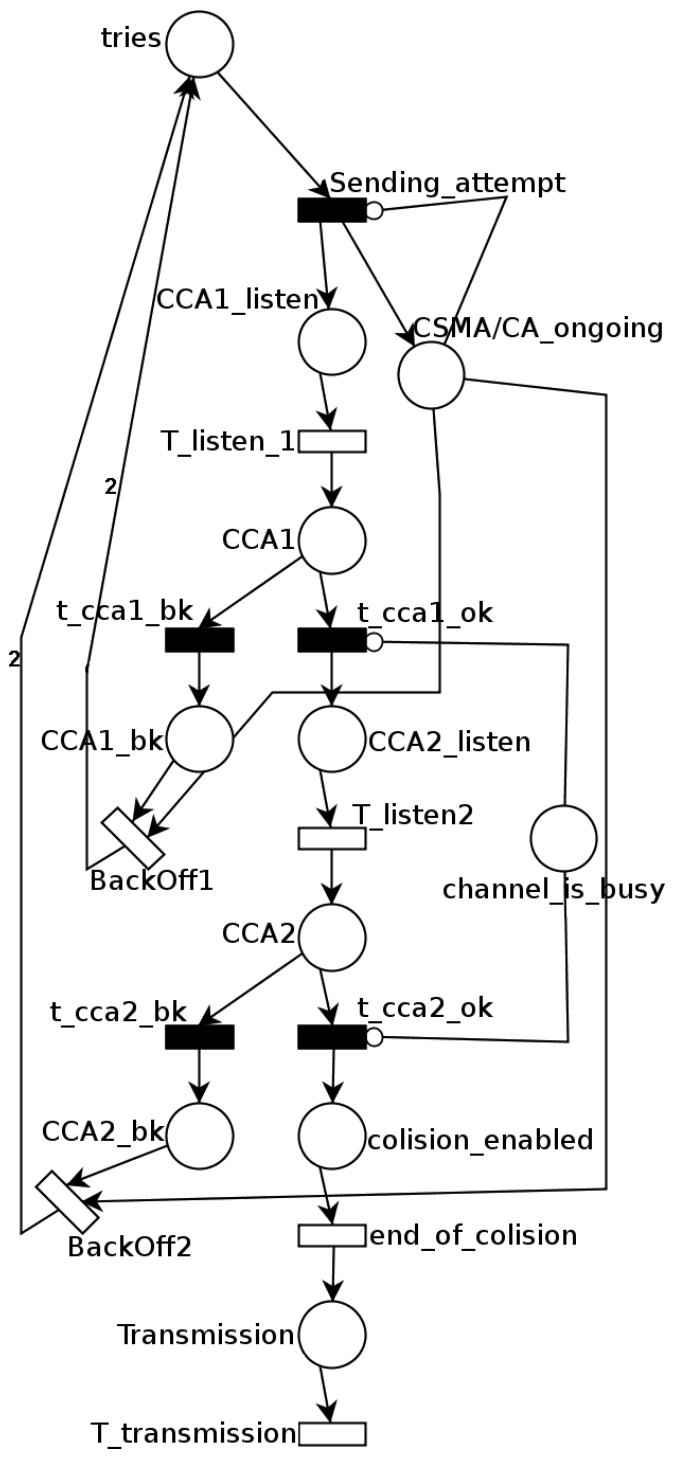

Fonte: Autor 
Se estas condições forem falsas e não houver outra tentativa de transmissão no momento (representada pelo arco inibidor na transição SENDING ATTEMPT na Figura 23), a tentativa de transmissão inicia-se. O comportamento desejado só é obtido se as prioridades das transições obedecerem a seguinte relação:

$$
\operatorname{Pr}(\text { MAXIMUM TRIES REACHED })>\operatorname{Pr}(\text { SENDING ATTEMPT })
$$

Quando a tentativa de transmitir o quadro se inicia, o CCA (clear channel assessment) é realizado duas vezes seguidas (de acordo com o parâmetro de janela de contenção $\mathrm{CW}=2$, valor fixo do padrão). O CCA dura um período equivalente a 8 símbolos, computados nas transições T Listen1 e T Listen2. O canal é considerado ocupado se houver alguma outra transmissão de quadro em curso no momento em que o CCA terminar.

Se o canal de comunicação for dado como ocupado em qualquer um dos CCA, um backoff é executado antes da próxima tentativa de transmissão. O número de tentativas é incrementado pelo peso dois nos arcos das transições BackOff1 e BackOff2 para o lugar TRIES. Estas transições também causam a remoção da marca do lugar CSMA/CA ONGOING, para, em seguida, permitir uma nova tentativa de envio. A duração do backoff é sorteada de uma distribuição uniforme no intervalo $\left[0,2^{B E}-1\right]$ multiplicado pelo valor base, onde BE é o backoff exponent e o valor base é o tempo equivalente a 20 símbolos, chamado de aUnitBackoffPeriod. A hipótese simplificadora de reiniciar o valor do BE a cada transmissão foi adotada.

Figura 24: Colisão

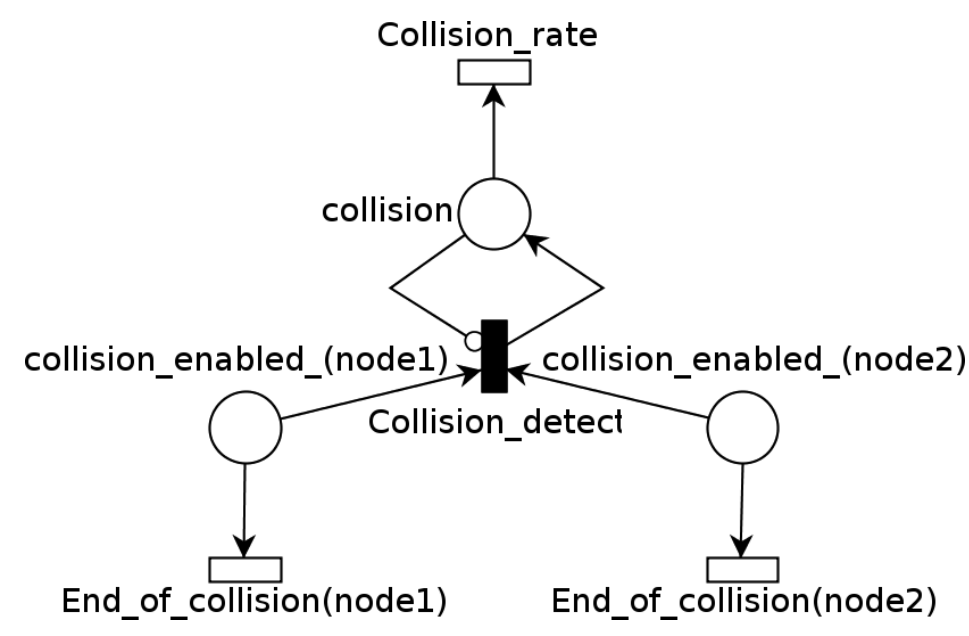

Fonte: Autor 
Se o canal for encontrado livre em ambos CCAs, o nó inicia a transmissão do quadro, embora continue suscetível a colisões (devido ao atraso de propagação do sinal ou execução simultânea dos CCAs). A Figura 24 exibe o trecho que detecta a ocorrência de uma colisão, no momento em que dois nós tentam enviar um quadro ao mesmo tempo. A taxa de colisão é medida pela transição COLLISION RATE.

O risco de colisão reduz-se a zero após um período de tempo, modelado pela transição END OF COLLISION na Figura 23. Este período simboliza o tempo que o sinal demora para ser percebido de um nó para outro.

Então, um quadro é entregue com sucesso após um período de tempo modelado pela transição T TRANSmission. Sua taxa de disparo é relacionada ao tamanho do quadro e a taxa de símbolos adotada, incluindo overheads como o ACK e o interframe spacing (IFS).

Após concatenar todas os segmentos apresentados, o modelo completo do nó de rede é obtido. Tal composição é exibida na Figura 25.

O canal de comunicação foi modelado abstratamente, não sendo representado como uma entidade centralizada. Como explicado anteriormente, a propagação e transmissão são modeladas junto ao modelo de nó. 
Figura 25: Modelo de nó da rede

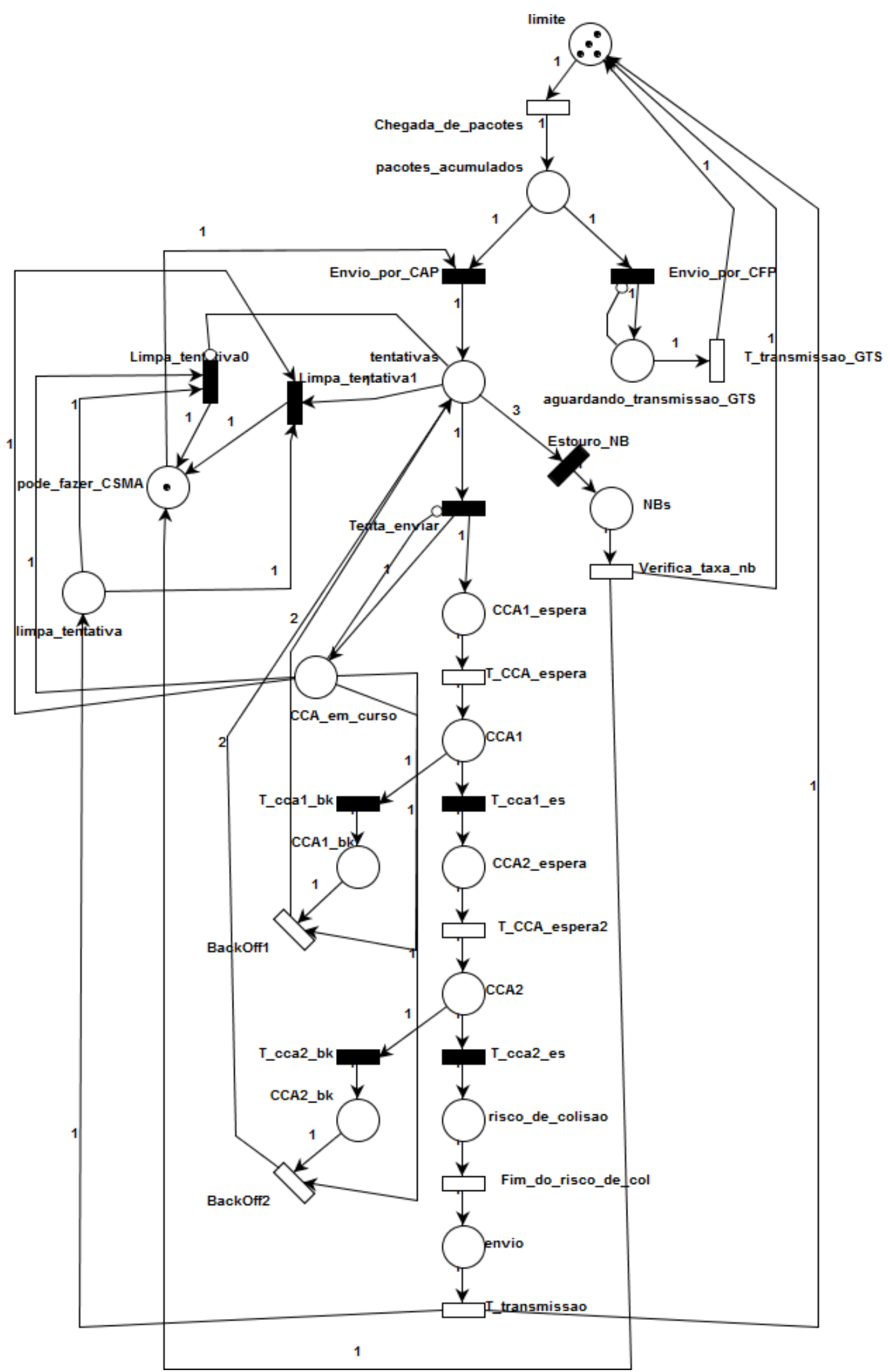

Fonte: Autor 


\subsection{Validação}

Esta seção apresenta os resultados de validação comparando valores obtidos através da resolução do modelo proposto e comparação com simulações utilizando o Network Simulator 2 (NS2). A definição das métricas e como foram obtidas, os cenários e discussão de resultados são apresentados.

\subsubsection{Métricas de Desempenho}

Esta seção tem o objetivo de definir as métricas de desempenho e explicar como são obtidas através do modelo em Rede de Petri (RdP) e do arquivo de saída gerado pelo NS2 (trace).

\subsubsection{Vazão}

A vazão de um nó é definida como a quantidade de quadros por ele enviados que foram entregues com sucesso ao seu destino na unidade de tempo.

No escopo do modelo, a vazão do nó é calculada pela taxa de disparo observada na transição T TRANSMISSION somada à taxa de disparo da transição CFP TRANSMISSION relativas a transmissões no CAP e CFP.

Para extrair este resultado do NS2 o arquivo de trace da simulação é processado filtrando-se as linhas em que há entrega de quadro na camada adequada (MAC). A quantidade de quadros é acumulada e a vazão é calculada pelo quociente deste valor pelo tempo de simulação.

\subsubsection{Taxa de perdas por nó}

Um quadro é classificado como perdido se a sua transmissão não foi bem sucedida. A taxa de perdas de quadro é medida em número de quadros perdidos em uma unidade de tempo.

No modelo existem três tipos de taxa de perdas: as relativas ao excesso de número de tentativas, colisões e estouro de buffer. As duas primeiras taxas são as relativas às transições MAXIMUM TRIES REACHED e COLLISION RATE. A taxa de estouro de buffer é medida pelo produto da probabilidade de haver zero marcas no lugar FRAME LIMIT pela taxa de chegada de quadros. 
Nos resultados de simulação com NS2 a taxa de perdas é obtida verificandose a quantidade de quadros enviados que não atingiram o seu destino na camada de aplicação.

\subsubsection{Número médio de tentativas}

A quantidade de tentativas que um quadro precisa para ser entregue com sucesso está relacionada ao grau de congestionamento da rede. O número de tentativas mínimo é igual a 1 e é incrementado a cada vez que o canal for encontrado ocupado. Se o número máximo de retransmissões é alcançado, o quadro é descartado.

Esta métrica é calculada pelo número médio de marcas no lugar TRIES, porém considerando somente os momentos em que o nó está tentando enviar um quadro. Todas as transições que partem deste lugar são instantâneas, portanto, para calcular esta métrica é preciso adicionar 1 ao número médio de marcas no lugar TRIES, condicionado à existência de uma marca no lugar CSMA/CA ONGOING.

Esta métrica é extraída das simulações em NS2 através do número de colisões e do total de quadros enviados pela camada MAC. O número médio de tentativas é calculado pelo número médio de colisões adicionado de 1 , uma vez que cada colisão representa uma tentativa de transmissão a mais.

\subsubsection{Cenários}

Dez cenários foram utilizados para comparar modelo e simulação, resumidos na Tabela 8. Os experimentos foram projetados de forma a aumentar a carga da rede a cada cenário.

Tabela 8: Taxas de chegada de quadros

\begin{tabular}{|c|c|c|c|c|c|c|c|c|c|c|}
\hline Cenário & 0 & 1 & 2 & 3 & 4 & 5 & 6 & 7 & 8 & 9 \\
\hline Taxa de chegada & 1 & 2 & 4 & 8 & 16 & 32 & 64 & 128 & 256 & 512 \\
\hline
\end{tabular}

Fonte: Autor

O número total de nós utilizado foi dois (para evitar a explosão combinatória do espaço de estados), o limite de buffer foi escolhido como 5 quadros e o tamanho dos quadros foi 64 bytes. Este valor é consistente, pois dispositivos de RSSF têm 
poucos kB de memória RAM. Para analisar o impacto desta restrição, simulações com buffer grande também foram executadas.

Quanto às simulações em NS2, foi utilizada topologia em estrela com nós estáticos. Um nó coordenador exercendo a função de sorvedouro de dados foi posicionado no centro da rede, 4 metros distante de cada um dos outros dois nós. Todos os nós estão ao alcance um do outro. Cada cenário foi simulado dez vezes, pois esta quantidade de replicações de experimentos foi suficiente para atingir dispersão pequena (menor que 4\% em relação à ordem de grandeza das métricas) de acordo com o nível de confiança adotado (95\%). Como a interferência de protocolos de camadas mais altas é indesejada nas simulações em NS2, o protocolo de roteamento utilizado foi o DumbAgent (i.e. sem qualquer roteamento). Analogamente, o protocolo da camada de transporte utilizado foi o UDP (POSTEL, 1980), que não faz retransmissões. A distribuição de probabilidade da taxa de chegada foi a Poisson, pois é a mesma assumida pelo modelo em Rede de Petri.

Os parâmetros utilizados estão resumidos na Tabela 9 . O valor padrão de BO e SO é igual a 15, o que desabilita o modo Beacon. Como deseja-se atuar no modo Beacon, os valores utilizados foram 7 e 8 , respectivamente, resultando nas duas primeiras linhas da Tabela 9. Os outros valores desta tabela são predefinidos pelo padrão, e são os mesmos utilizados na implementação do NS2 (DELOS, 2012) (embora não seja possível alterá-los sem a recompilação do simulador).

Tabela 9: Tempos - modelo de nó

\begin{tabular}{|c|c|c|}
\hline Propriedade & Valor $[\mathrm{ms}]$ & Taxa equivalente $[\mathrm{Hz}]$ \\
\hline \hline Active time & 1966.08 & 0.5086 \\
\hline Inactive time & 1966.08 & 0.5086 \\
\hline Total time & 3932.16 & 0.2543 \\
\hline BackOff1 & 4.8 & 208.33 \\
\hline BackOff2 & 9.92 & 100.81 \\
\hline Transmission & 3.31 & 301.93 \\
\hline
\end{tabular}

Fonte: Autor

Os valores de backoff da Tabela 9 foram calculados considerando a unidade de tempo básica do padrão, que é aUnitBackoffPeriod $=20$ símbolos. O valor inicial do BE (Backoff Exponent) é 3, contudo, os valores de backoff do modelo são calculados em relação a $\mathrm{BE}=4$ e $\mathrm{BE}=5$, introduzidos no modelo através das transições BackOff1 e BackOff2.

Além disso, foi considerado que um quadro carrega 512 bits de dados, equi- 
valente a um período de 2 milissegundos. É necessário acrescentar o overhead relativo à transmissão do quadro de ACK (40 bits) e ao intervalo de tempo entre transmissões (LIFS e t_ack, de tamanhos 40 e 32, símbolos respectivamente). Após adicionar estes períodos de tempo, o tempo total de transmissão de um quadro no modelo é igual a $3.3 \mathrm{~ms}$.

Por fim, a taxa da transição END OF COLLISION foi determinada por $604 \mathrm{~Hz}$, estipulada pela estimativa do tempo que um nó demora para perceber o sinal de outro nó.

Um resumo dos parâmetros de simulação utilizados no NS2 é apresentado na Tabela 10.

Tabela 10: Sumário de parâmetros - NS2

\begin{tabular}{|c|c|}
\hline Parâmetro & Valor \\
\hline Modelo de propagação & TwoRayGround \\
Tipo de fila & DropTail \\
Modelo de antena & OmniAntenna \\
Protocolo de roteamento & DumbAgent \\
Tamanho do grid & $50 \times 50$ \\
Tamanho do buffer & low buffer: 5 \\
& high buffer: 1000 \\
\hline
\end{tabular}

Fonte: Autor

\subsubsection{Resultados e Discussão}

Esta seção apresenta os resultados da validação do modelo face a resultados de simulação. Métricas foram obtidas pela resolução do modelo através do Platform Independent Petri net Editor - PIPE (BONET et al., 2007), versão 4.2, executado no sistema operacional Windows 764 bit, com 4 GB de memória RAM e um processador Intel Quad2 de quatro núcleos e frequência de $2.4 \mathrm{GHz}$.

Simulações de cenários equivalentes foram realizadas com o simulador NS2, versão 2.34, provido da implementação do padrão IEEE 802.15.4 de 2007 (RAMACHANDRAN; DAS; ROY, 2007). O ambiente de execução do NS2 foi uma máquina virtual Xubuntu 8.04, provida com 512 MB de memória RAM e um processador de $2.4 \mathrm{GHz}$.

As métricas aferidas de todos os cenários de simulação propostos são exibidas nos gráficos a seguir, que fazem uso dos seguintes mnemônicos: ModELO RDP, 
resultados do modelo; NS2 LOW BUF, simulação com buffer reduzido (5 quadros); NS2 HIGH BUF, simulação com buffer grande (1000 quadros).

Os resultados foram calculados com intervalo de confiança de 95\%, mas estes não constam nos gráficos pois são muito pequenos em relação à escala do gráfico. A Tabela 11 exibe o tamanho do intervalo de confiança em valor absoluto e em relação ao valor médio da métrica de acordo com o cenário, para as simulções com buffer reduzido. O maior valor relativo é de 3.9\%, descontando os cenários iniciais de perdas, pois nestes casos o valor da métrica é próximo de zero.

Tabela 11: Intervalo de confiança (95\%) para as simulações NS2 LOW BUF: valor absoluto e em relação ao valor médio da métrica

\begin{tabular}{|c|c|c|c|c|c|c|}
\hline & \multicolumn{3}{|c|}{ Valores Absolutos } & \multicolumn{3}{c|}{ Valores Relativos } \\
\hline Taxa de quadros & Vazão & Perdas & Tentativas & Vazão & Perdas & Tentativas \\
\hline 1 & 0.018 & 0.006 & 0.00045 & $1.8 \%$ & $16.9 \%$ & $0.0 \%$ \\
\hline 2 & 0.018 & 0.023 & 0.00046 & $1.0 \%$ & $6.0 \%$ & $0.0 \%$ \\
\hline 4 & 0.015 & 0.046 & 0.00045 & $0.5 \%$ & $2.3 \%$ & $0.0 \%$ \\
\hline 8 & 0.102 & 0.236 & 0.00124 & $2.1 \%$ & $3.9 \%$ & $0.1 \%$ \\
\hline 16 & 0.130 & 0.286 & 0.00093 & $1.5 \%$ & $2.0 \%$ & $0.1 \%$ \\
\hline 32 & 0.161 & 0.443 & 0.00179 & $1.0 \%$ & $1.5 \%$ & $0.2 \%$ \\
\hline 64 & 0.202 & 0.684 & 0.00182 & $0.6 \%$ & $1.1 \%$ & $0.2 \%$ \\
\hline 128 & 0.114 & 1.174 & 0.00243 & $0.2 \%$ & $0.7 \%$ & $0.2 \%$ \\
\hline 256 & 0.069 & 1.835 & 0.00208 & $0.1 \%$ & $0.4 \%$ & $0.2 \%$ \\
\hline 512 & 0.096 & 1.890 & 0.00142 & $0.2 \%$ & $0.2 \%$ & $0.1 \%$ \\
\hline
\end{tabular}

Fonte: Autor

Os resultados de vazão são exibidos na Figura 26a. Os valores no cenário de 1 quadro/s foram bastante próximos para ambas simulações e para o modelo, pois o buffer reduzido ainda é capaz de suportar a baixa demanda de tráfego. A diferença relativa entre o resultado do modelo e da simulação com buffer grande e buffer reduzido foi de $9 \%$ e $5 \%$, respectivamente.

Do cenário de 2 quadro/s ao 32 quadro/s, a limitação de buffer faz com que a vazão das simulações com buffer grande seja pelo menos uma vez e meia maior que a vazão do modelo ou da simulação com buffer reduzido, estes dois últimos com resultados similares (diferença relativa inferior à 3.1\%). A capacidade de buffer reduzida tem grande efeito durante o período ocioso do superframe, uma vez que quadros continuam chegando à fila do nó, porém, não é permitido que se envie nenhum deles, causando perdas. 
Figura 26: Vazão

(a) Vazão em quadros por segundo

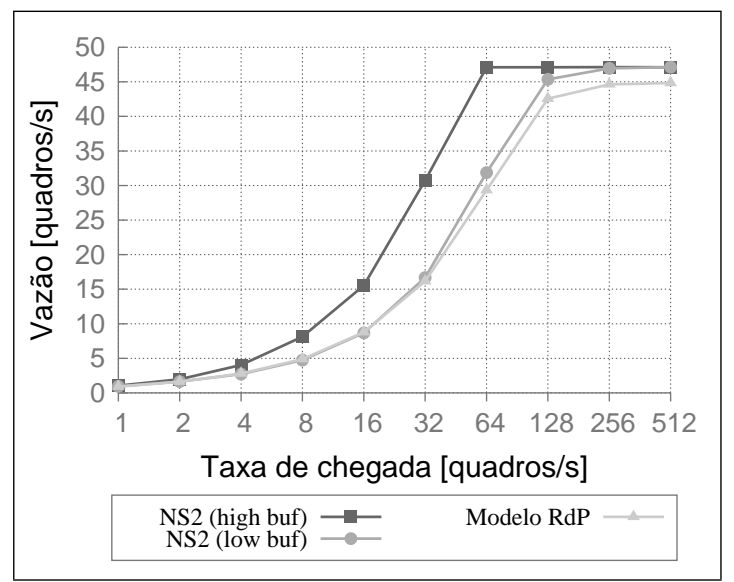

(b) Vazão relativa

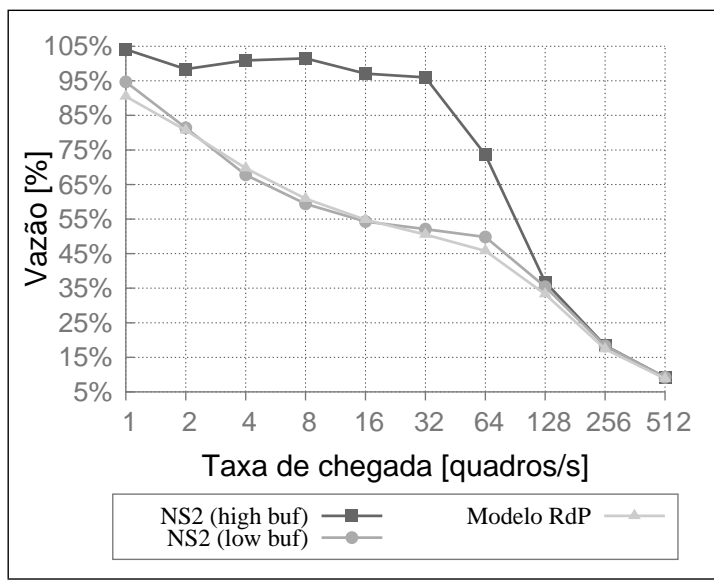

Fonte: Autor

A partir do cenário 6, a vazão da simulação com buffer grande satura. Quanto ao modelo e simulação com buffer reduzido, a vazão máxima não é alcançada no cenário 6, pois a taxa de chegada de quadros em si não é o suficiente para causar a saturação (sem todos os quadros que seriam armazenados no buffer durante o período ocioso).

Todos os casos atingem a saturação nos últimos dois cenários. Os resultados do modelo foram levemente inferiores nestes cenários (diferença relativa em torno de 5\%), significando que é conservativo em relação a esta métrica.

Alternativamente, a vazão pode ser medida em relação à taxa de chegada de quadros nominal, conforme mostrado na Figura 26b. Como esperado, simulações com buffer grande resultaram próximo a $100 \%^{1}$ até atingir saturação.

Os resultados do modelo e da simulação com buffer limitado foram bastante próximos, diferindo no máximo por 4 pontos percentuais. É interessante notar que o valor percentual da vazão flutua em torno da metade da taxa de chegada, efeito do duty cicle de 50\% imposto pela escolha dos parâmetros BO e SO. Nos últimos três cenários, todos os resultados convergem para a saturação.

Valores de taxa de perdas são exibidos na Figura 27. Esta é a taxa de perdas total, considerando os dois nós ativos da rede. Os gráficos exibem uma curva com formato exponencial, comportamento coerente com a teoria, pois diz que a taxa

\footnotetext{
${ }^{1}$ Valores acima de $100 \%$ ocorrem devido a variação estatística
} 
de erros de métodos de acesso aleatório (baseados em Aloha) é proporcional ao inverso da ocupação do canal (que por sua vez é proporcional à vazão).

Figura 27: Taxa de perdas

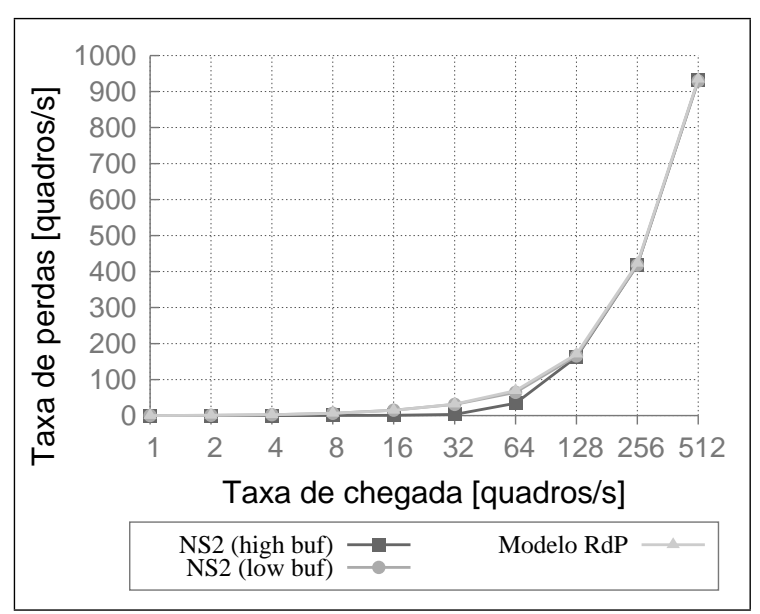

Fonte: Autor

Espera-se que a soma da vazão e taxa de perdas seja equivalente à taxa de chegada, ou seja, todos os quadros que chegam ao sistema ou são entregues com sucesso ou são perdidos. A Tabela 12 exibe a soma destes valores para cada cenário. Os resultados de simulação se aproximam do valor esperado, exceto por variações estatísticas. O modelo proveu exatamente o valor esperado, uma vez que a sua resolução não depende de aleatoriedade. Este é um bom indicador de que as métricas foram aferidas corretamente.

Tabela 12: Taxa de perdas somada à Vazão [quadros/s]

\begin{tabular}{|c|cccccccccc|}
\hline Cenário & 0 & 1 & 2 & 3 & 4 & 5 & 6 & 7 & 8 & 9 \\
\hline NS2 high buf & 0.9 & 2.0 & 4.0 & 8.0 & 15.9 & 32.1 & 64.1 & 128.5 & 256.6 & 512.4 \\
NS2 low buf & 1.0 & 2.0 & 3.9 & 7.9 & 15.9 & 32.1 & 64.0 & 128.0 & 255.9 & 511.6 \\
Petri Net & 1 & 2 & 4 & 8 & 16 & 32 & 64 & 128 & 256 & 512 \\
\hline
\end{tabular}

Fonte: Autor

Os resultados de número de tentativas são exibidos na Figura 28. O número médio de tentativas para enviar um quadro está intimamente relacionado com a probabilidade de se encontrar o canal de comunicação ocupado.

Conforme a carga de tráfego aumenta, o número de tentativas também aumenta para todas as três curvas. O motivo pelo qual a simulação com buffer grande apresenta maior número de tentativas é que, neste caso, todos os quadros armazenados no período ocioso passam por tentativas de envio. Contudo, o mo- 
delo apresenta valores aproximadamente 3\% maiores nos últimos cenários, uma vez que a taxa de chegada aumenta rapidamente e o modelo é conservativo.

Figura 28: Número de tentativas

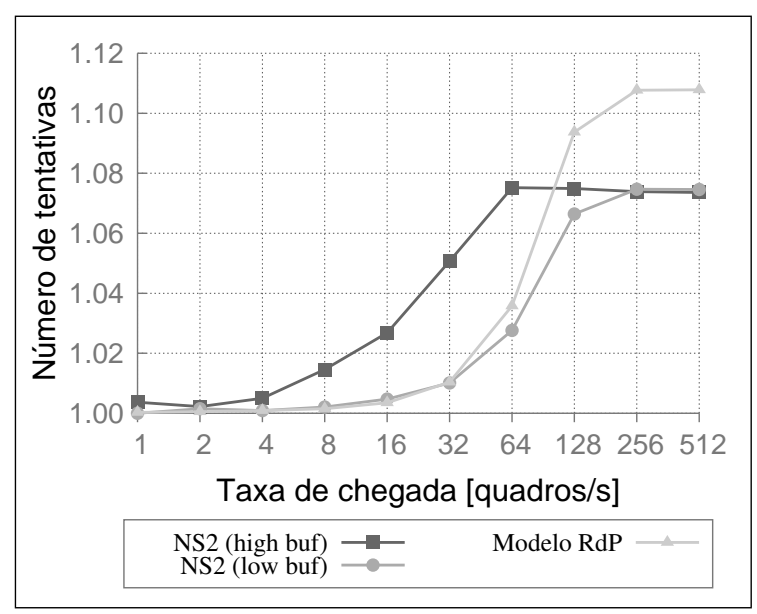

Fonte: Autor

\subsection{Considerações do Capítulo}

Neste capítulo foi proposto e validado um modelo do padrão IEEE 802.15.4 que contempla o modo de operação com Beacon com Redes de Petri Estocástica Generalizada. Este modelo é auto-contido e passível de solução analítica por ferramentas genéricas de Rede de Petri. A maioria dos parâmetros do protocolo são configuráveis no modelo, tal como os tempos de duração de um super frame (BO e SO), o número máximo de tentativas para enviar um quadro e tempos de backoff.

O modelo apresentado possui restrições no tocante à quantidade de nós e ao tamanho de buffer. Apesar destas limitações, os resultados apresentados foram promissores, principalmente quando a restrição de buffer do modelo é aplicada à simulação.

Estas restrições poderiam ser suavizadas através do aumento da marcação inicial do lugar FRAME LIMIT e da replicação do segmento de nó da rede, sendo este último um procedimento manual. A Figura 29 exibe o modelo para 3 nós. Neste caso a resolução do modelo seria inviável devido à explosão do espaço de estados. Nos testes realizados, com tamanho de buffer igual a quatro, havia cerca de 2,5 GB de memória RAM disponível para a execução da ferramenta 
PIPE (BONET et al., 2007), porém toda memória foi utilizada antes do término da resolução do modelo. Uma alternativa seria a simulação do modelo, pois as marcações raramente atingidas seriam ignoradas (não atingidas) no processo de simulação, causando pouco impacto no resultado final. Contudo, a versão utilizada da ferramenta não suporta simulação.

Desta forma, com o objetivo de aproveitar os bons resultados, um outro modelo foi proposto para superar estas questões. O formalismo utilizado foi a Rede de Petri Colorida, que permite utilizar a mesma estrutura para designar o funcionamento de diversos nós, evitando o trabalho de replicação manual. Além disso, a ferramenta utilizada, o CPN Tools (RATZER et al., 2003) possui ferramentas de simulação adequadas para extrair as métricas desejadas. Por fim, o alto nível deste formalismo permite eliminar simplificações do modelo anterior, como o valor fixo do backoff exponent (BE), redução do macMaxCSMABackoffs (NB) e abstração de quadros de controle.

Figura 29: Modelo com três nós

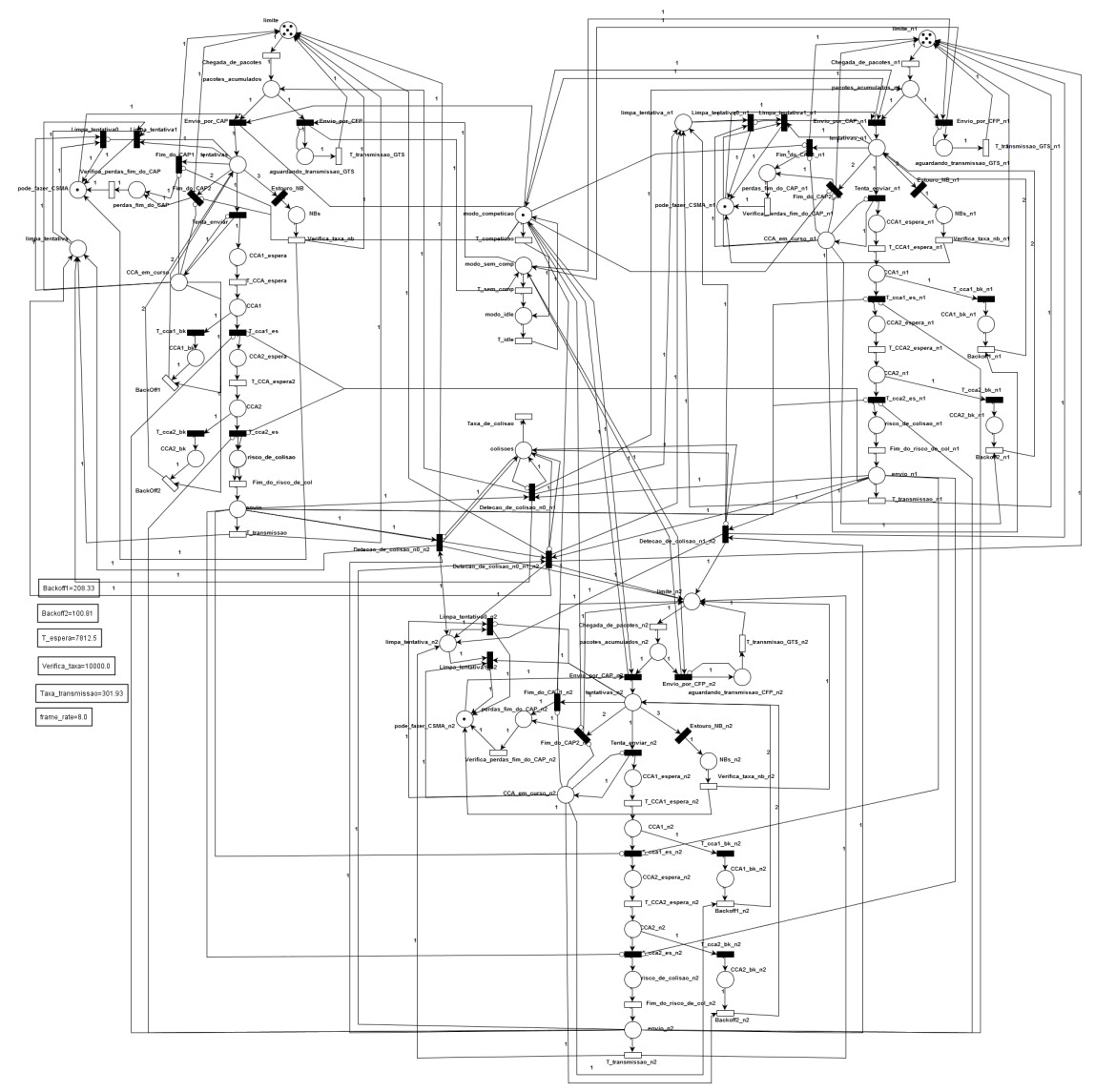

Fonte: Autor 


\section{MODELO EM REDE DE PETRI COLORIDA}

Este capítulo contém o processo de modelagem e validação de um modelo comportamental do padrão IEEE 802.15.4 baseado em Rede de Petri Colorida. As métricas de interesse são vazão, taxa de entrega, atraso e gasto de energia, utilizadas para validar o modelo em comparação com resultados de simulador e para avaliar o desempenho de uma rede em outras situações.

O objetivo de realizar modelagem comportamental foi mantido, além de superar as limitações do modelo em rede de Petri estocástica descrito no capítulo 3, permitindo a análise de redes com maior número de nós, dispositivos com mais posições de buffer e a eliminação de outras simplificações.

Para reaproveitar o que já havia sido desenvolvido, uma estrutura análoga ao modelo anterior foi empregada em uma primeira tentativa de concretizar este modelo. Esta abordagem foi inadequada porque a estrutura do modelo anterior dificulta usufruir de todo o potencial do formalismo.

Este modelo inicial foi descartado e dois modelos diferentes, porém semelhantes, foram projetados. A razão para se criar dois modelos foi realizar tanto a análise do espaço de estados (model checking) quanto a análise de desempenho, sendo que existe um modelo que é mais favorável para uma análise ou outra. O modelo para análise do espaço de estados tem o objetivo de verificar a aderência do modelo à especificação, enquanto que o modelo de análise de desempenho tem a finalidade de fornecer os valores das métricas relevantes para os cenários desejados.

Detalhes do desenvolvimento dos modelos e seus resultados estão descritos nas seções seguintes. Os nomes de lugares e transições estão escritos em SMALL CAPS. 


\subsection{Modelo para análise do espaço de estados}

Este modelo foi concebido para realizar a análise do espaço de estados. Além de obter o modelo final, o processo de concepção do modelo serve para verificar se há falhas na especificação do padrão. Por exemplo, alguma hipótese implícita ou um caso especial para o qual não há comportamento definido poderiam ser revelados. Para o caso desta modelagem, não foram encontrados problemas deste tipo.

Após finalizar o modelo, pode-se obter o espaço de estados, que é utilizado para verificar se as possibilidades de sequência de passos assumida pelo modelo é a mesma que a prevista pela especificação. Ou seja, verifica-se a pertinência do modelo à especificação. Contudo, as diferenças, se encontradas, devem ser cuidadosamente analisadas para verificar se o problema reside no modelo ou na especificação. Os resultados da análise do espaço de estados são exibidos na Seção 4.1.5.

Para este tipo de análise é desejável obter um espaço de estados finito e pequeno, mantendo todos os comportamentos críticos do padrão conforme a especificação. Estes aspectos foram levados em conta na proposição do modelo, que é descrito nas subseções a seguir.

\subsubsection{Visão Geral}

O modelo foi organizado hierarquicamente em três módulos e conectados conforme exibido na Figura 30. Os módulos são macro transições que contém o comportamento de um nó da rede, da basestation e do meio de transmissão, descritos nas próximas subseções.

Os lugares SuCCESS e FAILURE contém os quadros considerados como entregues com sucesso ou como envio falho, respectivamente, pelos nós da rede. Além destes, foram adicionados lugares auxiliares para conectar os módulos, representando a interação entre os nós e o meio (NoDEsIn e NoDESOUt) e entre a basestation e o meio (BSIn e BsOut). 
Figura 30: Modelo CPN - Visão geral

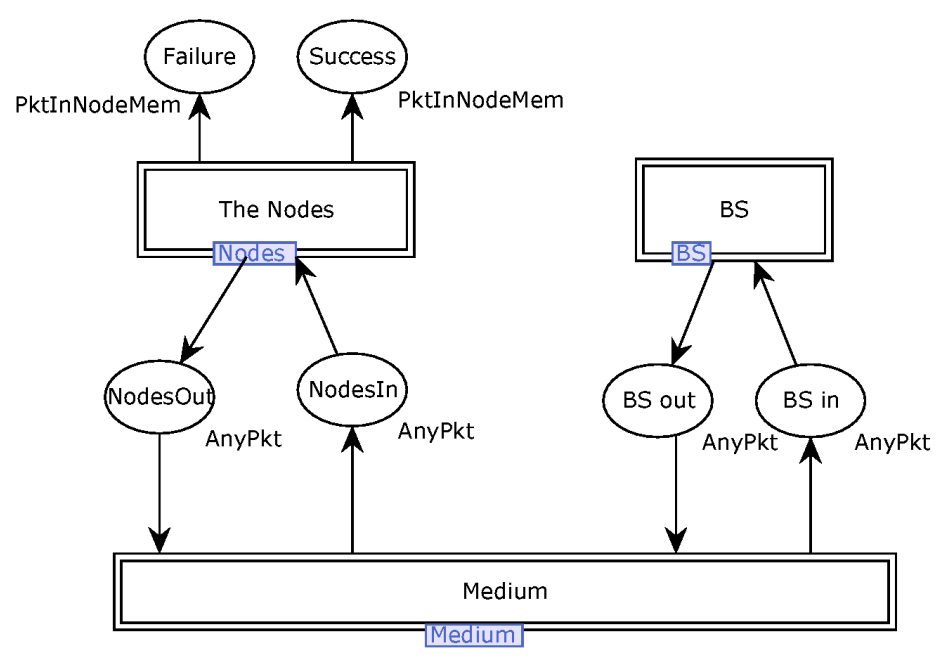

Fonte: Autor

\subsubsection{Nó da rede}

O submodelo exibido na Figura 31 contém o comportamento de um nó que envia dados conforme o padrão IEEE 802.15.4. Um nó é suficiente pois o objeto de estudo é o procedimento de envio de quadros, que é o mesmo para todas as estações. As únicas interações que ocorrem entre estações são no momento de verificar se o meio está livre (clear channel assesment - CCA) ou na ocorrência de colisões, que foram modeladas abstratamente. O modelo se atém ao envio de quadros, assumindo que o nó já está associado à basestation com alocação fixa de slots durante o Contention Free Period (CFP).

Figura 31: Nó da rede

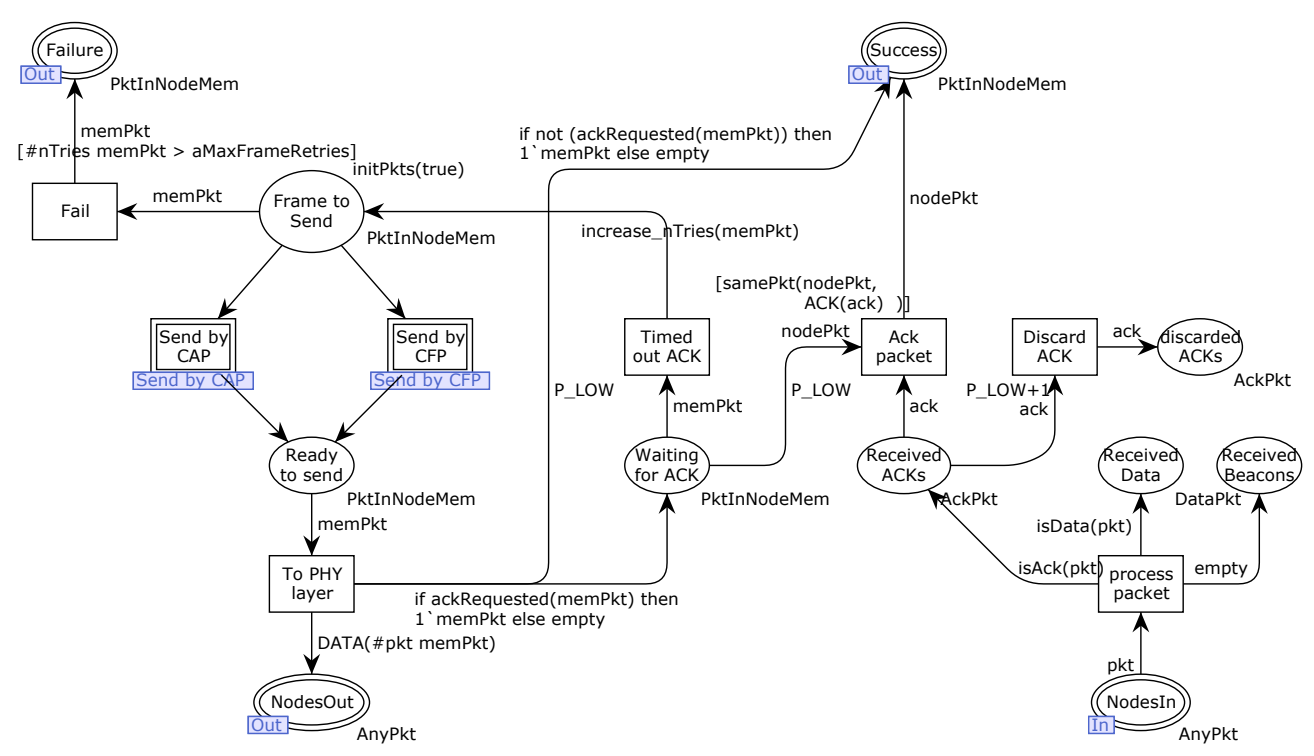

Fonte: Autor 
O foco da análise deste modelo é verificar o que acontece ao enviar um quadro a partir de sua chegada de uma camada superior da pilha de protocolos. Somente um quadro é o suficiente para a avaliação pois um segundo quadro se comportaria exatamente como o primeiro, com a diferença de aguardar no buffer do nó até que o primeiro termine seu processo de envio. Por esta razão, o lugar Frame TO SEND tem como marcação inicial um quadro, definido pela função INITPKTS, descrita no Trecho de Código 4.1.

Trecho de Código 4.1: Função INITPkTS

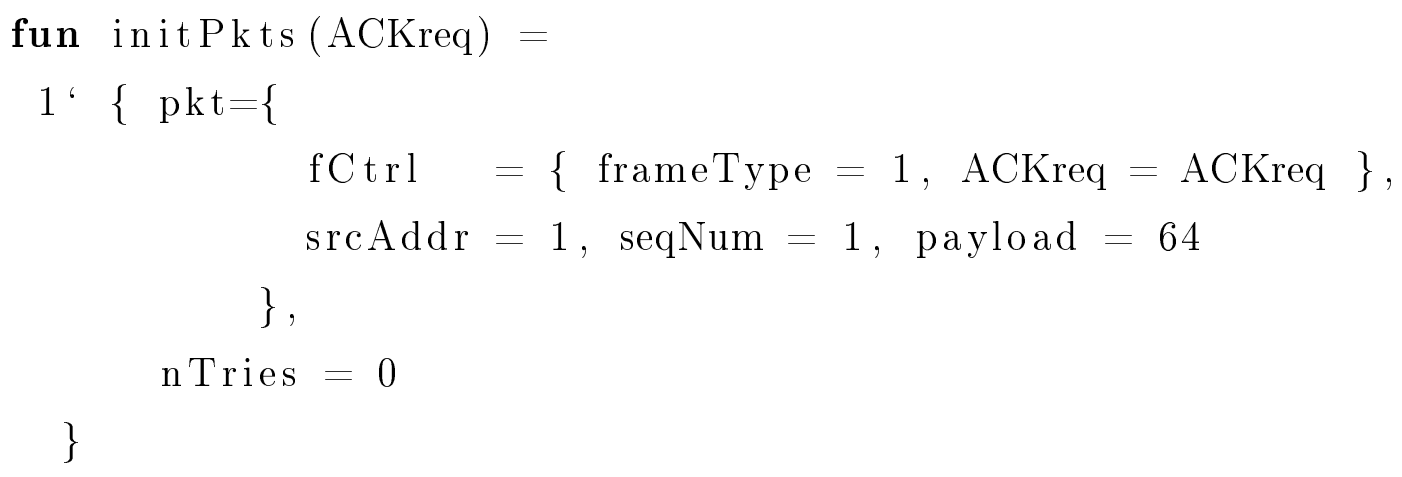

O tipo do lugar Frame to Send é PKTInNodeMem, definido na Tabela 13. Este colorset representa o formato do quadro na memória do nó, consistindo do quadro de dados propriamente dito (incluindo cabeçalhos) e de um contador de número de tentativas.

Tabela 13: Colorsets de nó

\begin{tabular}{|ll|}
\hline colset FrameControl $=$ & $\begin{array}{l}\text { record } \\
\text { frameType : INT2 } *\end{array}$ \\
& ACKreq $:$ BOOL; \\
\hline colset DataPkt $=$ & record \\
& fCtrl : FrameControl $*$ \\
& srcAddr : INT $*$ \\
& seqNum : OCT $*$ \\
& payload : INT; \\
\hline colset PktInNodeMem $=$ & record \\
& pkt : DataPkt $*$ \\
& nTries : INT; \\
\hline colset AnyPkt $=$ & union \\
& DATA : DataPkt + \\
& ACK : AckPkt; \\
\hline
\end{tabular}

Fonte: Autor 
O quadro de dados contém informações básicas do quadro, baseado na especificação do padrão. As informações são: tipo de quadro, requisição de ACK, endereço de destino, número de sequência e os dados, representados pelo seu tamanho em bytes. Se um lugar puder conter quadros tanto de dados quanto de ACK, utiliza-se o colorset ANYPKY.

O quadro pode ser enviado através do CAP (Contention Access Period) ou CFP (Contention Free Period), processos representados pelas macro-transições SEND By CAP e SEND By CFP, que são explicados nas próximas subseções. O quadro chega ao lugar READY TO SEND, e é enviado para o meio através da transição TO PHY LAYER. Esta transição também tem a função de iniciar o timeout no caso de ACK requerido. Se o timeout estourar, o número de tentativas é incrementado e uma nova tentativa de envio é realizada. Em caso de transmissão sem ACK, o quadro é dado como bem sucedido e o ciclo de vida dele no tocante ao nó está terminado.

A transição PROCESS PACKET é utilizada para processar os quadros recebidos. Se for um quadro de dados, ele é simplesmente armazenado. Se for um quadro de ACK, verifica-se se o ACK contém o número de sequência correto através da função SAMEPKT (Trecho de Código 4.2) e, em caso positivo, o quadro é dado como entregue com sucesso. Se o número de sequência do ACK não for o correto, o ACK é descartado.

\section{Trecho de Código 4.2: Função SAMEPKT}

fun samePkt (

$$
\begin{aligned}
& \{\text { pkt }=\{\operatorname{seqNum}, \ldots\}, \ldots\}: \text { PktInNodeMem }, \\
& \operatorname{ACK}(\{\operatorname{ackSeqNum}, \ldots\}) \\
)=(\operatorname{seqNum}= & \operatorname{ackSeqNum})
\end{aligned}
$$

A prioridade das transições TIMED OUT ACK e ACK PACKET tem um efeito importante no modelo. A prioridade do timeout deve ser baixa, caso contrário, ela poderia disparar a qualquer momento, não correspondendo à realidade. Se as duas prioridades forem igualmente baixas, um timeout poderia ocorrer mesmo se o ACK tiver chegado à estação, representando um timeout precoce. Se a prioridade de processar o ACK for maior, somente haverá timeout se não houver quadro de ACK. Estas duas situações são plausíveis. A outra alternativa, deixar a prioridade do timeout maior que do ACK, não é plausível, pois neste caso o ACK 
nunca seria processado. Um resumo destas situações é exibido na Tabela 14 .

Tabela 14: Consequência da escolha das prioridades das transições relacionadas ao ACK, TIMED OUT ACK e ACK PACKET

\begin{tabular}{|c|c|c|}
\hline $\begin{array}{c}\text { Prioridade de } \\
\text { Timed out ACK }\end{array}$ & $\begin{array}{c}\text { Prioridade de } \\
\text { ACK PACKET }\end{array}$ & Consequência \\
\hline Alta & Alta, normal ou baixa & Inválido \\
Normal & Normal ou baixa & Inválido \\
Baixa & Normal & $\begin{array}{c}\text { Timeout somente } \\
\text { se quadro perdido } \\
\text { Possibilidade de } \\
\text { timeout precoce }\end{array}$ \\
\hline
\end{tabular}

Fonte: Autor

Por fim, em caso de consecutivos timeouts ou falhas de CSMA/CA, a transmissão é dada como falha através da transição FAIL se o limite de tentativas estabelecido no padrão for ultrapassado.

\subsubsection{Envio por CFP}

A principal tarefa a ser realizada ao enviar quadros de dados pelo CFP é sincronizar o envio com os slots alocados. Como neste modelo não são considerados os efeitos temporais, a única tarefa executada é passar o quadro para a próxima etapa, como ilustrado na Figura 32.

Figura 32: Envio por Contention Free Period

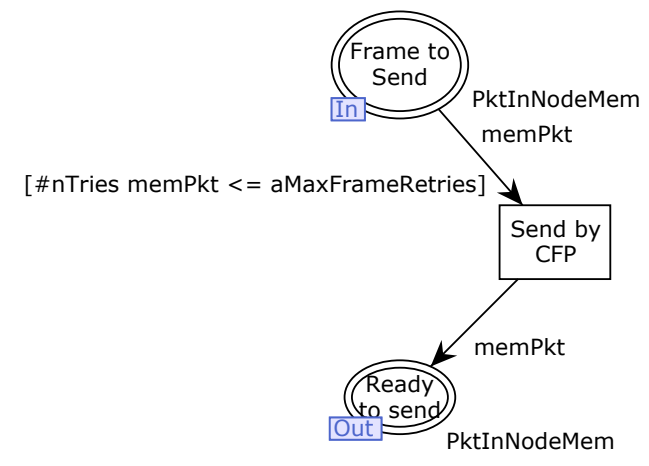

Fonte: Autor

\subsubsection{Envio por CAP}

Este submodelo segue a execução do algoritmo de CSMA/CA previsto no padrão IEEE 802.15.4. A rede de Petri exibida na Figura 33 verifica continuamente 
o meio através das transições Free Medium e Busy Medium.

Figura 33: Rede de Petri para model check do algoritmo de CSMA/CA

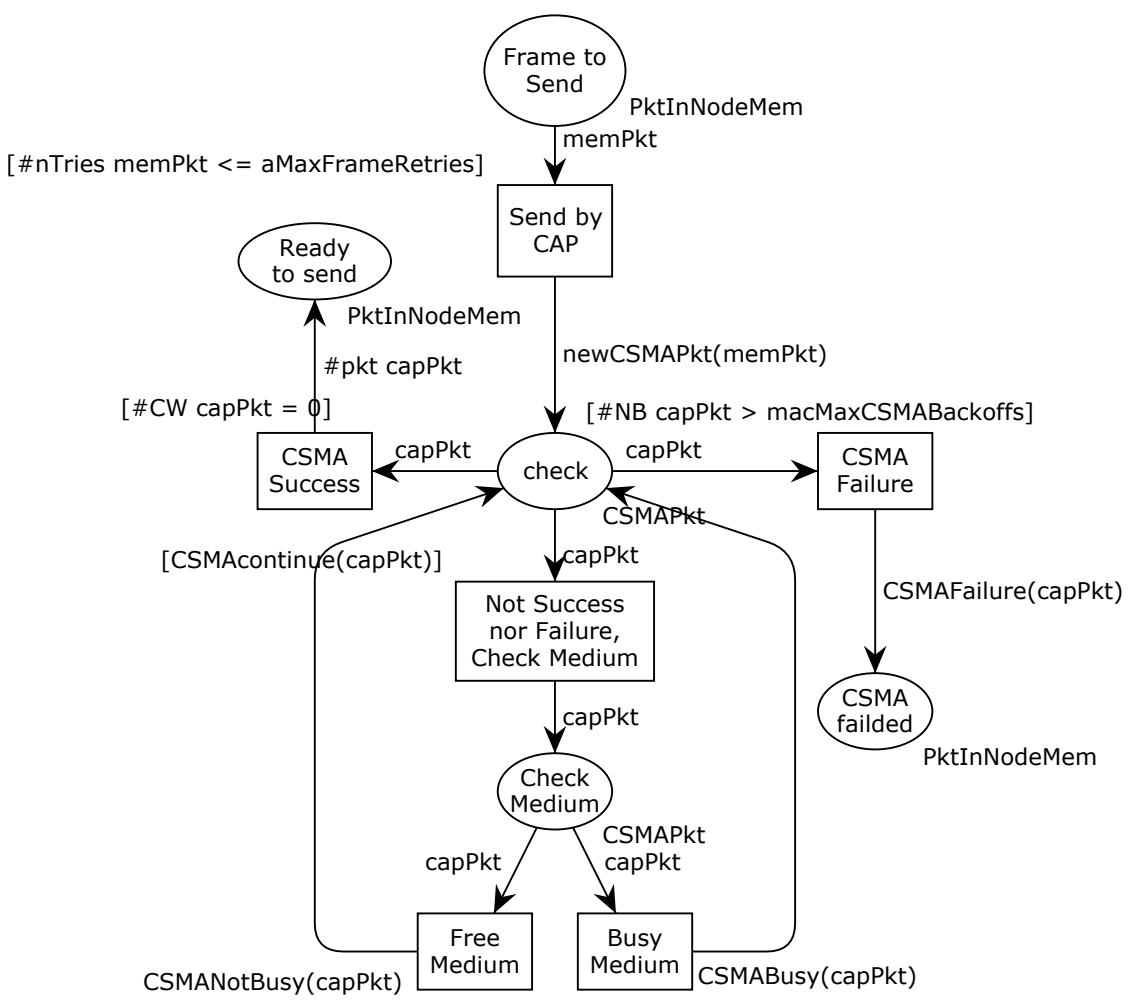

Fonte: Autor

Se alguma das condições de contorno tiverem sido alcançadas, isto é, se o meio foi encontrado livre duas vezes seguidas ou se o meio foi encontrado ocupado mais de cinco vezes (parâmetro macMaxCSMABackoffs), o algoritmo termina a execução com sucesso ou falha (transições CSMA sUCCESS e CSMA FAILURE), respectivamente. Se nenhuma destas condições tiver sido alcançada, o meio continua sendo verificado.

Para verificar se o meio está livre (realizar o clear channel assesment), o segmento de rede de Petri que representa o meio não é de fato verificado como no modelo para a análise de desempenho. O objetivo deste modelo é verificar as possibilidades de sequências de execução, por isso o meio é dado como ocupado ou livre de forma aleatória (ou, se desejado, pode sempre ser dado como livre). Para o modelo de análise de desempenho, verificar se o meio está realmente ocupado será de vital importância.

O colorset CSMAPkt (Trecho de Código 4.3) é utilizado neste caso para armazenar as variáveis de controle utilizadas na execução do algoritmo: NB (number 
of backoff periods), BE (backoff exponent) e CW (contention window), todas do tipo número inteiro. O tipo PktInNodeMem foi definido na Tabela 13.

Trecho de Código 4.3: Colorset CSMAPKT

$$
\begin{aligned}
& \text { colset CSMAPkt }=\text { record pkt }: \text { PktInNodeMem * } \\
& \text { NB }: \text { INT * } \\
& \text { BE }: \text { INT * } \\
& \text { CW : INT; }
\end{aligned}
$$

Algumas funções auxiliares foram utilizadas com a finalidade de alterar as variáveis de controle conforme a situação encontrada.

A função definida no Trecho de Código 4.4 é acionada ao encontrar o meio ocupado durante o CCA do CSMA/CA, reiniciando o valor da janela de contenção (CW) e incrementando o contador de quantidade de backoffs e o BACKOFF EXPONENT, que é limitado pelo parâmetro AMAXBE.

\section{Trecho de Código 4.4: Função CSMABusy}

(*incrementa NB e BE e reseta $C W$ em caso de meio ocupado*)

fun CSMABusy (inPKT:CSMAPkt) =

$$
\begin{aligned}
\{\mathrm{pkt} & =(\# \mathrm{pkt} \text { inPKT }), \\
\mathrm{NB} & =((\# \mathrm{NB} \text { inPKT })+1), \\
\mathrm{BE} & =\text { Int } \min (((\# \mathrm{BE} \text { inPKT })+1), \text { aMaxBE }), \\
\mathrm{CW} & =\text { initialCW }\}
\end{aligned}
$$

Se o CCA detectar que o meio está livre, a função CSMANotBusy, definida no Trecho de Código 4.5, é acionada. Neste caso, a única variável alterada é a janela de contenção $(\mathrm{CW})$, que é decrementada.

Trecho de Código 4.5: Função CSMANotBusy

$$
\begin{aligned}
& \text { (* diminui CW em caso de meio livre *) } \\
& \text { fun CSMANotBusy(inPKT:CSMAPkt) }= \\
& \text { CSMAPkt.set_CW inPKT ((\#CW inPKT) -1); }
\end{aligned}
$$

Se o número máximo de backoffs foi atingido, a função descrita no Trecho de Código 4.6 é acionada, incrementando a quantidade de tentativas de envio do quadro. 
Trecho de Código 4.6: Função CSMAFAilure

(* retorna quadro com número de tentativas incrementado*)

fun CSMAFailure (inPKT:CSMAPkt) =

PktInNodeMem.set_nTries (\#pkt inPKT)

$((\#$ nTries $(\#$ pkt inPKT $))+1)$;

Por fim, a função CSMACONTinue (Trecho de Código 4.7) verifica se o algoritmo do CSMA/CA deve continuar sua execução, baseando-se na janela de contenção (CW) e na quantidade de backoffs (NB).

Trecho de Código 4.7: Função CSMAcontinue

(* condição em que o CSMA ainda ñ̃o acabou de executar*)

fun CSMAcontinue (inPKT:CSMAPkt) $=$

$$
\begin{aligned}
& (\# \mathrm{CW} \text { inPKT }>0) \text { andalso } \\
& (\# \mathrm{NB} \text { inPKT }<=\text { macMaxCSMABackoffs }) ;
\end{aligned}
$$

\subsubsection{Sorvedouro}

A função da Base Station (ou sorvedouro) é receber os quadros de dados e, se estiver indicado no cabeçalho, enviar um quadro de ACK de volta para a estação de origem. Este comportamento pode ser modelado através de uma única transição, conforme exibido na Figura 34.

Figura 34: Basestation

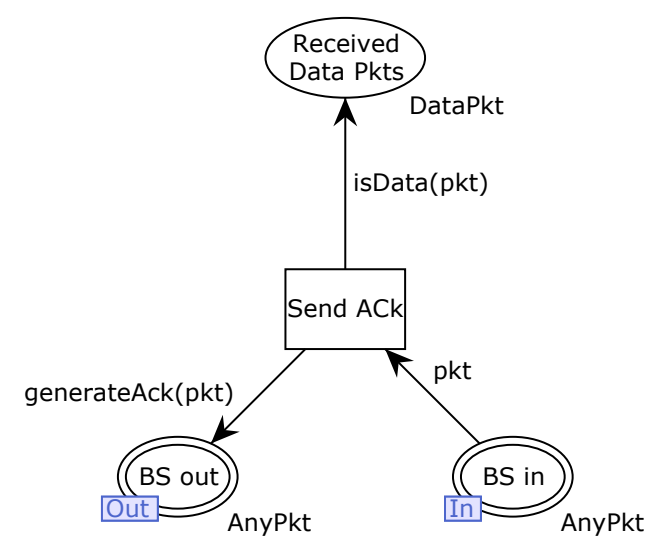

Fonte: Autor

O colorset que define quadros de ACK é definido no Trecho de Código 4.8. 
Trecho de Código 4.8: Colorset ACKPKT

colset AckPkt $=$ record

$$
\begin{aligned}
& \text { fCtrl : FrameControl * } \\
& \text { ackSeqNum : OCT; }
\end{aligned}
$$

A função utilizada para gerar o ACK é exibida no Trecho de Código 4.9, necessitando o quadro recebido como entrada.

Trecho de Código 4.9: Função GenerateACK

fun generateAck $(\mathrm{DATA}(\{\mathrm{fCtrl}=\{$ frameType=DataFrameType, ACKreq $=$ true $\}$, seqNum, ... $))=$

1 'ACK( $\{\mathrm{fCtrl}=\{$ frameType=AckFrameType, $\mathrm{ACKreq}=$ fals e $\}$, $\operatorname{ackSeqNum}=$ seqNum $\}$ )

generateAck $(\ldots)=\operatorname{empty}$

\subsubsection{Meio de transmissão}

O meio de transmissão foi modelado através de duas transições, TO NoDES e To BS, representando o envio de quadros da BS para os nós e vice-versa. Para representar a possibilidade de perdas, o envio do quadro está condicionado à escolha aleatória de uma marca existente no lugar SuCCESS. Manipulando a marcação inicial deste lugar pode-se definir a possibilidade de erros na transmissão de quadros. No caso da Figura 35, a transmissão pode falhar ou não.

Figura 35: Meio de transmissão

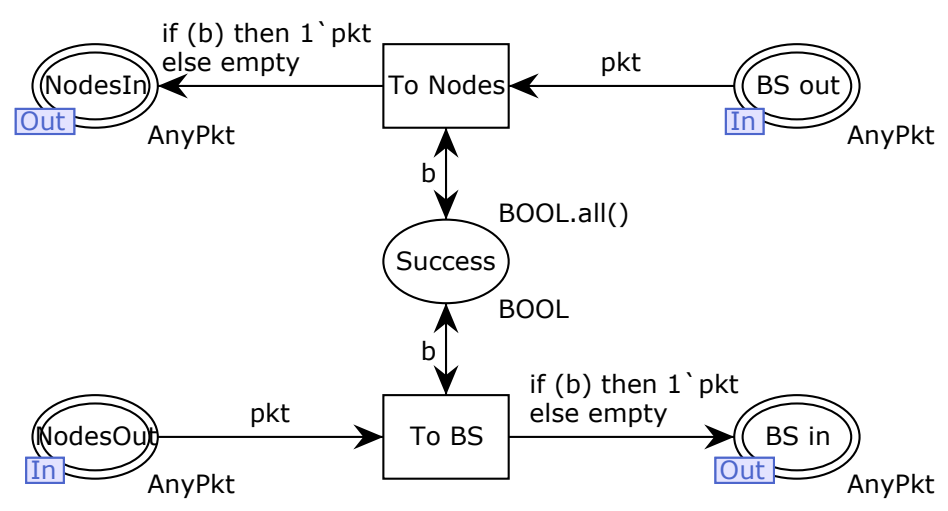

Fonte: Autor 


\subsubsection{Análise do Modelo de rede}

Os resultados obtidos com a análise do modelo descrito anteriormente são apresentados nesta seção.

A análise foi feita através do espaço de estados, com a finalidade de verificar se a ordem de ocorrência dos eventos e se as marcações finais são as esperadas. $O$ procedimento foi realizado para as variações mais significativas de parâmetros do modelo. Os parâmetros escolhidos são binários (sim/não) e são listados a seguir:

- Perdas do meio físico (devido a interferências ou colisões);

- Falha do procedimento de CSMA/CA;

- Transmissão com ACK;

- Timeout precoce.

A partir destes parâmetros, oito cenários foram escolhidos, de forma que cada cenário ficasse mais complexo que o anterior, conforme a Tabela 15.

Tabela 15: Cenários de model checking

\begin{tabular}{|c|c|c|c|c|c|c|}
\hline$\#$ & Perdas & $\begin{array}{c}\text { CSMA/CA } \\
\text { Falível }\end{array}$ & Com ACK & $\begin{array}{c}\text { Timeout } \\
\text { precoce }\end{array}$ & \# Marcações & $\begin{array}{c}\text { \# Marcações } \\
\text { finais }\end{array}$ \\
\hline 1 & Não & Não & Não & Não & 5 & 1 \\
\hline 2 & Não & Não & Sim & Não & 8 & 1 \\
\hline 3 & Sim & Não & Não & Não & 6 & 2 \\
\hline 4 & Sim & Sim & Não & Não & 26 & 9 \\
\hline 5 & Não & Não & Sim & Sim & 74 & 5 \\
\hline 6 & Sim & Sim & Sim & Não & 104 & 15 \\
\hline 7 & Sim & Não & Sim & Não & 104 & 15 \\
\hline 8 & Sim & Sim & Sim & Sim & 239 & 35 \\
\hline
\end{tabular}

Fonte: Autor

Nos dois primeiros cenários, nos quais o canal de transmissão é livre de falhas e o CSMA/CA sempre é bem-sucedido, a análise é trivial. Para o caso sem ACK, as cinco marcações são sequenciais e correspondem ao trânsito do quadro até a BS, conforme exibido na Figura 36. A marcação final representa o quadro dado como entregue com sucesso pela estação e recebido somente uma vez pela BS. 
Figura 36: Espaço de estados do cenário 1: sem perdas e sem ACK

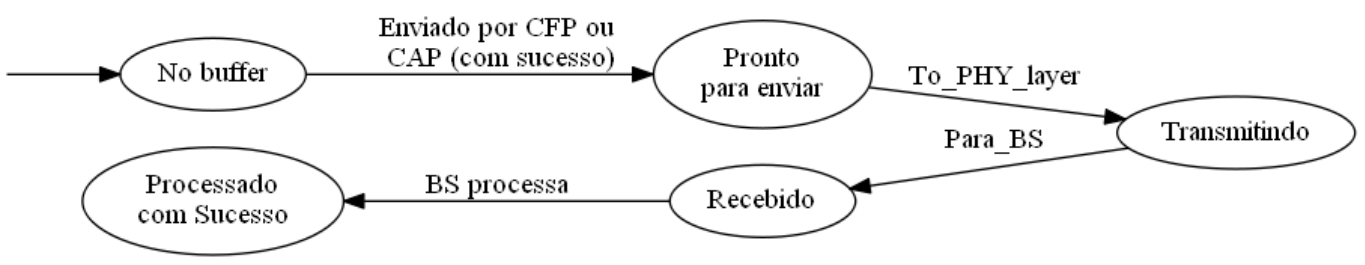

Fonte: Autor

No caso sem perdas porém com ACK, a análise é semelhante, porém há 8 marcações no total. As três marcações a mais em relação ao caso anterior surgem devido ao envio do quadro de ACK da BS para a estação, como indicado na Figura 37.

Figura 37: Espaço de estados do cenário 2: sem perdas e com ACK

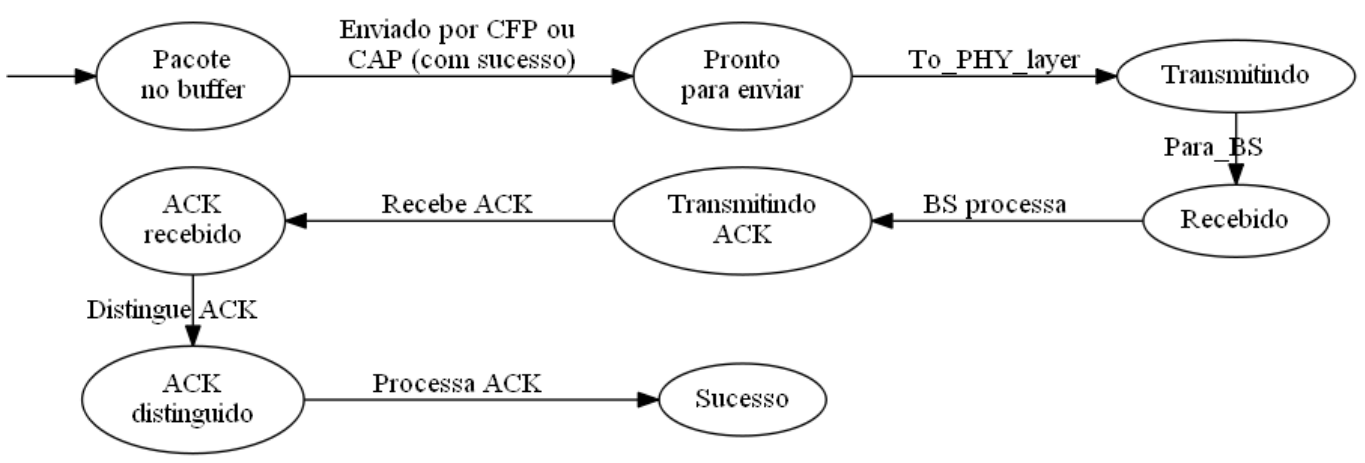

Fonte: Autor

No terceiro cenário o CSMA/CA é considerado sempre bem sucedido, porém, pode haver falhas na transmissão do quadro, o que representa o caso de uma estação transmitindo sozinha, porém, em um meio ruidoso, ou o caso do terminal oculto $^{1}$. Como não há envio de ACK, a estação sempre considera que o quadro foi entregue com sucesso, porém, ao contrário de cenário 1, existe a possibilidade de que o quadro nunca chegue a BS, resultando em duas marcações finais possíveis. A Figura 38 exibe a evolução das marcações.

Ao introduzir as possibilidades do CSMA/CA falhar e de ocorrer perdas no meio físico, o grafo do espaço de estados torna-se ramificado de acordo com as possibilidades de perdas e erros. Para o caso sem ACK, observa-se um padrão bem definido: para cada execução bem sucedida do algoritmo de CSMA/CA há duas possibilidades: quadro entregue com sucesso à BS ou perda durante a

\footnotetext{
${ }^{1}$ Cenário em que uma terceira estação não pode ser ouvida pelo transmissor, porém, interfere na recepção do quadro pela BS.
} 
transmissão. Como o envio de ACK não é requerido, a estação considera que o quadro foi entregue com sucesso em ambos os casos.

Figura 38: Espaço de estados do cenário 3: CSMA ok, com perdas e sem ACK

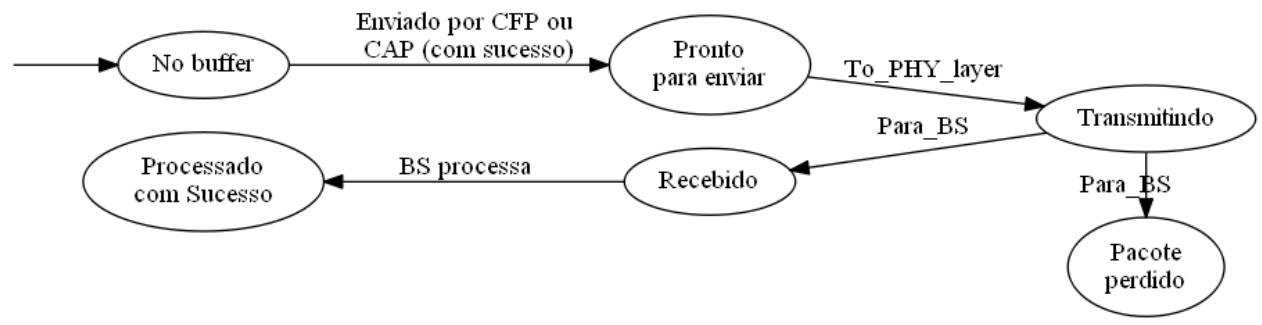

Fonte: Autor

O diagrama da Figura 39 ilustra este padrão de comportamento, onde partimos de uma marcação em que já foram feitas $n$ tentativas de transmissão e $r$ quadros já foram recebidos pela BS, sendo que $n$ e $r$ são iguais a zero no início da exploração do espaço de estados.

Figura 39: Padrão do cenário 4: com perdas e sem ACK

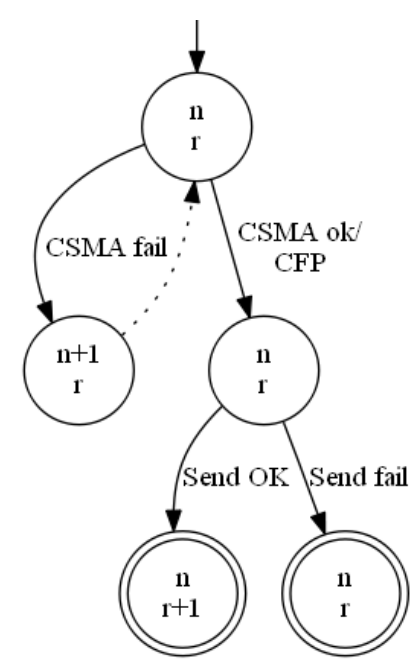

Fonte: Autor

De acordo com o parâmetro aMaxFrameRetries do protocolo, o CSMA/CA pode falhar até três vezes antes que o envio do quadro termine com status de erro. No diagrama, uma falha do CSMA/CA causa incremento de $n$. Assim, há duas marcações finais, $r=0$ e $r=1$, para cada possibilidade de quantidade de falhas do CSMA/CA ( $n$ variando de 0 até 3 ), somando 8 marcações finais. A nona marcação final é o caso em que o CSMA/CA falhou quatro vezes seguidas, configurando uma falha no envio de quadro. 
O quinto cenário introduz a possibilidade de que o timeout de ACK expire precocemente, isto é, permite que haja nova tentativa de envio do quadro apesar do sucesso das etapas de execução do CSMA/CA, envio do quadro e envio do ACK. Uma interpretação para esta suposição é que o timeout precoce ocorre na iminência do recebimento do ACK. As marcações finais referem-se à quantidade de quadros recebidos pela BS, que varia com a quantidade de timeouts precoces, de 1 até 4 . Além disso, existe o caso em que a BS também recebe 4 quadros, porém, a estação não recebe o ACK a tempo, causando falha no envio do quadro. A estrutura do espaço de estados é exibida na Figura 40. Este cenário demonstra que é importante que o tempo de timeout seja bem dimensionado, caso contrário podem ocorrer desperdícios mesmo se o meio estiver em condições ideais.

Figura 40: Padrão do cenário 5: com ACK, sem perdas, com timeout precoce

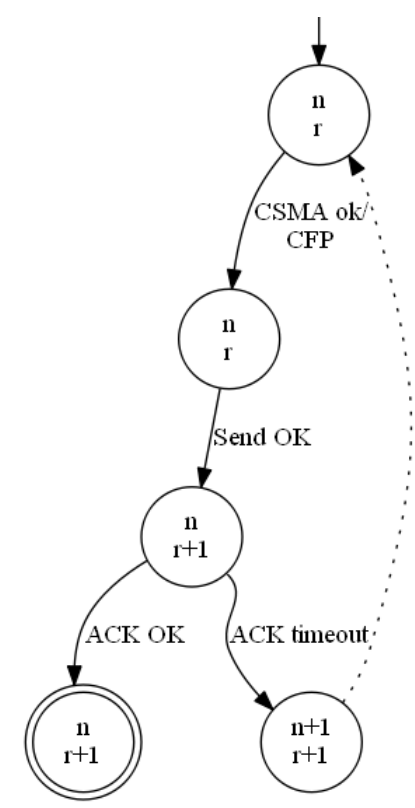

Fonte: Autor

O próximo cenário inclui transmissão com ACK e falhas na rede. Tanto o quadro de dados quanto o de ACK podem ser perdidos. O espaço de estados é quatro vezes maior em relação ao cenário 4, porém, um padrão de comportamento semelhante é observado.

As marcações finais refletem a variação entre o número de tentativas realizadas para enviar o quadro e a quantidade de quadros recebidos pela BS. Mais de uma cópia do mesmo quadro pode ser recebida pela BS devido a falhas no envio do ACK e, consequente, retransmissão do quadro. O padrão observado está representado de forma simplificada na Figura 41a. Novamente partimos de 
uma marcação em que já foram feitas $n$ tentativas de transmissão e $r$ quadros já foram recebidos pela BS, valores que são inicialmente iguais a zero.

Figura 41: Cenários 6 e 7 - com perdas e com ACK

(a) Padrão do cenário 6: com possibilidade de erro de CSMA/CA

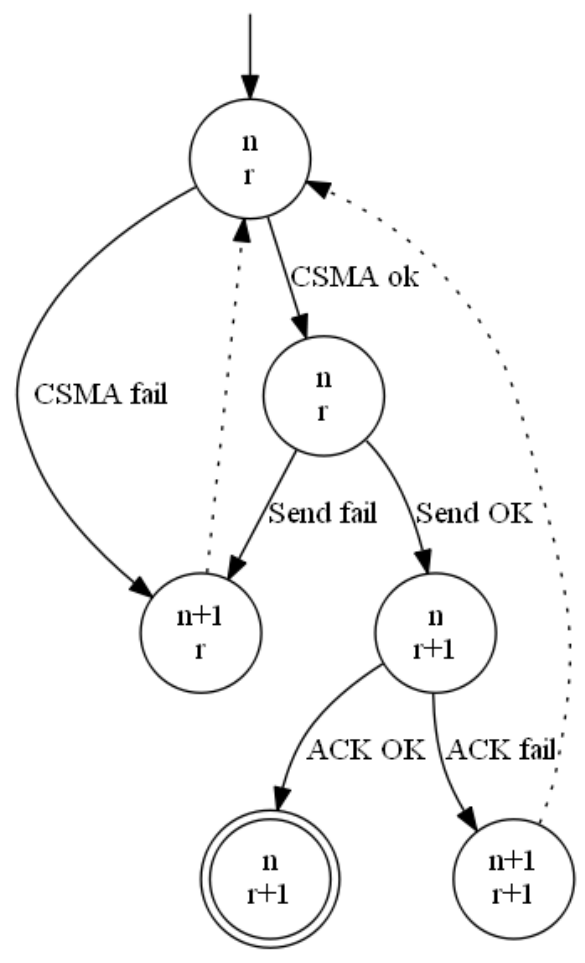

(b) Padrão do cenário 7: sem possibilidade de erro de CSMA/CA

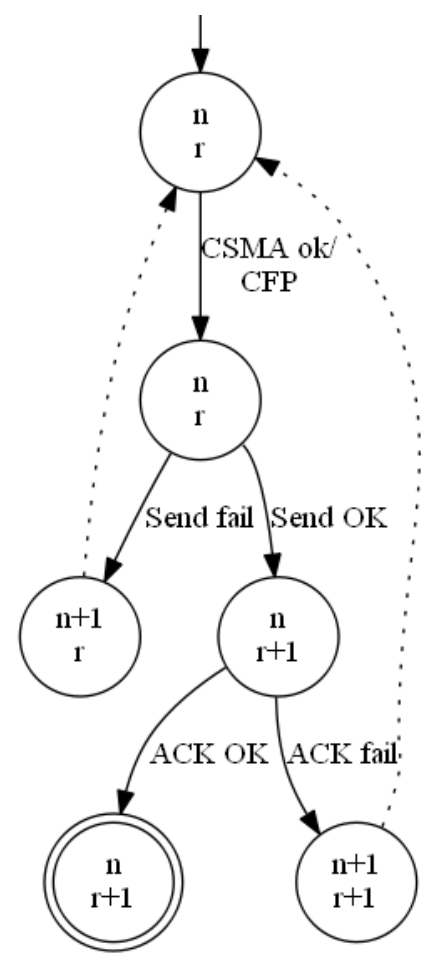

Fonte: Autor

Se o CSMA/CA for bem sucedido (ou se o CFP for utilizado), o quadro chegar com sucesso à BS e o ACK retornar com sucesso, temos uma marcação final na qual não foram realizadas novas tentativas de transmitir o quadro (valor de $n$ não muda) e o BS recebeu mais uma cópia do quadro, causando incremento de $r$.

Porém, se o CSMA/CA falhar ou se o CSMA/CA for bem sucedido, mas houver erro na transmissão, a estação realizará reenvio do quadro, seja devido à impossibilidade de encontrar o meio livre ou devido ao timeout de recebimento do ACK. Nesses casos, haverá o incremento do número de tentativas $(n)$ sem incremento de quadro recebidos pela $\mathrm{BS}(r)$. O procedimento executado pela estação retorna ao início do diagrama com o valor de $n$ atualizado.

Por fim, o quadro pode ser enviado com sucesso à BS, porém, o quadro de ACK pode ser perdido. O timeout da estação será disparado e a estação iniciará nova tentativa de transmissão, retornando ao início do diagrama com $n+1$ e $r+1$. 
O ciclo de tentativas de envio termina se o quadro e respectivo ACK forem entregues com sucesso ou se o número de tentativas de enviar o quadro ultrapassar aMaxFrameRetries. Note que, em caso de sucesso, para cada $n$ tentativas de envio realizadas, a BS pode ter recebido até $n+1$ cópias do quadro, sendo que $n$ varia de 0 a 3. Para o caso de falha, a BS pode ter recebido de 0 a 4 quadros. Estas combinações geram o total de $15\left(\sum_{i=0}^{4} i+1\right)$ marcações finais indicado pela Tabela 15 .

O cenário 7 é semelhante ao anterior, porém, o CSMA/CA sempre retorna sucesso, representando o caso de uma estação transmitindo quadros sozinha em um meio ruidoso ou o caso do terminal oculto. O espaço de estados apresenta o mesmo número de marcações (finais ou não), pois o fato de não haver falha de CSMA/CA apenas altera a quantidade de arcos do espaço de estados, uma vez que o efeito produzido pela falha do CSMA/CA é equivalente ao caso bem sucedido seguido de falha na transmissão do quadro. Comparando as Figuras 41a e 41b, esta diferença fica evidente pela falta do arco CSMA fail.

Por fim, o cenário 8 apresenta a combinação mais complexa de parâmetros, no sentido de que apresenta o maior número de cursos alternativos em relação ao ideal. A estrutura do espaço de estados é ramificada como ilustrado na Figura 42. A forma é semelhante ao cenário 7 (Figura 41a), porém, a variável $a$ foi introduzida com a função de contar a quantidade de ACKs rejeitados pela estação, e há uma ramificação a mais devido à possibilidade de timeout.

Poderia se argumentar que o timeout pode ocorrer em qualquer momento, e não somente na iminência de recebimento do ACK, como foi modelado. Porém esta hipótese é razoável, pois o tempo de timeout previsto no padrão IEEE 802.15.4 é dimensionado de acordo com o tempo previsto de propagação do quadro de dados e de propagação e transmissão do quadro de ACK. Desta forma, o timeout precoce ocorreria somente em caso de ocorrência de algum assincronismo ou atraso de processamento inesperado por parte da estação base. 
Figura 42: Padrão do cenário 8: com perdas, com ACK e com timeout precoce

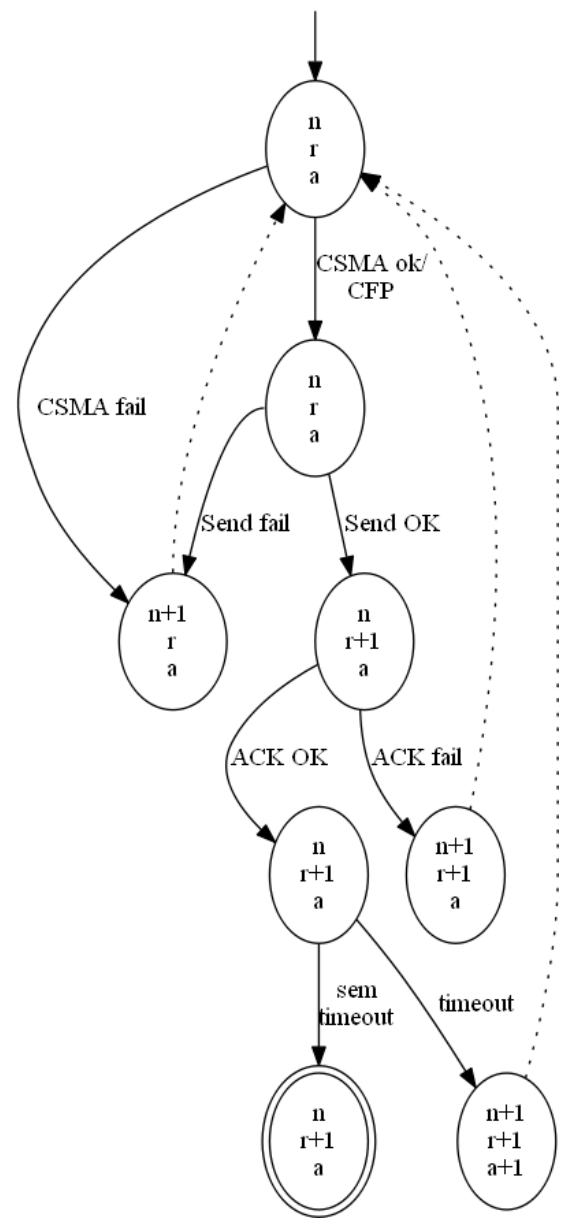

Fonte: Autor

As marcações finais obtidas neste cenário contemplam as possíveis variações entre quantidade de quadros recebidos pela BS, quantidade de tentativas de enviar o quadro pela estação e quantidade de ACKs rejeitados pela estação. Se houve $n$ tentativas de enviar um quadro, a BS pode ter recebido de 1 até $n$ e para cada $r$ quadros recebidos dessa maneira, a estação pode ter rejeitado de 0 a $r-1$ ACKs. Como $n$ varia de 1 até 5 , a quantidade de marcações finais é $35\left(\sum_{i=1}^{5} \sum_{j=1}^{i} j\right)$.

Dos dezesseis cenários potencialmente obtidos pela variação dos quatro parâmetros foram contemplados apenas oito, pois os outros são muito semelhantes aos já analisados ou porque não fazem sentido. Os casos que combinariam timeout precoce com transmissão sem ACK não fazem sentido, pois em transmissões sem ACK nenhum timeout é preparado. Cenários em que há possibilidade de haver falha no CSMA/CA, porém o meio está sempre livre, foram considerados como uma situação muito improvável e foram descartados. Por fim, o caso com perdas 
no meio, porém sem falhas de CSMA/CA e com possibilidade de timeout precoce foi descartado pela semelhança com o cenário equivalente sem timeout precoce.

\subsubsection{Análise do Modelo de CSMA/CA}

No tocante ao model checking, a análise do algoritmo de CSMA/CA foi realizada separadamente do fluxo de troca de quadros. Desta forma, a quantidade de marcações no espaço de estados referente ao CSMA/CA e à troca de quadros foi diminuída em comparação a uma análise que levasse em conta os dois aspectos simultaneamente, tornando a análise mais concisa e simples, sem comprometer as conclusões. O trecho de rede de Petri utilizado foi explicado na Seção 4.1.2.2

O espaço de estados possui um total de 34 marcações, partindo do ponto em que um quadro é enviado pelo CAP e está prestes a inicializar o algoritmo de CSMA/CA (um quadro no lugar FRAME TO SEND). As duas marcações finais representam as saídas possíveis do algoritmo: sucesso ou falha.

Figura 43: Fragmentos do espaço de estados CSMA/CA

(a) Primeira iteração

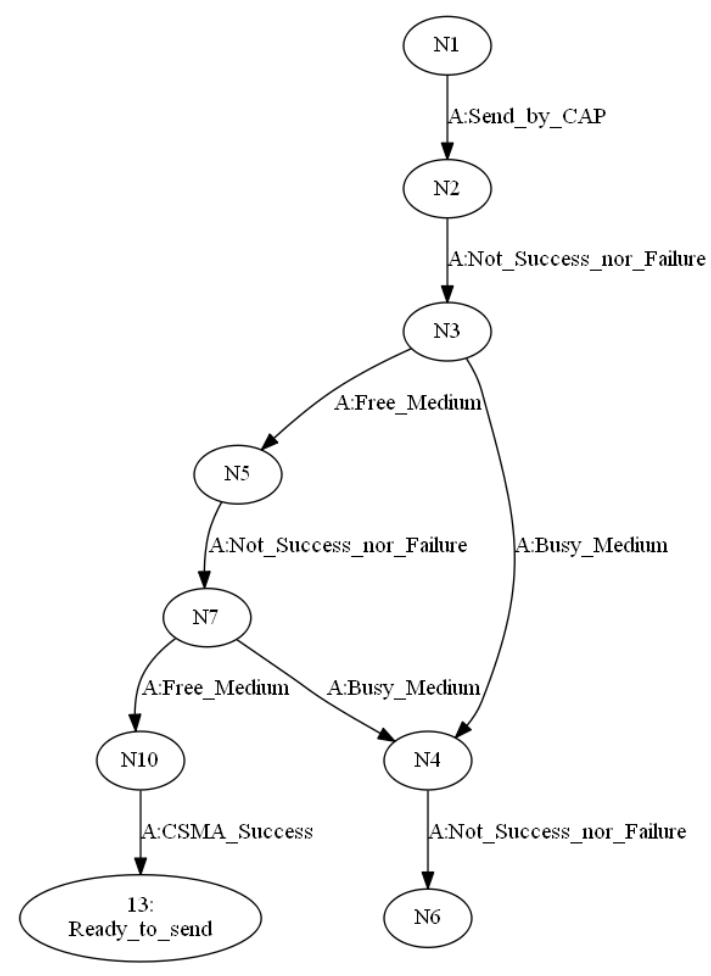

Fonte: Autor (b) Última iteração

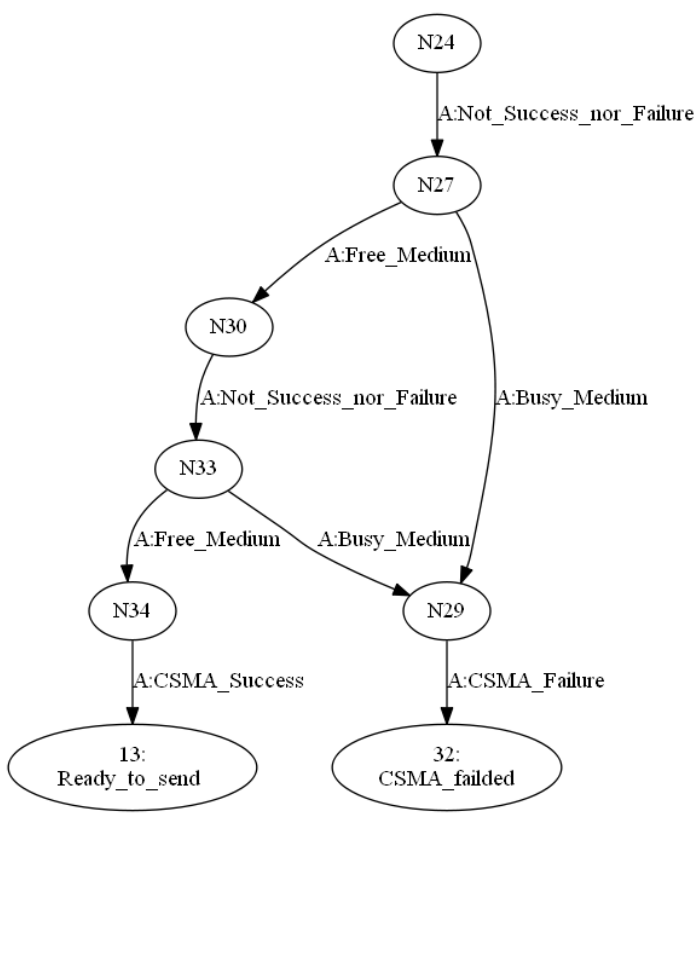

O espaço de estados se desenvolve exatamente como o esperado, com o algo- 
ritmo terminando em sucesso sempre que o meio for encontrado livre duas vezes consecutivas. Um padrão composto de 5 marcações é notado no diagrama de espaço de estados, exibido na Figura 43. O início é exibido na Figura 43a, onde o algoritmo é iniciado.

Nota-se que, se o meio for encontrado livre duas vezes consecutivas, chega-se a uma marcação final. Caso contrário, uma nova tentativa é realizada seguindo o mesmo padrão. A Figura 43b exibe a última iteração do algoritmo, em que há a possibilidade de terminar em falha. Este padrão de cinco marcações ocorre seis vezes, totalizando 30 marcações. Existem quatro outras marcações, referentes às marcações iniciais (N1 e N2 na Figura 43a) e a duas marcações finais, totalizando as 34 marcações do espaço de estados.

\subsubsection{Considerações da seção}

Os objetivos do modelo apresentado nesta seção foram alcançados. O espaço de estados obtido está em conformidade com a sequência de execução prevista na especificação do padrão IEEE 802.15.4. Este modelo e a sua validação servem de base para o modelo de análise de desempenho, que leva em conta os fenômenos temporais. Os detalhes deste modelo são apresentados na seção seguinte.

\subsection{Modelo para análise de desempenho}

Esta seção aborda o modelo concebido para realizar análise de desempenho. As métricas utilizadas para verificar o desempenho do sistema modelado são extraídas através de simulações temporais, observando-se os eventos que ocorrem na rede.

A estrutura deste modelo é fortemente baseada no anterior, com objetivo de manter a ordem de execução dos passos algoritmicamente correta. Porém, diversas modificações são necessárias para realizar a análise temporal e comportar a coexistência de diversos nós executando o mesmo procedimento simultaneamente.

Em contrapartida, estas modificações dificultam a análise do espaço de estados, uma vez que o seu tamanho aumenta significativamente, pois, cada alteração de tempo e cada combinação possível dos estados dos diversos nós representam marcações diferentes. No modelo para análise do espaço de estados, estas marca- 
ções seriam reduzidas a uma única marcação, já que este modelo considera apenas o processo de transmissão de um nó e não modela aspectos temporais.

As alterações realizadas são razoáveis, uma vez que o processo e a ordem de execução dos algoritmos não foram alterados, de forma que as verificações realizadas anteriormente são válidas também para este modelo. Embora não tenha sido realizada uma prova formal, verificou-se empiricamente que erros imprevistos não foram introduzidos no modelo.

Os ajustes realizados e os resultados obtidos são exibidos nas próximas subseções.

\subsubsection{Visão Geral}

A estrutura hierárquica do modelo para análise de desempenho foi mantida semelhante à estrutura do modelo para análise do espaço de estados, com três macro transições representando o comportamento dos nós da rede, da basestation e da transmissão de quadros, como exibido na Figura 44.

Figura 44: Visão geral do modelo CPN para análise de desempenho

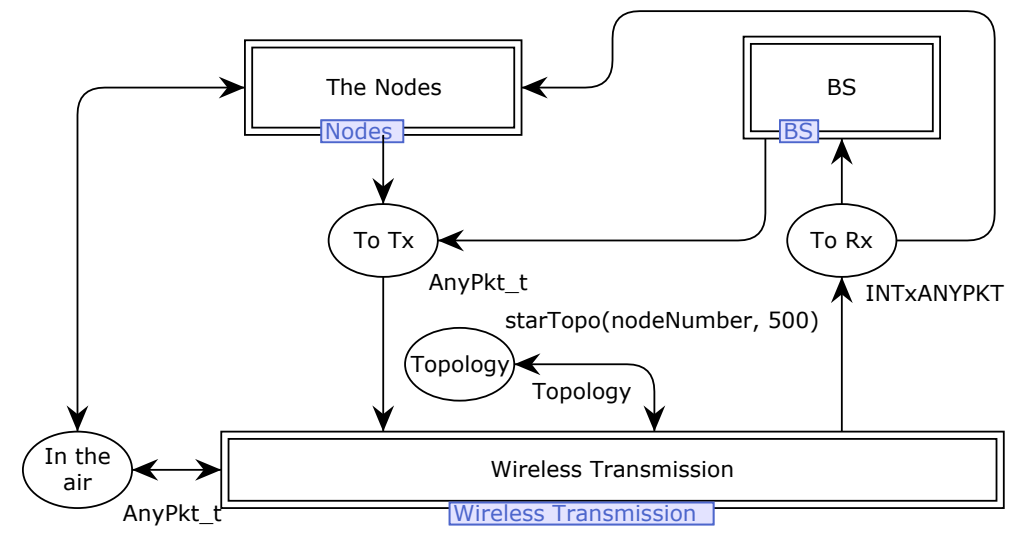

Fonte: Autor

Porém há diferenças. O modelo de transmissão de quadro foi generalizado, e, em decorrência disso, os lugares de interface entre os nós e o meio de transmissão foram reduzidos para um lugar de entrada e de saída, unificado tanto para os nós quanto para a BS.

A maioria dos colorsets utilizados anteriormente possui uma versão temporizada, que possui o mesmo nome que antes seguido de _ $t$ (por exemplo, ANYPKT e ANYPKT_T). 
A unidade de tempo básica do modelo é contabilizada em símbolos. A ferramenta utilizada marca o tempo como uma variável inteira, não suportando que o tempo seja contabilizado como um número real. Como o símbolo é a unidade de tempo mínima a partir da qual todos os outros tempos são definidos no IEEE 802.15.4, é natural escolhê-lo como unidade básica de tempo.

Dois lugares foram adicionados. O lugar IN THE AIR tem a função de possibilitar que os nós da rede verifiquem o meio durante o processo de envio de quadros. O lugar TOPOLOGY modela a topologia da rede e determina a distância entre cada par de nós.

Os submodelos e detalhes das alterações realizadas serão explicados nas próximas subseções.

\subsubsection{Nó da rede}

O comportamento de um nó segundo a especificação do padrão IEEE 802.15.4 levando em conta os aspectos temporais é exibido nas Figuras 45 e 46 . Novamente o modelo foi baseado em sua versão apresentada na seção 4.1.2, com modificações feitas para incorporar tempo ao modelo. Para melhorar a explicação, o modelo foi dividido em duas figuras: uma para a parte semelhante ao modelo para análise do espaço de estados e outra para o novo trecho intrinsecamente temporal.

Na Figura 45 está o trecho de modelo semelhante à Figura 31. O fluxo de envio de um quadro inicia-se pela macro transição ARRIVAL PROCESS (Seção 4.2.2.1), responsável pelo gerenciamento da fila e chegada de quadros.

Após sair da fila de envio, o quadro aguarda o início do seu processo de transmissão no lugar FrAme To SEND. O próximo passo é o processo de acesso ao meio (Seções 4.2.2.2 e 4.2.2.3). O quadro é então enviado para a camada física, momento em que é transmitido de fato.

O procedimento para aguardar o ACK é iniciado no instante do início da transmissão do quadro; mais detalhes são apresentados na Seção 4.2.2.4. Caso haja sucessivas falhas no acesso ao meio ou esgotamento do timeout relativo ao ACK, o quadro é descartado através da transição FAIL ao atingir aMaxFrameRetries tentativas de envio. A quantidade de quadros falhos é armazenada no lugar Nodes Successes \& Failures, separadamente para cada nó. 
Figura 45: Nó da rede - fragmento análogo ao modelo da Seção 4.1

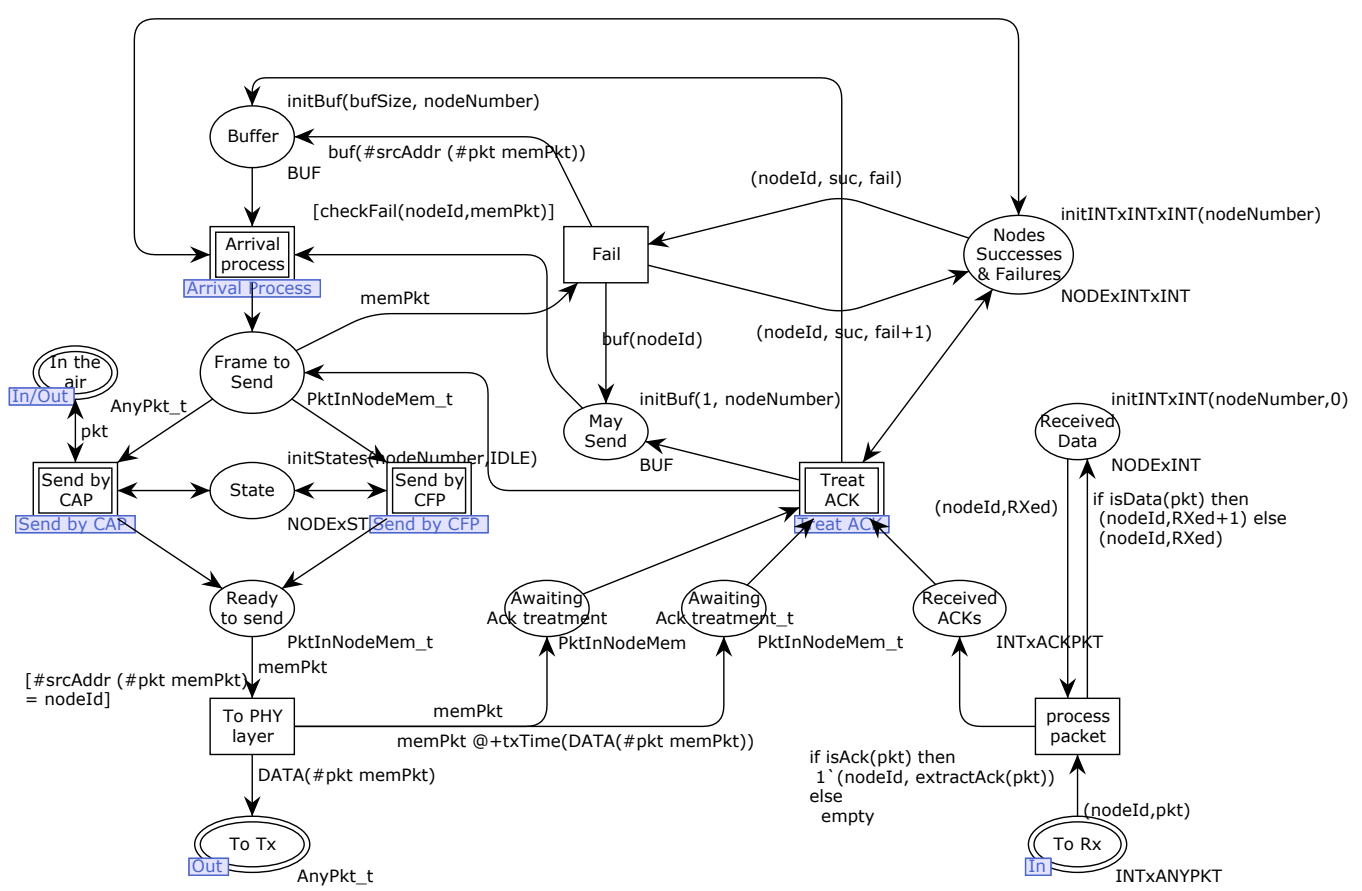

Fonte: Autor

Os quadros recebidos permanecem no lugar To Rx e são tratados de acordo com o seu tipo. A quantidade de quadros de dados recebidos é contabilizada no lugar RECEIVED DATA, mesmo que o quadro não tenha sido destinado para o nó em questão. Os quadros de ACK são tratados conforme a especificação do padrão (Seção 4.2.2.4).

Na Figura 46 temos o segmento de rede de Petri que tem a função de controlar o estado do superframe vigente de cada nó, de acordo com a sua duração. Este trecho não assume que os nós estão sincronizados, e é projetado de tal forma que cada nó possa ter parâmetros definidos separadamente e estar em estados diferentes.

A transição responsável por mudar o estado de cada nó é a CHANGE NoDESTATE, através da função NEXTSTATE. Os parâmetros BO, SO e duração do CFP são utilizados pela função STATEDURATION para calcular a duração do próximo estado, como descrito no Trecho de Código 4.10. 
Figura 46: Nó da rede - fragmento de controle de tempo

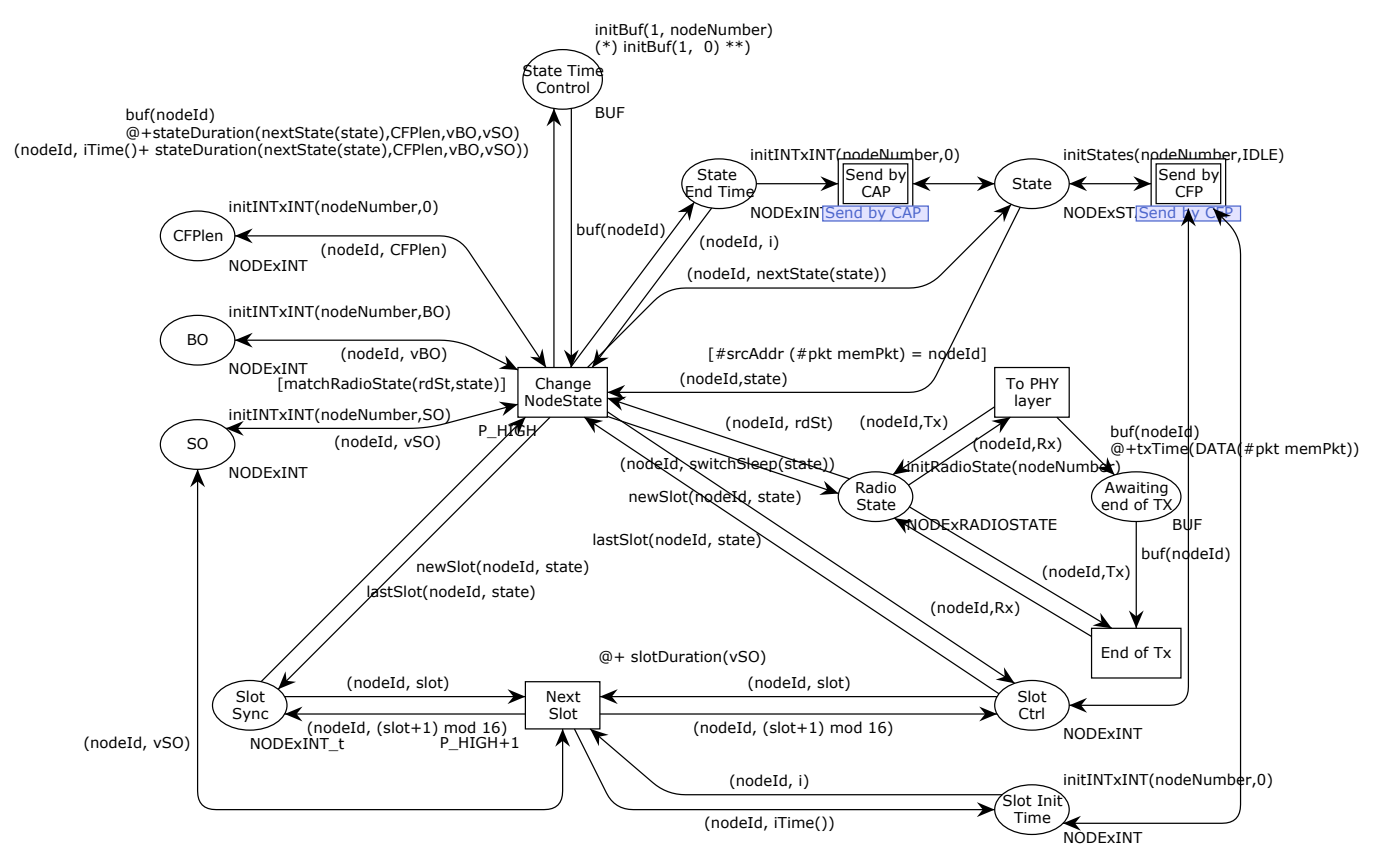

Fonte: Autor

Trecho de Código 4.10: Função STATEDuRATion

fun stateDuration (CAP, CFPlen, _, SO) = aBaseSuperframeDuration * pow $(2, \mathrm{SO})-$ CFPlen stateDuration (CFP, CFPlen, _, _) = CFPlen stateDuration (IDLE, _, BO, SO) = aBaseSuperframeDuration * $(\operatorname{pow}(2, \mathrm{BO})-\operatorname{pow}(2, \mathrm{SO}))$;

O estado é mantido no lugar STATE e seu colorset é NODEXSTATE, definido no Trecho de Código 4.11. Este colorset é não temporal para permitir verificações a qualquer instante, enquanto que o lugar State Time Control controla o tempo de mudança do estado e, por essa razão, deve ter um colorset temporal. O lugar STATE END TIME registra o tempo de término do estado vigente, utilizado para verificar se há tempo suficiente para realizar uma nova transmissão.

Trecho de Código 4.11: Colorsets e Função NEXTSTATE

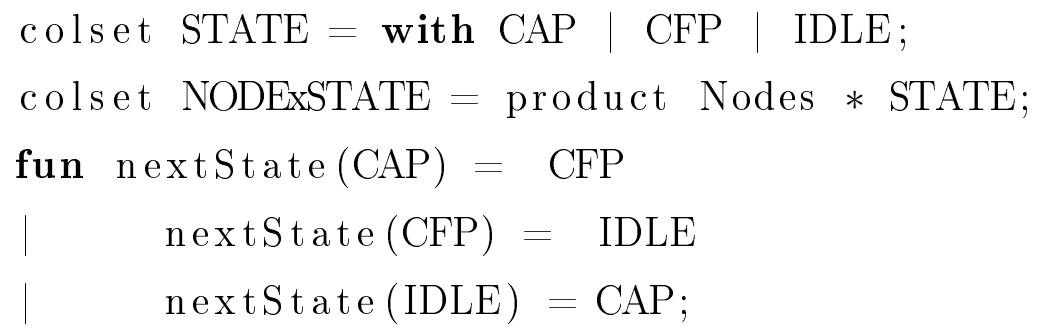


O período ativo de um superframe é dividido em 16 slots, unidades de tempo alocáveis para transmissão de dados utilizando o $C F P$. Ao se iniciar o período ativo, ou seja o CAP, os lugares Slot Sync e Slot Control são inicializados com um par ordenado composto pelo identificador do nó e o número 15, que é o último slot. Porém, devido à prioridade da transição, antes que qualquer outro evento ocorra, o contador de slot é transformado em zero.

O lugar Slot SyNC é temporizado e tem a função de marcar o tempo de troca de slot, enquanto que o Slot Ctrl tem a função de informar ao CFP o slot atual. Há um terceiro lugar, o Slot Init Time, cuja função é informar ao CFP o instante de início do slot, utilizado para verificar se há tempo suficiente para realizar uma nova transmissão (ver Seção 4.2.2.2).

Os parâmetros iniciais utilizados para calcular o tempo de duração dos estados e dos slots são definidos nos lugares CFPLEN, BO e SO e consultados sempre que necessário.

Os lugares Radio State e Awaiting End of TX foram adicionados para auxiliar no cálculo da potência média dispendida pelo rádio. O colorset de RADIO STATE armazena o estado atual do rádio, que pode ser transmitindo, recebendo ou dormindo (Trecho de Código 4.12), alterado conforme o nó inicia e termina o envio de quadros ou entra no período ocioso do superframe.

Trecho de Código 4.12: Colorset RadioState

colset RadioState $=$ with $\operatorname{Tx}|\operatorname{Rx}|$ Sleep;

colset NODExRADIOSTATE $=$ product INT $*$ RadioState;

\subsubsection{Processo de chegada de quadros}

O processo de chegada de quadros é exibido na Figura 47. Um quadro chega a este nível da pilha de protocolo sempre que a transição PACKET ARRIVAL dispara. Associada a esta transição, o intervalo entre chegada de quadros é determinado pela função ARRIVALRATE(), que determina o tempo em que o próximo quadro chegará. Este tempo fica armazenado no lugar DSNS RDY TO GO, que também contém os valores de data sequence number, armazenados na forma de um par ordenado de inteiros (Trecho de Código 4.13), inicializados com valores aleatórios, chegando no máximo a 255, retornando a zero depois. 
Trecho de Código 4.13: Colorsets novos

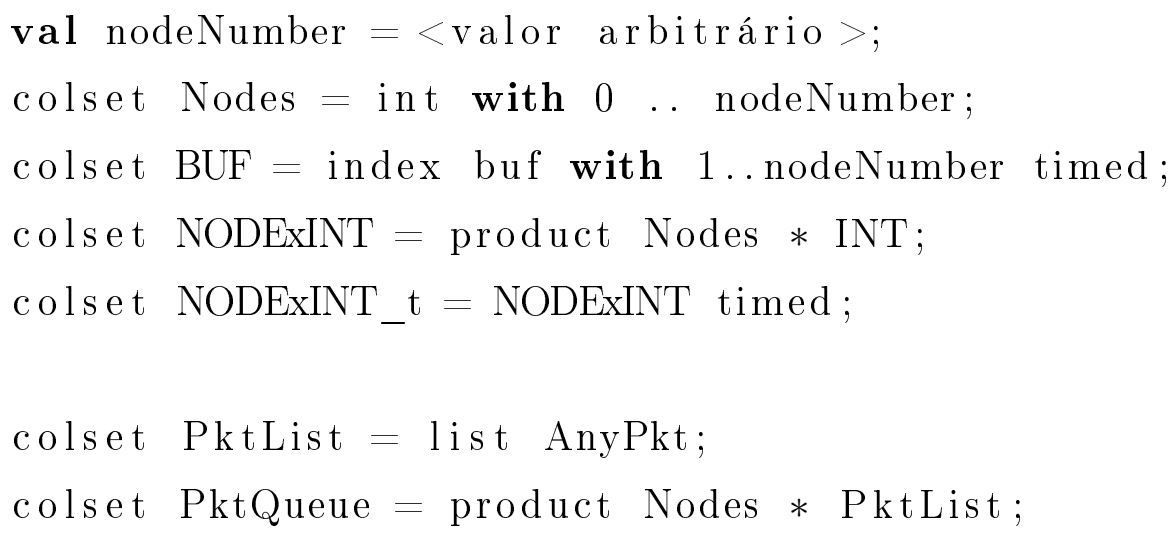

Figura 47: Chegada de quadros

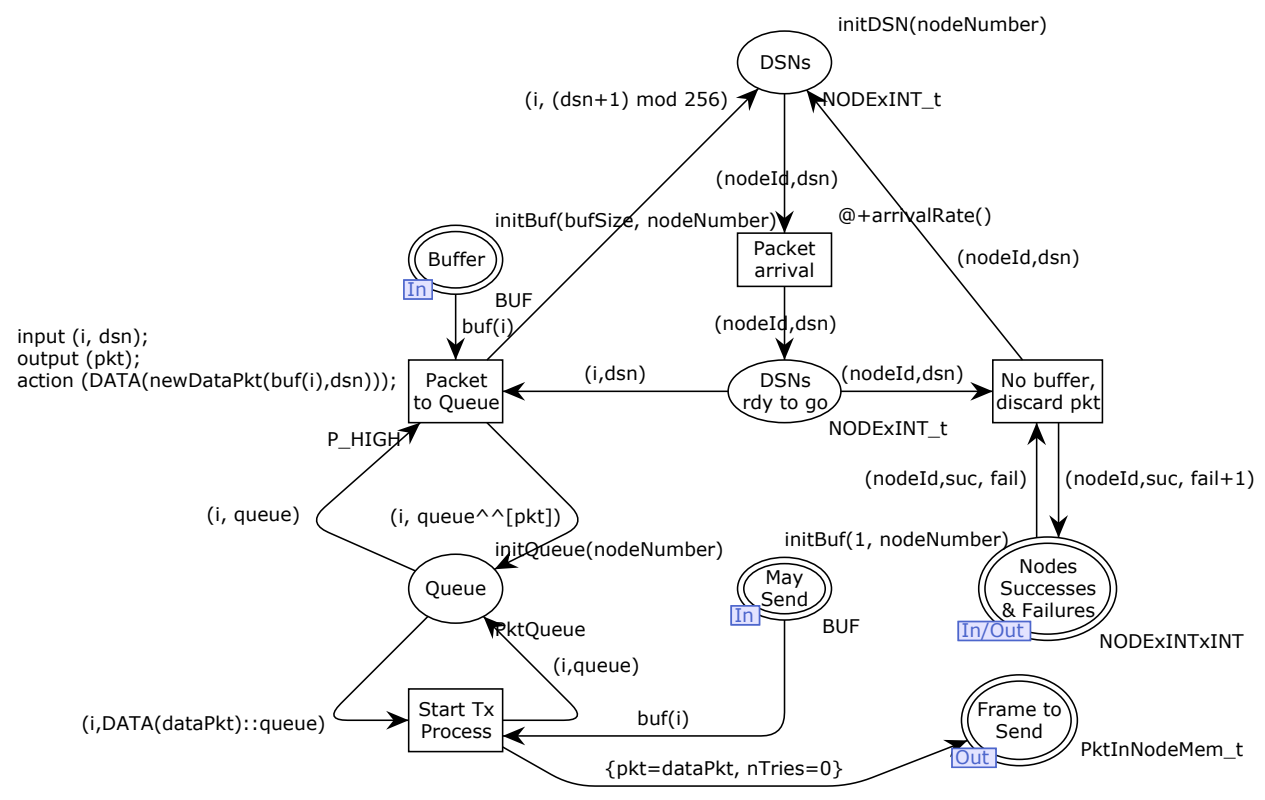

Fonte: Autor

O quadro entra na fila de transmissão somente se houver ao menos uma posição livre no buffer do nó. Neste caso a transição PACKET TO QUEUE dispara, consumindo uma marca de BUF (esta marca retornará ao lugar BUFFER somente no final do processo de transmissão do quadro) e adicionando uma marca no lugar DSN, incrementando o valor do número de sequência.

A fila de quadros de cada nó é armazenada no lugar Queue do tipo PKTQueue. Cada fila é modelada como uma lista, com a finalidade de manter a ordem de chegada dos quadros. O quadro inicia o processo de transmissão assim que ele for o primeiro da fila e não houver outro quadro em transmissão pelo mesmo nó, o que é controlado pelo lugar MAY SEND. 
Se não houver buffer disponível, a transição NO BUFFER, DISCARD PKT será disparada e o quadro não passa para a fila de transmissão. Os quadros descartados dessa maneira são contabilizados no lugar Nodes Successes \& FAilures. Observe-se que essas transições levam em conta o identificador dos nós, permitindo uma quantidade arbitrária de nós no modelo, configurável através de uma variável, conforme ilustrado no Trecho de Código 4.13. Nesta implementação, o identificador e o endereço MAC dos nós são os mesmos. Se for desejado que o endereço dos nós possa ser alterado ao longo de uma simulação, esta associação deverá ser desfeita, modificando o modelo.

Os buffers dos nós são modelados no lugar BuFfer, do tipo BUF (Trecho de Código 4.13), inicializado com a quantidade de marcas igual à quantidade de quadros máxima do buffer para cada nó.

Resumindo, se no momento agendado para a chegada do quadro houver buffer disponível, o quadro passa para fila de envio. Mas se não houver, o quadro é descartado e aguarda-se a chegada do próximo quadro para repetir o procedimento. É importante que o colorset BUF seja temporizado, pois, dessa forma, o momento em que o buffer torna-se disponível é contabilizado corretamente.

\subsubsection{Envio por CFP}

O processo de envio por CFP é exibido na Figura 48. Há somente uma transição envolvida, pois não há uma sequência de passos a serem realizados, porém várias verificações são necessárias.

Figura 48: Envio por Contention Free Period

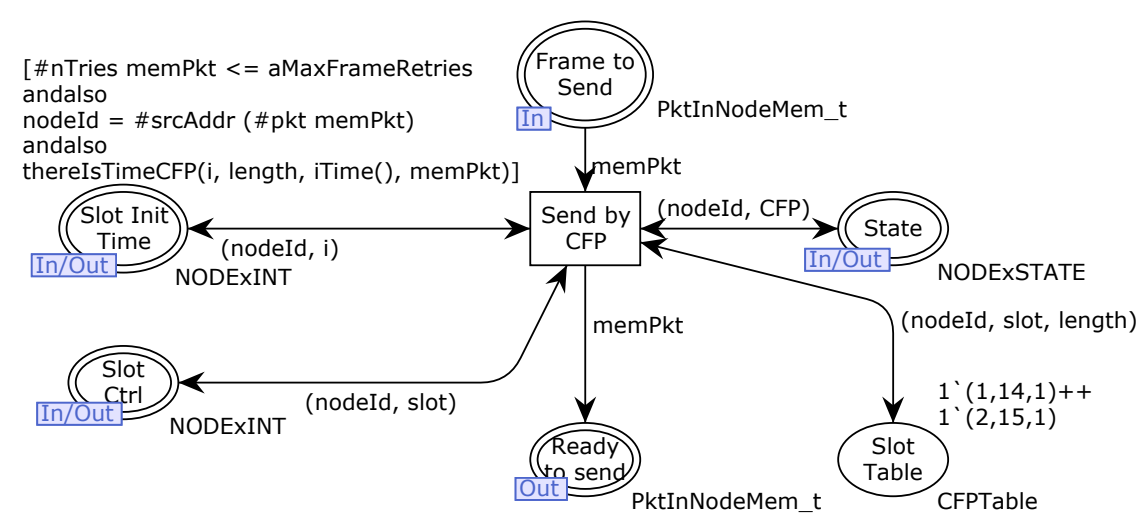

Fonte: Autor 
Ao todo cinco itens devem ser verdadeiros para que o quadro seja enviado:

1. O nó deve estar no estado de $C F P$, o que é verificado pelo lugar STATE.

2. Deve haver ao menos um slot alocado ao nó, o que é verificado pelo lugar Slot TABle. O colorset utilizado é CFPTABle, que é um trio ordenado no qual o primeiro número representa o identificador do nó, o segundo representa o slot em que o nó pode enviar dados e o terceiro é a quantidade de slots contíguos alocados.

3. O slot alocado ao nó deve estar transcorrendo no momento do envio, o que é verificado através do lugar Slot CTRL, vinculado ao lugar SLOT TABLE com o uso da mesma variável SLOT nos arcos que conectam estes lugares à transição SEND BY CFP.

4. O quadro não pode ter excedido a quantidade máxima de tentativas de envio.

5. Deve haver tempo suficiente para enviar o quadro e, se requerido, receber o ACK antes do término dos slots alocados.

A verificação de tempo disponível é feita pela função THEREIsTimeCFP() (Trecho de Código 4.14), através do cálculo dos tempos de transmissão envolvidos.

Trecho de Código 4.14: Função THEREIsTimeCFP

fun thereIsTimeCFP (slotStartTime, noOfSlots, currentTime, pkt:PktInNodeMem) =

let

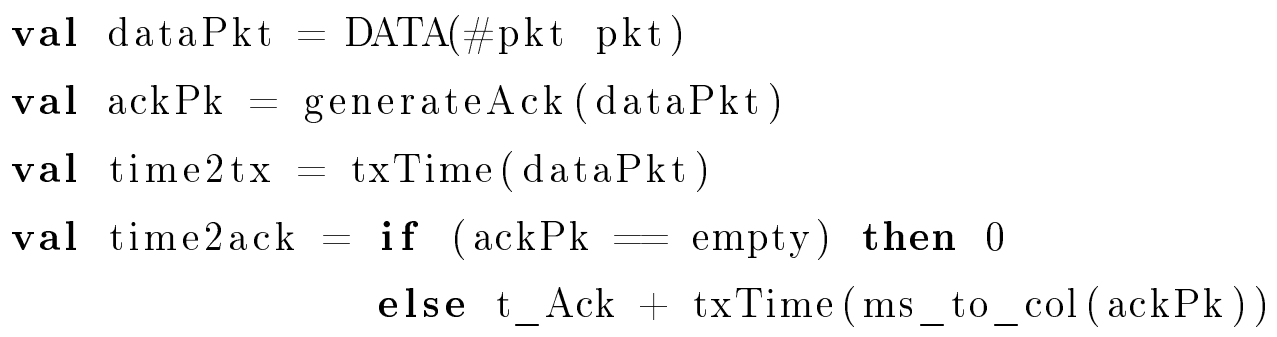

in

( (currentTime + time $2 \mathrm{tx}+$ time2ack $)<$ (slotStartTime + noOfSlots $*$ slotDuration $(\mathrm{SO}))$ )

end ; 


\subsubsection{Envio por CAP}

Para adicionar tempo ao processo de envio de quadros utilizado durante o CAP utilizou-se o submodelo apresentado na Seção 4.1.2.2 como base. As principais modificações realizadas foram feitas para modelar a interação com o meio de transmissão e para modelar com precisão o comportamento do nó na situação em que, enquanto um quadro está sob o processo do CSMA/CA, não há mais tempo para que seu envio ocorra antes do término do CAP. A Figura 49 exibe estas modificações.

Figura 49: Modelo temporal do algoritmo de CSMA/CA

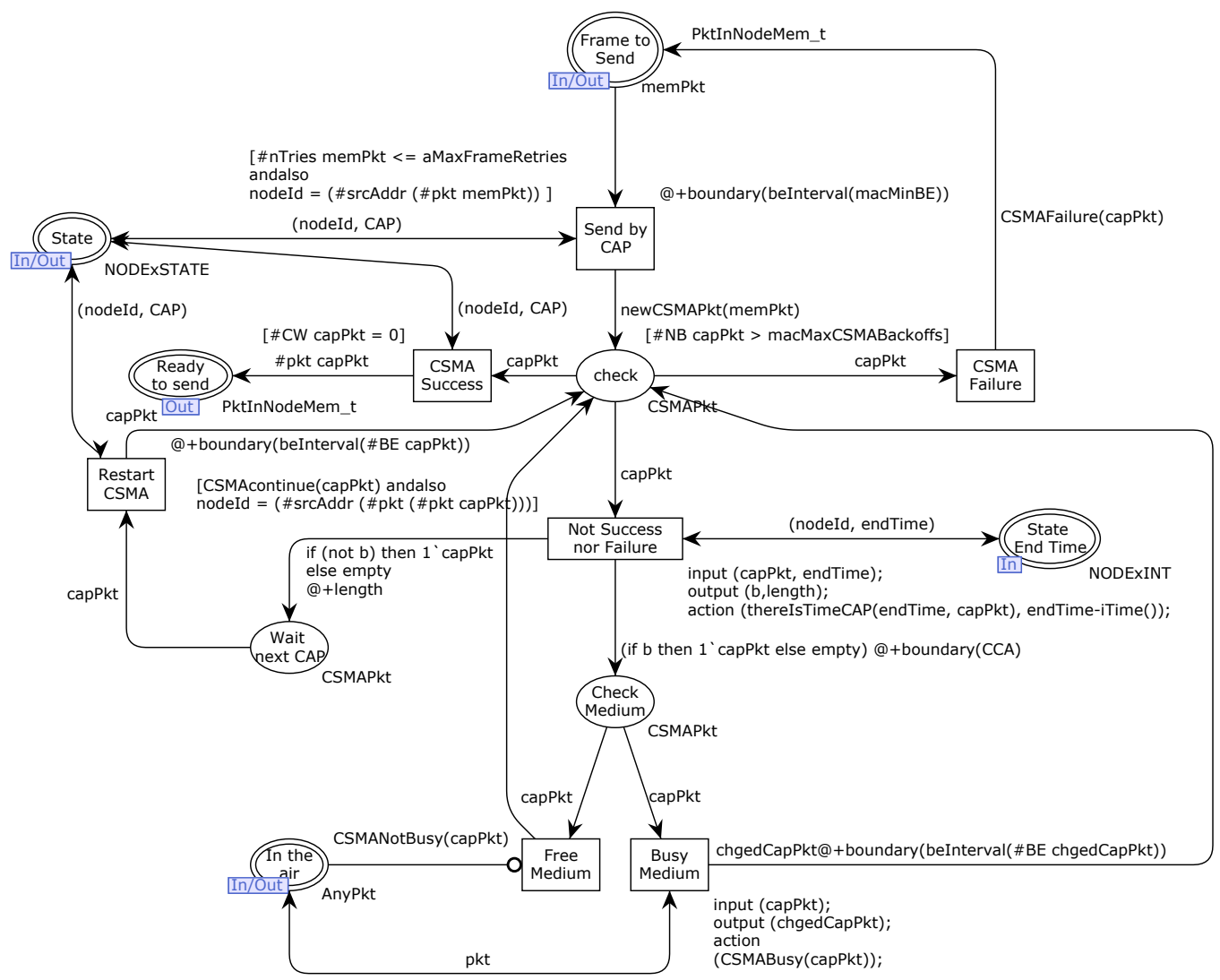

Fonte: Autor

Um quadro pode iniciar o seu processo de envio durante o CAP através do disparo da transição SEND BY CAP se o nó realmente estiver no CAP (lugar STATE) e se o número de tentativas realizadas para enviar o quadro for inferior a aMaxFrameRetries (condição de guarda da transição SEND BY CAP). Ao disparar a transição é calculado um atraso de backoff correspondente à primeira iteração do algoritmo de CSMA/CA. 
A partir deste momento, o meio é verificado seguidamente até que seja encontrado livre duas vezes seguidas ou até que seja encontrado ocupado aMaxCSMABackoffs vezes, não necessariamente consecutivas. No primeiro caso, o quadro é enviado com o disparo da transição CSMA SuCCESS, e no segundo caso retorna para o lugar FrAmes TO SEND através da transição CSMA FAILURE.

Se não tiver ocorrido o sucesso ou a falha, o meio deve ser verificado, sendo que este processo é disparado pela transição Not SUCCESS NOR FAILURE. Isto é feito na borda de um backoff period, encontrada através das função BOUNDARY (Trecho de Código 4.15). Se o meio for encontrado ocupado, um tempo de backoff aleatório é sorteado a partir do valor do Backoff Exponent (BE) do quadro através da função BeInTERval (Trecho de Código 4.15).

Trecho de Código 4.15: Funções BOUndary e BEINTERVAL

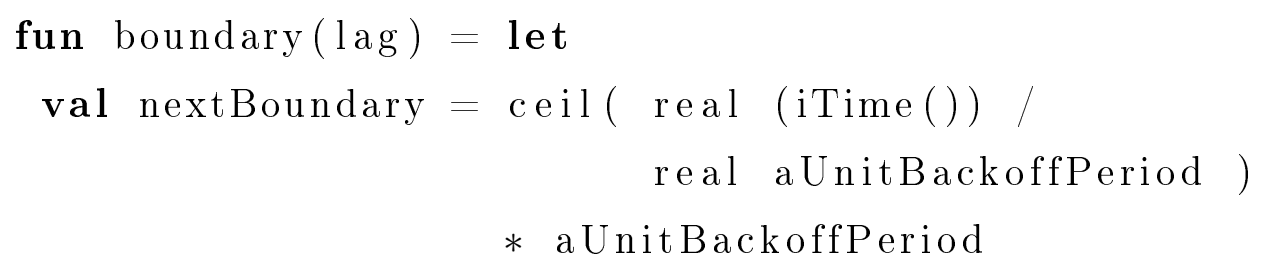

in

$\operatorname{lag}+($ nextBoundary - iTime ()$)$

end ;

fun beInterval $(\mathrm{BE})=20 *$

discrete (1, round (Math.pow $(2.0$, real BE) ));

O lugar IN THE AIR foi introduzido para que o meio seja verdadeiramente verificado. Este lugar é o mesmo que há no submodelo do meio de transmissão, explicado na Seção 4.2.4. O arco inibidor e o arco de consulta provenientes deste lugar impossibilitam que as transições Free Medium e Busy Medium fiquem habilitadas no mesmo instante.

Há um curso alternativo ao disparar a transição Not SUCCESS NOR FAILURE, condicionado à função THEREIsTimeCAP, definida no Trecho de Código 4.16. Esta função verifica se há tempo suficiente para enviar o quadro antes do término do CAP. Se houver tempo suficiente, o procedimento segue normalmente.

Porém, se não houver tempo suficiente, o quadro tem seu processo de envio interrompido, aguardando no lugar WAIT NEXT CAP até o próximo CAP para 
continuar. Note que o quadro é atrasado até o final do CAP atual (ENDTimeITIME()), porém, a transição de mudança de estado tem prioridade maior e não há a possibilidade do quadro ser enviado durante o CFP ou IDLE, portanto o quadro espera até o próximo CAP.

A transição RESTART CSMA ficará habilitada no início do próximo CAP, e, ao ser disparada, o quadro retornará ao curso de procedimento normal. Para evitar colisões, um atraso é introduzido, baseado no backoff exponent (BE).

Trecho de Código 4.16: Função THeREIsTimeCAP

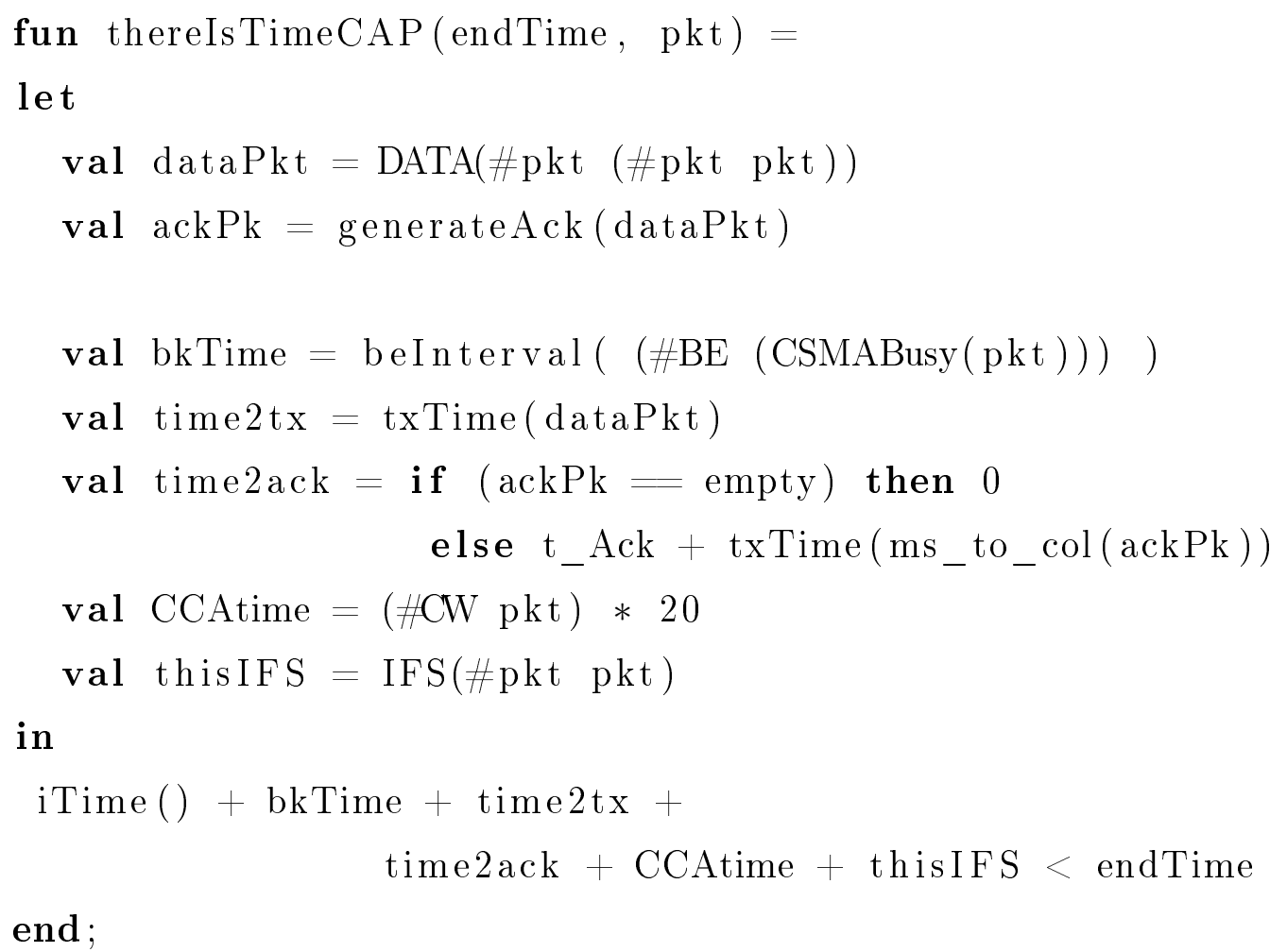

\subsubsection{Tratamento de ACK}

Outro submodelo do nó é o trecho que trata os acknowledgements, exibido na Figura 50. A primeira verificação é se o quadro requer ACK, feita pela transição Is ACKED?. Se não requerer, o procedimento de ACK é finalizado, devolvendo as marcações de controle aos lugares Buffer e MAY SEnd. Neste caso, o quadro é dado como bem sucedido, incrementando o contador relativo ao nó, armazenado no lugar Nodes Successes \& FAILuREs.

Se for uma transmissão com ACK, o timeout é programado no lugar WAITING FOR ACK T, de acordo com o parâmetro macAckWaitDuration e uma marca de 
controle é adicionada ao lugar WAITING FOR ACK.

Se passar o tempo de espera antes da chegada do ACK, a transição TimEOUT torna-se habilitada e então ocorre a desistência da espera pelo ACK. Neste caso, o quadro retorna para o lugar Frame to SEnd. Caso o quadro de ACK chegue atrasado, ele será descartado pela transição DISCARD ACK.

Figura 50: Tratamento de ACK

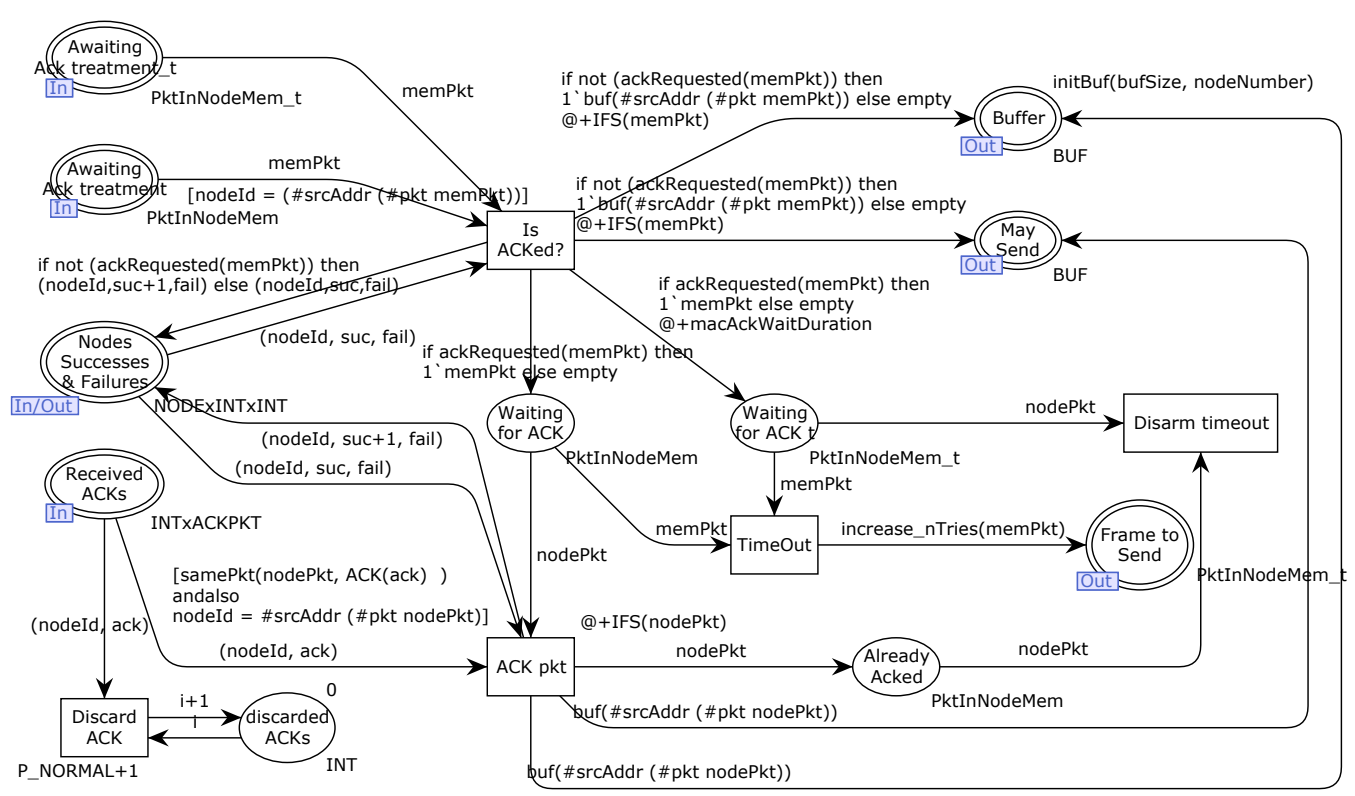

Fonte: Autor

Se o quadro de ACK chegar antes do timeout, a transição ACK PKT torna-se habilitada. A condição de guarda desta transição garante que o ACK foi recebido pelo nó correto e que os números de sequência do ACK e do quadro são os mesmos, com auxílio da função SAMEPKT, descrita no Trecho de Código 4.17.

Trecho de Código 4.17: Função SAMEPKT

fun samePkt (

$$
\begin{aligned}
& \{\mathrm{pkt}=\{\operatorname{seqNum}, \ldots\}, \ldots\}: \text { PktInNodeMem } \\
& \operatorname{ACK}(\{\operatorname{ackSeqNum}, \ldots\}) \\
& )=(\text { seqNum }=\operatorname{ackSeqNum})
\end{aligned}
$$

Após disparada, esta transição determina que o quadro foi enviado com sucesso, permite que o timeout seja desarmado adicionando uma marca ao lugar AlREADY ACKED e devolve as marcas de controle aos lugares MAY SEND e Buffer. Por último, a marca em WAiting for ACK T é eliminada pela transição Disarm timeout, concluindo o ciclo de envio do quadro. 


\subsubsection{Sorvedouro}

A função do sorvedouro (ou base station - BS) é a mesma que no modelo anterior: receber quadros de dados e enviar o ACK correspondente se for requerido. Porém, três modificações foram introduzidas devido à incorporação do aspecto temporal. Ao invés de armazenar todos os quadros recebidos no lugar RECEIVED DATA PKTs, a quantidade de quadros recebidos é contada.

Figura 51: Basestation

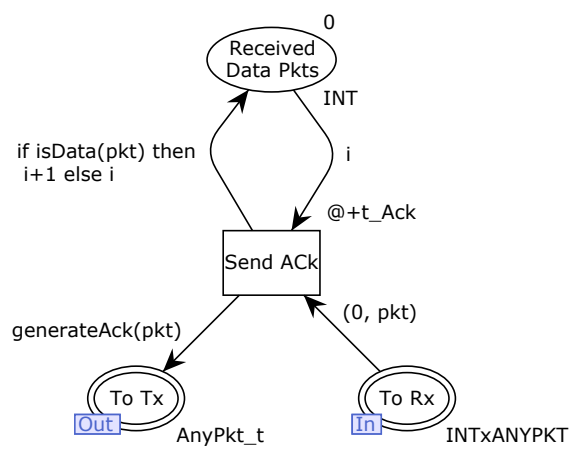

Fonte: Autor

O modelo convenciona que o identificador da BS é igual a zero. Por isso, o arco partindo do lugar To Rx está indexado pelo valor 0 . Por fim, foi adicionado o intervalo de tempo que deve existir entre a BS receber um quadro e enviar o respectivo ACK, o valor $t_{a c k}$, que deve ter um valor entre macSIFSPeriod (12 símbolos) emacSIFSPeriod + aUnitBackoffPeriod (32 símbolos). Para o modelo, o valor escolhido foi 16 símbolos. É importante ressaltar que este modelo é baseado na versão do IEEE 802.15.4 de 2007, e, portanto, não é necessário que o ACK seja enviado de forma sincronizada ao slot boundary.

Trecho de Código 4.18: Função GENERATEACK

\section{fun generateAck ( DATA $(\{\mathrm{fCtrl}=\{$}

frameType $=$ DataFrameType, ACKreq $=$ true,$\ldots\}$, seqNum,$\ldots\})$ ) $=$ $1 \cdot \operatorname{ACK}(\{\mathrm{fCtrl}=\{$

$$
\begin{aligned}
& \text { frameType }=\text { AckFrameType, } \\
& \text { framePending } \quad=\text { false, } \\
& \text { panIDcompression }=\text { false, } \text { ACKreq }=\text { false , } \\
& \text { destAddrMode } \quad=0, \quad \text { srcAddrMode }=0 \\
& \}, \operatorname{ackSeqNum}=\operatorname{seqNum}\})
\end{aligned}
$$

generateAck $(\ldots)=\operatorname{empty}$ 


\subsubsection{Meio de transmissão}

Em relação ao modelo para análise do espaço de estados, o submodelo do meio de transmissão foi completamente remodelado, conforme a Figura 52. Um quadro começa a ser transmitido a partir do lugar To Tx. A transição TrAnsmit torna-se habilitada e transfere o quadro para três lugares. O IN THE AIR TIMED é o lugar com colorset temporal que tem a função de indicar o tempo de término da transmissão, permitindo que as transições TX NOT OK ou TX OK fiquem habilitadas após o tempo de transmissão do quadro, que é determinado pela função TXTime (Trecho de Código 4.19).

Figura 52: Meio de transmissão

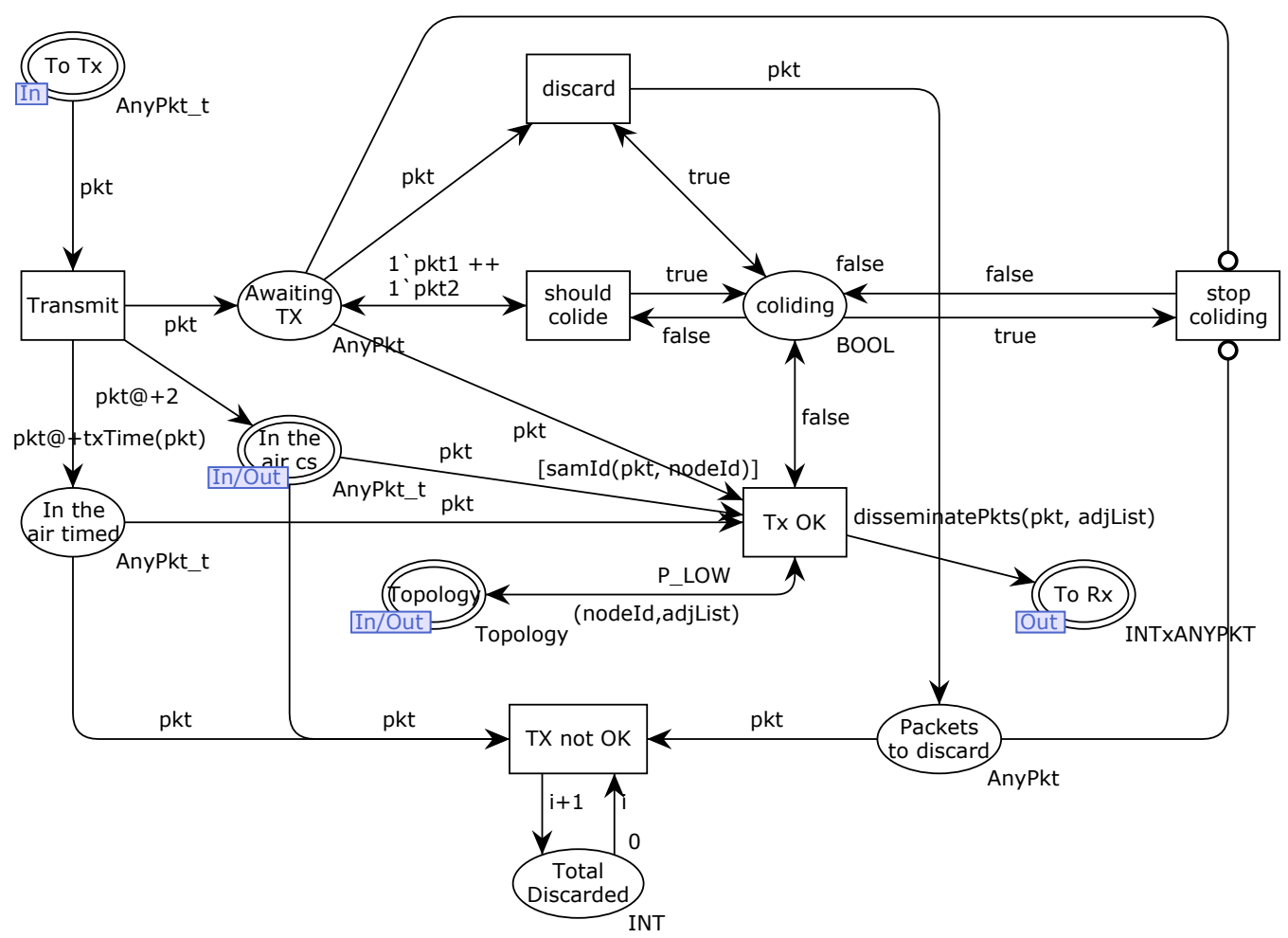

Fonte: Autor

Trecho de Código 4.19: Função TXTime

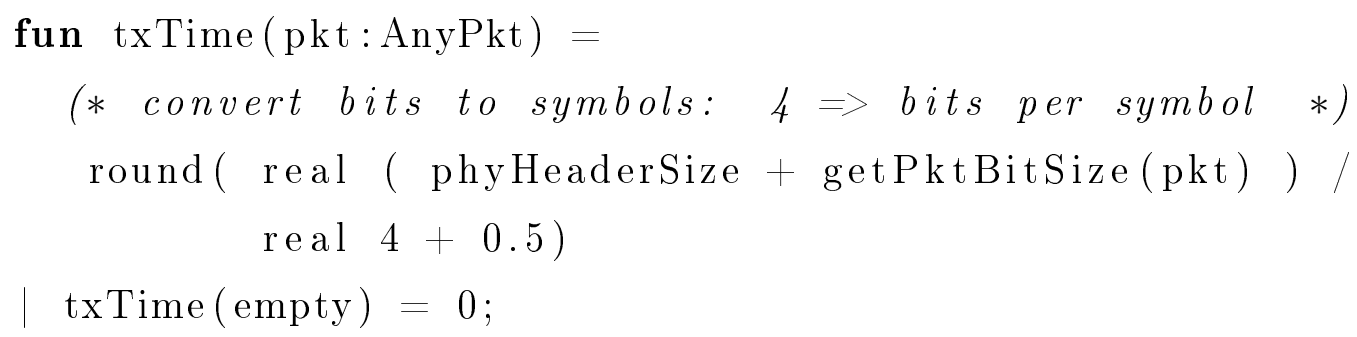


O lugar IN THE AIR também é temporal e tem a função de informar os nós sobre a ocupação do meio durante a transmissão, conforme explicado na Seção 4.2.2.3. O atraso sofrido pelo quadro neste lugar é equivalente ao tempo que os nós vizinhos demoram para perceber que o quadro está sendo transmitido. A marcação deste lugar será sempre igual a de IN THE AIR TIMED (exceto pelo tempo).

Se não houver colisão, representada pela marca FALSE no lugar COLIDING, a transição TX OK será disparada eventualmente. O quadro será entregue para todos os nós no alcance do nó de origem, de acordo com a topologia armazenada no lugar Topology. A função DisSEminatePkTs() se encarrega de realizar a duplicação dos quadros para cada um de seus destinos (Trecho de Código 4.20). Por esta razão o colorset do lugar To Rx é do tipo INTXANYPKT, uma vez que os quadros a serem entregues devem ser indexados de acordo com seu destino. Esta função também adiciona o atraso de propagação aos quadros.

Trecho de Código 4.20: Função DisseminatePkTs colset INTXANYPKT $=$ product INT $*$ AnyPkt timed

fun disseminatePkts ( pkt, nil ) = empty

$$
\begin{aligned}
& \text { disseminatePkts }(\operatorname{pkt},(\text { dest, dist }):: 1)=1^{\prime}(\text { dest, pkt) } \\
& + \text { disseminatePkts }(\operatorname{pkt}, 1) ;
\end{aligned}
$$

Porém, se dentro do tempo de transmissão de um quadro chegar pelo menos mais um quadro haverá colisão. Se houver pelo menos dois quadros no lugar AWAITING TX a transição SHOULD COLIDE torna-se habilitada. Ressalte-se que isso só ocorre porque o colorset de AwAiting TX não é temporal. Após o disparo desta transição o lugar COLIDING muda sua marca de FALSE para TRUE.

Neste ponto a transição DISCARD torna-se habilitada e é disparada continuamente até que o todos quadros sejam transferidos do lugar AwAITING TX para o lugar PACKETS TO DISCARD. Considerando o meio de transmissão em estado de colisão, essa transição é a única possivelmente habilitada, pois todas as outras envolvem marcas temporais com um tempo maior que o atual, ou o quadro já teria sido enviado. 
O próximo passo é o descarte dos quadros colididos, proporcionado pela transição TX NOT OK. Esta transição também armazena a quantidade de quadros descartados no lugar TOTAL DiscaRDED. Os quadros só são descartados no instante em que sua transmissão teria terminado, ou seja, somente no momento em que parariam de interferir na transmissão de outros quadros.

Até que todos os quadros sejam descartados, quadros recém chegados serão marcados para descarte automaticamente, efeito obtido pelos arcos inibidores em STOP COLIDING. Depois que todos os quadros forem descartados, a transição STOP COLIDING é disparada, retornando a rede à condição inicial.

Este modelo é, na verdade, uma simplificação, uma vez que as colisões ocorrem de fato nos receptores dos rádios e não soltas no ar, de forma que o instante de detecção de colisão deveria ser o momento de chegada dos quadros ao receptor e não o momento de envio dos quadros. Porém, para a topologia em estrela, esta aproximação é razoável pois os nós são equidistantes da BS.

\subsubsection{Validação}

Nesta seção serão apresentados resultados de experimentos realizados com objetivo de validar o modelo. A validação foi realizada através da comparação de valores de métricas obtidos com o modelo proposto e com simulações do Network Simulator 2 (NS2) (MCCANNE; FLOYD, 2012). A definição das métricas e como foram obtidas, os cenários e discussão de resultados são apresentados nas subseções seguintes.

\subsubsection{Métricas de Desempenho}

As métricas de desempenho de interesse, definidas abaixo, são vazão, taxa de entrega, atraso e energia. A lógica utilizada para obter estas métricas do modelo e dos arquivos de saída gerados pelo NS2 (trace) será descrita.

\subsection{Vazão}

A vazão da rede é definida como a quantidade média de quadros enviados pelos nós que foram entregues com sucesso ao seu destino na unidade de tempo. 
No modelo, a quantidade de disparos da transição ACK_PKT é dividida pelo tempo de simulação e pelo número de nós na rede em questão, resultando na vazão média.

Analogamente, para extrair este resultado do NS2 o arquivo de trace da simulação é processado filtrando-se as linhas em que há entrega de quadros de ACK. Esta verificação é feita após a rede ter se estabilizado, ou seja, todos nós estarem associados à BS. A quantidade de quadros é acumulada e a vazão é calculada pelo quociente deste valor pelo tempo de observação.

\subsection{Taxa de entrega}

A taxa de entrega da rede é a porcentagem de quadros de dados que foram criados e chegaram com sucesso ao seu destino.

No modelo esta métrica é aferida através do lugar Nodes Successes \& FAiLures. O cálculo da razão de envios bem sucedidos por quadros criados é feito para cada nó. O valor final é a média destes valores.

Para o simulador, é feita uma relação de todos os quadros criados e de todos os quadros recebidos. A razão entre o tamanho destas listas resulta na taxa de entrega.

\subsection{Atraso}

O atraso médio da rede é o tempo médio que um quadro demora para chegar ao seu destino, a partir do seu momento de chegada na camada MAC. Se o quadro não for entregue, não será contabilizado nesta métrica.

Os quadros do modelo são marcados com o momento de criação. O atraso é calculado na transição SEND ACK que marca o seu recebimento pela basestation, realizando a diferença do tempo atual pelo instante de criação do quadro. A média de todos os atrasos individuais resulta na métrica desejada.

Um processo semelhante é utilizado para extrair a métrica do simulador, onde é feita uma listagem dos quadros entregues e então descobre-se o momento em que foram criados. A média destas diferenças resulta no atraso médio 


\subsection{Energia}

A métrica de energia, medida em joules, é dependente do tempo de operação dos nós. Por esta razão, optou-se por aferir a potência média dissipada, que é a energia média gasta em uma unidade de tempo.

Assim, a potência gasta pela rede é a média das potências gasta pelos nós transmissores. A potência instantânea é determinada em maior parte pelo rádio, que pode estar nos estados de transmissão, recepção ou baixa energia (sleep).

No modelo, o estado do rádio é mantido no lugar Radio State. Durante o período idle do superframe o estado do rádio é considerado como sleep. No período ativo, o estado é considerado como recebendo, exceto no momento de transmissão dos quadros, que estará no estado de transmissão. A potência média é calculada pela média das potências, ponderada pelo tempo de permanência em cada estado.

No NS2, a potência média é calculada verificando o nível de energia inicial e final dos nós. Assim, a potência é calculada pela diferença de energia dividida pelo tempo de observação.

\subsubsection{Cenários}

Duas baterias de testes foram feitas para validar o modelo. A primeira com o objetivo de verificar os resultados do modelo para diferentes taxas de tráfego. Na segunda sequência de testes o parâmetro variado foi a quantidade de nós na rede.

Exceto pelos fatores de variação, os parâmetros utilizados foram os mesmos para todas as simulações. Os valores utilizados de BO e SO foram 8 e 7, respectivamente. O tamanho de todos os quadros de dados foi considerado igual a 64 bytes e a capacidade do buffer foi limitada em 5 quadros. Todos os outros parâmetros do IEEE 802.15.4 foram definidos com o valor padrão. A topologia estrela foi empregada com nós simetricamente posicionados em relação ao coordenador, que exerce a função de sorvedouro.

Os parâmetros de simulação utilizados no NS2 são os mesmos empregados anteriormente para a validação do modelo GSPN, conforme indicado na Tabela 10. 
No tocante à variação de taxa de tráfego, foram utilizados os mesmos cenários para validar o modelo anterior, repetidos na Tabela 16, novamente considerando a existência de dois nós na rede, fora o sorvedouro. Esta tabela também exibe o tempo de execução e o tamanho dos arquivos gerados pelas simulações no NS2 e no CPN Tools.

Tabela 16: Variação de taxas de chegada de quadros e tempos de execução

\begin{tabular}{|c|c|c|c|c|}
\hline $\begin{array}{c}\text { Taxas de } \\
\text { Chegada }\end{array}$ & $\begin{array}{c}\text { Tempo de } \\
\text { Execução } \\
\text { CPN Tools [s] }\end{array}$ & $\begin{array}{c}\text { Tempo de } \\
\text { Execução } \\
\text { NS2 [s] }\end{array}$ & $\begin{array}{c}\text { Tamanho do } \\
\text { arquivo de trace } \\
\text { do NS2 [MB] }\end{array}$ & $\begin{array}{c}\text { Tamanho dos arquivos } \\
\text { gerados pelo } \\
\text { CPN Tools [KB] }\end{array}$ \\
\hline 1 & 2 & 2 & 2 & $\sim 130$ \\
\hline 2 & 4 & 4 & 4 & $\sim 130$ \\
\hline 4 & 7 & 7 & 7 & $\sim 130$ \\
\hline 8 & 11 & 1 & 11 & $\sim 130$ \\
\hline 16 & 18 & 3 & 21 & $\sim 130$ \\
\hline 32 & 35 & 5 & 40 & $\sim 130$ \\
\hline 64 & 70 & 9 & 79 & $\sim 130$ \\
\hline 128 & 111 & 16 & 135 & $\sim 130$ \\
\hline 256 & 131 & 22 & 209 & 352 \\
\hline 512 & 163 & 35 & & \\
\hline
\end{tabular}

Fonte: Autor

Para os experimentos com variação de número de nós, foram utilizados os cenários exibidos na Tabela 17, que também contém o tempo de execução e tamanho dos arquivos gerados pelas simulações no NS2 e no CPN Tools. Para todos os casos, foi considerada uma taxa de 2 quadro/s.

Tabela 17: Variação do número de nós e tempos de execução

\begin{tabular}{|c|c|c|c|c|}
\hline $\begin{array}{c}\text { Taxas de } \\
\text { Chegada }\end{array}$ & $\begin{array}{c}\text { Tempo de } \\
\text { Execução } \\
\text { CPN Tools [s] }\end{array}$ & $\begin{array}{c}\text { Tempo de } \\
\text { Execução } \\
\text { NS2 [s] }\end{array}$ & $\begin{array}{c}\text { Tamanho do } \\
\text { arquivo de trace } \\
\text { do NS2 [MB] }\end{array}$ & $\begin{array}{c}\text { Tamanho dos arquivos } \\
\text { gerados pelo } \\
\text { CPN Tools [KB] }\end{array}$ \\
\hline 2 & 4 & 4 & 4 & $\sim 130$ \\
\hline 4 & 10 & 9 & 10 & $\sim 130$ \\
\hline 8 & 27 & 25 & 25 & $\sim 130$ \\
\hline 16 & 95 & 73 & 70 & $\sim 130$ \\
\hline 32 & 379 & 240 & 182 & $\sim 130$ \\
\hline 64 & 2118 & 715 & 522 & $\sim 130$ \\
\hline
\end{tabular}

Fonte: Autor

Apesar da execução do modelo demorar mais do que o simulador nos casos em que há muitos nós ou taxa de tráfego elevada, o consumo de espaço em disco é pequeno e aproximadamente constante. Além disso, os tempos exibidos para 
o NS2 não levam em conta o tempo gasto com o processamento dos arquivos de trace. Também é interessante notar que a quantidade de nós exerce mais impacto no tempo de simulação do que a taxa de tráfego.

\subsubsection{Resultados e Discussão}

Os resultados apresentados abaixo foram obtidos com o simulador NS2, com a mesma versão e ambiente utilizados anteriormente, conforme descrito na Seção 3.4.3. O modelo foi implementado no CPN Tools versão 4.0 (RATZER et al., 2003) e executado em uma máquina com sistema operacional Windows 764 bit, com 4 GB de memória RAM e um processador Intel Quad2 de quatro núcleos e frequência de $2.4 \mathrm{GHz}$.

A Tabela 18 exibe o tamanho do intervalo de confiança em valor absoluto e em relação ao valor médio das métricas de acordo com o cenário, para o nível de confiança de $95 \%$. Os valores foram obtidos a partir de dez repetições de cada cenário, tanto no modelo como NS2. Com esta quantidade de repetições a dispersão obtida foi pequena, menor que $5 \%$ em relação à ordem de grandeza das métricas (exceto em um cenário).

As simulações, tanto no modelo como no simulador, foram executadas por um tempo equivalente à 1200 segundos. Constatou-se este intervalo de tempo era insuficiente para atinger o regime permanente nos cenários com pequena quantidade de eventos (nos três primeiros de cada conjunto de experimentos). Nestes casos a simulação foi executada por 9000 segundos.

Os resultados de vazão para variação da taxa de quadro são exibidos na Figura 53a. A curva do modelo é aderente à curva da simulação, apresentado o mesmo comportamento em cenários com e sem saturação. A maior diferença relativa foi $6.6 \%$ no cenário de 4 quadro/s, sendo que os outros cenários apresentaram diferença relativa menor que $5 \%$.

Os resultados de vazão para variação de número de nós são exibidos na Figura 53b. Nos primeiros quatro cenários os resultados do simulador e do modelo são bastante próximos (diferença relativa inferior à 4.8\%). Nos cenários com 32 e 64 nós há diferenças significativas da ordem de $20 \%$ e 25\%, respectivamente, o que indica que existe diferença nas hipóteses da implementação do NS2 e do modelo aqui desenvolvido que interfere no mecanismo de colisão ou no CCA. 
Tabela 18: Intervalo de confiança (95\%) para as resultados do modelo CPN e do NS2: valor em relação ao valor médio da métrica

\begin{tabular}{|c|c|c|c|c|c|c|c|c|}
\cline { 2 - 9 } \multicolumn{1}{c|}{} & \multicolumn{2}{c|}{ Potência } & \multicolumn{2}{c|}{ Atraso } & \multicolumn{2}{c|}{ Taxa de Entrega } & \multicolumn{2}{c|}{ Vazão } \\
\hline $\begin{array}{c}\text { Taxa de } \\
\text { quadros }\end{array}$ & CPN & NS2 & CPN & NS2 & CPN & NS2 & CPN & NS2 \\
\hline 1 & $0.0004 \%$ & $0.04 \%$ & $2.65 \%$ & $1.45 \%$ & $0.14 \%$ & $0.27 \%$ & $2.18 \%$ & $1.80 \%$ \\
\hline 2 & $0.0005 \%$ & $0.03 \%$ & $1.38 \%$ & $1.26 \%$ & $0.38 \%$ & $0.57 \%$ & $1.34 \%$ & $1.01 \%$ \\
\hline 4 & $0.0006 \%$ & $0.02 \%$ & $1.54 \%$ & $0.66 \%$ & $0.55 \%$ & $0.58 \%$ & $0.88 \%$ & $0.50 \%$ \\
\hline 8 & $0.0005 \%$ & $0.03 \%$ & $0.81 \%$ & $2.14 \%$ & $0.76 \%$ & $1.73 \%$ & $0.57 \%$ & $2.06 \%$ \\
\hline 16 & $0.0009 \%$ & $0.02 \%$ & $0.45 \%$ & $1.42 \%$ & $0.37 \%$ & $1.14 \%$ & $0.49 \%$ & $1.45 \%$ \\
\hline 32 & $0.0014 \%$ & $0.01 \%$ & $0.37 \%$ & $1.13 \%$ & $0.27 \%$ & $0.79 \%$ & $0.40 \%$ & $0.96 \%$ \\
\hline 64 & $0.0025 \%$ & $0.01 \%$ & $0.27 \%$ & $0.92 \%$ & $0.28 \%$ & $0.46 \%$ & $0.37 \%$ & $0.63 \%$ \\
\hline 128 & $0.0008 \%$ & $0.02 \%$ & $0.16 \%$ & $0.90 \%$ & $0.16 \%$ & $0.56 \%$ & $0.07 \%$ & $0.25 \%$ \\
\hline 256 & $0.0009 \%$ & $0.01 \%$ & $0.10 \%$ & $0.75 \%$ & $0.12 \%$ & $0.38 \%$ & $0.08 \%$ & $0.15 \%$ \\
\hline 512 & $0.0009 \%$ & $0.03 \%$ & $0.10 \%$ & $0.55 \%$ & $0.15 \%$ & $0.23 \%$ & $0.08 \%$ & $0.20 \%$ \\
\hline $\begin{array}{c}\text { Número } \\
\text { de nós }\end{array}$ & & & & & & & & \\
\hline 2 & $0.0007 \%$ & $0.03 \%$ & $1.78 \%$ & $1.26 \%$ & $0.44 \%$ & $0.57 \%$ & $1.81 \%$ & $1.01 \%$ \\
\hline 4 & $0.0005 \%$ & $0.03 \%$ & $1.28 \%$ & $0.63 \%$ & $0.40 \%$ & $0.35 \%$ & $0.99 \%$ & $1.27 \%$ \\
\hline 8 & $0.0002 \%$ & $0.02 \%$ & $0.98 \%$ & $0.38 \%$ & $0.17 \%$ & $0.21 \%$ & $0.51 \%$ & $0.57 \%$ \\
\hline 16 & $0.0002 \%$ & $0.02 \%$ & $0.66 \%$ & $0.43 \%$ & $0.20 \%$ & $0.27 \%$ & $0.40 \%$ & $0.29 \%$ \\
\hline 32 & $0.0002 \%$ & $0.22 \%$ & $0.65 \%$ & $0.65 \%$ & $0.30 \%$ & $0.69 \%$ & $0.26 \%$ & $0.72 \%$ \\
\hline 64 & $0.0001 \%$ & $10.03 \%$ & $0.62 \%$ & $1.51 \%$ & $0.29 \%$ & $3.64 \%$ & $0.26 \%$ & $4.79 \%$ \\
\hline
\end{tabular}

Fonte: Autor

Figura 53: Vazão

(a) Variação de taxa de quadros

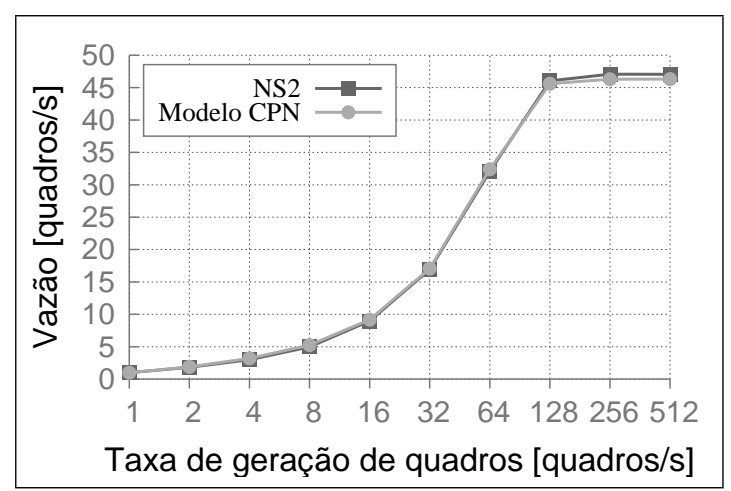

(b) Variação de número de nós

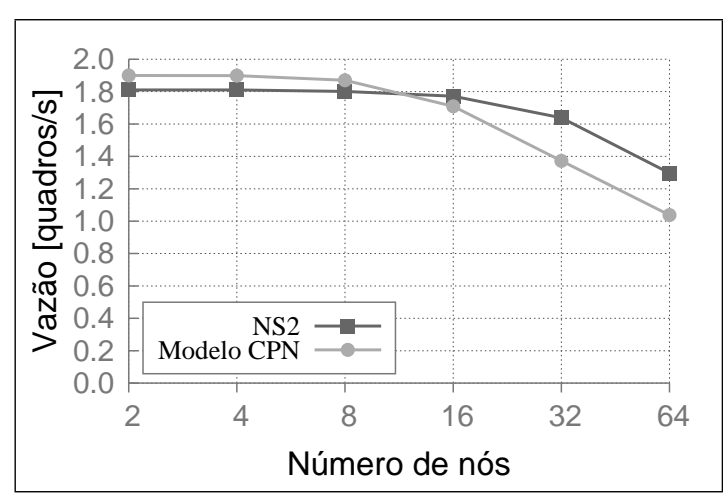

Fonte: Autor

Assim, quanto maior o número de nós, mais acentuada esta diferença se torna, sendo imperceptível nos casos em que o mecanismo em questão não é o gargalo do desempenho. 
As curvas de taxa de entrega são apresentadas na Figura 54. Considerando a variação de taxa de quadros, a diferença relativa entre os valores obtidos varia no intervalo de $1 \%$ a $5 \%$. Nota-se uma diminuição progressiva da taxa de entrega. As perdas até o cenário de 64 quadros/s ocorrem majoritariamente devido à restrição de buffer, enquanto que nos cenários finais a rede chega à saturação, além da limitação de buffer.

Figura 54: Taxa de Entrega

(a) Variação de taxa de quadros

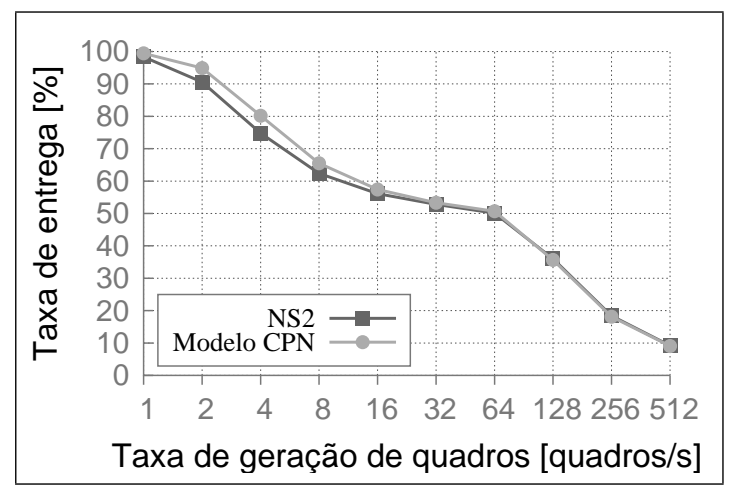

Fonte: Autor (b) Variação de número de nós

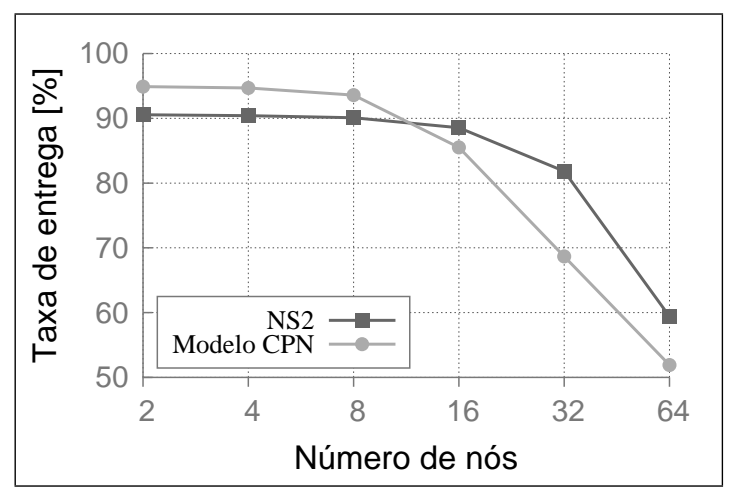

padrão observado na Figura 54b assemelha-se ao da Figura 53b. Isso ocorre pois a taxa de entrega está intimamente relacionada com a vazão. As mesmas observações feitas sobre as possíveis fontes de diferença de resultados também se aplicam para esta métrica. Nota-se que a diferença observada para o cenário com 64 nós é menor para o caso da taxa de entregas (15\% invés de $25 \%$ ). Este fato indica que para este cenário houve uma diferença na taxa de chegada de quadros efetiva, impactando a vazão subsequente.

Os resultados de atraso são exibidos na Figura 55, para variação de taxa de quadros e variação de número de nós. Para a Figura 55a, os valores obtidos são próximos a partir do cenário de 16 quadros/s, com diferença máxima em torno de $10 \mathrm{~ms}$.

A massa de dados utilizada para obter esta métrica foi analisada para entender as diferenças apresentadas nos cenários iniciais. Ao colocar amostras de dados coletados em um histograma, nota-se que tanto para o modelo quanto para o simulador, os atrasos que ocorrem com maior frequência concentram-se na faixa de zero a 10 milissegundos. 
Figura 55: Atraso

(a) Variação de taxa de quadros

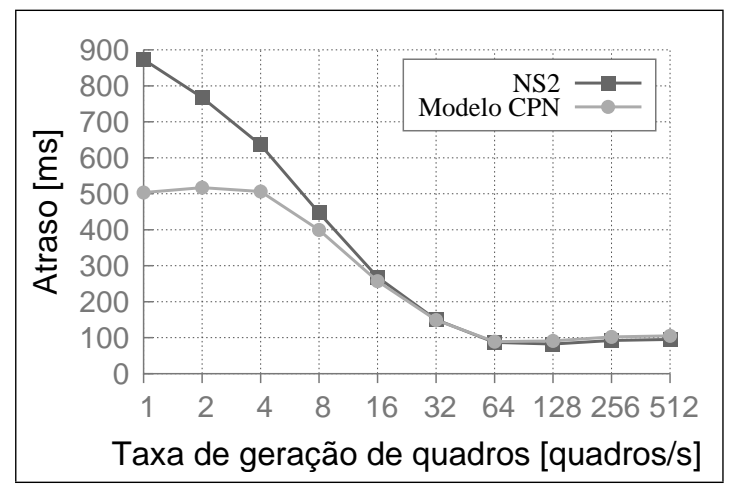

(b) Variação de número de nós

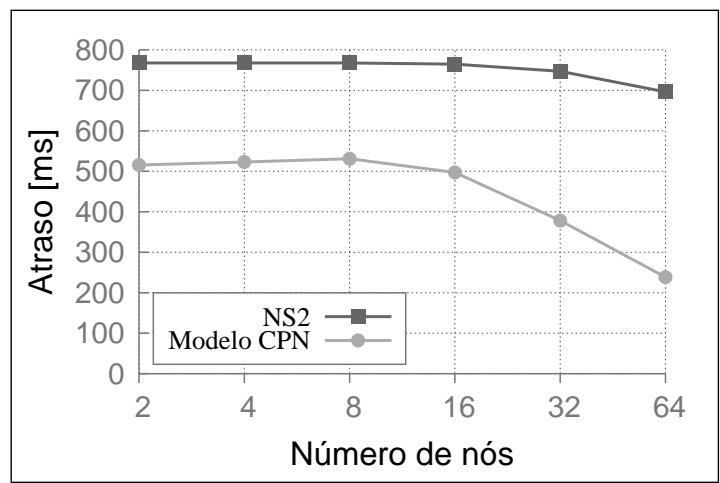

Fonte: Autor

Porém, no NS2, existe também uma grande concentração de valores na faixa de 1970 a 1980 milissegundos. Esta faixa de valores coincide com o tempo de duração do período ocioso do superframe adicionado do tempo de transmissão de um quadro.

A concentração de valores de atraso nesta faixa existe em todos os cenários, porém, a partir do cenário de 16 quadros/s, o acúmulo de valores dilui-se perante os outros valores.

Um teste adicional foi realizado, simulando uma rede com somente um nó além da BS. Mesmo assim, analisando o histograma de atrasos, os resultados do NS2 continuam apresentado uma concentração de valores na faixa de 1970 a 1980 milissegundos, conforme indicado pela Figura 56.

Figura 56: Histograma dos valores de atraso

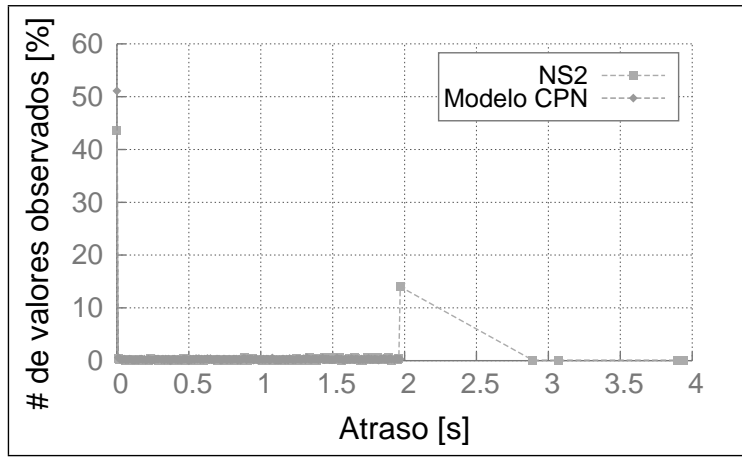

Fonte: Autor

Como este fenômeno acontece somente no simulador, conclui-se que não está relacionada com divergências de modelagem relacionadas ao mecanismo de colisão 
ou ao algoritmo de CSMA/CA.

Outra possibilidade para a origem desta diferença poderia ser uma diferença nas distribuições de geração de quadros. A Figura 57 exibe um histograma do intervalo entre chegada de quadros com largura de intervalo de $0.1 s$. Este gráfico mostra que tanto a distribuição utilizada pelo simulador como a do modelo são aderentes à curva teórica da distribuição exponencial.

Figura 57: Amostragem da taxa de chegada de pacotes

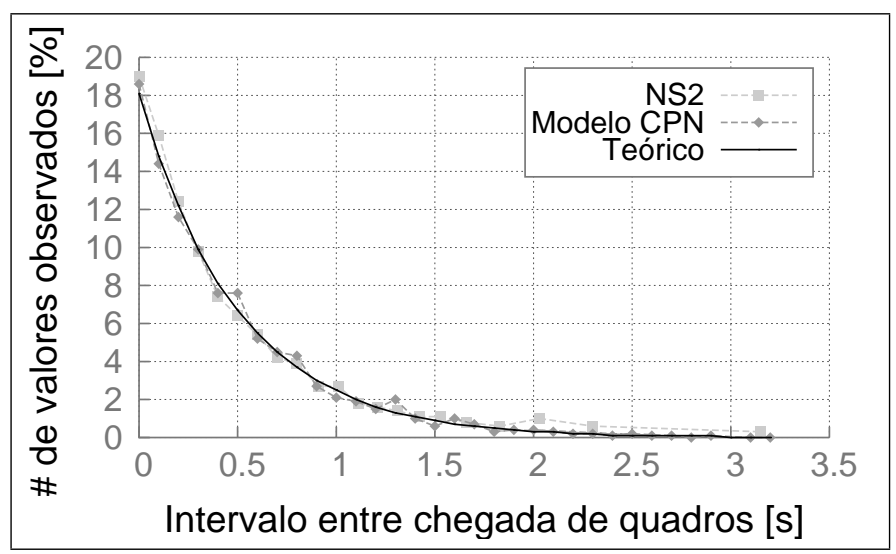

Fonte: Autor

No modelo, as faixas de valores estão com uma quantidade de valores distribuída uniformemente. Considera-se que o momento de chegada do quadro é aleatório, ou seja, uniformemente distribuído ao longo do superframe. A duração do superframe é aproximadamente $3.93 \mathrm{~s}$ para $\mathrm{BO}=8$, e a porção ativa dura a metade disso, ou aproximadamente $1.97 \mathrm{~s}$, para $\mathrm{SO}=7$.

Durante o período ativo, os quadros demoram cerca de $5 \mathrm{~ms}$ para serem enviados, já que praticamente quase não existem colisões para baixas taxas de chegada de quadros. Durante o período inativo, o atraso de cada quadro depende do seu momento de chegada, e é aproximadamente igual ao tempo que falta para chegar à próxima parte ativa, adicionado do tempo de transmissão. A Figura 58 exibe este comportamento.

Ao calcular a média dos atrasos esperados, o valor obtido resulta em cerca de $500 \mathrm{~ms}$, indicando que o resultado do modelo está de acordo com esta hipótese. Apesar de todas as investigações realizadas, o motivo pelo qual o simulador NS2 apresenta valores de atraso concentrado na faixa de 1970 a $1980 \mathrm{~ms}$ ainda é desconhecido. 
Figura 58: Atraso de quadros ao longo do superframe

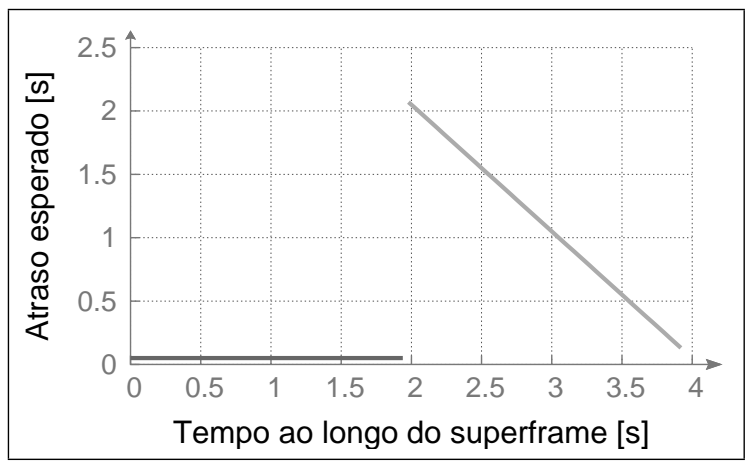

Fonte: Autor

A discrepância de resultados exibida na Figura 55b é reflexo desta diferença de comportamento entre modelo e simulador. Observe-se que foi adotada a taxa de 2 quadros/s para estes experimentos, assim, a diferença é semelhante e tem a mesma origem da constatada na Figura 55a.

No cenário com 64 nós vemos que o modelo apresenta uma queda mais acentuada do atraso médio dos quadros. Analisando os dados, verifica-se que a ocorrência de colisões concentra-se no início de período ativo do superframe de forma mais acentuada no modelo do que no simulador, como pode ser observado na Figura 59.

Figura 59: Histograma dos instantes de ocorrência de colisão

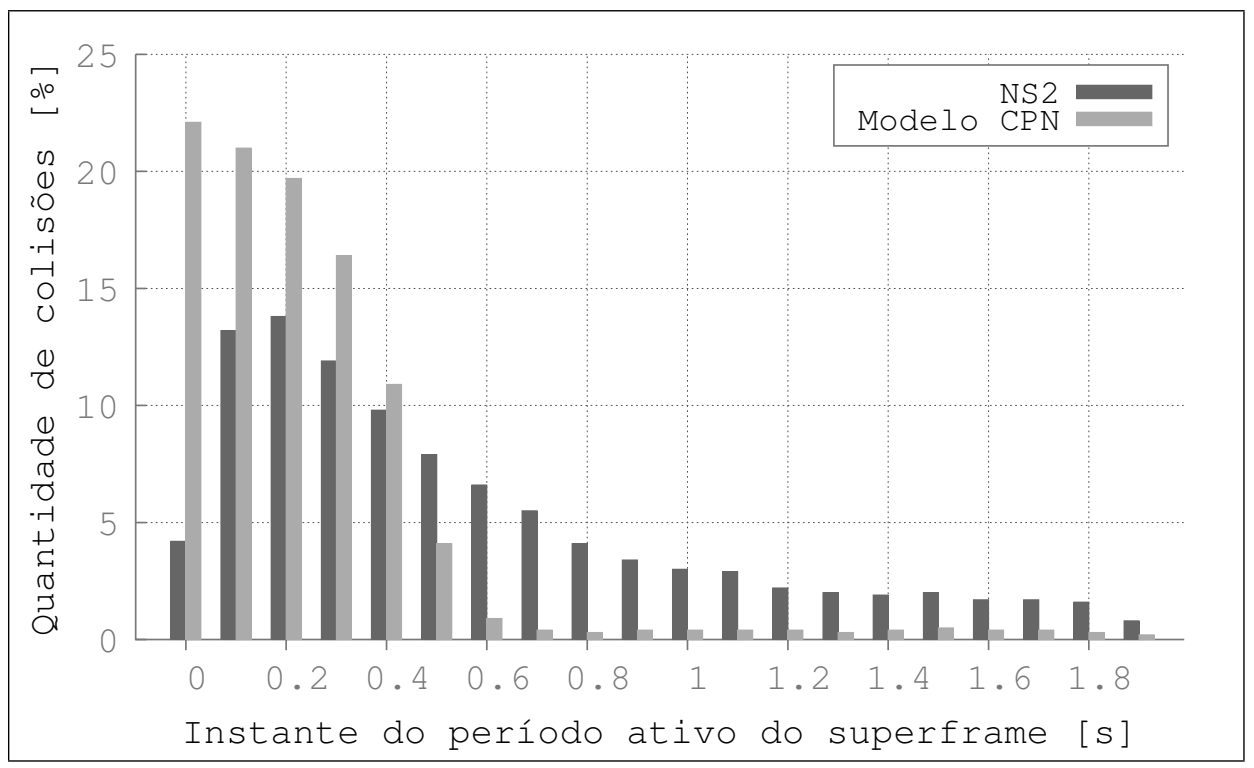

Fonte: Autor

Estas colisões impedem que os quadros acumulados no buffer no início da porção ociosa sejam entregues em sua maioria. Como esses quadros são os que 
apresentam o maior atraso e os quadros descartados não são contabilizados nesta métrica, a média observada diminui. No simulador, um fenômeno semelhante é observado, porém, não é tão acentuado a ponto de interferir significativamente na métrica.

Por fim, a métrica de potência média gasta é exibida na Figura 60 para os fatores variantes de taxa de quadros e número de nós. Para os cenários da Figura 60a, os resultados são coerentes para valores de taxa de chegada de quadros até 32 quadros/s, com diferenças relativas inferiores à $0.2 \%$.

Nos cenários subsequentes, o modelo demonstra que há uma diminuição do consumo médio de energia, indicando que há um aumento de tempo em que os nós ficam no estado de transmissão.

Figura 60: Potência

(a) Variação de taxa de quadros

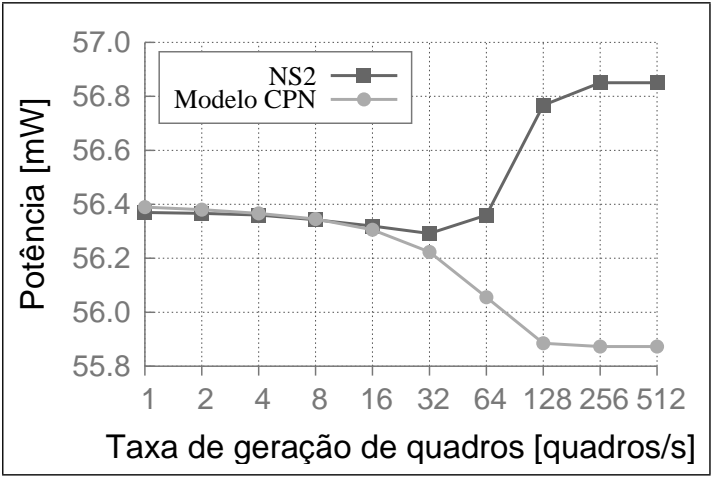

(b) Variação de número de nós

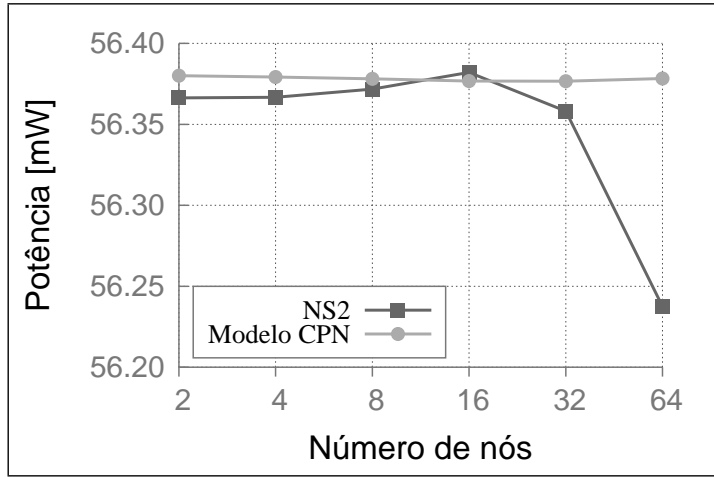

Fonte: Autor

Este comportamento é esperado, pois um aumento da taxa de envio de quadros indica que o tempo no estado de transmissão deve aumentar. Nos últimos cenários os valores atingem um patamar aproximadamente constante devido à saturação.

Nos últimos casos de teste, o resultado apresentado pelo simulador é incoerente, pois a potência média excede a potência máxima alcançável por um nó $(56,4 m W)$. Suspeita-se que há incoerências no modelo de energia adotado pelo simulador. Outro experimento que evidencia a existência de problemas consiste em realizar uma simulação com potência de recepção igual zero. Em simulações com este parâmetro, o simulador acusa que a energia gasta com recepção de dados resulta em um valor negativo. Desta forma, a confiabilidade nos resultados 
do simulador em relação a esta métrica diminui.

Na Figura 60b exibe-se os valores de potência para variação do número de nós. Os valores absolutos são próximos, com diferença inferior à $0.1 \%$, semelhante ao cenário de 2 quadros/s da Figura 60a. Para o cenário de 64 nós o simulador aponta uma queda na potência, indicando um aumento da porção do tempo em que os nós ficam no estado de transmissão. Em termos absolutos a diferença é pequena, de apenas $0.14 \mathrm{~W}$ ou $0.25 \%$, indicando uma boa aproximação do resultado, apesar de possíveis problemas no simulador.

\subsection{Considerações do Capítulo}

Neste capítulo, dois modelos baseados em Rede de Petri Colorida do padrão IEEE 802.15.4, um para análise do espaço de estados e outro para análise de desempenho, foram projetados, avaliados e testados. As limitações encontradas com o modelo feito com base em Redes de Petri Estocástica Generalizada foram superadas.

O modelo GSPN explora todo o espaço de estados para obter os resultados de regime permanente através da resolução da cadeia de Markov subjacente, de forma a obter resultados determinísticos, dada uma configuração de rede a ser estudada. A principal limitação, referente ao número máximo de nós da rede, ocorre devido ao grande aumento do número de estados ao incrementar a quantidade de nós da rede.

A rede de Petri colorida não diminui a quantidade de marcações alcançáveis, apenas possui uma forma mais concisa de representação através da diferenciação das marcas (cores). Através deste formalismo, é possível obter resultados de redes com maior quantidade de nós pois utilizou-se o artifício de simulação. Uma vez que a simulação é um processo probabilístico, faz-se necessário realizar diversas simulações para obter um resultado estatisticamente válido. Em suma, a questão de escalabilidade do modelo GSPN foi resolvida, porém o modelo agora precisa ser simulado sem a possibilidade de se obter resultados fechados.

Outro aspecto que difere entre os modelos GSPN e CPN é a estabilidade dos valores das métricas. Enquanto que no modelo GSPN os valores se referem ao regime permanente por construção, no modelo CPN é necessário simular 
por tempo suficiente para superar o transitório. Este procedimento foi realizado empiricamente neste trabalho.

Porém, as características essenciais do modelo GSPN foram mantidas, como a contemplação do modo Beacon, a possibilidade de ajuste de parâmetros, e não necessitar realizar o cálculo explícito de probabilidades através da construção de um modelo comportamental. Diversos experimentos foram realizados para validar o modelo frente ao simulador NS2, através das métricas de vazão, taxa de entrega, gasto de energia e atraso. 


\section{USO DO MODELO PARA ANÁLISE DE VARIAÇÃO DE PARÂMETROS}

Este capítulo tem o objetivo de, após validar o modelo, demonstrar o seu uso prático. Três conjuntos de experimentos foram realizados: 1) avaliação da variação de parâmetros, o que é difícil de realizar com o simulador NS2 ou nós reais, 2) avaliação de situações de assimetria de taxa de tráfego, que os outros modelos não são capazes de avaliar e 3) avaliação de um cenário de uso geral do modelo.

Da mesma forma que foi feito na Seção 4.2.5, os parâmetros utilizados foram os mesmos para todas as simulações, exceto pelos fatores de variação. Os valores de BO e SO utilizados foram 7 e 8, respectivamente. A capacidade do buffer foi limitada em 5 quadros. Quando não explicitamente indicado, todos os outros parâmetros do padrão IEEE 802.15.4 foram definidos com o valor padrão e o tamanho dos quadros de dados foi considerado igual a 64 bytes.

A topologia estrela foi empregada com nós simetricamente posicionados em relação ao coordenador, que exerce a função de sorvedouro. Todas as avaliações utilizam as métricas de vazão, taxa de entrega, atraso e energia, definidas na Seção 4.2.5.1.

Os experimentos foram realizados em três máquinas diferentes, todas com sistema operacional Windows 7 e versão 4.0 do CPN Tools, sendo um processador Intel Quad2 2.4 GHz com 4 GB de memória RAM, um processador i7 $2.4 \mathrm{GHz}$ com $8 \mathrm{~GB}$ de RAM e o último computador munido de processador i7 $1.7 \mathrm{GHz}$ com 4 GB de memória RAM. 


\subsection{Variação de Parâmetros}

No tocante à variação de parâmetros, quatro fatores serão variados: AMAXFrameRetries, macMaxCSMABACKOFFs, initialCW e AUnitBackoffPERIOD, conforme indicado na Tabela 19. Os valores porcentuais apresentados nos gráficos referem-se à diferença da métrica aferida em relação ao cenário sem variação do parâmetro, de acordo com o seguinte cálculo: $\frac{v_{\text {parametro alterado }}-v_{\text {original }}}{v_{\text {original }}}$.

Tabela 19: Parâmetros variados

\begin{tabular}{|c|c|c|c|c|c|}
\hline Nome do Parâmetro & Valor original & \multicolumn{4}{|c|}{ Valores variados } \\
\hline AMAXFRAMERETRIES & 3 & 6 & 10 & 18 & 30 \\
\hline MACMAXCSMABACKOFFS & 5 & 10 & 20 & 30 & 40 \\
\hline INITIALCW & 2 & 3 & 4 & 5 & 6 \\
\hline AUNITBACKOFFPERIOD & 20 & 25 & 35 & 50 & 75 \\
\hline
\end{tabular}

Fonte: Autor

Os cenários com variação de taxa de tráfego são constituídos por dois nós além do sorvedouro, partindo de 1 quadro/s aumentando exponencialmente até 512 quadros/s. Analogamente, cenários com variação de número de nós apresentam taxa de tráfego individual de 2 quadros/s, com cenários partindo de 2 até 64 nós, aumentando exponencialmente.

Todos os cenários foram executados dez vezes, pois observou-se que o desvio padrão torna-se pequeno o suficiente com esta quantidade, inferior à $4.2 \% \mathrm{em}$ relação ao valor da métrica. O Apêndice A apresenta todos os valores de desvio padrão obtidos.

O primeiro parâmetro estudado é o MACMAXFrAmERETRIES, que limita a quantidade de tentativas de envio de um quadro após o término da execução errônea do CSMA/CA ou expiração do tempo de espera pelo ACK.

Os resultados para variação de taxa de chegada de quadro são exibidos na Figura 61. Não houve variações significativas para as métricas avaliadas, com diferença de desempenho variando desde uma queda de 0,8\% até um aumento de cerca de 1,5\%. A razão para as diferenças serem pequenas é que o limite de retransmissões não é atingido com frequência nestes cenários.

Nos cenários a partir de 128 quadros/s observa-se uma melhora de todas as métricas, exceto a potência, independentemente do novo valor adotado pelo parâmetro. Nos outros cenários, entre 1 e 64 quadros/s, exibiram as menores di- 
Figura 61: Variação do parâmetro AMAXFrAMERETRIES - Taxa de tráfego

(a) Vazão

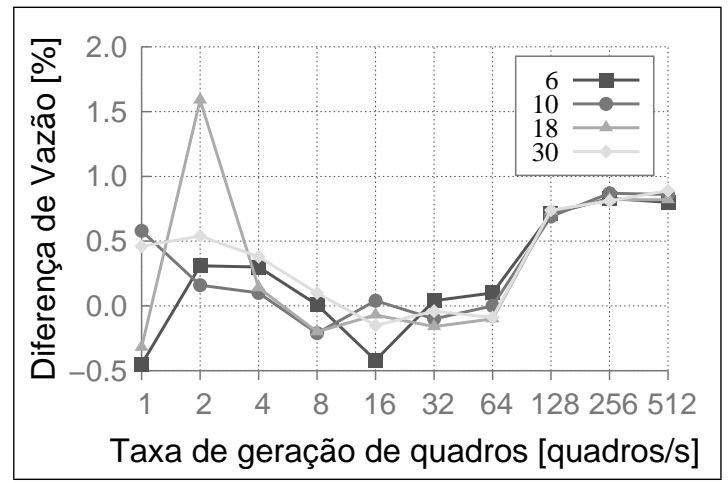

(c) Atraso

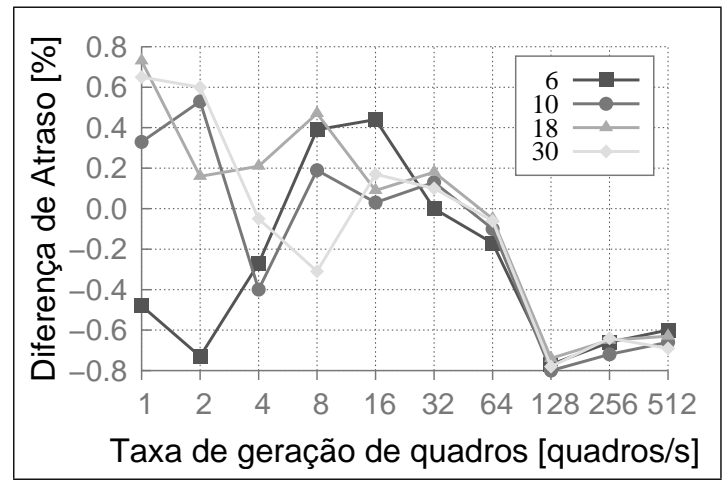

Fonte: Autor (b) Taxa de Entrega

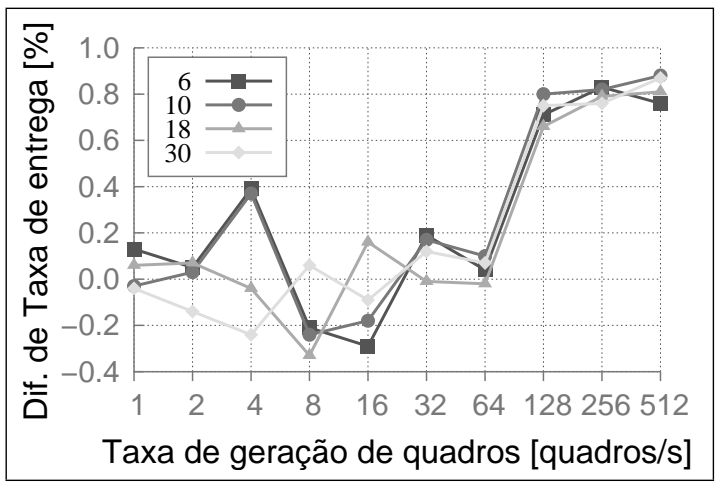

(d) Potência

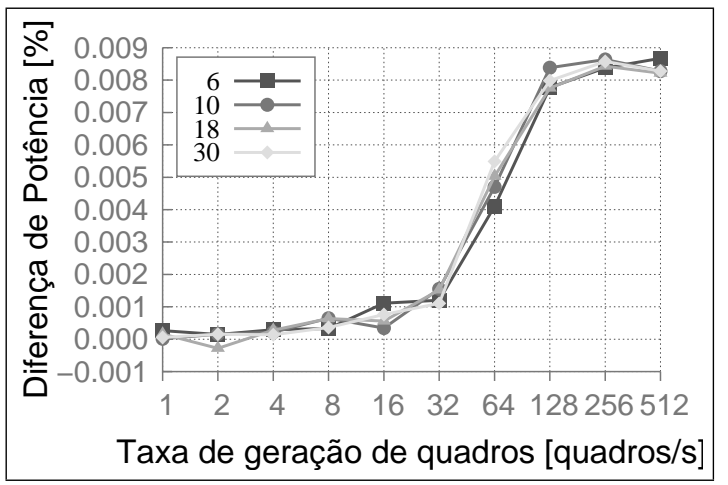

Taxa de geração de quadros [quadros/s]

ferenças, exceto para o atraso, que apresentou aumento. Porém, devido à pequena amplitude das diferenças (inferiores à $2 \%$ ) os resultados não são conclusivos.

Os resultados para variação de número de nós são exibidos na Figura 62 . O impacto da variação deste parâmetro foi maior para os cenários com variação do número de nós, devido à consequente maior disputa pelo meio. 
Figura 62: Variação do parâmetro AMAXFrAmERETRIES - Número de nós

(a) Vazão

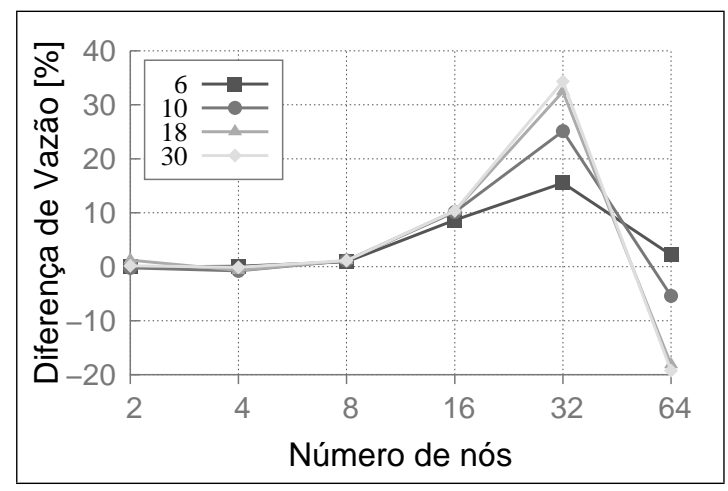

(c) Atraso

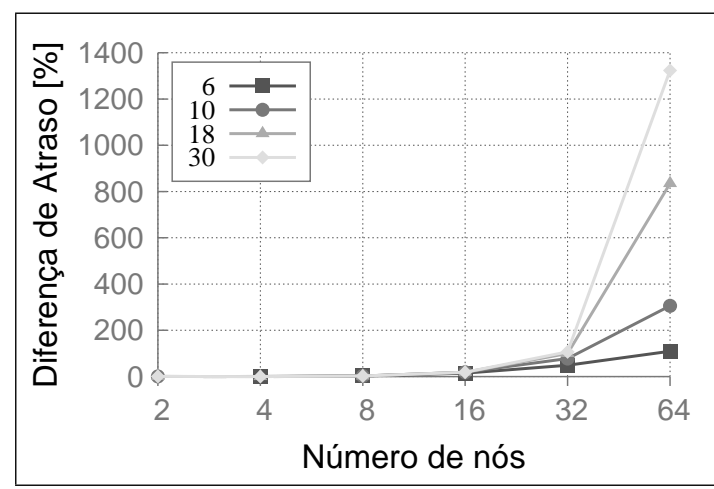

Fonte: Autor (b) Taxa de Entrega

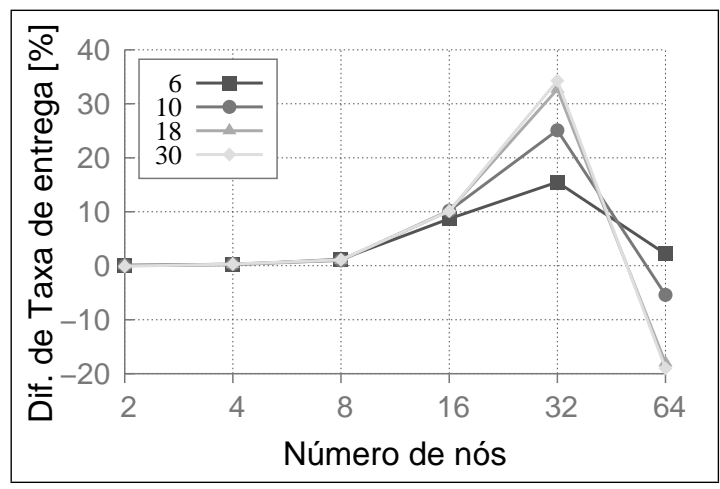

(d) Potência

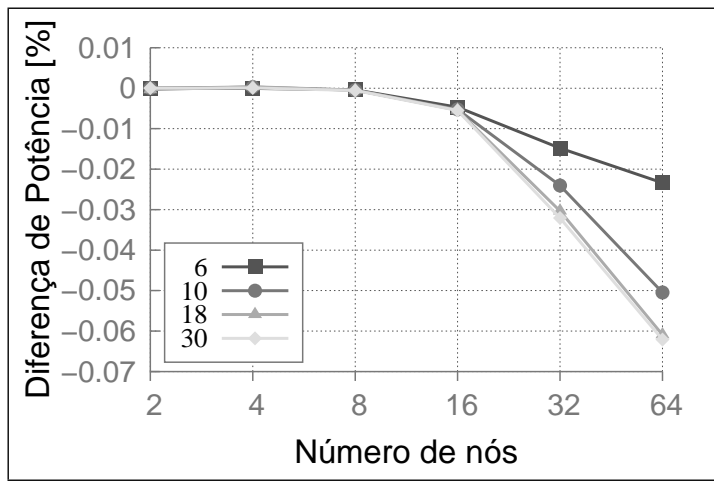

À medida que o número de nós aumenta, existe uma tendência de aumento de vazão e taxa de entrega ao mesmo tempo em que o atraso também aumenta. Isto ocorre devido ao aumento da quantidade de colisões e da chance de se encontrar o canal ocupado. Assim, quadros que seriam descartados com o parâmetro original têm mais chances de serem enviados, até que alguns eventualmente conseguem. Este comportamento implica que os quadros ficam mais tempo aguardando na fila de envio, acarretando o aumento do atraso. Para o cenário com 16 nós a vazão aumenta cerca de $10 \%$, enquanto o atraso aumenta cerca de $18 \%$ para todos os valores do parâmetro. Para 32 nós a vazão e atraso podem aumentar em até $35 \%$ e $107 \%$, respectivamente.

A métrica de potência mostra uma leve queda, indicando aumento do tempo em que o rádio fica no estado de transmissão. Porém, a economia de energia apontada é menor que $0.1 \%$ e não justificaria a mudança do valor do parâmetro.

Para valores de parâmetro maior ou igual a 10 em cenários com 64 nós to- 
Figura 63: Variação do parâmetro MACMAXCSMABACKOFFs - Taxa de tráfego

(a) Vazão

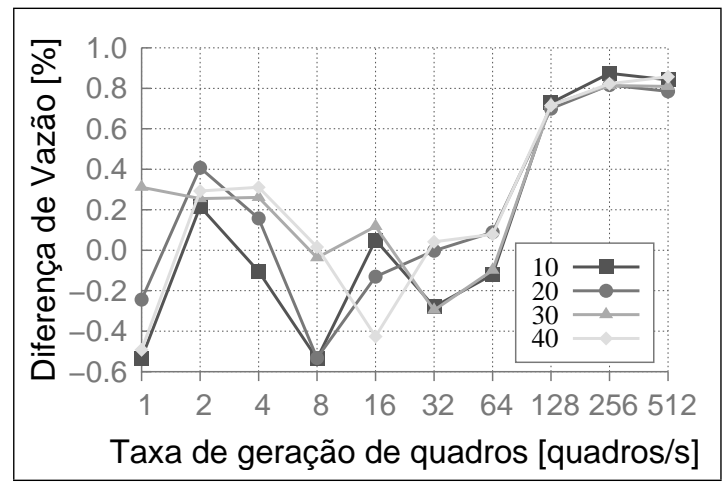

(c) Atraso

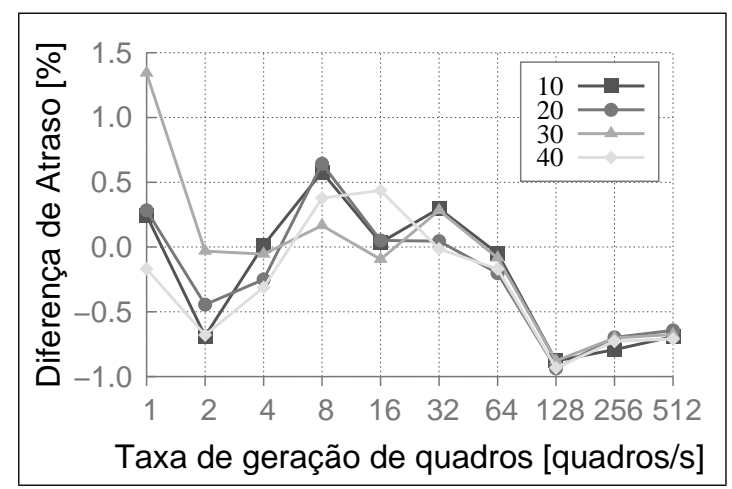

Fonte: Autor (b) Taxa de Entrega

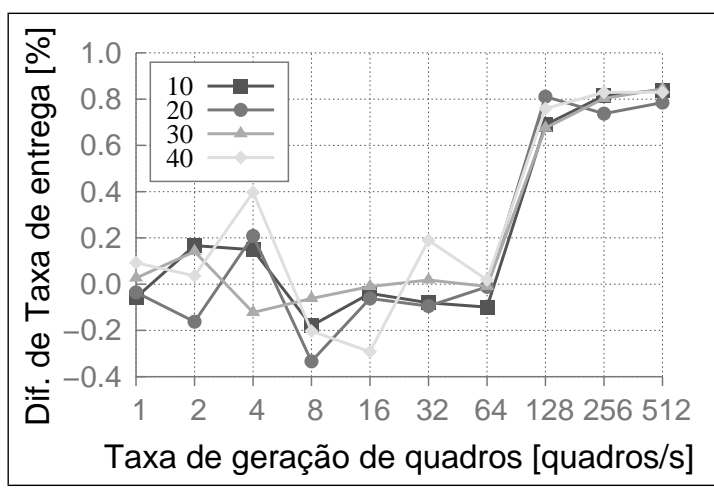

(d) Potência

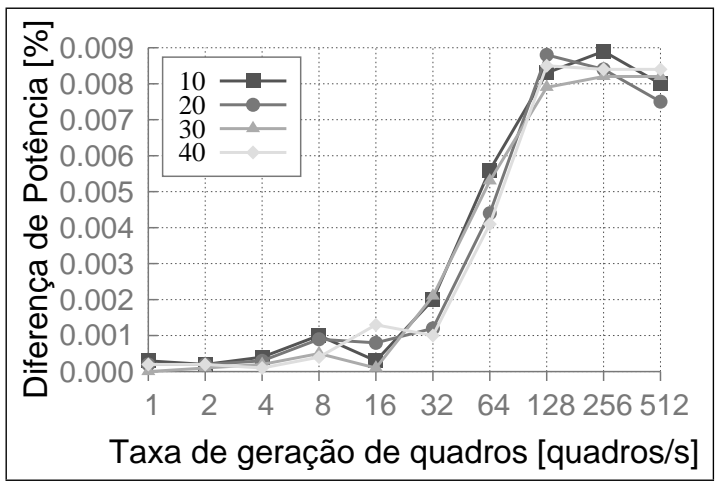

das as métricas tiveram resultado negativo, exceto pela potência, cujo ganho foi pequeno. A perda de desempenho de vazão ocorre devido ao aumento do atraso, causando maiores perdas devido ao estouro de buffer. Na combinação 64 nós e parâmetro igual a 6 houve pequenos ganhos de vazão e taxa de entrega (apenas $2 \%$ ), porém o aumento de atraso foi muito grande (mais de 100\%). Claramente não é interessante alterar o parâmetro neste tipo de cenário.

Nos outros cenários cabe a discussão, dependendo do tipo de aplicação envolvida. Se a consistência dos dados for importante, taxas de entrega maiores devem ser priorizadas apesar do aumento de atraso. Porém, muitos casos de aplicações de RSSF requerem os dados mais recentes, indicando que a diminuição do atraso deve ser priorizada.

O parâmetro estudado nas Figuras 63 e 64 é o MACMAXCSMABACKOFFs, referente à quantidade máxima de backoffs que podem ser executados durante o algoritmo de CSMA/CA. 
Figura 64: Variação do parâmetro MACMAXCSMABACKOFFS - Número de nós

(a) Vazão

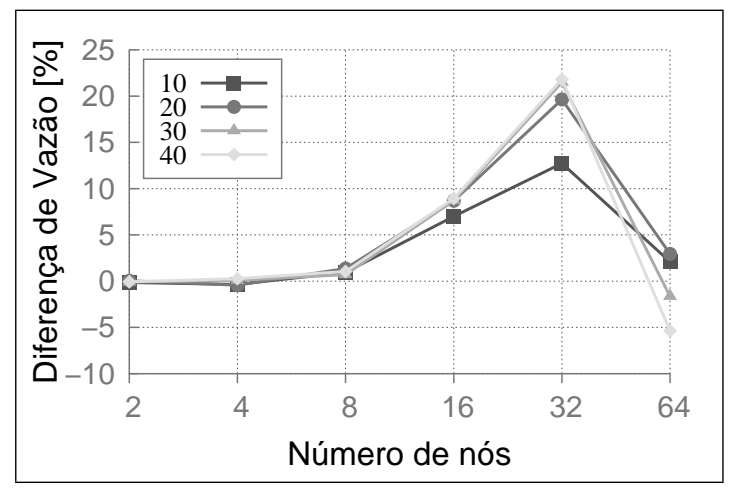

(c) Atraso

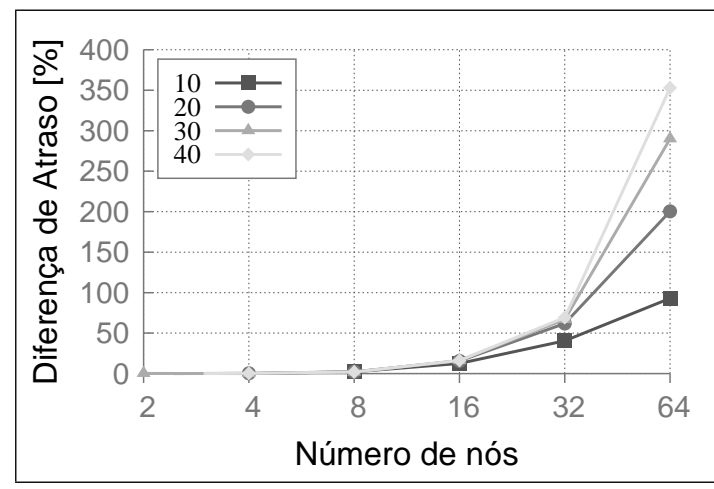

Fonte: Autor (b) Taxa de Entrega

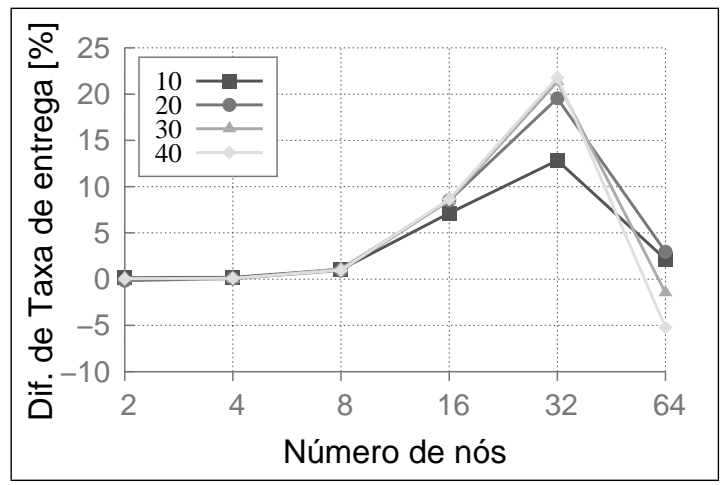

(d) Potência

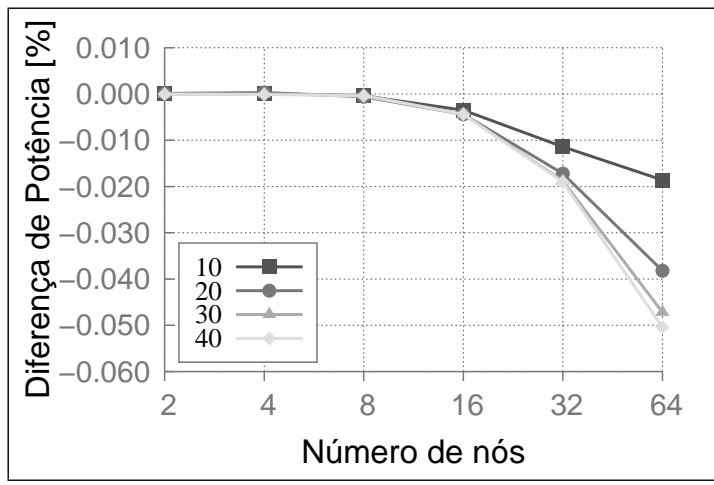

De forma análoga ao parâmetro AMAXFRAMERETRIES (Figura 61) este parâmetro tem maior influência para cenários em que há grande contenção de acesso ao meio. Nos cenários da Figura 63, que contam apenas dois nós, o limite de backoffs não é atingido com frequência, mesmo quando a taxa de quadros é alta. A faixa de variação ficou aproximadamente de $-1 \%$ até $1,5 \%$.

Ainda em comparação com os resultados da Figura 61, nos cenários a partir de 128 quadros/s há uma indicação de melhora de todas as métricas, exceto a potência, para todos os valores testados. Nos outros cenários há variação dos resultados, o que, em conjunto com o pequeno valor das variações, impossibilitam maiores conclusões.

O impacto da variação deste parâmetro é mais visível ao observar seu comportamento com a quantidade do número de nós (Figura 64), que novamente apresenta características comuns em relação ao parâmetro AMAXFRAMERETRIES (Figura 62). Há uma melhora progressiva das métricas de vazão e taxa de entrega 
em troca de uma penalidade no desempenho do atraso.

Figura 65: Variação do parâmetro INITIALCW - Taxa de tráfego

(a) Vazão

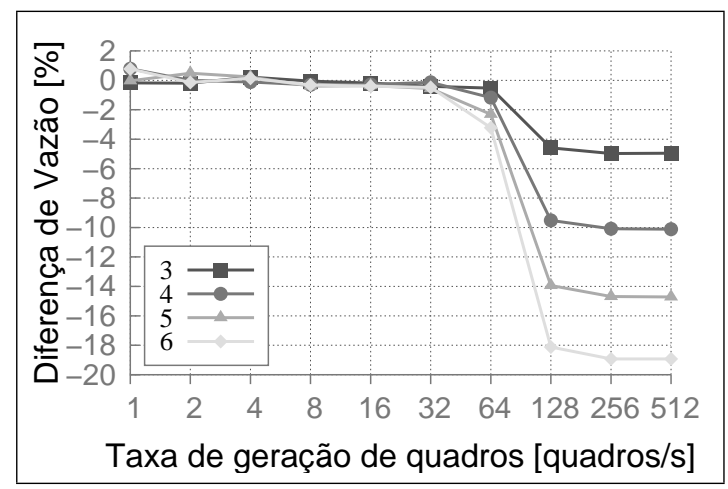

(c) Atraso

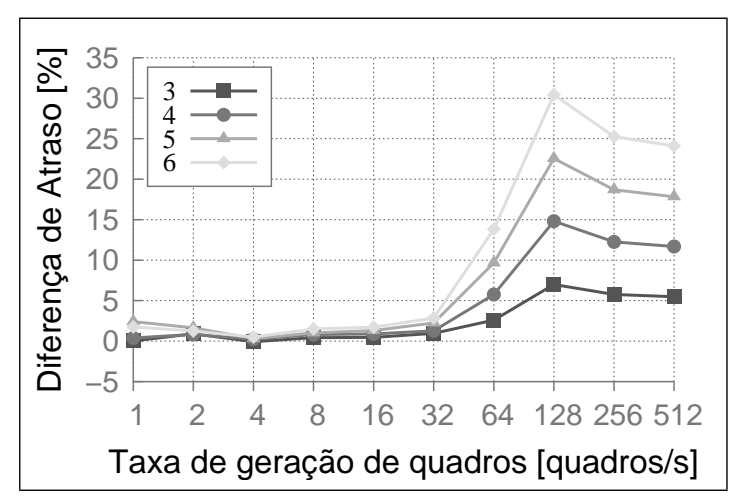

Fonte: Autor (b) Taxa de Entrega

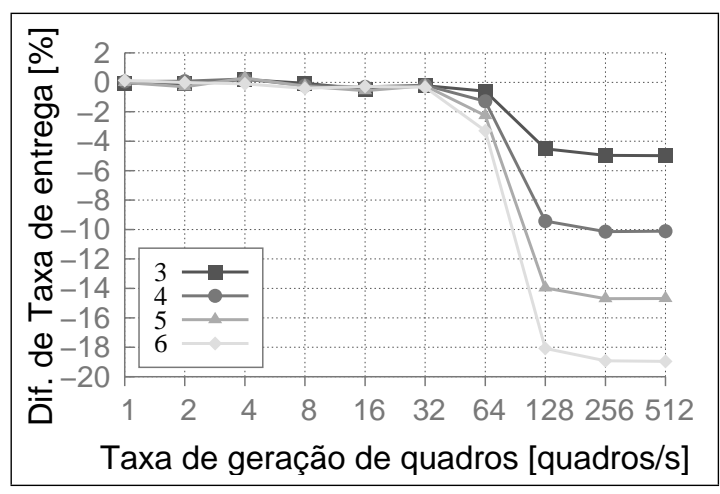

(d) Potência

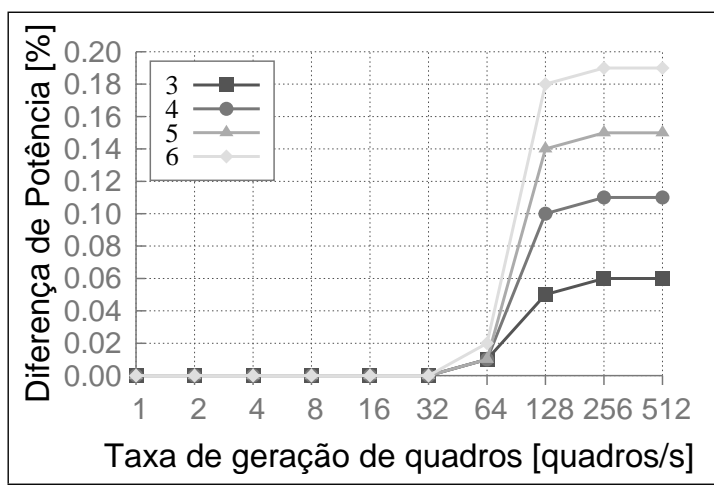

Para MACMAXCSMABACKOFFs igual a 10, a vazão melhora cerca de $7 \%$ para 16 nós e $12 \%$ para 32 nós, com aumento do atraso aproximado de $12 \%$ e $40 \%$, respectivamente. Não houve grande diferença entre os outros valores do parâmetro testados, apresentando melhoras de $9 \%$ e $21 \%$ para a vazão e deterioramento de $16 \%$ e $65 \%$ para o atraso, considerando cenários com 16 e 32 nós, respectivamente.

As métricas pioram abruptamente no cenário com 64 nós, com diminuição do ganho (cerca de $2 \%$ ) ou com perda (cerca de $5 \%$ ) de vazão e piora do atraso de $93 \%$ a $353 \%$. Isto ocorre pois o atraso para enviar o quadro torna-se grande a ponto de aumentar a perda de quadros por estouro de buffer.

A métrica de potência é um caso à parte, pois apresenta apenas melhora ínfima, inferior à $1 \%$ em todos os cenários. Os ganhos porcentuais com vazão são sempre inferiores às perdas com o atraso, de forma que fazer a alteração deste 
parâmetro seria indicado apenas em aplicações específicas condizentes com estes valores esperados das métricas.

Figura 66: Variação do parâmetro INITIALCW - Número de nós

(a) Vazão

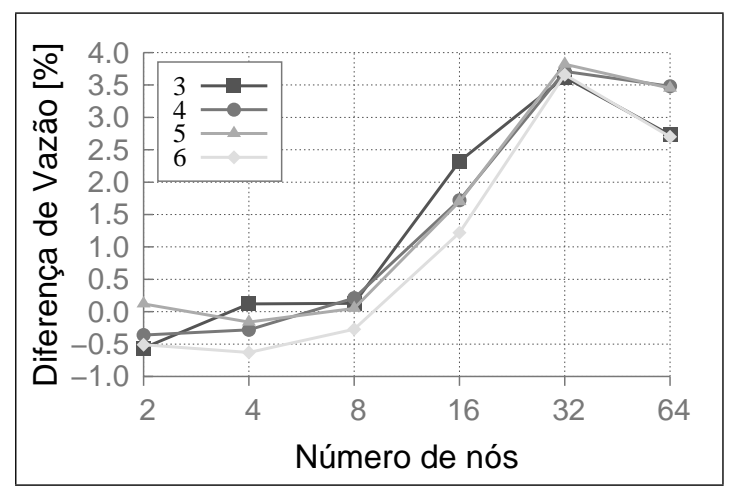

(c) Atraso

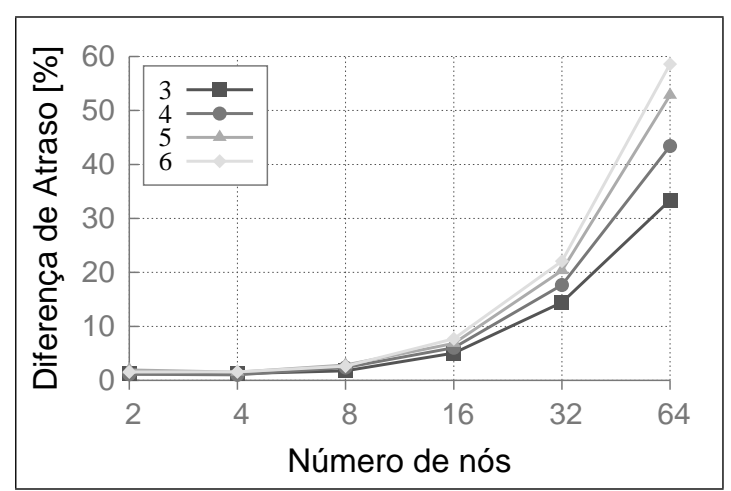

Fonte: Autor (b) Taxa de Entrega

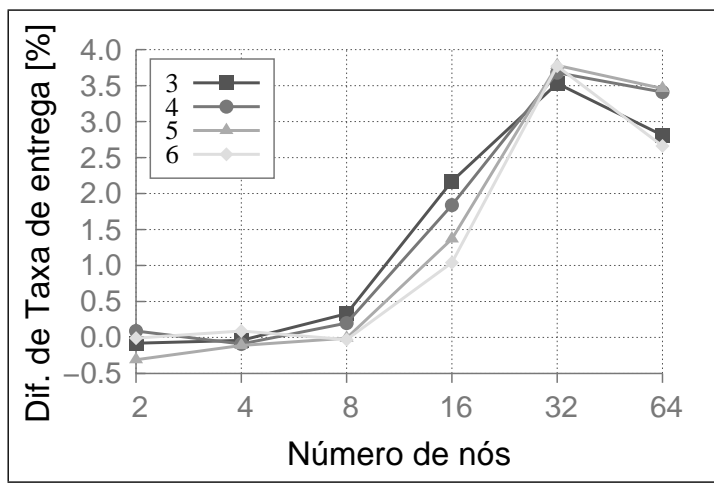

(d) Potência

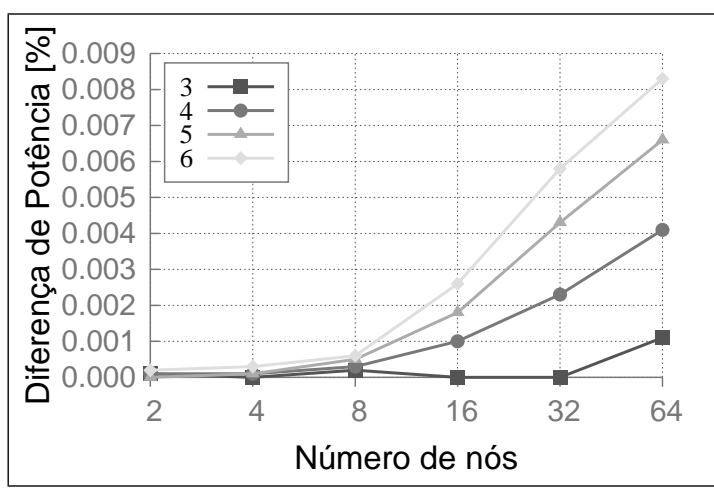

O terceiro parâmetro analisado é o initial contention window size (initialCW). Este parâmetro é utilizado durante o algoritmo de CSMA/CA, correspondendo à quantidade de vezes seguidas que o meio deve ser encontrado livre para iniciar a transmissão.

Os resultados para variação de taxa de quadros e número de nós são exibidos nas Figuras 65 e 66. Para o primeiro caso, todas as métricas apresentaram desempenho até $0.8 \%$ superior ou inferior ao cenário com o valor padrão do parâmetro, com piora acentuada nos cenários com taxas a partir de 128 quadros/s, nos quais há saturação da rede. Quanto maior o valor do parâmetro, pior o desempenho, atingindo mais de $19 \%$ de diminuição de vazão e aumento de até $30 \%$ de atraso.

Considerando a variação do número de nós, os resultados indicam que não é vantajoso alterar este parâmetro. Apesar de pequeno aumento da vazão, a 
Figura 67: Variação do parâmetro AUniTBACKOFFPERIOD - Taxa de tráfego

(a) Vazão

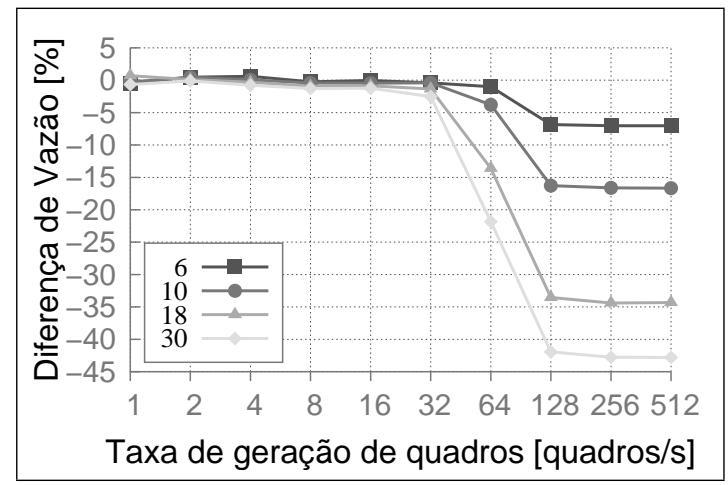

(c) Atraso

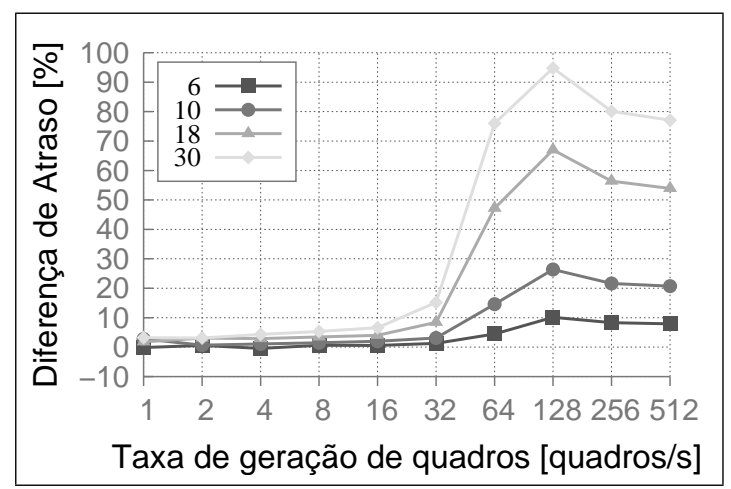

(b) Taxa de Entrega

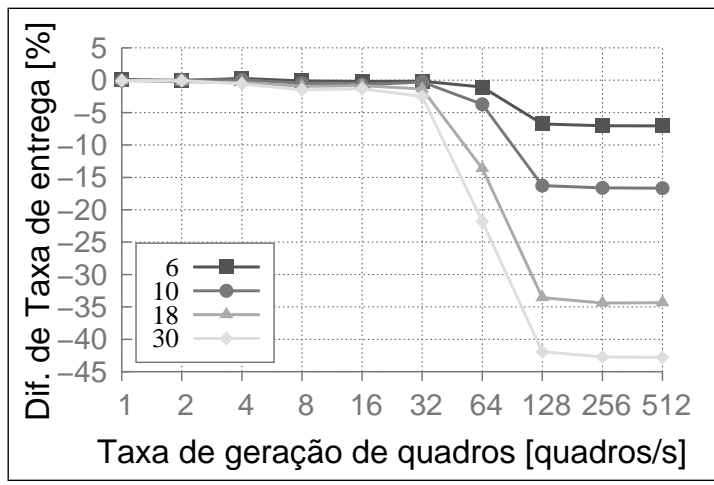

(d) Potência

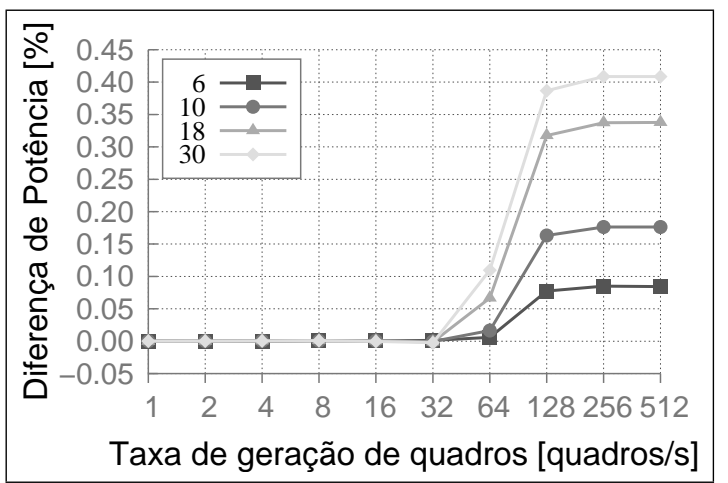

Fonte: Autor

desvantagem em relação ao atraso é substancialmente maior. O cenário com valores mais equilibrados seria o de 16 nós, com ganho de vazão de $2 \%$ e aumento de atraso de 6\%, aproximadamente. Em suma, o valor padrão deste parâmetro é recomendado para a grande maioria dos casos.

O último parâmetro analisado é o AUNiTBACKOFFPERIOD, que é a quantidade de símbolos que forma a unidade de tempo base utilizada pelo algoritmo de CSMA/CA. Por exemplo, é utilizado para definir o intervalo de tempo do backoff.

Os resultados obtidos assemelham-se aos resultados negativos obtidos com a variação do parâmetro INITIALCW. A Figura 67 exibe os valores das métricas para variação de taxa de quadros. O impacto foi pequeno para cenários até 16 quadros/s em comparação com os outros cenários, com variação de vazão inferior a $1.5 \%$ e aumento do atraso de até $6.6 \%$. De 32 a 128 quadros/s as métricas pioram progressivamente, atingindo um patamar nos cenários finais para todos valores assumidos pelo parâmetro. Quanto maior o valor do parâmetro, 
pior o desempenho, apresentando perdas de vazão entre $7 \%$ e $43 \%$ e aumento de atraso de $7.9 \%$ até $95 \%$, dependendo do valor do parâmetro. A potência dissipada aumenta até cerca de $0.4 \%$.

Figura 68: Variação do parâmetro AUnitBACKOFfPERIOD - Número de nós

(a) Vazão

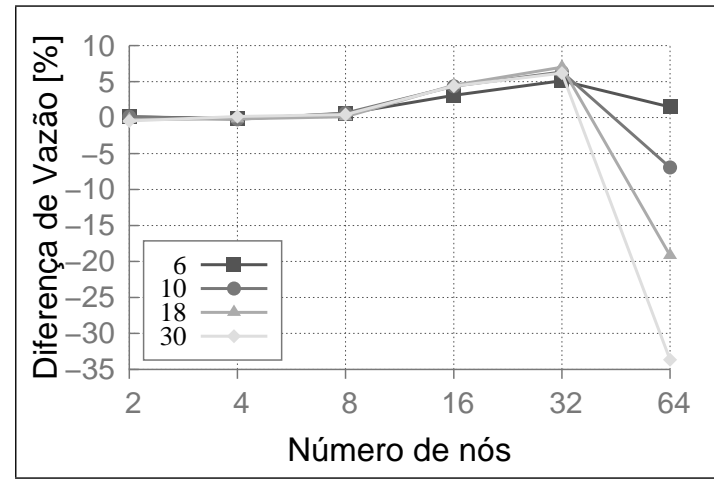

(c) Atraso

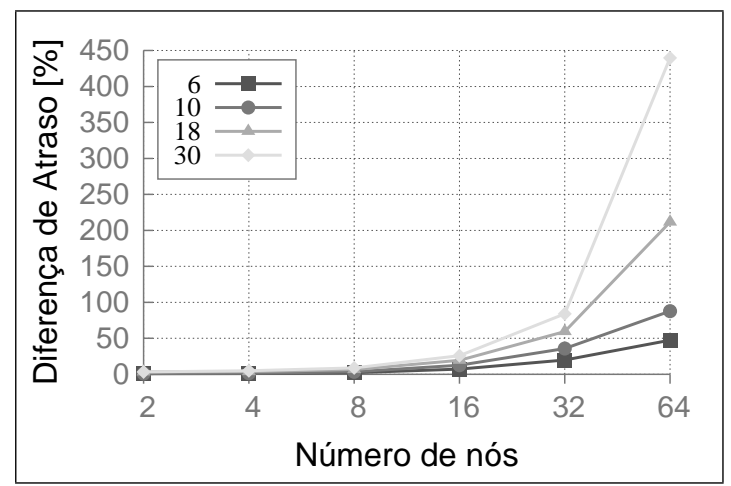

(b) Taxa de Entrega

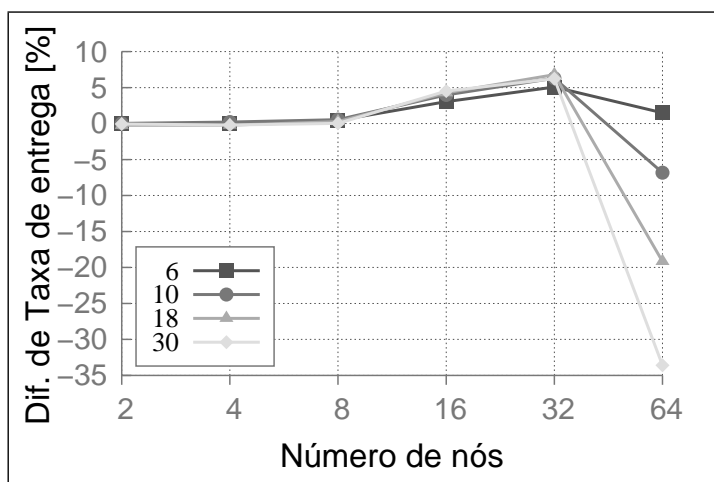

(d) Potência

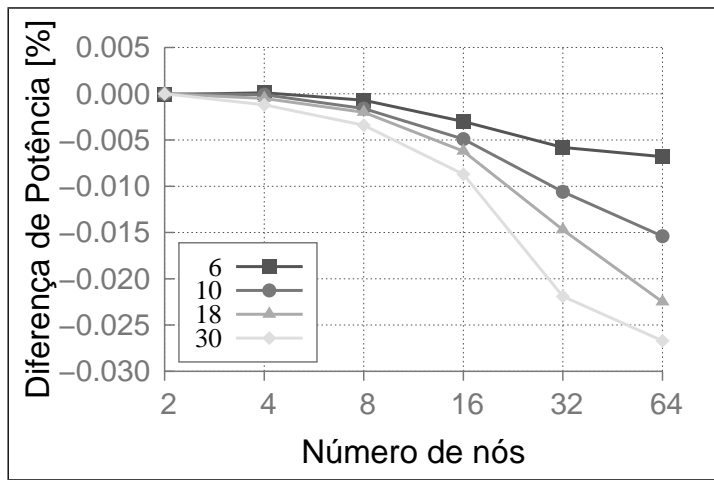

Fonte: Autor

Na Figura 68, na qual são exibidos os resultados para variação do número de nós, há uma leve tendência de melhora da vazão e taxa de entrega, em troca de aumento do atraso. Os cenários nos quais há mais impacto são nos de 16 e 32 nós, com aumento de vazão nos intervalos $[3 \% ; 4,5 \%]$ e $[5 \% ; 7 \%]$ e atraso dentro dos intervalos $[7 \% ; 26 \%]$ e $[19 \% ; 85 \%]$, respectivamente, apresentando maiores valores quanto maior o parâmetro adotado.

Para 64 nós, o ganho com vazão diminui ou deixa de existir e, em contrapartida, o aumento de atraso pelo menos dobra em relação ao cenário com 32 nós. No tocante à potência, há pequenos ganhos que não atingem $0,1 \%$. Da mesma forma que o parâmetro INITIALCW, recomenda-se que o valor padrão seja mantido, exceto se os pequenos ganhos de vazão sejam estritamente desejados. 


\subsection{Tráfego assimétrico}

O objetivo do próximo experimento é estudar as consequências de assimetria de tráfego. Foram considerados cenários com dois nós, nos quais a taxa de um nó é um múltiplo da taxa do outro. As taxas escolhidas foram 4, 8, 16, 32 e 64 combinadas com os multiplicadores 2,4 e 8.

Os gráficos da Figura 69 apresentam resultados de experimentos em comparação com cenários onde a taxa de tráfego é simétrica, considerando que a taxa de quadros somada seria distribuída igualmente entre os dois nós. O eixo das abscissas indica a menor taxa de quadros enquanto que as diferentes curvas são os diferentes multiplicadores.

Nos resultados de vazão, as variações são inferiores a $1 \%$ nos cenários em que a vazão total é baixa (multiplicador igual a 2 ou multiplicadores maiores com taxa do nó 1 entre 4 e 8 quadros/s). Nos outros cenários há ligeira diminuição desta métrica, de até $3.6 \%$, pois há concentração da taxa de chegadas em um nó, aumentando as perdas por estouro de buffer.

Os valores de taxa de entrega apontados podem ser um pouco enganosos devido à forma como são calculados. Esta métrica é obtida pela média das taxas de entrega dos nós presentes na rede. Ao desbalancear as taxa de tráfego, o nó com menor taxa possui pequenas perdas devido a estouro de buffer, o que causa aumento em sua taxa de entrega. Consequentemente, a taxa de entregas geral é aumentada em até $3.3 \%$ para multiplciador igual a dois e $85 \%$ para o maior multiplicador.

O atraso sofrido pelos quadros é mitigado, pois o desequilíbrio de taxas de chegada de quadro diminui a competição pelo meio, evitando a ocorrência de backoffs e colisões. Quanto maior o multiplicador, maior a atenuação, atingindo $3.3 \%$ para multiplicador 2 e $13 \%$ para multiplicador 8 .

A métrica de potência não foi alterada significativamente, apresentando incremento inferior à $0.1 \%$, indicando tendência de passar mais tempo no estado de recepção do que transmissão.

Em suma, não há evidências de que assimetrias de tráfego causam mudanças significativas nas métricas da rede, dadas as condições de canal ideal do modelo. 
Figura 69: Estudo com tráfegos assimétricos

(a) Vazão

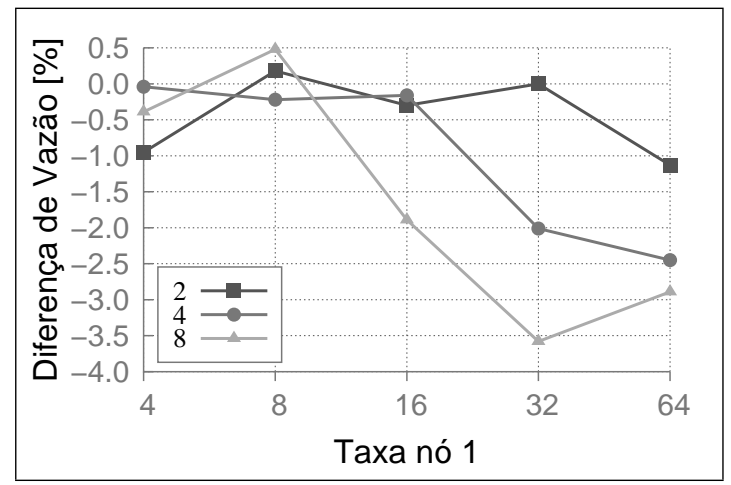

(c) Atraso

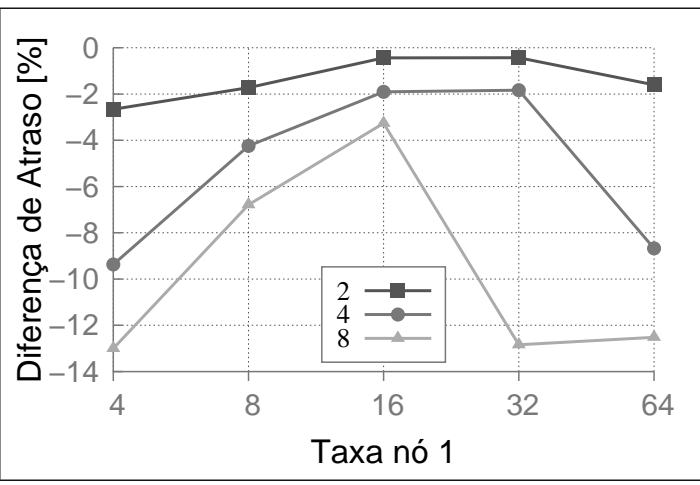

Fonte: Autor (b) Taxa de Entrega

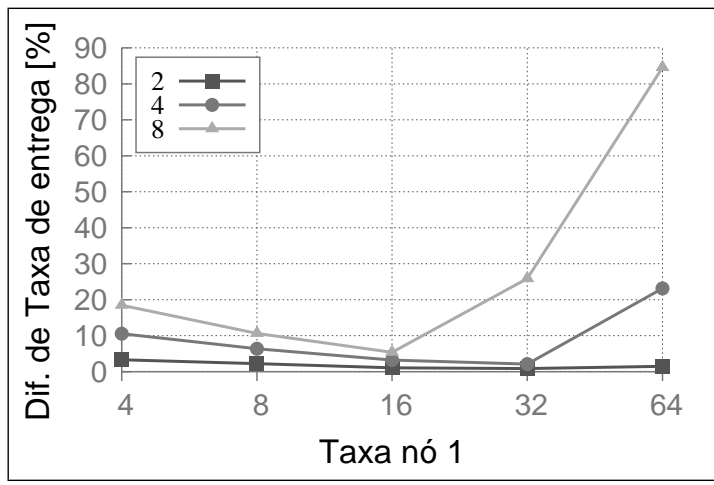

(d) Potência

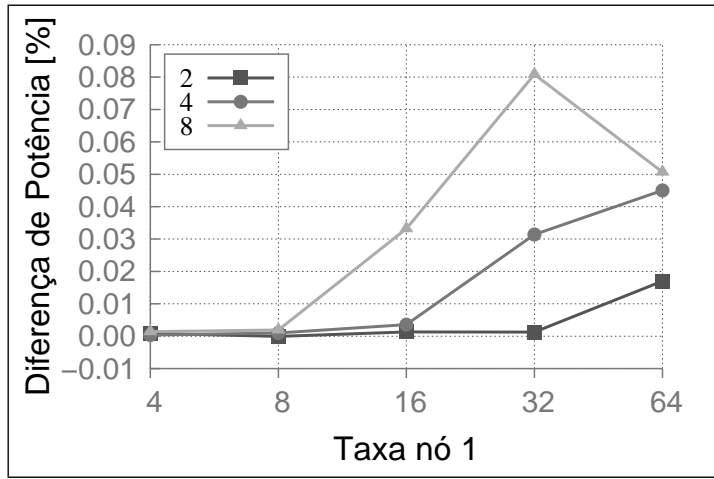

\subsection{Cenário de uso geral}

O último estudo realizado visa a verificar a relação de compromisso entre taxa de chegada de quadros e o tamanho dos quadros, mantendo uma taxa de bits constante. A motivação deste experimento é verificar o potencial de ganho de desempenho utilizando agregação de dados prévia ao envio, diminuindo a quantidade de quadros enviados mas aumentado seu tamanho.

Os valores empregados são exibidos na Tabela 20, combinando taxas de bit de 256, 512 e 1024, tamanhos de quadro de 16 a 128 bytes e taxas de quadro de 4 a 64 quadros/s. De acordo com o padrão IEEE 802.15.4, o tamanho máximo de um quadro é 127 bytes, porém, adotou-se o valor 128 nos experimentos para manter o padrão de valores potências de dois.

Os resultados das métricas são expostos na Figura 70, na qual as curvas indicam as taxas de quadros empregadas e o eixo das abscissas indica a proporção entre o tamanho do quadro e a taxa de chegada (última coluna da Tabela 20). 
Tabela 20: Valores de taxa de bits e parâmetros adotados

\begin{tabular}{|c|c|c|c|}
\hline Taxa [bps] & Tamanho [Bytes] & Taxa [quadros/s] & Relação Tamanho/Taxa \\
\hline \hline \multirow{3}{*}{256} & 16 & 16 & 1 \\
\cline { 2 - 4 } & 32 & 8 & 4 \\
\cline { 2 - 4 } & 64 & 4 & 16 \\
\cline { 2 - 4 } & 128 & 2 & 64 \\
\hline \hline \multirow{3}{*}{512} & 16 & 32 & 0.5 \\
\cline { 2 - 4 } & 32 & 16 & 2 \\
\cline { 2 - 4 } & 64 & 8 & 8 \\
\hline \hline \multirow{3}{*}{1024} & 128 & 4 & 0.25 \\
\cline { 2 - 4 } & 16 & 32 & 1 \\
\cline { 2 - 4 } & 32 & 16 & 4 \\
\cline { 2 - 4 } & 64 & 8 & 16 \\
\hline
\end{tabular}

Fonte: Autor

Figura 70: Estudo de variação da proporção entre tamanho de quadro e taxa de quadro com taxa de bits constante

(a) Vazão

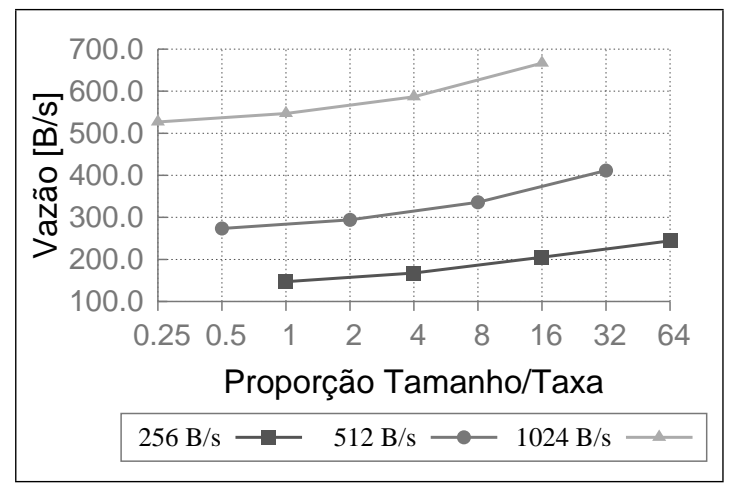

(c) Atraso

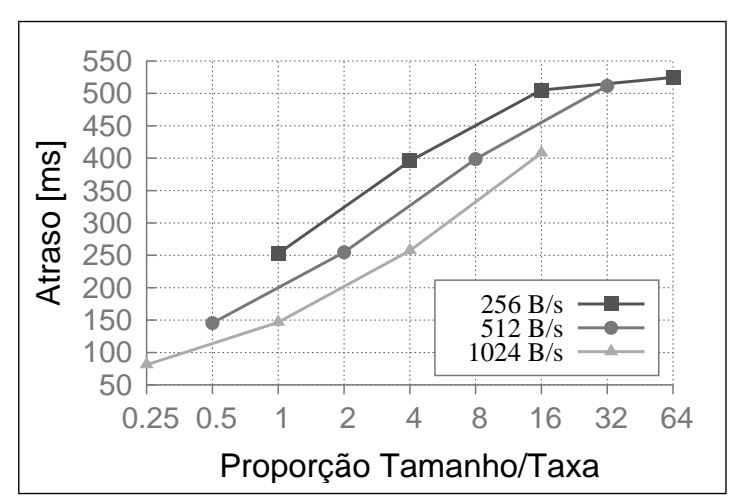

(b) Taxa de Entrega

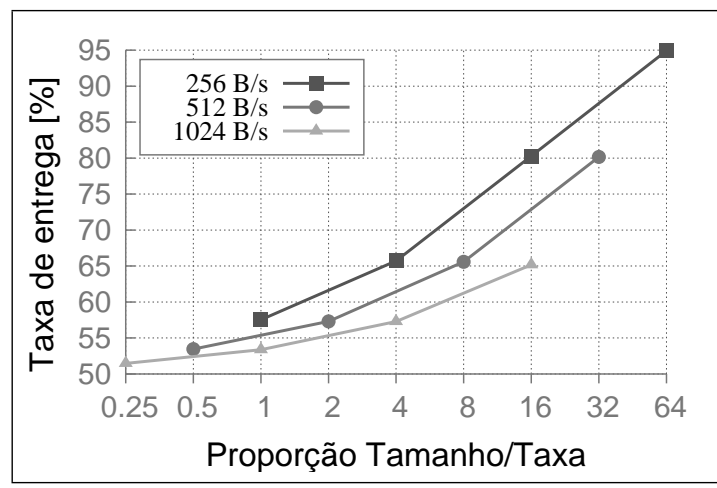

(d) Potência

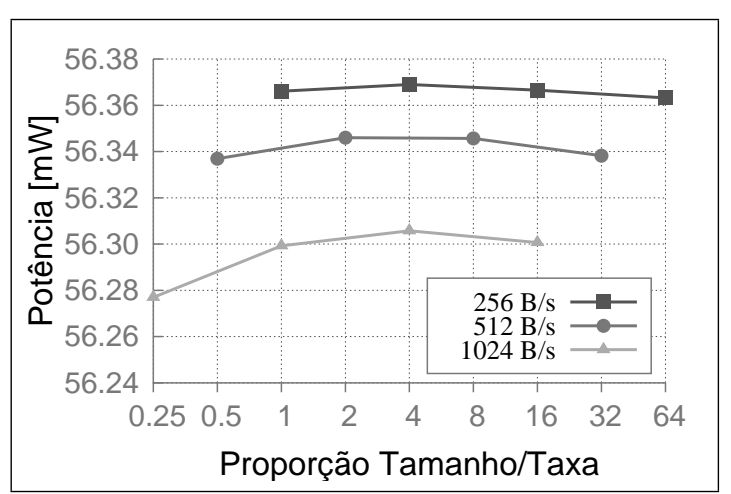

Fonte: Autor 
Em todas as taxas de bits testadas, as métrica de vazão, taxa de entrega e atraso mostraram uma tendência de aumentar conforme aumenta a proporção tamanho/taxa, ou seja, com maior agregação de dados. A Tabela 21 exibe quanto cada métrica aumentou comparando o cenário com maior agregação com o de menor agregação para cada taxa de bits. A medida que a taxa de dados diminui, a competição pelo meio também diminui, melhorando as métricas de vazão e taxa de entrega.

Maiores taxas de tráfego proporcionam menor atraso. Este fenômeno ocorre devido ao duty cicle de $50 \%$ imposto pelos parâmetros BO e SO adotados. As taxas de tráfego elevadas proporcionam um rápido preenchimento do buffer no período ocioso do superframe e uma quantidade maior de quadros entregues no período ativo. Assim, a proporção de quadros entregues em um curto período de tempo é maior do que nos casos com baixas taxas de quadros. A eficiência da agregação é melhor nas taxas de bit menores, pois há maior aumento da vazão para menos incremento no atraso.

No que se refere à potência, observa-se que existe um ponto intermediário em que há mais dissipação (ou seja, mais tempo em estado de recepção). O aumento da proporção tamanho/taxa leva a maior tempo de transmissão devido ao aumento do tamanho dos quadros, enquanto que, ao assumir um valor pequeno, a elevada taxa de entrega causa o aumento deste tempo. Contudo, em linhas gerais não houve grandes variações desta métrica, com variações entre máximo e mínimo inferiores à $0.06 \%$.

Tabela 21: Aumento dos valores das métricas nos cenários com maior agregação de dados em relação ao cenário com menos agregação

\begin{tabular}{|c|c|c|c|}
\cline { 2 - 4 } \multicolumn{1}{c|}{} & \multicolumn{3}{c|}{ Métricas } \\
\hline Taxa de bits & Vazão & Taxa de Entrega & Atraso \\
\hline 256 & $65.8 \%$ & $64.9 \%$ & $107.5 \%$ \\
\hline 512 & $50.4 \%$ & $49.9 \%$ & $251.6 \%$ \\
\hline 1024 & $26.6 \%$ & $26.7 \%$ & $403.8 \%$ \\
\hline
\end{tabular}

Fonte: Autor

\subsection{Considerações do capítulo}

Em suma, a maioria dos ajustes de parâmetros possíveis, sejam parâmetros do padrão IEEE 802.15.4 ou parâmetros de aplicação, indicam uma relação de con- 
flito entre as métricas de vazão e atraso, ao mesmo tempo que não há alterações substanciais de dissipação de potência. Desta forma, o ajuste de parâmetros deve ser feito com a aplicação final em mente, com a finalidade de prover a qualidade de desempenho adequada. 


\section{CONSIDERAÇÕES FINAIS}

O padrão IEEE 802.15.4 é proeminente em termos de camada de enlace em dispositivos embarcados e de baixo custo utilizados em redes ad-hoc e redes de sensores sem fio. Este trabalho tem o objetivo de oferecer uma ferramenta para analisar e estudar o comportamento deste padrão em diferentes circunstâncias.

As contribuições deste trabalho incluem três modelos: um com rede de Petri estocástica generalizada e dois com rede de Petri colorida, utilizados para análise do espaço de estados e análise de desempenho. Estes modelos foram construídos com uma abordagem comportamental, e o modelo CPN abrange todas métricas de interesse.

O projeto final do modelo, concretizado com rede de Petri colorida, foi testado com sucesso em comparação com o simulador NS2 e utilizado em diversos cenários de análise de variação de parâmetros, demostrando seu uso prático com larga variação de parâmetro do padrão IEEE 802.15.4 e diferentes cenários em relação à taxa de tráfego e quantidade de nós, permitindo até mesmo assimetrias na rede.

\subsection{Trabalhos Futuros}

O modelo apresentado possui foco em redes com topologia estrela na qual os nós enviam quadros para um sorvedouro comum.

Porém, o padrão IEEE 802.15.4 define outros mecanismos que podem ser modelados e analisados, por exemplo a associação e desassociação a coordenadores, criação de PANs e gerenciamento de GTS. Não é conhecido um modelo que aborde estes procedimentos.

Outra proposta de interesse é permitir que o desempenho de outras topologias seja analisado, bem como transmissões entre os nós da rede em oposição ao 
fluxo de dados único para a BS. A dificuldade destas propostas está na influência exercida pelo modelo subjacente da camada de aplicação, dificultando uma modelagem genérica.

\subsection{Publicações}

Os resultados intermediários desta dissertação foram apresentados nos I e II Workshop de Pós-Graduação da Área de Concentração Engenharia de Computação. Os resultados de pesquisa apresentados no Capítulo 3 foram publicados na conferência internacional ACM PE-WASUN 2013 (ALVES; MARGI, 2013). Os resultados de pesquisa apresentados no Capítulo 4 estão sendo preparados para submissão em periódico internacional.

Além disso, houve duas publicações e uma submissão não diretamente relacionadas ao conteúdo deste documento, decorrentes de um trabalho utilizando RSSF aplicada à fisioterapia, abrangendo uma conferência nacional (SBSI), um periódico nacional (iSys) e um periódico internacional (IoT journal) (ALVES et al., 2012; ALVES et al., 2013; ALVES et al., 2014). 


\section{REFERÊNCIAS}

AlveS, R. C.; MARGI, C. B. A timed Petri net model for frame transmission on IEEE 802.15.4 beacon-enabled mode. In: Proceedings of the 10th ACM Symposium on Performance Evaluation of Wireless Ad Hoc, Sensor, \& Ubiquitous Networks. New York, NY, USA: ACM, 2013. (PE-WASUN '13), p. 89-96. ISBN 978-1-4503-2360-4.

ALVES, R. C. A. et al. Assisting physical (hydro)therapy with wireless sensors networks. IEEE Internet of Things Journal - em revisão. 2014.

- Redes de sensores sem fio aplicadas à fisioterapia: Implementação e validação de um sistema de monitoramento de amplitude de movimento. iSys - Revista Brasileira de Sistemas de Informação, Sociedade Brasileira de Computação, 2013.

- Sistema de monitoramento de amplitude de movimento baseado em redes de sensores sem fio aplicado à fisioterapia. In: VIII Simpósio Brasileiro de Sistemas de Informação. São Paulo, Brasil: Sociedade Brasileira de Computação, 2012.

ANASTASI, G. et al. Monitoring high-quality wine production using wireless sensor networks. In: HICSS '09. 42nd Hawaii International Conference on System Sciences. Havaí: IEEE, 2009. p. 1 -7. ISSN 1530-1605.

ATZORI, L.; IERA, A.; MORABITO, G. The internet of things: A survey. Computer Networks, v. 54, n. 15, p. 2787 - 2805, 2010. ISSN 1389-1286. Disponível em: <http://www.sciencedirect.com/science/article/pii/S1389128610001568>.

BIANCHI, G. Performance analysis of the IEEE 802.11 distributed coordination function. Selected Areas in Communications, IEEE Journal on, v. 18, n. 3, p. 535-547, March 2000. ISSN 0733-8716.

BONET, P. et al. Pipe v2.5.: a Petri Net Tool for Performance Modelling. San Jose, Costa Rica, out. 2007.

BURATTI, C. Performance analysis of IEEE 802.15.4 beacon-enabled mode. Vehicular Technology, IEEE Transactions on, v. 59, n. 4, p. 2031-2045, May 2010. ISSN 0018-9545.

BURATTI, C.; VERDONE, R. Performance analysis of IEEE 802.15.4 non beacon-enabled mode. Vehicular Technology, IEEE Transactions on, v. 58, n. 7, p. 3480-3493, Sept 2009. ISSN 0018-9545. 
CHIOLA, G. et al. Generalized stochastic petri nets: a definition at the net level and its implications. Software Engineering, IEEE Transactions on, v. 19, n. 2, p. 89-107, Feb 1993. ISSN 0098-5589.

CULLER, D.; ESTRIN, D.; SRIVASTAVA, M. Overview of sensor networks. Computer Magazine, IEEE Computer Society, v. 37, n. 8, p. 41-49, 2004.

DAM, T. van; LANGENDOEN, K. An adaptive energy-efficient MAC protocol for wireless sensor networks. In: Proceedings of the 1st international conference on Embedded networked sensor systems. New York, NY, USA: ACM, 2003. (SenSys '03), p. 171-180. ISBN 1-58113-707-9.

DELOS, A. Simulation of a sensor network embedded in rail train. Dissertação (Mestrado) - Universitat Politècnica da Catalunya, oct 2012.

FARIDI, A. et al. Comprehensive evaluation of the IEEE 802.15.4 MAC layer performance with retransmissions. Vehicular Technology, IEEE Transactions on, v. 59, n. 8 , p. $3917-3932$, oct. 2010. ISSN 0018-9545.

FRUTH, M. Probabilistic model checking of contention resolution in the IEEE 802.15.4 low-rate wireless personal area network protocol. In: Second International Symposium on Leveraging Applications of Formal Methods, Verification and Validation, 2006. ISoLA 2006. Chipre: IEEE, 2006. p. 290-297.

GOYAL, M. et al. A stochastic model for beaconless IEEE 802.15.4 MAC operation. In: Performance Evaluation of Computer Telecommunication Systems, 2009. SPECTS 2009. International Symposium on. Istanbul: IEEE, 2009. v. 41, p. 199-207.

HEINZELMAN, W. R.; CH, A.; BALAKRISHNAN, H. Energy-efficient communication protocol for wireless microsensor networks. In: Proceedings of the 33rd Annual Hawaii International Conference on System Sciences. Havaí: IEEE, 2000. p. 3005-3014.

IEEE. 802.15.4-2003 - IEEE Standard for Telecommunications and Information Exchange Between Systems - LAN/MAN Specific Requirements - Part 15: Wireless Medium Access Control (MAC) and Physical Layer (PHY) Specifications for Low Rate Wireless Personal Area Networks (WPAN). 2003.

. 802.15.4-2006 - IEEE Standard for Local and metropolitan area networks-Part 15.4: Low-Rate Wireless Personal Area Networks (LR-WPANs). 2006 .

802.15.4-2011 - IEEE Standard for Local and metropolitan area networks-Part 15.4: Low-Rate Wireless Personal Area Networks (LR-WPANs). 2011.

. 802.15.4e-2012 - IEEE Standard for Local and metropolitan area networks-Part 15.4: Low-Rate Wireless Personal Area Networks (LR-WPANs) Amendment 1: MAC sublayer. 2012. 
802.15.4f-2012 - IEEE Standard for Local and metropolitan area networks-Part 15.4: Low-Rate Wireless Personal Area Networks (LR-WPANs) Amendment 2: Active Radio Frequency Identification (RFID) System Physical Layer (PHY). 2012.

802.15.4g-2012 - IEEE Standard for Local and metropolitan area networks-Part 15.4: Low-Rate Wireless Personal Area Networks (LR-WPANs) Amendment 3: Physical Layer (PHY) Specifications for Low-Data-Rate, Wireless, Smart Metering Utility Network. 2012.

802.15.4j-2013 - IEEE Standard for Local and metropolitan area networks - Part 15.4: Low - Rate Wireless Personal Area Networks (LR-WPANs) Amendment 4: Alternative Physical Layer Extension to Support Medical Body Area Network (MBAN) Services Operating in the $2360 \mathrm{MHz}-2400 \mathrm{MHz}$ Band. 2013.

- 802.15.4k-2013 - IEEE Standard for Local and metropolitan area networks - Part 15.4: Low - Rate Wireless Personal Area Networks (LRWPANs)-Amendment 5: Physical Layer Specifications for Low Energy, Critical Infrastructure Monitoring Networks. 2013.

IETF. The Dynamic Source Routing Protocol (DSR) for Mobile Ad Hoc Networks for IPv4. [S.1.]: IETF, fev. 2007. Disponível em: http: //tools.ietf.org/html/rfc4728. Acesso em: setembro 2014.

INTANAGONWIWAT, C. et al. Directed diffusion for wireless sensor networking. IEEE/ACM Trans. Netw., IEEE Press, Piscataway, NJ, USA, v. 11, n. 1, p. 2-16, fev. 2003. ISSN 1063-6692.

ISO Standard. Open Systems Interconnection (OSI) model (ISO/IEC 7498-1). 1994.

JEnSEn, K.; KRISTENSEN, L. M. Coloured Petri Nets: Modelling and Validation of Concurrent Systems. Springer, 2009.

JIN, J. et al. An information framework for creating a smart city through internet of things. Internet of Things Journal, IEEE, v. 1, n. 2, p. 112-121, April 2014. ISSN 2327-4662.

JUANG, P. et al. Energy-efficient computing for wildlife tracking: design tradeoffs and early experiences with zebranet. SIGOPS Oper. Syst. Rev., ACM, New York, NY, USA, v. 36, n. 5, p. 96-107, out. 2002. ISSN 0163-5980.

JUNG, C. et al. Enhanced markov chain model and throughput analysis of the slotted csma/ca for ieee 802.15.4 under unsaturated traffic conditions. Vehicular Technology, IEEE Transactions on, v. 58, n. 1, p. 473-478, Jan 2009. ISSN 0018-9545.

KAWADIA, V.; KUMAR, P. R. Experimental investigations into tcp performance over wireless multihop networks. In: Proceedings of the 2005 ACM SIGCOMM Workshop on Experimental Approaches to Wireless Network Design 
and Analysis. New York, NY, USA: ACM, 2005. (E-WIND '05), p. 29-34. ISBN 1-59593-026-4.

KULIK, J.; HEINZELMAN, W.; BALAKRISHNAN, H. Negotiation-based protocols for disseminating information in wireless sensor networks. Wirel. Netw., Springer-Verlag New York, Inc., Secaucus, NJ, USA, v. 8, n. 2/3, p. 169-185, mar. 2002. ISSN 1022-0038.

LING, X. et al. A general analytical model for the IEEE 802.15.4 contention access period. In: Wireless Communications and Networking Conference, 200\%. WCNC 2007. IEEE. Kowloon: IEEE, 2007. p. 316-321. ISSN 1525-3511.

LU, J. et al. The smart thermostat: using occupancy sensors to save energy in homes. In: Proceedings of the 8th ACM Conference on Embedded Networked Sensor Systems. New York, NY, USA: ACM, 2010. (SenSys '10), p. 211-224. ISBN 978-1-4503-0344-6.

MAHMOOD, D. et al. Investigating impact of ack in non-beacon enabled slotted IEEE 802.15.4. In: Advanced Information Networking and Applications (AINA), 2014 IEEE 28th International Conference on. Canada: IEEE, 2014. p. 429-434. ISSN 1550-445X.

MARGI, C. et al. Impact of operating systems on wireless sensor networks (security) applications and testbeds. In: Computer Communications and Networks (ICCCN), 2010 Proceedings of 19th International Conference on. Zurich: IEEE, 2010. p. 1 -6. ISSN 1095-2055.

MARTALÒ, M.; BUSANELLI, S.; FERRARI, G. Markov chain-based performance analysis of multihop IEEE 802.15.4 wireless networks. Perform. Eval., Elsevier Science Publishers B. V., Amsterdam, The Netherlands, The Netherlands, v. 66, n. 12, p. 722-741, dez. 2009. ISSN 0166-5316.

MCCANNE, S.; FLOYD, S. NS Network Simulator. 2012. Disponível em: http://www.isi.edu/nsnam/ns/. Acesso em: agosto 2013.

MEMSIC INC. telosB product details. Massachusetts, USA, 2004. Disponível em: http://www.memsic.com. Acesso em: março 2012.

MERLIN, P. M. A Study of the Recoverability of Computing Systems. Tese (Doutorado) - University of California, 1974.

MISIC, J.; MISIC, V.; SHAFI, S. Performance of IEEE 802.15.4 beacon enabled PAN with uplink transmissions in non-saturation mode - access delay for finite buffers. p. $416-425$, oct. 2004 .

MOLLOY, M. K. Performance analysis using stochastic petri nets. IEEE Trans. Comput., IEEE Computer Society, Washington, DC, USA, v. 31, n. 9, p. 913-917, set. 1982. ISSN 0018-9340.

MURATA, T. Petri nets: Properties, analysis and applications. Proceedings of the IEEE, v. 77, n. 4, p. 541 -580, apr 1989. ISSN 0018-9219. 
NORRIS, J. R. Markov Chains. Cambridge: Cambridge University Press, 1998. ISBN 0521633966.

Opnet Modeler. http://opnet.com/. 2014. Acessado em 15/06/2014.

OSTERLIND, F. et al. Cross-level sensor network simulation with cooja. In: Local Computer Networks, Proceedings 2006 31st IEEE Conference on. Estados Unidos: IEEE, 2006. p. 641-648. ISSN 0742-1303.

PARK, P.; FISCHIONE, C.; JOHANSSON, K. H. Modeling and stability analysis of hybrid multiple access in the IEEE 802.15.4 protocol. ACM Trans. Sen. Netw., ACM, New York, NY, USA, v. 9, n. 2, p. 13:1-13:55, abr. 2013. ISSN 1550-4859.

PARK, T. et al. Throughput and energy consumption analysis of IEEE 802.15.4 slotted CSMA/CA. Electronics Letters, v. 41, n. 18, p. 1017 - 1019, sept. 2005. ISSN 0013-5194.

PERKINS, C.; ROYER, E. Ad-hoc on-demand distance vector routing. In: Mobile Computing Systems and Applications, 1999. Proceedings. WMCSA '99. Second IEEE Workshop on. Nova Orleans: IEEE Computer Society, 1999. p. 90 -100 .

PERKINS, C. E.; BHAGWAT, P. Highly dynamic destination-sequenced distance-vector routing ( $\mathrm{dsdv}$ ) for mobile computers. In: Proceedings of the conference on Communications architectures, protocols and applications. New York, NY, USA: ACM, 1994. (SIGCOMM '94), p. 234-244. ISBN 0-89791-682-4.

PETROVA, M. et al. Performance study of IEEE 802.15.4 using measurements and simulations. In: Wireless Communications and Networking Conference, 2006. WCNC 2006. Las Vegas: IEEE, 2006. v. 1, p. 487 -492. ISSN 1525-3511.

POLLIN, S. et al. Performance analysis of slotted carrier sense IEEE 802.15.4 medium access layer. Wireless Communications, IEEE Transactions on, v. 7, n. 9, p. 3359-3371, September 2008. ISSN 1536-1276.

POSTEL, J. RFC, User Datagram Protocol. August 1980. 3 p. Disponível em: http://www.rfc-editor.org/rfc/rfc768.txt. Acesso em: maio 2013.

RAJENDRAN, V.; GARCIA-LUNA-AVECES, J.; OBRACZKA, K. Energyefficient, application-aware medium access for sensor networks. In: IEEE International Conference on Mobile Adhoc and Sensor Systems Conference. Washington: IEEE, 2005. p. 8 pp. -630 .

RAJENDRAN, V.; OBRACZKA, K.; GARCIA-LUNA-ACEVES, J. J. Energy-efficient collision-free medium access control for wireless sensor networks. In: Proceedings of the 1st international conference on Embedded networked sensor systems. New York, NY, USA: ACM, 2003. (SenSys '03), p. 181-192. ISBN 1-58113-707-9. 
RAMACHANDRAN, I.; DAS, A. K.; ROY, S. Analysis of the contention access period of IEEE 802.15.4 MAC. ACM Trans. Sen. Netw., ACM, New York, NY, USA, v. 3, n. 1, mar. 2007. ISSN 1550-4859.

RAMCHANDANI, C. Analysis of Asynchronous Concurrent Systems by Timed Petri Nets. Cambridge, MA, USA, 1974.

RATZER, A. et al. CPN Tools for Editing, Simulating, and Analysing Coloured Petri Nets. In: AALST, W.; BEST, E. (Ed.). Applications and Theory of Petri Nets 2003. Eindhoven, The Netherlands: Springer Berlin Heidelberg, 2003, (Lecture Notes in Computer Science, v. 2679). p. 450-462. ISBN 978-3-540-40334-0.

SEMPREBOM, T. et al. Dynamic GTS scheduling of periodic skippable slots in IEEE 802.15.4 wireless sensor networks. Hanyang University, Republic of Korea, v. 8, 2009 .

SHAH, R. C. et al. Data mules: Modeling a three-tier architecture for sparse sensor networks. In: First IEEE International Workshop on Sensor Network Protocols and Applications. Anchorage: IEEE, 2003. p. 30-41.

SHUAIB, A. H.; MAHMOODI, T.; AGHVAMI, A. H. A timed Petri Net model for the IEEE 802.15.4 CSMA-CA process. 2009 IEEE 20th International Symposium on Personal Indoor and Mobile Radio Communications, IEEE, Tóquio, p. 1204-1210, 2009.

SILVA, V. H. de Souza Ferreira da; ALVARO, A. Uma plataforma para cidades inteligentes baseada na internet das coisas. In: VIII Simpósio Brasileiro de Sistemas de Informação. São Paulo, Brasil: Sociedade Brasileira de Computação, 2012 .

SMITH, E. Principles of high-level net theory. In: REISIG, W.; ROZENBERG, G. (Ed.). Lectures on Petri Nets I: Basic Models. [S.l.]: Springer Berlin Heidelberg, 1998, (Lecture Notes in Computer Science, v. 1491). p. 174-210. ISBN 978-3-540-65306-6.

VALLE, O. et al. Uma nova classe de mensagens para redes IEEE 802.15.4. In: XXX Simpósio Brasileiro de Telecomunicações. Brasilia: SBC, 2012.

WEN, H. et al. An improved Markov model for IEEE 802.15.4 slotted CSMA/CA mechanism. J. Comput. Sci. Technol., v. 24, n. 3, p. 495-504, 2009.

YE, W.; HEIDEMANN, J.; ESTRIN, D. Medium access control with coordinated, adaptive sleeping for wireless sensor networks. ACM/IEEE Transactions on Networking, v. 12, n. 3, p. 493-506, June 2004.

ZANELLA, A. et al. Internet of things for smart cities. Internet of Things Journal, IEEE, v. 1, n. 1, p. 22-32, Feb 2014. ISSN 2327-4662. 


\section{APÊNDICE A - TABELAS DE DISPERSÃO RELATIVAS AO USO DO MODELO PARA VARIAÇÃO DE PARÂMETROS}

As Tabelas 22 até 27 apresentam o valor do desvio padrão em relação ao valor médio de cada métrica para cada conjunto de simulações relativas à uma configuração de teste realizada no Capítulo 5. Todos os valores foram inferiores à $4.2 \%$. 
Tabela 22: Variação do parâmetro AMAXFRAMERETRIES - desvio padrão em relação ao valor médio da métrica

\begin{tabular}{|c|c|c|c|c|c|c|c|c|c|c|c|c|c|c|c|c|}
\hline & \multicolumn{4}{|c|}{ Potência } & \multicolumn{4}{|c|}{ Atraso } & \multicolumn{4}{|c|}{ Taxa de Entrega } & \multicolumn{4}{|c|}{ Vazão } \\
\hline $\begin{array}{l}\text { Taxa de } \\
\text { quadros }\end{array}$ & 6 & 10 & 18 & 30 & 6 & 10 & 18 & 30 & 6 & 10 & 18 & 30 & 6 & 10 & 18 & 30 \\
\hline 1 & $3.2 \mathrm{E}-6$ & $3.9 \mathrm{E}-6$ & $4.8 \mathrm{E}-6$ & $3.0 \mathrm{E}-6$ & $1.80 \%$ & $2.63 \%$ & $1.79 \%$ & $3.99 \%$ & $0.19 \%$ & $0.16 \%$ & $0.17 \%$ & $0.18 \%$ & $1.74 \%$ & $1.74 \%$ & $2.18 \%$ & $1.49 \%$ \\
\hline 2 & $6.1 \mathrm{E}-6$ & $3.3 \mathrm{E}-6$ & $4.4 \mathrm{E}-6$ & $4.8 \mathrm{E}-6$ & $1.72 \%$ & $2.16 \%$ & $1.27 \%$ & $1.37 \%$ & $0.39 \%$ & $0.45 \%$ & $0.34 \%$ & $0.45 \%$ & $2.02 \%$ & $0.94 \%$ & $1.32 \%$ & $1.09 \%$ \\
\hline 4 & $3.4 \mathrm{E}-6$ & $4.7 \mathrm{E}-6$ & $5.1 \mathrm{E}-6$ & $4.0 \mathrm{E}-6$ & $1.88 \%$ & $1.94 \%$ & $0.93 \%$ & $1.19 \%$ & $0.97 \%$ & $0.75 \%$ & $0.51 \%$ & $0.49 \%$ & $0.67 \%$ & $0.96 \%$ & $0.81 \%$ & $0.66 \%$ \\
\hline 8 & $6.8 \mathrm{E}-6$ & $8.0 \mathrm{E}-6$ & $7.2 \mathrm{E}-6$ & $5.5 \mathrm{E}-6$ & $0.80 \%$ & $0.67 \%$ & $0.75 \%$ & $0.75 \%$ & $0.51 \%$ & $0.36 \%$ & $0.60 \%$ & $0.49 \%$ & $0.84 \%$ & $0.76 \%$ & $0.57 \%$ & $0.52 \%$ \\
\hline 16 & $9.6 \mathrm{E}-6$ & $1.6 \mathrm{E}-5$ & $9.1 \mathrm{E}-6$ & $8.7 \mathrm{E}-6$ & $0.65 \%$ & $0.84 \%$ & $0.50 \%$ & $0.54 \%$ & $0.47 \%$ & $0.58 \%$ & $0.54 \%$ & $0.54 \%$ & $0.58 \%$ & $0.98 \%$ & $0.54 \%$ & $0.51 \%$ \\
\hline 32 & $9.2 \mathrm{E}-6$ & $1.4 \mathrm{E}-5$ & $1.5 \mathrm{E}-5$ & $1.6 \mathrm{E}-5$ & $0.28 \%$ & $0.37 \%$ & $0.42 \%$ & $0.40 \%$ & $0.18 \%$ & $0.32 \%$ & $0.25 \%$ & $0.25 \%$ & $0.28 \%$ & $0.39 \%$ & $0.44 \%$ & $0.46 \%$ \\
\hline 64 & $2.6 \mathrm{E}-5$ & $2.0 \mathrm{E}-5$ & $2.5 \mathrm{E}-5$ & $2.5 \mathrm{E}-5$ & $0.24 \%$ & $0.17 \%$ & $0.24 \%$ & $0.18 \%$ & $0.26 \%$ & $0.25 \%$ & $0.22 \%$ & $0.21 \%$ & $0.30 \%$ & $0.29 \%$ & $0.34 \%$ & $0.32 \%$ \\
\hline 128 & $6.9 \mathrm{E}-6$ & $9.8 \mathrm{E}-6$ & $7.6 \mathrm{E}-6$ & $6.3 \mathrm{E}-6$ & $0.15 \%$ & $0.22 \%$ & $0.11 \%$ & $0.12 \%$ & $0.20 \%$ & $0.23 \%$ & $0.14 \%$ & $0.22 \%$ & $0.06 \%$ & $0.07 \%$ & $0.07 \%$ & $0.09 \%$ \\
\hline 256 & $5.2 \mathrm{E}-6$ & $6.8 \mathrm{E}-6$ & $9.1 \mathrm{E}-6$ & $1.3 \mathrm{E}-5$ & $0.09 \%$ & $0.09 \%$ & $0.08 \%$ & $0.07 \%$ & $0.12 \%$ & $0.15 \%$ & $0.17 \%$ & $0.14 \%$ & $0.08 \%$ & $0.08 \%$ & $0.09 \%$ & $0.07 \%$ \\
\hline 512 & $9.2 \mathrm{E}-6$ & $1.0 \mathrm{E}-5$ & $8.1 \mathrm{E}-6$ & $6.8 \mathrm{E}-6$ & $0.10 \%$ & $0.06 \%$ & $0.12 \%$ & $0.11 \%$ & $0.16 \%$ & $0.12 \%$ & $0.16 \%$ & $0.14 \%$ & $0.10 \%$ & $0.06 \%$ & $0.12 \%$ & $0.10 \%$ \\
\hline $\begin{array}{l}\text { Número } \\
\text { de nós }\end{array}$ & & & & & & & & & & & & & & & & \\
\hline 2 & $6.1 \mathrm{E}-6$ & $3.3 \mathrm{E}-6$ & $4.4 \mathrm{E}-6$ & $4.8 \mathrm{E}-6$ & $1.72 \%$ & $2.16 \%$ & $1.27 \%$ & $1.37 \%$ & $0.39 \%$ & $0.45 \%$ & $0.34 \%$ & $0.45 \%$ & $2.02 \%$ & $0.94 \%$ & $1.32 \%$ & $1.09 \%$ \\
\hline 4 & $5.4 \mathrm{E}-6$ & $3.5 \mathrm{E}-6$ & $4.7 \mathrm{E}-6$ & $5.3 \mathrm{E}-6$ & $1.10 \%$ & $0.70 \%$ & $1.39 \%$ & $1.15 \%$ & $0.35 \%$ & $0.22 \%$ & $0.32 \%$ & $0.31 \%$ & $1.28 \%$ & $1.16 \%$ & $1.31 \%$ & $1.29 \%$ \\
\hline 8 & $2.7 \mathrm{E}-6$ & $2.7 \mathrm{E}-6$ & $3.5 \mathrm{E}-6$ & $2.6 \mathrm{E}-6$ & $0.84 \%$ & $0.92 \%$ & $0.61 \%$ & $0.97 \%$ & $0.21 \%$ & $0.19 \%$ & $0.20 \%$ & $0.33 \%$ & $0.48 \%$ & $0.50 \%$ & $0.79 \%$ & $0.38 \%$ \\
\hline 16 & $2.2 \mathrm{E}-6$ & $2.5 \mathrm{E}-6$ & $4.3 \mathrm{E}-6$ & $1.9 \mathrm{E}-6$ & $0.77 \%$ & $0.71 \%$ & $0.91 \%$ & $0.46 \%$ & $0.17 \%$ & $0.18 \%$ & $0.20 \%$ & $0.10 \%$ & $0.38 \%$ & $0.44 \%$ & $0.53 \%$ & $0.39 \%$ \\
\hline 32 & $2.6 \mathrm{E}-6$ & $3.7 \mathrm{E}-6$ & $4.9 \mathrm{E}-6$ & $4.4 \mathrm{E}-6$ & $0.70 \%$ & $0.36 \%$ & $0.40 \%$ & $0.43 \%$ & $0.32 \%$ & $0.14 \%$ & $0.11 \%$ & $0.18 \%$ & $0.29 \%$ & $0.20 \%$ & $0.25 \%$ & $0.32 \%$ \\
\hline 64 & $2.5 \mathrm{E}-6$ & $2.3 \mathrm{E}-6$ & $2.1 \mathrm{E}-6$ & $1.8 \mathrm{E}-6$ & $0.46 \%$ & $0.67 \%$ & $0.48 \%$ & $0.25 \%$ & $0.40 \%$ & $0.59 \%$ & $0.69 \%$ & $0.30 \%$ & $0.20 \%$ & $0.39 \%$ & $0.38 \%$ & $0.30 \%$ \\
\hline
\end{tabular}

Fonte: Autor 
Tabela 23: Variação do parâmetro MACMAXCSMABACKOFFS - desvio padrão em relação ao valor médio da métrica

\begin{tabular}{|c|c|c|c|c|c|c|c|c|c|c|c|c|c|c|c|c|}
\hline & \multicolumn{4}{|c|}{ Potência } & \multicolumn{4}{|c|}{ Atraso } & \multicolumn{4}{|c|}{ Taxa de Entrega } & \multicolumn{4}{|c|}{ Vazão } \\
\hline $\begin{array}{l}\text { Taxa de } \\
\text { quadros }\end{array}$ & 10 & 20 & 30 & 40 & 10 & 20 & 30 & 40 & 10 & 20 & 30 & 40 & 10 & 20 & 30 & 40 \\
\hline 1 & $3.5 \mathrm{E}-6$ & $3.1 \mathrm{E}-6$ & $5.3 \mathrm{E}-6$ & $2.4 \mathrm{E}-6$ & $3.35 \%$ & $3.86 \%$ & $2.88 \%$ & $2.94 \%$ & $0.27 \%$ & $0.16 \%$ & $0.15 \%$ & $0.21 \%$ & $1.94 \%$ & $1.86 \%$ & $2.31 \%$ & $1.78 \%$ \\
\hline 2 & $4.7 \mathrm{E}-6$ & $4.9 \mathrm{E}-6$ & $5.1 \mathrm{E}-6$ & $7.7 \mathrm{E}-6$ & $1.87 \%$ & $1.19 \%$ & $1.42 \%$ & $1.75 \%$ & $0.38 \%$ & $0.55 \%$ & $0.39 \%$ & $0.40 \%$ & $1.39 \%$ & $1.14 \%$ & $1.47 \%$ & $2.03 \%$ \\
\hline 4 & $5.6 \mathrm{E}-6$ & $6.5 \mathrm{E}-6$ & $4.9 \mathrm{E}-6$ & $3.7 \mathrm{E}-6$ & $1.42 \%$ & $1.16 \%$ & $1.46 \%$ & $1.86 \%$ & $0.44 \%$ & $0.85 \%$ & $0.82 \%$ & $0.95 \%$ & $0.51 \%$ & $1.00 \%$ & $0.71 \%$ & $0.68 \%$ \\
\hline 8 & $5.1 \mathrm{E}-6$ & $5.8 \mathrm{E}-6$ & $8.4 \mathrm{E}-6$ & $8.3 \mathrm{E}-6$ & $0.69 \%$ & $0.80 \%$ & $0.88 \%$ & $0.83 \%$ & $0.65 \%$ & $0.31 \%$ & $0.65 \%$ & $0.54 \%$ & $0.53 \%$ & $0.57 \%$ & $0.93 \%$ & $0.89 \%$ \\
\hline 16 & $1.0 \mathrm{E}-5$ & $9.4 \mathrm{E}-6$ & $7.2 \mathrm{E}-6$ & $1.1 \mathrm{E}-5$ & $0.79 \%$ & $0.56 \%$ & $0.45 \%$ & $0.64 \%$ & $0.56 \%$ & $0.36 \%$ & $0.31 \%$ & $0.48 \%$ & $0.63 \%$ & $0.58 \%$ & $0.49 \%$ & $0.58 \%$ \\
\hline 32 & $1.7 \mathrm{E}-5$ & $7.1 \mathrm{E}-6$ & $1.0 \mathrm{E}-5$ & $9.0 \mathrm{E}-6$ & $0.48 \%$ & $0.22 \%$ & $0.29 \%$ & $0.25 \%$ & $0.31 \%$ & $0.24 \%$ & $0.19 \%$ & $0.17 \%$ & $0.53 \%$ & $0.18 \%$ & $0.29 \%$ & $0.27 \%$ \\
\hline 64 & $2.1 \mathrm{E}-5$ & $2.5 \mathrm{E}-5$ & $1.8 \mathrm{E}-5$ & $2.1 \mathrm{E}-5$ & $0.27 \%$ & $0.23 \%$ & $0.20 \%$ & $0.25 \%$ & $0.31 \%$ & $0.29 \%$ & $0.13 \%$ & $0.26 \%$ & $0.34 \%$ & $0.34 \%$ & $0.27 \%$ & $0.31 \%$ \\
\hline 128 & $1.5 \mathrm{E}-5$ & $9.3 \mathrm{E}-6$ & $1.1 \mathrm{E}-5$ & $1.3 \mathrm{E}-5$ & $0.24 \%$ & $0.17 \%$ & $0.10 \%$ & $0.17 \%$ & $0.18 \%$ & $0.20 \%$ & $0.15 \%$ & $0.18 \%$ & $0.11 \%$ & $0.10 \%$ & $0.08 \%$ & $0.07 \%$ \\
\hline 256 & $8.7 \mathrm{E}-6$ & $7.3 \mathrm{E}-6$ & $6.2 \mathrm{E}-6$ & $5.8 \mathrm{E}-6$ & $0.07 \%$ & $0.10 \%$ & $0.08 \%$ & $0.10 \%$ & $0.12 \%$ & $0.13 \%$ & $0.15 \%$ & $0.14 \%$ & $0.07 \%$ & $0.10 \%$ & $0.06 \%$ & $0.08 \%$ \\
\hline 512 & 7.1E-6 & $6.9 \mathrm{E}-6$ & 7.7E-6 & 7.9E-6 & $0.06 \%$ & $0.06 \%$ & $0.07 \%$ & $0.11 \%$ & $0.12 \%$ & $0.09 \%$ & $0.14 \%$ & $0.17 \%$ & $0.07 \%$ & $0.05 \%$ & $0.07 \%$ & $0.10 \%$ \\
\hline $\begin{array}{l}\text { Número } \\
\text { de nós }\end{array}$ & & & & & & & & & & & & & & & & \\
\hline 2 & $4.7 \mathrm{E}-6$ & $4.9 \mathrm{E}-6$ & $5.1 \mathrm{E}-6$ & 7.7E-6 & $1.87 \%$ & $1.19 \%$ & $1.42 \%$ & $1.75 \%$ & $0.38 \%$ & $0.55 \%$ & $0.39 \%$ & $0.40 \%$ & $1.39 \%$ & $1.14 \%$ & $1.47 \%$ & $2.03 \%$ \\
\hline 4 & $4.5 \mathrm{E}-6$ & $2.9 \mathrm{E}-6$ & $3.7 \mathrm{E}-6$ & $4.0 \mathrm{E}-6$ & $1.12 \%$ & $1.58 \%$ & $0.96 \%$ & $1.28 \%$ & $0.43 \%$ & $0.34 \%$ & $0.40 \%$ & $0.46 \%$ & $1.04 \%$ & $0.55 \%$ & $1.01 \%$ & $1.05 \%$ \\
\hline 8 & $2.7 \mathrm{E}-6$ & $3.0 \mathrm{E}-6$ & $3.1 \mathrm{E}-6$ & $2.6 \mathrm{E}-6$ & $0.68 \%$ & $1.27 \%$ & $0.89 \%$ & $0.45 \%$ & $0.15 \%$ & $0.25 \%$ & $0.27 \%$ & $0.22 \%$ & $0.59 \%$ & $0.59 \%$ & $0.63 \%$ & $0.55 \%$ \\
\hline 16 & $2.0 \mathrm{E}-6$ & $3.0 \mathrm{E}-6$ & $2.8 \mathrm{E}-6$ & $2.3 \mathrm{E}-6$ & $0.72 \%$ & $0.47 \%$ & $0.27 \%$ & $0.57 \%$ & $0.25 \%$ & $0.14 \%$ & $0.15 \%$ & $0.21 \%$ & $0.35 \%$ & $0.44 \%$ & $0.38 \%$ & $0.26 \%$ \\
\hline 32 & $2.3 \mathrm{E}-6$ & $3.1 \mathrm{E}-6$ & $4.5 \mathrm{E}-6$ & $3.7 \mathrm{E}-6$ & $0.53 \%$ & $0.29 \%$ & $0.50 \%$ & $0.71 \%$ & $0.23 \%$ & $0.27 \%$ & $0.38 \%$ & $0.32 \%$ & $0.61 \%$ & $0.35 \%$ & $0.29 \%$ & $0.34 \%$ \\
\hline 64 & $1.4 \mathrm{E}-6$ & $2.6 \mathrm{E}-6$ & $2.1 \mathrm{E}-6$ & $2.3 \mathrm{E}-6$ & $0.52 \%$ & $0.51 \%$ & $0.93 \%$ & $0.75 \%$ & $0.31 \%$ & $0.35 \%$ & $0.52 \%$ & $0.55 \%$ & $0.25 \%$ & $0.23 \%$ & $0.33 \%$ & $0.40 \%$ \\
\hline
\end{tabular}

Fonte: Autor 
Tabela 24: Variação do parâmetro INITIALCW - desvio padrão em relação ao valor médio da métrica

\begin{tabular}{|c|c|c|c|c|c|c|c|c|c|c|c|c|c|c|c|c|}
\hline & \multicolumn{4}{|c|}{ Potência } & \multicolumn{4}{|c|}{ Atraso } & \multicolumn{4}{|c|}{ Taxa de Entrega } & \multicolumn{4}{|c|}{ Vazão } \\
\hline $\begin{array}{l}\text { Taxa de } \\
\text { quadros }\end{array}$ & 3 & 4 & 5 & 6 & 3 & 4 & 5 & 6 & 3 & 4 & 5 & 6 & 3 & 4 & 5 & 6 \\
\hline 1 & $3.2 \mathrm{E}-6$ & $4.1 \mathrm{E}-6$ & $3.1 \mathrm{E}-6$ & $4.4 \mathrm{E}-6$ & $2.50 \%$ & $1.58 \%$ & $2.06 \%$ & $1.53 \%$ & $0.14 \%$ & $0.20 \%$ & $0.20 \%$ & $0.10 \%$ & $1.54 \%$ & $2.06 \%$ & $1.50 \%$ & $2.31 \%$ \\
\hline 2 & $6.0 \mathrm{E}-6$ & $3.2 \mathrm{E}-6$ & $3.2 \mathrm{E}-6$ & $5.4 \mathrm{E}-6$ & $1.40 \%$ & $2.88 \%$ & $1.76 \%$ & $1.83 \%$ & $0.62 \%$ & $0.62 \%$ & $0.49 \%$ & $0.55 \%$ & $1.43 \%$ & $0.79 \%$ & $1.07 \%$ & $1.26 \%$ \\
\hline 4 & $2.6 \mathrm{E}-6$ & $4.9 \mathrm{E}-6$ & $7.3 \mathrm{E}-6$ & $8.2 \mathrm{E}-6$ & $1.43 \%$ & $1.23 \%$ & $1.72 \%$ & $1.99 \%$ & $0.69 \%$ & $0.71 \%$ & $0.66 \%$ & $0.92 \%$ & $0.61 \%$ & $0.86 \%$ & $1.24 \%$ & $1.35 \%$ \\
\hline 8 & $6.7 \mathrm{E}-6$ & $5.3 \mathrm{E}-6$ & $7.5 \mathrm{E}-6$ & $9.2 \mathrm{E}-6$ & $0.60 \%$ & $0.63 \%$ & $0.93 \%$ & $0.92 \%$ & $0.25 \%$ & $0.43 \%$ & $0.80 \%$ & $0.64 \%$ & $0.70 \%$ & $0.62 \%$ & $0.78 \%$ & $0.94 \%$ \\
\hline 16 & $8.7 \mathrm{E}-6$ & $1.1 \mathrm{E}-5$ & $1.5 \mathrm{E}-5$ & $1.6 \mathrm{E}-5$ & $0.38 \%$ & $0.71 \%$ & $0.95 \%$ & $0.97 \%$ & $0.38 \%$ & $0.54 \%$ & $0.51 \%$ & $0.58 \%$ & $0.48 \%$ & $0.68 \%$ & $0.84 \%$ & $0.95 \%$ \\
\hline 32 & $2.1 \mathrm{E}-5$ & $9.3 \mathrm{E}-6$ & $1.4 \mathrm{E}-5$ & $1.3 \mathrm{E}-5$ & $0.62 \%$ & $0.26 \%$ & $0.40 \%$ & $0.42 \%$ & $0.34 \%$ & $0.23 \%$ & $0.43 \%$ & $0.25 \%$ & $0.66 \%$ & $0.30 \%$ & $0.42 \%$ & $0.43 \%$ \\
\hline 64 & $2.1 \mathrm{E}-5$ & $1.5 \mathrm{E}-5$ & $2.0 \mathrm{E}-5$ & $1.8 \mathrm{E}-5$ & $0.29 \%$ & $0.20 \%$ & $0.16 \%$ & $0.13 \%$ & $0.30 \%$ & $0.21 \%$ & $0.20 \%$ & $0.24 \%$ & $0.32 \%$ & $0.26 \%$ & $0.28 \%$ & $0.22 \%$ \\
\hline 128 & $9.6 \mathrm{E}-6$ & $6.7 \mathrm{E}-6$ & $1.2 \mathrm{E}-5$ & $6.3 \mathrm{E}-6$ & $0.15 \%$ & $0.11 \%$ & $0.15 \%$ & $0.14 \%$ & $0.19 \%$ & $0.24 \%$ & $0.19 \%$ & $0.15 \%$ & $0.07 \%$ & $0.09 \%$ & $0.09 \%$ & $0.09 \%$ \\
\hline 256 & $8.2 \mathrm{E}-6$ & $8.1 \mathrm{E}-6$ & $7.1 \mathrm{E}-6$ & $6.2 \mathrm{E}-6$ & $0.11 \%$ & $0.12 \%$ & $0.09 \%$ & $0.13 \%$ & $0.11 \%$ & $0.16 \%$ & $0.14 \%$ & $0.16 \%$ & $0.10 \%$ & $0.10 \%$ & $0.11 \%$ & $0.12 \%$ \\
\hline 512 & $6.0 \mathrm{E}-6$ & $9.1 \mathrm{E}-6$ & $4.6 \mathrm{E}-6$ & $5.1 \mathrm{E}-6$ & $0.10 \%$ & $0.13 \%$ & $0.10 \%$ & $0.08 \%$ & $0.15 \%$ & $0.15 \%$ & $0.14 \%$ & $0.08 \%$ & $0.12 \%$ & $0.11 \%$ & $0.07 \%$ & $0.04 \%$ \\
\hline $\begin{array}{l}\text { Número } \\
\text { de nós }\end{array}$ & & & & & & & & & & & & & & & & \\
\hline 2 & $6.0 \mathrm{E}-6$ & $3.2 \mathrm{E}-6$ & $3.2 \mathrm{E}-6$ & $5.4 \mathrm{E}-6$ & $1.40 \%$ & $2.88 \%$ & $1.76 \%$ & $1.83 \%$ & $0.62 \%$ & $0.62 \%$ & $0.49 \%$ & $0.55 \%$ & $1.43 \%$ & $0.79 \%$ & $1.07 \%$ & $1.26 \%$ \\
\hline 4 & $3.5 \mathrm{E}-6$ & $3.9 \mathrm{E}-6$ & $2.7 \mathrm{E}-6$ & $5.6 \mathrm{E}-6$ & $1.78 \%$ & $1.07 \%$ & $1.45 \%$ & $1.49 \%$ & $0.30 \%$ & $0.37 \%$ & $0.33 \%$ & $0.35 \%$ & $0.99 \%$ & $0.96 \%$ & $0.73 \%$ & $1.26 \%$ \\
\hline 8 & $2.6 \mathrm{E}-6$ & $2.4 \mathrm{E}-6$ & $2.7 \mathrm{E}-6$ & $1.8 \mathrm{E}-6$ & $1.28 \%$ & $0.95 \%$ & $1.27 \%$ & $0.99 \%$ & $0.27 \%$ & $0.22 \%$ & $0.22 \%$ & $0.20 \%$ & $0.68 \%$ & $0.64 \%$ & $0.65 \%$ & $0.32 \%$ \\
\hline 16 & 2.9E-6 & $1.5 \mathrm{E}-6$ & $2.3 \mathrm{E}-6$ & $1.5 \mathrm{E}-6$ & $0.48 \%$ & $0.61 \%$ & $0.60 \%$ & $0.71 \%$ & $0.19 \%$ & $0.22 \%$ & $0.26 \%$ & $0.24 \%$ & $0.58 \%$ & $0.24 \%$ & $0.49 \%$ & $0.42 \%$ \\
\hline 32 & $1.4 \mathrm{E}-6$ & $9.9 \mathrm{E}-7$ & $1.5 \mathrm{E}-6$ & $1.2 \mathrm{E}-6$ & $0.67 \%$ & $0.65 \%$ & $0.63 \%$ & $0.49 \%$ & $0.43 \%$ & $0.23 \%$ & $0.25 \%$ & $0.34 \%$ & $0.41 \%$ & $0.38 \%$ & $0.32 \%$ & $0.43 \%$ \\
\hline 64 & $1.2 \mathrm{E}-6$ & $1.2 \mathrm{E}-6$ & $7.8 \mathrm{E}-7$ & $1.3 \mathrm{E}-6$ & $0.45 \%$ & $0.34 \%$ & $0.50 \%$ & $0.58 \%$ & $0.37 \%$ & $0.30 \%$ & $0.22 \%$ & $0.30 \%$ & $0.22 \%$ & $0.25 \%$ & $0.29 \%$ & $0.25 \%$ \\
\hline
\end{tabular}

Fonte: Autor 
Tabela 25: Variação do parâmetro AUNITBACKOFFPERIOD - desvio padrão em relação ao valor médio da métrica

\begin{tabular}{|c|c|c|c|c|c|c|c|c|c|c|c|c|c|c|c|c|}
\hline & \multicolumn{4}{|c|}{ Potência } & \multicolumn{4}{|c|}{ Atraso } & \multicolumn{4}{|c|}{ Taxa de Entrega } & \multicolumn{4}{|c|}{ Vazão } \\
\hline $\begin{array}{l}\text { Taxa de } \\
\text { quadros }\end{array}$ & 25 & 35 & 50 & 75 & 25 & 35 & 50 & 75 & 25 & 35 & 50 & 75 & 25 & 35 & 50 & 75 \\
\hline 1 & $2.9 \mathrm{E}-6$ & $3.7 \mathrm{E}-6$ & $5.8 \mathrm{E}-6$ & $3.6 \mathrm{E}-6$ & $1.8 \%$ & $2.2 \%$ & $2.8 \%$ & $4.1 \%$ & $0.2 \%$ & $0.2 \%$ & $0.3 \%$ & $0.2 \%$ & $1.7 \%$ & $1.9 \%$ & $2.9 \%$ & $1.9 \%$ \\
\hline 2 & $6.4 \mathrm{E}-6$ & $5.2 \mathrm{E}-6$ & $5.7 \mathrm{E}-6$ & $4.5 \mathrm{E}-6$ & $1.0 \%$ & $1.9 \%$ & $1.4 \%$ & $2.0 \%$ & $0.5 \%$ & $0.4 \%$ & $0.5 \%$ & $0.5 \%$ & $1.5 \%$ & $1.5 \%$ & $1.7 \%$ & $1.1 \%$ \\
\hline 4 & $8.7 \mathrm{E}-6$ & $6.4 \mathrm{E}-6$ & $6.2 \mathrm{E}-6$ & $5.9 \mathrm{E}-6$ & $1.7 \%$ & $1.6 \%$ & $1.2 \%$ & $1.6 \%$ & $0.8 \%$ & $1.1 \%$ & $0.7 \%$ & $0.7 \%$ & $1.3 \%$ & $1.0 \%$ & $0.8 \%$ & $0.9 \%$ \\
\hline 8 & $6.4 \mathrm{E}-6$ & $9.9 \mathrm{E}-6$ & $7.2 \mathrm{E}-6$ & $5.2 \mathrm{E}-6$ & $0.9 \%$ & $1.4 \%$ & $1.0 \%$ & $0.6 \%$ & $0.5 \%$ & $0.8 \%$ & $0.7 \%$ & $0.5 \%$ & $0.7 \%$ & $1.1 \%$ & $0.7 \%$ & $0.4 \%$ \\
\hline 16 & $7.4 \mathrm{E}-6$ & $6.5 \mathrm{E}-6$ & $1.1 \mathrm{E}-5$ & $8.2 \mathrm{E}-6$ & $0.5 \%$ & $0.4 \%$ & $0.5 \%$ & $0.5 \%$ & $0.4 \%$ & $0.3 \%$ & $0.4 \%$ & $0.5 \%$ & $0.4 \%$ & $0.4 \%$ & $0.6 \%$ & $0.5 \%$ \\
\hline 32 & $1.5 \mathrm{E}-5$ & $1.1 \mathrm{E}-5$ & $1.7 \mathrm{E}-5$ & $1.5 \mathrm{E}-5$ & $0.5 \%$ & $0.4 \%$ & $0.4 \%$ & $0.4 \%$ & $0.3 \%$ & $0.3 \%$ & $0.3 \%$ & $0.4 \%$ & $0.5 \%$ & $0.3 \%$ & $0.5 \%$ & $0.4 \%$ \\
\hline 64 & $2.4 \mathrm{E}-5$ & $1.4 \mathrm{E}-5$ & $1.0 \mathrm{E}-5$ & $1.1 \mathrm{E}-5$ & $0.3 \%$ & $0.2 \%$ & $0.3 \%$ & $0.2 \%$ & $0.2 \%$ & $0.2 \%$ & $0.2 \%$ & $0.2 \%$ & $0.4 \%$ & $0.2 \%$ & $0.2 \%$ & $0.2 \%$ \\
\hline 128 & 7.0E-6 & $7.1 \mathrm{E}-6$ & $8.7 \mathrm{E}-6$ & $8.3 \mathrm{E}-6$ & $0.2 \%$ & $0.2 \%$ & $0.1 \%$ & $0.2 \%$ & $0.2 \%$ & $0.1 \%$ & $0.2 \%$ & $0.2 \%$ & $0.1 \%$ & $0.1 \%$ & $0.1 \%$ & $0.2 \%$ \\
\hline 256 & $7.5 \mathrm{E}-6$ & $8.4 \mathrm{E}-6$ & $9.6 \mathrm{E}-6$ & $4.8 \mathrm{E}-6$ & $0.1 \%$ & $0.1 \%$ & $0.1 \%$ & $0.2 \%$ & $0.1 \%$ & $0.2 \%$ & $0.2 \%$ & $0.2 \%$ & $0.1 \%$ & $0.1 \%$ & $0.2 \%$ & $0.2 \%$ \\
\hline 512 & $6.8 \mathrm{E}-6$ & $8.3 \mathrm{E}-6$ & $7.3 \mathrm{E}-6$ & $8.8 \mathrm{E}-6$ & $0.1 \%$ & $0.1 \%$ & $0.1 \%$ & $0.2 \%$ & $0.2 \%$ & $0.1 \%$ & $0.1 \%$ & $0.2 \%$ & $0.1 \%$ & $0.1 \%$ & $0.1 \%$ & $0.2 \%$ \\
\hline $\begin{array}{l}\text { Número } \\
\text { de nós }\end{array}$ & & & & & & & & & & & & & & & & \\
\hline 2 & $6.4 \mathrm{E}-6$ & $5.2 \mathrm{E}-6$ & $5.7 \mathrm{E}-6$ & $4.5 \mathrm{E}-6$ & $1.0 \%$ & $1.9 \%$ & $1.4 \%$ & $2.0 \%$ & $0.5 \%$ & $0.4 \%$ & $0.5 \%$ & $0.5 \%$ & $1.5 \%$ & $1.5 \%$ & $1.7 \%$ & $1.1 \%$ \\
\hline 4 & $2.4 \mathrm{E}-6$ & $5.6 \mathrm{E}-6$ & $3.5 \mathrm{E}-6$ & $2.9 \mathrm{E}-6$ & $1.0 \%$ & $1.7 \%$ & $1.7 \%$ & $1.2 \%$ & $0.3 \%$ & $0.3 \%$ & $0.3 \%$ & $0.4 \%$ & $0.6 \%$ & $1.3 \%$ & $0.8 \%$ & $0.7 \%$ \\
\hline 8 & $3.8 \mathrm{E}-6$ & $2.7 \mathrm{E}-6$ & $2.8 \mathrm{E}-6$ & $3.9 \mathrm{E}-6$ & $0.7 \%$ & $0.7 \%$ & $0.7 \%$ & $0.6 \%$ & $0.3 \%$ & $0.2 \%$ & $0.2 \%$ & $0.3 \%$ & $0.5 \%$ & $0.6 \%$ & $0.5 \%$ & $0.8 \%$ \\
\hline 16 & $2.7 \mathrm{E}-6$ & $1.9 \mathrm{E}-6$ & $3.2 \mathrm{E}-6$ & $2.8 \mathrm{E}-6$ & $0.5 \%$ & $0.8 \%$ & $0.7 \%$ & $0.6 \%$ & $0.3 \%$ & $0.2 \%$ & $0.2 \%$ & $0.2 \%$ & $0.5 \%$ & $0.4 \%$ & $0.5 \%$ & $0.4 \%$ \\
\hline 32 & $1.6 \mathrm{E}-6$ & $2.1 \mathrm{E}-6$ & $1.5 \mathrm{E}-6$ & $2.8 \mathrm{E}-6$ & $0.7 \%$ & $0.4 \%$ & $0.4 \%$ & $0.4 \%$ & $0.2 \%$ & $0.3 \%$ & $0.3 \%$ & $0.4 \%$ & $0.3 \%$ & $0.4 \%$ & $0.3 \%$ & $0.2 \%$ \\
\hline 64 & $1.1 \mathrm{E}-6$ & $1.7 \mathrm{E}-6$ & $1.8 \mathrm{E}-6$ & $1.6 \mathrm{E}-6$ & $0.7 \%$ & $0.7 \%$ & $0.4 \%$ & $0.4 \%$ & $0.2 \%$ & $0.3 \%$ & $0.5 \%$ & $0.5 \%$ & $0.2 \%$ & $0.3 \%$ & $0.3 \%$ & $0.4 \%$ \\
\hline
\end{tabular}

Fonte: Autor 
Tabela 26: Estudo com tráfegos assimétricos - desvio padrão em relação ao valor médio da métrica

\begin{tabular}{|c|c|c|c|c|c|c|c|c|c|c|c|c|}
\hline \multirow{3}{*}{$\begin{array}{l}\text { Taxa } \\
\text { nó } 1\end{array}$} & \multicolumn{12}{|c|}{ Multiplicador } \\
\hline & \multicolumn{3}{|c|}{ Potência } & \multicolumn{3}{|c|}{ Atraso } & \multicolumn{3}{|c|}{ Taxa de Entrega } & \multicolumn{3}{|c|}{ Vazão } \\
\hline & 2 & 4 & 8 & 2 & 4 & 8 & 2 & 4 & 8 & 2 & 4 & 8 \\
\hline 4 & $6.2 \mathrm{E}-6$ & $8.9 \mathrm{E}-6$ & $7.2 \mathrm{E}-6$ & $0.80 \%$ & $0.71 \%$ & $0.65 \%$ & $0.79 \%$ & $0.55 \%$ & $0.73 \%$ & $0.62 \%$ & $0.88 \%$ & $0.40 \%$ \\
\hline 8 & $9.4 \mathrm{E}-6$ & $1.3 \mathrm{E}-5$ & $1.7 \mathrm{E}-5$ & $1.10 \%$ & $0.71 \%$ & $0.53 \%$ & $0.63 \%$ & $0.55 \%$ & $0.39 \%$ & $0.69 \%$ & $0.57 \%$ & $0.44 \%$ \\
\hline 16 & $9.3 \mathrm{E}-6$ & $1.6 \mathrm{E}-5$ & $2.0 \mathrm{E}-5$ & $0.42 \%$ & $0.38 \%$ & $0.20 \%$ & $0.12 \%$ & $0.44 \%$ & $0.30 \%$ & $0.40 \%$ & $0.42 \%$ & $0.26 \%$ \\
\hline 32 & $1.7 \mathrm{E}-5$ & $2.1 \mathrm{E}-5$ & $7.2 \mathrm{E}-6$ & $0.32 \%$ & $0.18 \%$ & $0.08 \%$ & $0.23 \%$ & $0.23 \%$ & $0.29 \%$ & $0.37 \%$ & $0.27 \%$ & $0.09 \%$ \\
\hline 64 & $2.0 \mathrm{E}-5$ & $9.2 \mathrm{E}-6$ & $6.7 \mathrm{E}-6$ & $0.19 \%$ & $0.17 \%$ & $0.16 \%$ & $0.16 \%$ & $0.21 \%$ & $0.23 \%$ & $0.17 \%$ & $0.10 \%$ & $0.07 \%$ \\
\hline
\end{tabular}

Fonte: Autor

Tabela 27: Estudo de variação da proporção entre tamanho de quadro e taxa de quadro com taxa de bits constante - desvio padrão em relação ao valor médio da métrica

\begin{tabular}{|c|c|c|c|c|c|c|c|c|c|c|c|c|}
\hline \multirow{3}{*}{$\begin{array}{l}\text { Tamanho } \\
\text { do quadro }\end{array}$} & \multicolumn{12}{|c|}{ Taxa de Bits } \\
\hline & \multicolumn{3}{|c|}{ Potência } & \multicolumn{3}{|c|}{ Atraso } & \multicolumn{3}{|c|}{ Taxa de Entrega } & \multicolumn{3}{|c|}{ Vazão } \\
\hline & 256 & 512 & 1024 & 256 & 512 & 1024 & 256 & 512 & 1024 & 256 & 512 & 1024 \\
\hline 16 & $3.81 \mathrm{E}-06$ & $3.64 \mathrm{E}-06$ & $05 \mathrm{E}-06$ & $0.69 \%$ & $0.32 \%$ & $0.34 \%$ & $0.45 \%$ & $0.31 \%$ & 0.35 & $0.65 \%$ & $0.31 \%$ & $0.32 \%$ \\
\hline 32 & $3.89 \mathrm{E}-06$ & $5.8 \mathrm{E}-06$ & $1.31 \mathrm{E}-05$ & $0.78 \%$ & $0.68 \%$ & $0.59 \%$ & $0.73 \%$ & $0.52 \%$ & $0.44 \%$ & $0.75 \%$ & $0.59 \%$ & $0.66 \%$ \\
\hline 64 & $4.35 \mathrm{E}-06$ & $6.69 \mathrm{E}-06$ & $9.91 \mathrm{E}-06$ & $1.19 \%$ & $0.87 \%$ & $0.57 \%$ & $0.50 \%$ & $0.59 \%$ & $0.47 \%$ & $0.76 \%$ & $0.70 \%$ & $0.56 \%$ \\
\hline 128 & $6.33 \mathrm{E}-06$ & $1.02 \mathrm{E}-05$ & $1.38 \mathrm{E}-05$ & $1.96 \%$ & $1.14 \%$ & $0.84 \%$ & $0.46 \%$ & $0.52 \%$ & $0.73 \%$ & $1.19 \%$ & $0.85 \%$ & $0.82 \%$ \\
\hline
\end{tabular}

Fonte: Autor 